\title{
Global warming potentials and radiative efficiencies of halocarbons and related compounds: a comprehensive review
}

Article

Published Version

OnlineOpen

Hodnebrog, O., Etminam, M., Fuglestvedt, J. S., Marston, G., Myhre, G., Nielsen, C. J., Shine, K. P. and Wallington, T. J. (2013) Global warming potentials and radiative efficiencies of halocarbons and related compounds: a comprehensive review. Review of Geophysics, 51 (2). pp. 300-378. ISSN 1944-9208 doi: https://doi.org/10.1002/rog.20013 Available at https://centaur.reading.ac.uk/31338/

It is advisable to refer to the publisher's version if you intend to cite from the work. See Guidance on citing.

Published version at: http://onlinelibrary.wiley.com/doi/10.1002/rog.20013/abstract

To link to this article DOI: http://dx.doi.org/10.1002/rog.20013

Publisher: Wiley

All outputs in CentAUR are protected by Intellectual Property Rights law, including copyright law. Copyright and IPR is retained by the creators or other copyright holders. Terms and conditions for use of this material are defined in the End User Agreement. 


\section{CentAUR}

Central Archive at the University of Reading

Reading's research outputs online 


\title{
GLOBAL WARMING POTENTIALS AND RADIATIVE EFFICIENCIES OF HALOCARBONS AND RELATED COMPOUNDS: A COMPREHENSIVE REVIEW
}

\author{
Ø. Hodnebrog, ${ }^{1}$ M. Etminan, ${ }^{2}$ J. S. Fuglestvedt, ${ }^{1}$ G. Marston, ${ }^{3}$ G. Myhre, ${ }^{1}$ C. J. Nielsen, ${ }^{4}$ \\ K. P. Shine, ${ }^{2}$ and T. J. Wallington ${ }^{5}$ \\ Received 30 July 2012; revised 18 April 2013; accepted 20 April 2013; published 26 June 2013.
}

[1] In the mid-1970s, it was recognized that chlorofluorocarbons (CFCs) were strong greenhouse gases that could have substantial impacts on radiative forcing of climate change, as well as being substances that deplete stratospheric ozone. Around a decade later, this group of radiatively active compounds was expanded to include a large number of replacements for ozone-depleting substances such as chlorocarbons, hydrochlorocarbons, hydrochlorofluorocarbons (HCFCs), hydrofluorocarbons (HFCs), perfluorocarbons (PFCs), bromofluorocarbons, and bromochlorofluorocarbons. This paper systematically reviews the published literature concerning the radiative efficiencies (REs) of CFCs, bromofluorocarbons and bromochlorofluorocarbons (halons), HCFCs, HFCs, PFCs, sulfur hexafluoride, nitrogen trifluoride, and related halogen containing compounds. In addition, we provide a comprehensive and self-consistent set of new calculations of REs and global warming potentials (GWPs) for these compounds, mostly employing atmospheric lifetimes taken from the available literature. We also present global temperature change potentials for selected gases. Infrared absorption spectra used in the RE calculations were taken from databases and individual studies and from experimental and ab initio computational studies. Evaluations of REs and GWPs are presented for more than 200 compounds. Our calculations yield REs significantly ( $>5 \%$ ) different from those in the Intergovernmental Panel on Climate Change Fourth Assessment Report (AR4) for 49 compounds. We present new RE values for more than 100 gases which were not included in AR4. A widely used simple method to calculate REs and GWPs from absorption spectra and atmospheric lifetimes is assessed and updated. This is the most comprehensive review of the radiative efficiencies and global warming potentials of halogenated compounds performed to date.

Citation: Hodnebrog, Ø., M. Etminan, J. S. Fuglestvedt, G. Marston, G. Myhre, C. J. Nielsen, K. P. Shine, and T. J. Wallington (2013), Global warming potentials and radiative efficiencies of halocarbons and related compounds: A comprehensive review, Rev. Geophys., 51, 300-378, doi:10.1002/rog.20013.

\section{TABLE OF CONTENTS}

1. Introduction . . . . . . . . . . . . 2

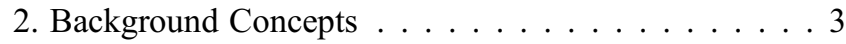

2.1. Molecular Radiative Properties .... . . . . 3

Additional supporting information may be found in the online version of this article.

${ }^{1}$ Center for International Climate and Environmental Research-Oslo (CICERO), Oslo, Norway. UK.

${ }^{2}$ Department of Meteorology, University of Reading, Reading, Berks,

${ }^{3}$ Department of Chemistry, University of Reading, Reading, Berks, UK.

${ }^{4}$ Department of Chemistry, University of Oslo, Oslo, Norway.

${ }^{5}$ Ford Motor Company, Research and Advanced Engineering, Dearborn, Michigan, USA.

Corresponding author: J. S. Fuglestvedt, Center for International Climate and Environmental Research-Oslo (CICERO), P.O. Box 1129 Blindern, N-0318 Oslo, Norway. (j.s.fuglestvedt@cicero.oslo.no)
2.2. Radiative Forcing and Radiative Efficiency-

Concepts ................. . 4

2.3. Calculation of Radiative Efficiency . . . . . . . 6

2.4. Atmospheric Lifetimes . . . . . . . . . . . 7

2.5. Climate Impact Metrics . . . . . . . . . . . . . . 8

3. Data and Method . . . . . . . . . . . . 9

3.1. Absorption Cross Sections . . . . . . . . . . 9

3.2. Atmospheric Lifetimes . . . . . . . . . . . 11

3.3. Radiative Forcing Efficiency . . . . . . . . . . 12

3.4. Discussion of Impact of Functional Groups on

Spectra/Radiative Forcing . . . . . . . . . . 18

3.5. Description of Metrics . . . . . . . . . . 18

3.6. Uncertainty-Sensitivity to Assumptions. . . . . 20

4. Results and Discussion . . . . . . . . . . . . . 24

4.1. Infrared Spectra, REs, and GWPs . . . . . . . . 24

4.2. Additional Metrics for the Most Important Gases:

GTPs and GWPs for Other Time Horizons. . . . 68

5. Summary and Conclusions . . . . . . . . . . 70 


\section{INTRODUCTION}

[2] Concern was raised in the 1970s that emissions of chlorofluorocarbons (CFCs), a class of compounds developed for a range of industrial and domestic uses, could lead to stratospheric ozone depletion [Molina and Rowland, 1974]. This concern was realized a decade later with the discovery of the Antarctic ozone hole [Farman et al., 1985] and a less severe but global-scale stratospheric ozone depletion [e.g., Stolarski et al., 1992].

[3] At about the same time, it was also recognized that the CFCs were strong absorbers of infrared radiation and that sustained emissions could lead to accumulations in the atmosphere which would have significant climate impacts [Ramanathan, 1975; Wang et al., 1976]. This climatic role was re-emphasized during the 1980s and expanded to more classes of gases, including chlorocarbons, hydrochlorocarbons, hydrochlorofluorocarbons (HCFCs), hydrofluorocarbons (HFCs), perfluorocarbons (PFCs), and the bromofluorocarbons and bromochlorofluorocarbons (referred to here as halons) [e.g., Hansen et al., 1989; Ramanathan et al., 1985; Ramanathan et al., 1987]. These studies indicated that the increase in atmospheric concentrations of CFCs and related compounds was contributing a decadal radiative forcing which was around $30-40 \%$ of that due to the increase in carbon dioxide concentrations. Furthermore, it was noted that this share could increase, if the growth in emissions of the CFCs and related molecules was unconstrained.

[4] The landscape for considering the climate impact of halocarbons (organic compounds containing one, or more, halogen atom) changed as a result of global environmental agreements under the auspices of the United Nations. First, the Montreal Protocol on Substances that Deplete the Ozone Layer (http://ozone.unep.org/new_site/en/montreal_protocol. php)_signed in 1987 and entered into force two years later - and its subsequent amendments and adjustments led to the phasing out of production and emissions (with some exceptions) of CFCs, chlorocarbons, and halons; it also included a schedule for the phasing out of emissions of HCFCs. Then the Kyoto Protocol to the United Nations Framework Convention on Climate Change (UNFCCC) (http://unfccc.int/kyoto_protocol/items/2830.php)_signed in 1997 and entered into force in 2005 - set limits on the emissions of a "basket" of greenhouse gases by developed countries. The basket of greenhouse gases included a number of PFCs and hydrofluorocarbons (HFCs), the latter being most commonly used as CFC replacements. The initial Kyoto Protocol covered emissions in the so-called first commitment period of 2008 2012. The Doha Amendment to the Kyoto Protocol covers emissions in a second commitment period of 2013-2020 and added nitrogen trifluoride to the basket of greenhouse gases.

[5] Some of the issues concerning the halocarbons can be illustrated by reference to Figure $1[W M O / G A W, 2011]$, which shows quasi-global average atmospheric concentrations of 10 of the more abundant halocarbons. During the 1980s, the halocarbon abundance and growth was dominated by two CFCs (CFC-11 $\left(\mathrm{CCl}_{3} \mathrm{~F}\right)$ and $\mathrm{CFC}-12$
$\left.\left(\mathrm{CCl}_{2} \mathrm{~F}_{2}\right)\right)$. There were also significant contributions from CFC-113 $\left(\mathrm{CCl}_{2} \mathrm{FCClF}_{2}\right)$, methyl chloroform $\left(\mathrm{CH}_{3} \mathrm{CCl}_{3}\right)$, and carbon tetrachloride $\left(\mathrm{CCl}_{4}\right)$. During the $1990 \mathrm{~s}$, there was a dramatic change in the growth rates of the three CFCs and methyl chloroform. The changes were driven by the effects of the Montreal Protocol which led to rapidly declining emissions of these gases. The influence of the atmospheric lifetime of the different gases is also clear from Figure 1. Methyl chloroform has a relatively short lifetime ( 5 years) and its atmospheric concentration responds rapidly to decreased emissions. In contrast, CFC-12 and CFC-113 have atmospheric lifetimes of 100 and 85 years, respectively, and their atmospheric concentrations respond more slowly to decreased emissions. CFC-11 has an atmospheric lifetime of 45 years and its atmospheric concentration is more responsive than CFC-12 but less responsive than methyl chloroform to decreased emissions. The fact that the atmospheric concentrations of carbon tetrachloride (26 year lifetime) have only declined modestly over the past 30 years reflects continued emissions from developing nations [WMO, 2011].

[6] Figure 1 shows that concentrations of HCFC-22 $\left(\mathrm{CHClF}_{2}\right)$, an important interim replacement for several CFCs, continue to grow, despite being controlled by the Montreal Protocol-its concentration is now close to that of CFC-11. HFC-134a $\left(\mathrm{CH}_{2} \mathrm{FCF}_{3}\right)$, which is included within the Kyoto Protocol, has been the fastest growing HFC, mainly because of its use as a replacement for CFC-12 in refrigeration and vehicle air-conditioning applications. Its relatively short lifetime (13.4 years) compared to the CFCs means that for the same emission rate the atmospheric abundance of HFC-134a would be much lower than the CFCs it replaces (see section 2.4). Estimating future atmospheric concentrations of HCFCs and HFCs is challenging as it requires estimation of future emissions which are difficult to predict. For example, future concentrations of HFC-134a will depend on the growth of the global vehicle fleet and the impact of legislation and improved technology which would limit the use of HFC-134a or its leakage from that fleet. If the current emission rate (149 $\pm 27 \mathrm{kt} \mathrm{yr}^{-1}$ in 2008) [WMO, 2011] were maintained, the tropospheric concentration of HFC-134a would stabilize at $120 \pm 20 \mathrm{ppt}$ within a few decades. In addition to the gases shown in Figure 1, there are other halogenated alkanes (e.g., HFC-125 $\left(\mathrm{CF}_{3} \mathrm{CF}_{2} \mathrm{H}\right), \mathrm{HFC}-143 \mathrm{a}\left(\mathrm{CF}_{3} \mathrm{CH}_{3}\right)$, HFC$32\left(\mathrm{CH}_{2} \mathrm{~F}_{2}\right), \mathrm{HFC}-245 \mathrm{fa}\left(\mathrm{CHF}_{2} \mathrm{CH}_{2} \mathrm{CF}_{3}\right), \mathrm{C}_{2} \mathrm{~F}_{6}$, and $\left.\mathrm{C}_{3} \mathrm{~F}_{8}\right)$ that have been detected in the atmosphere at levels of 1-10 ppt.

[7] While the Montreal Protocol was designed to protect the ozone layer, its impact on climate change has been substantial, since it also controlled the atmospheric abundance of species that are powerful greenhouse gases-indeed it can be argued that it had a greater influence on the radiative forcing of climate change than the Kyoto Protocol [e.g., Velders et al., 2007].

[8] To make the multi-gas approach embedded in the UNFCCC operational, the Kyoto Protocol from 1997 adopted a framework whereby emissions of non- $\mathrm{CO}_{2}$ greenhouse gases were placed on a " $\mathrm{CO}_{2}$-equivalent" scale. As will be discussed in section 2 , there is no unique way of 
assigning a $\mathrm{CO}_{2}$-equivalence to an emission of a non- $\mathrm{CO}_{2}$ gas, but the Kyoto Protocol adopted one available metric, the Global Warming Potential with a 100 year time-horizon (GWP(100)). The Protocol uses values of GWP(100) for specific gases as reported in the Intergovernmental Panel on Climate Change (IPCC) Second Assessment Report (SAR) [IPCC, 1995]. It has not, so far, taken into account either revisions to those GWP values (as a result of improved understanding, and changing background concentrations of gases) or the expansion of the list to include additional species (including, for example, hydrofluoroethers (HFEs)) that have been catalogued in subsequent IPCC reports [e.g., IPCC, 2001, 2007] and World Meteorological Organization (WMO)/United Nations Environment Program (UNEP) Scientific Assessment of Ozone Depletion [ $W M O$, 2003, 2007, 2011]. In addition the parties to the UNFCCC have not considered in any detail and depth the use of alternative metrics to the GWP(100). For the second commitment period of the Kyoto Protocol, which is covered by the Doha Amendment, a draft decision (which is described in UNFCCC Decision 2/CMP.8 (http://unfccc.int/resource/ docs/2012/cmp8/eng/13a01.pdf) which itself refers to Decision 4/CMP.7 (http://unfccc.int/resource/docs/2011/cmp7/ eng/10a01.pdf) has been made to adopt the GWP(100) values reported by the IPCC's Fourth Assessment Report in the Errata to Table 2.14 of the Working Group 1 report (see http://www.ipcc.ch/publications_and_data/ar4/wg1/en/ errataserrata-errata.html), but this decision has not been confirmed at the time of writing.

[9] The GWP values for specific gases given in successive IPCC and WMO Ozone Assessment reports are drawn from a range of sources which use a variety of techniques to derive the input parameters (and in particular the "radiative efficiency" (RE) - which is, broadly, the "greenhouse" strength of a particular gas, on a per molecule basis-see section 2.2) needed to calculate the GWP. In addition, rather simplified considerations have sometimes been adopted to take into account discrepancies between values reported in the literature (e.g., averaging available values rather than assessing which are likely to be the more reliable).

[10] The primary aim of this review is to provide a comprehensive and consistent analysis of the input parameters required to calculate values of the GWP and other metrics for a large number of CFCs, chlorocarbons, hydrochlorocarbons, HCFCs, HFCs, PFCs, HFEs and other related halogenated substances (including, for example, nitrogen trifluoride $\left(\mathrm{NF}_{3}\right)$ and sulfur hexafluoride $\left(\mathrm{SF}_{6}\right)$ ). The particular emphasis will be on the method of calculation of the radiative efficiency. The review will also consider, in much less detail, atmospheric lifetimes, another important input parameter for the calculation of GWPs and other metrics - atmospheric lifetimes are, for the most part, taken from the existing literature, without detailed analysis. This then enables us to provide an extensive and selfconsistent set of GWPs for halocarbon gases; we also provide tabulations of values for an alternative metric (the global temperature change potential (GTP) - see section 4.2) for selected important gases.
[11] In addition to their direct radiative effects, some halocarbons cause additional (indirect) effects on the climate system by influencing the abundance of other climatically important gases - for example, stratospheric ozone, which is influenced by the CFCs and the halons. Such indirect effects are discussed elsewhere [e.g., Daniel et al., 1995; $W M O, 2011]$ and are not covered here.

[12] Section 2 provides the necessary background concepts, and section 3 presents the methodology we adopt to generate a consistent set of REs and lifetimes of the halocarbons, and related halogenated substances, including a discussion of the sensitivity of these parameters to uncertainties. Section 4 provides tabulations of the radiative efficiencies, lifetimes, GWPs, and GTPs. Section 5 presents our conclusions.

\section{BACKGROUND CONCEPTS}

[13] The computation of GWPs and similar metrics for a particular gas requires various inputs and model calculations. The two basic input parameters for the GWP calculations are, as will be described in section 2.5, the RE and the lifetime of the gas. The calculation of these two parameters requires, in turn, much additional information. Figure 2 summarizes the main steps required which are discussed in more detail below.

\subsection{Molecular Radiative Properties}

[14] The first stage in the determination of the RE is knowledge of the fundamental spectroscopic properties of a molecule. Here we are most concerned with its properties at thermal infrared (IR) wavelengths (i.e., wavelengths at which the Earth and its atmosphere emit significant amounts of infrared radiation) of roughly 4 to $200 \mu \mathrm{m}$ (2500 to $50 \mathrm{~cm}^{-1}$ ). We will mostly work in terms of the frequencylike variable, wavenumber (the inverse of wavelength, normally quoted in $\mathrm{cm}^{-1}$ ). The emission of infrared radiation by the Earth and atmosphere and the radiative properties of the atmosphere are strong functions of wavenumber. Hence it is necessary to determine the spectroscopic properties of the target molecule as a function of wavenumber. A general introduction to atmospheric radiative transfer can be found in Petty [2006] and introductions to general molecular spectroscopy can be found in Hollas [2004] and Atkins and Friedman [2010]. Fundamentally, the molecules of interest here absorb and emit radiation by transitions between their vibrational-rotational energy levels. The characteristic wavenumber of absorption is determined by the spacing of the vibrational energy levels, with the transitions between particular vibrational-rotational energy levels leading to that absorption being spread by typically $50 \mathrm{~cm}^{-1}$ around this characteristic wavenumber. For example, one of the simplest molecules, $\mathrm{CF}_{4}$ absorbs over a narrow range of wavenumbers near $1300 \mathrm{~cm}^{-1}$ which is associated with the stretching of the carbon-fluorine bonds in the molecule. Molecules containing the carbon-chlorine bond absorb characteristically around $800 \mathrm{~cm}^{-1}$. The more complex the structure of the molecule, the greater the number of possible modes of vibrations (including different stretching and 


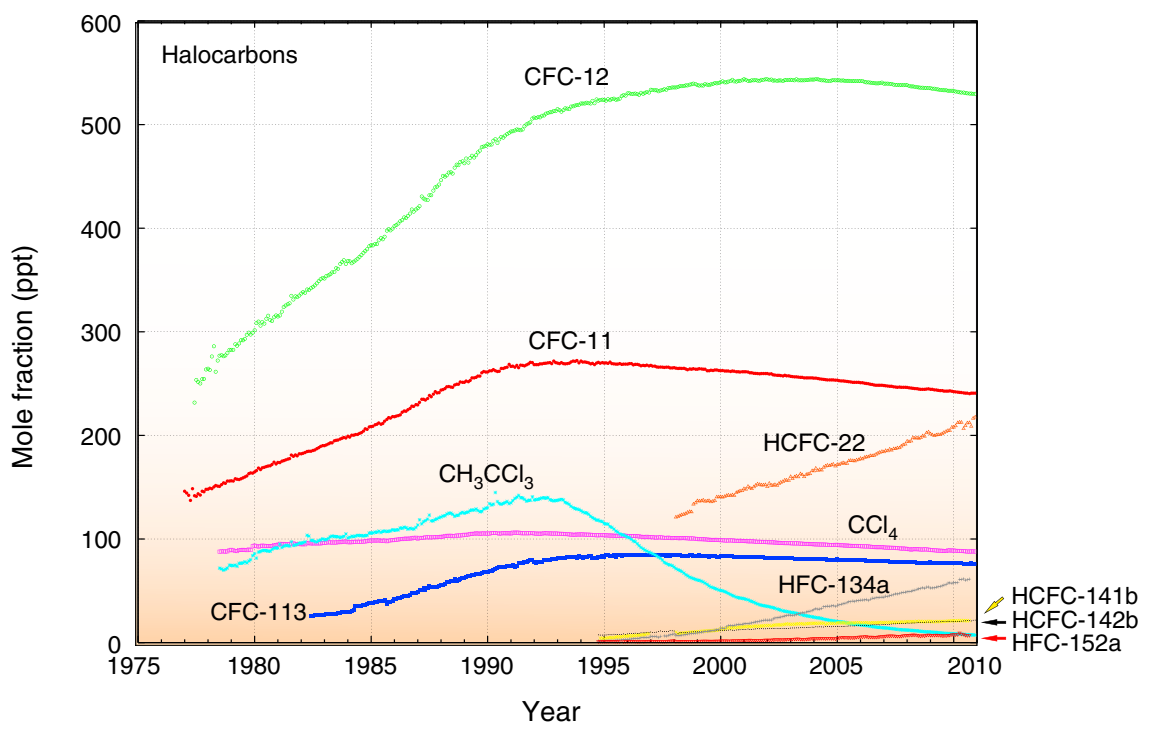

Figure 1. Atmospheric concentrations of 10 halocarbons from 1977 to 2010 averaged over the greenhouse gas monitoring network (between 7 and 10 stations) [from $W M O / G A W, 2011$ ].

bending modes) and hence the more complex the infrared absorption spectrum becomes. Figure 3 shows IR spectra of representative halocarbons and illustrates the increased number of IR absorption bands observed with larger, more complex and less symmetric molecules.

[15] In principle, it would be desirable to characterize the strength of each discrete vibrational-rotational transition, and indeed this is necessary for some atmospheric greenhouse gases such as water vapor and carbon dioxide, where the absorption spectrum consists of many sharp individual spectral lines with rapid variations of absorption with wavenumber. However, for halocarbons the individual transitions are so close together (as a result of the large masses of the atoms), and sufficiently broad, that under atmospheric conditions the individual transitions merge together leading to a spectrum that consists of broad absorption bands (see Figure 3). The spectrally resolved absorption cross sections (units of $\mathrm{cm}^{2}$ molecule ${ }^{-1}$ with typical peak cross sections of order $10^{-18}-10^{-17} \mathrm{~cm}^{2}$ molecule ${ }^{-1}$ for the molecules considered here) can be integrated over infrared wavenumbers to give the integrated cross section (typical values for halocarbons are of the order of $10^{-16} \mathrm{~cm}^{2}$ molecule $\left.{ }^{-1} \mathrm{~cm}^{-1}\right)$. The integrated cross section gives a useful measure of the overall strength of IR absorption but the variation of absorption with wavenumber (i.e., the absorption spectrum) must be known for calculation of the potential climate impact [e.g., Pinnock et al., 1995; Wallington et al., 2010].

[16] The most common way for determining the absorption cross sections of halocarbons is via laboratory measurements using Fourier Transform Infrared Spectrometry. Measurements are made at typically $0.5 \mathrm{~cm}^{-1}$ or better spectral resolution. In general, the absorption cross sections for halocarbons are only rather weakly dependent on temperature and pressure over the atmospherically relevant range and this dependence is generally neglected in RE calculations and likely uncertainties are about $\pm 5 \%$ [Highwood and Shine, 2000]. The absorption cross-section measurements are typically assessed to have an accuracy of approximately $\pm 5 \%$ [e.g., Ballard et al., 2000b; Clerbaux et al., 1993; Pinnock et al., 1995].

[17] More recently, absorption cross sections have begun to be determined by quantum mechanical electron structure calculations (we will refer to these as ab initio methods), which in principle only rely on the basic laws of nature. In practice, however, ab initio calculations involve approximations to solving the Schrödinger equation and residual errors remain [e.g., Blowers et al., 2007; Bravo et al., 2010b; Papasavva et al., 1997]. The ab initio methods show considerable promise, but it has been found that they need empirical corrections (particularly for the wavenumbers of the main vibrational modes) to agree with laboratory measurements. In addition, their capabilities have not been assessed for the full range of molecules considered here. Nevertheless they have already proven to be useful adjuncts to laboratory measurements and can provide data at wavenumbers that are difficult to study in the laboratory and allow rapid surveying of a broad range of compounds for which laboratory samples may not be easy to procure.

\subsection{Radiative Forcing and Radiative Efficiency-Concepts}

[18] Once the absorption cross sections have been obtained, the next step is to compute the impact that the addition of a particular halocarbon to the atmosphere has on the radiation budget. The resulting change in the radiation budget is generally referred to as "radiative forcing" (RF), but there are a number of nuances to the definition of RF that need to be elaborated on. Also, in general, radiative forcing (in units of $\mathrm{W} \mathrm{m}^{-2}$ ) refers to the effect of a specified change in the concentration of a species, often over some given time period. In this review, we focus on the radiative forcing per unit change in halocarbon mixing ratio - this is referred to as radiative efficiency $(\mathrm{RE})\left(\mathrm{W} \mathrm{m}^{-2} \mathrm{ppb}^{-1}\right)$. $\mathrm{RE}$ assumes that the $\mathrm{RF}$ is linear in mixing ratio-this is normally 


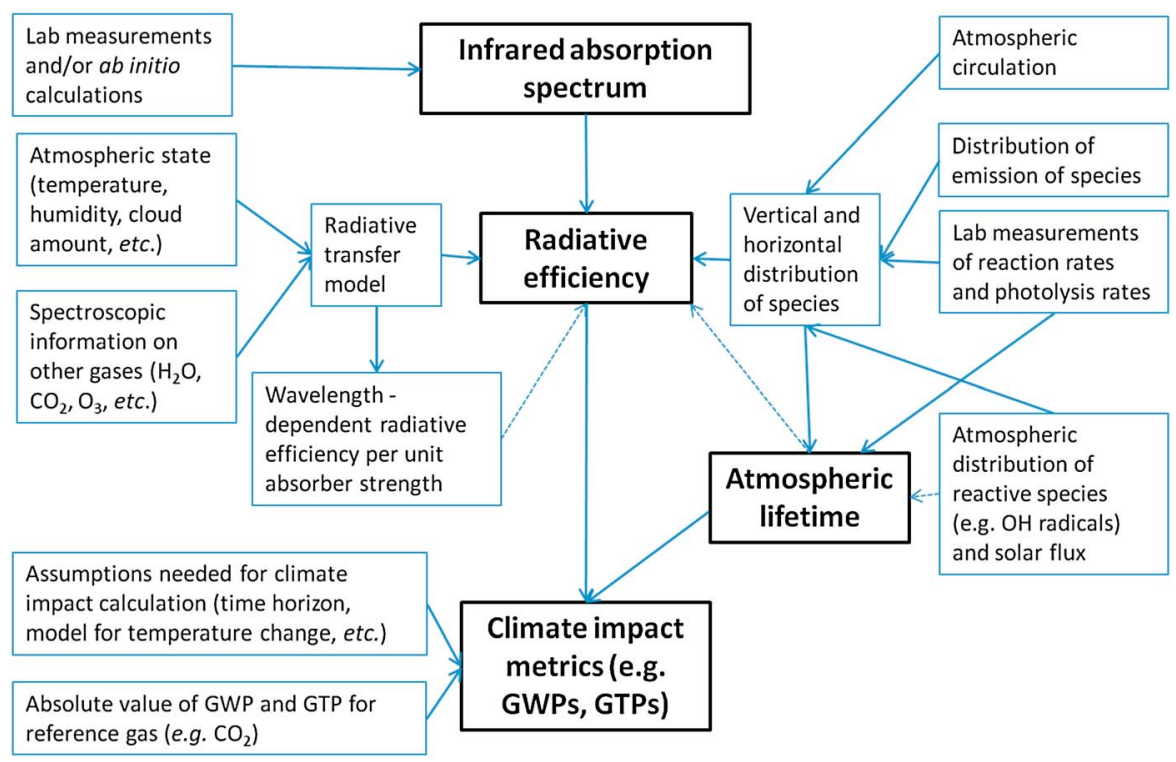

Figure 2. Schematic figure showing the main parameters required to compute climate impact metrics and the additional inputs required in the calculation of those parameters. Dashed lines show where simpler techniques (based on the more complex models) are often employed (as is the case in this review).

appropriate in the case of small perturbations in mixing ratio about current concentrations and is also appropriate for gases, such as the ones we consider here, which have low background concentrations.

[19] IPCC Assessment Reports [e.g., Forster et al., 2007] have addressed the rationale for using RF, outlined caveats in its use, and also defined possible alternative definitions of RF [see also discussions in e.g., Fuglestvedt et al., 2010; Hansen et al., 2005]. Studies using climate models indicate that there is a direct relationship between globalaveraged RF and the (equilibrium) global-mean surface temperature change, and so RF has been essentially used as a proxy for surface temperature change. RF is normally defined at the tropopause including stratospheric temperature adjustment [Forster et al., 2007], the rationale being that the tight coupling between the surface and troposphere means that they behave as a single thermodynamic system; hence it is the change in the input of energy into this system that drives the climate change.

[20] Instantaneous RF [e.g., Forster et al., 2007] is defined as the change in net irradiance at the tropopause, following (for example) a change in a greenhouse gas concentration. Earlier studies indicated that the instantaneous RF had less utility (i.e., models indicated a less close relationship between it and the resulting surface temperature change) than RF with stratospheric temperature adjustment. Part of the rationale for this is that, following a perturbation, the response time of the stratosphere is fast (around a few months) compared to the decadal time scale for the temperature of the surface-troposphere system to respond. It is found that for a number of forcings, the RF including stratospheric temperature adjustment has a closer relationship with modeled surface temperature change, than the instantaneous RF. For this definition of forcing, stratospheric temperatures are assumed to adjust in response to the change in greenhouse gas concentration - this change in temperature leads to a further change in the irradiance, as the downward emission by the stratosphere to the troposphere is dependent on this temperature. Some gases (notably $\mathrm{CO}_{2}$ ) lead to a cooling of the stratosphere which makes the stratospheric-adjusted forcing less than the instantaneous forcing. For others (including

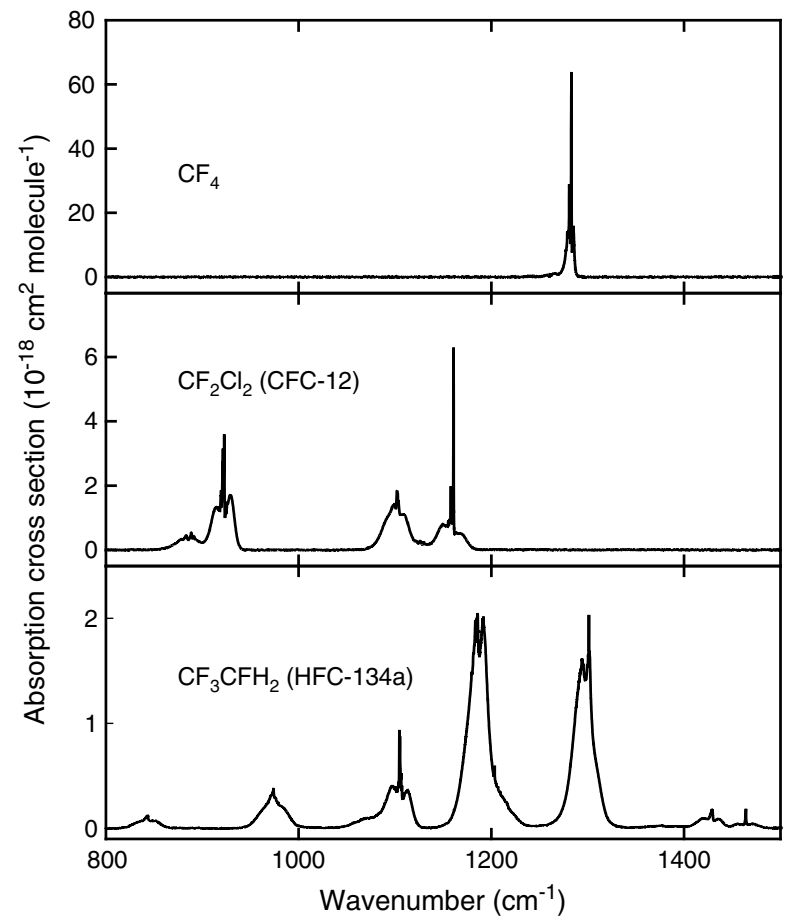

Figure 3. IR spectra of $\mathrm{CF}_{4}$ (top panel), $\mathrm{CF}_{2} \mathrm{Cl}_{2}$ (middle panel), and $\mathrm{CF}_{3} \mathrm{CFH}_{2}$ (bottom panel) measured using $0.5 \mathrm{~cm}^{-1}$ spectral resolution in 700 Torr of air diluent at 296 K [Forster et al., 2005; Hurley et al., 2005; Sihra et al., 2001]. 
many halocarbons) the reverse is true, as the stratosphere warms - see section 3.3.2 for further discussion.

[21] Early studies [Jain et al., 2000; Myhre and Stordal, 1997; Naik et al., 2000; Pinnock et al., 1995] quantified the difference between the instantaneous and stratosphericadjusted RF for a range of halocarbons, indicating that the instantaneous forcing is typically $5-10 \%$ lower than the stratospheric-adjusted RF. One drawback with the stratospheric-adjusted RF is that its calculation is computationally much more demanding; in this review, because of the large number of gases involved, we calculated instantaneous RE and then applied a correction, based on the available literature, to account for the effect of stratospheric adjustment (see section 3.3.2).

[22] More recently, there has been much work investigating alternative definitions of forcing [e.g., Andrews and Forster, 2008; Forster et al., 1997; Gregory et al., 2004; Hansen et al., 2005] — for example, fixing surface temperatures (sometimes sea-surface temperature only) but allowing tropospheric temperatures, humidity and cloudiness to adjust, in addition to the stratosphere. The rationale here is that there are so-called "fast feedbacks" or "rapid adjustments" operating in the troposphere that can change, for example, cloudiness in the absence of surface temperature change. Hence it is conceptually attractive to separate climate responses that operate on day-to-month timescales and are independent of changes in surface temperature from the "traditional" climate feedbacks (for example, water vapor feedback, ice albedo feedback and various cloud feedbacks) which are mediated by surface temperature change and hence act on decadal to century timescales.

[23] These rapid tropospheric adjustments can be particularly important for other forcings, such as those resulting from black carbon aerosols. Few model results are available on the effect of tropospheric adjustments for the gases considered here. Computation of such forcings requires long simulations using sophisticated climate models, and results would likely depend significantly on the climate model chosen. In addition, because of the inherent "unforced" natural variability in such climate models, it would be necessary to impose a large forcing (in excess of $1 \mathrm{~W} \mathrm{~m}^{-2}$ ) to easily extract a reliable signal from the model; this is many times the present-day RF of the most abundant CFC (CFC-12about $0.17 \mathrm{~W} \mathrm{~m}^{-2}$ ) [Forster et al., 2007] and orders of magnitude more than most other gases considered here, raising concerns about the linearity of the rapid tropospheric adjustments. Since research on these more advanced definitions of forcing is still at an early stage, and also because of the computational demands of performing these calculations, we believe it premature to adopt them here as a framework.

[24] An additional and related issue concerns the so-called climate efficacy. An underlying assumption in early work in this area was that the global-mean surface temperature response to an $\mathrm{RF}$ of, say, $1 \mathrm{~W} \mathrm{~m}^{-2}$, was the same irrespective of the cause of the forcing. Climate model simulations now indicate that this assumption is not strictly justified. Efficacy is a measure of the ability (per $\mathrm{W} \mathrm{m}^{-2}$ ) of a particular forcing to change surface temperature relative to, for example, a $1 \mathrm{~W} \mathrm{~m}^{-2}$ forcing due to a change in carbon dioxide. Relatively little research has been performed on the efficacy of the halocarbons. Forster and Joshi [2005] found an efficacy of CFC-12 (using the stratosphere adjusted forcing) to be 0.94 in their model. Hansen et al. [2005], by contrast, found an equivalent value (for a combination of CFC-11 and CFC-12) of 1.3 but also demonstrated that the efficacy depends on the definition of forcing that is adopted. An additional issue for the short-lived halocarbons, is that the efficacy likely depends on the spatial distribution of the halocarbon [Joshi et al., 2003] which in turn depends on the halocarbon's lifetime (see section 2.4) and the distribution of emissions. Given these uncertainties, we assume an efficacy of 1 throughout this review, although it is in principle possible to include non-unity values of efficacy within the GWP and GTP metrics.

\subsection{Calculation of Radiative Efficiency}

[25] The calculation of radiative efficiency requires, in addition to the absorption spectrum for the halocarbon in question, a calculation of atmospheric irradiances, accounting for atmospheric properties, such as the amounts, distributions and radiative properties of other infrared-absorbing components (water vapor, carbon dioxide, ozone, clouds, etc.), and temperatures. As the RE is a globally and annually averaged quantity, in principle it should be calculated locally and, say, monthly, and then averaged to produce the global and annual mean. In practice, it is possible, with about $5-10 \%$ accuracy, to calculate the RE using a globally averaged atmospheric profile or using two or three profiles representative of the tropics and mid/high latitudes [Freckleton et al., 1998; Myhre and Stordal, 1997]. Myhre et al. [2006] found that for calculations of the CFC-12 RE, the use of two atmospheric profiles (one for tropics and one extra-tropics) represents global simulations with a horizontal resolution of $2.5^{\circ} \times 2.5^{\circ}$ within $1 \%$. In addition, there are several possible choices of tropopause definition that impact on the calculated forcing at the 5\% level [Freckleton et al., 1998].

[26] The radiative transfer models that can be used for such calculations vary in complexity. The most complex (line-by-line (LBL) models) perform calculations at high (typically $0.01 \mathrm{~cm}^{-1}$ ) spectral resolution and resolve explicitly the individual spectral lines of atmospheric gases such as water vapor, carbon dioxide and ozone. These are computationally expensive and parameterized models are often used (for example to compute the effect of stratospheric adjustment). Narrow Band Models resolve the infrared spectrum at typically $10 \mathrm{~cm}^{-1}$ resolution, while computationally fast Broad Band Models (suitable for use in climate models) may resolve the thermal infrared region into typically 5 to 10 spectral intervals. Intercomparisons of such models both for greenhouse gases in general [e.g., Collins et al., 2006; Oreopoulos et al., 2012] and for halocarbons in particular [e.g., Forster et al., 2005; Gohar et al., 2004; Jain et al., 2000] are of importance in assessing the capabilities of the parameterized models. When these models are combined with vertical profiles of temperature, cloudiness and 
greenhouse gas concentrations, it is necessary to ensure that the model's global-and-annual outgoing longwave radiation, and the impact of clouds on the outgoing longwave budget, are in reasonable agreement with satellite observations; otherwise, biases in the resulting RE calculations can occur.

[27] In addition to the direct use of radiative transfer models to calculate REs, it is possible to use these models to produce simple techniques to compute the radiative forcing directly from the absorption cross sections. Pinnock et al. [1995] used a narrow-band model to compute the RE per unit absorption cross section as a function of wavenumber, using a global and annual mean atmosphere. This then indicates the spectral regions at which halocarbon radiative forcing is most effective. As shown in Figure 5 and discussed in section 3.3.1, where an update to the Pinnock et al. [1995] method is presented, molecules are most effective if they absorb in the $800-1200 \mathrm{~cm}^{-1}$ spectral region (a so-called "atmospheric window"), but can remain effective outside this region. If a halogenated compound absorbs at a wavelength where there is already substantial atmospheric absorption (for example by carbon dioxide near $670 \mathrm{~cm}^{-1}$ ) then the additional absorption by this compound will not contribute significantly to radiative forcing.

[28] Hence, if the spectrally varying radiative forcings calculated by Pinnock et al. [1995] are multiplied by the absorption cross sections representing a real halocarbon (averaged to the same spectral resolution as the radiation calculations) then an estimate of the RE can be achieved easily by summing over all wavenumbers, using a spreadsheet for example, without the need for a complex radiation code. Pinnock et al. [1995] demonstrated for a wide range of halocarbons that this simple technique could generate instantaneous REs that were accurate to within $0.3 \%$, relative to full calculations using the same radiation code that was used to generate the values in the simple technique, and using the same atmospheric profile. (It is emphasized that this is not the technique's absolute accuracy, as this is dependent on the accuracy of the radiation code and its input parameters). Consequently, the method developed by Pinnock et al. is simple and effective, and has been widely used.

[29] A further consideration in calculating the RE is that the horizontal and vertical distribution of the molecule must be specified - often the baseline assumption is that the molecule is well-mixed within the atmosphere (both horizontally and vertically); corrections to approximately account for the departure from this assumption are then applied-see section 2.4 and 3.3.4. However, it should be noted that for short-lived gases in particular, there is no unique value of $\mathrm{RE}$, as its value depends to some extent on the geographical (and seasonal) distribution of emissions, as these in turn influence the horizontal and vertical distribution of the gas.

\subsection{Atmospheric Lifetimes}

[30] The global atmospheric lifetime (year) of a gas is defined in the IPCC Third Assessment Report [IPCC, 2001] as "the burden (Tg) divided by the mean global sink
(Tg/yr) for a gas in steady state (i.e., with unchanging burden)." The report also identifies two important consequences of this definition, namely, (i) that "when in steady state (i.e., source strength = sink strength), the atmospheric burden of a gas equals the product of its lifetime and its emissions" and (ii) that "the integrated atmospheric abundance following a single emission is equal to the product of the steady state lifetime for that emission pattern and the amount emitted [Prather, 1996]." As will be discussed in section 2.5, the most frequently used climate metrics consider the impact of a pulse emission of a gas.

[31] The global atmospheric lifetime has also been referred to simply as "lifetime," or "turnover time" [Bolin and Rodhe, 1973; IPCC, 1995] reflecting the fact that it characterizes the time required to turn over the global atmospheric burden of the gas in question. It is sometimes thought of as the decay time (e-fold) following a perturbation, with its magnitude determined by chemical or photolytic loss rates. While conceptually appealing, this approach applies rigorously only for a gas whose local chemical lifetime is constant in space and time, such as for the noble gas radon, whose lifetime is fixed by the rate of its radioactive decay [IPCC, 2001]. In reality the chemical losses of pollutants vary in time and space and, if the magnitude of emissions are sufficient (e.g., for methane), the emissions themselves can influence the chemistry of the atmosphere and hence the pollutant's lifetime. As discussed in sections 3.3.3 and 3.3.4, many halocarbons have short lifetimes, are not well mixed in the atmosphere, and the spatial and temporal emission pattern needs to be accounted for in assessments of their radiative efficiencies.

[32] Halocarbons are removed from the atmosphere by two main mechanisms; reaction with $\mathrm{OH}$ radicals and photolysis. As a crude guide to understanding how the molecular structure of a halocarbon affects its reactivity towards $\mathrm{OH}$ radicals, for a given carbon backbone (e.g., $\mathrm{C}_{2}, \mathrm{C}_{3}, n-\mathrm{C}_{4}$, etc.) the more fluorine atoms in a haloalkane the longer its lifetime and the more bromine or iodine atoms the shorter its lifetime. For molecules containing hydrogen such as HCFCs, HFCs, HFEs and hydrochlorocarbons, the primary removal mechanism in the troposphere is reaction with the hydroxyl radical $\mathrm{OH}$. Lifetimes range from a few days to millennia, depending on the structure of the molecule - to first order, the more heavily halogenated a molecule, the longer its lifetime, although the precise arrangement and nature of those halogens in the molecule plays an important role [Atkinson et al., 2008; Sander et al., 2010]. Unsaturated molecules containing $>\mathrm{C}=\mathrm{C}<$ double bonds react rapidly with $\mathrm{OH}$ radicals. Including one, or more $>\mathrm{C}=\mathrm{C}<$ double bond is a particularly effective method of reducing the atmospheric lifetime of halocarbons. For example, $\mathrm{CF}_{3} \mathrm{CF}_{2} \mathrm{CH}_{3}$ (HFC-245cb) has a lifetime of 47.1 years while $\mathrm{CF}_{3} \mathrm{CFCH}_{2}$ (HFC-1234yf) has a lifetime of 10.5 days.

[33] For CFCs and halons, the primary destruction mechanism is ultraviolet photolysis in the stratosphere. CFCs are inert in the troposphere as sufficiently short wavelength ultra-violet radiation does not penetrate in to the troposphere. Indeed, it is their chemical inertness that made the 
CFCs so attractive in industrial and domestic usages. It is interesting and worth noting that when detection of CFCs in the atmosphere was first reported, the conclusion included the comment "The presence of these compounds [CFC-11 and CFC-12] constitutes no conceivable hazard" [Lovelock and Maggs, 1973]. Halons have atmospheric lifetimes in the approximate range of 10 to 70 years, while CFCs have atmospheric lifetimes ranging from about 45 to more than a thousand years. Calvert et al. [2008] have reviewed the mechanisms in the atmospheric photolysis of haloalkanes. Absorption at ultra-violet wavelengths involves an $n \rightarrow \sigma^{*}$ transition with a non-bonding electron of the halogen promoted into an anti-bonding sigma orbital of the $\mathrm{C}-\mathrm{X}$ bond. Ultra-violet absorption spectra for haloalkanes (RX) of similar carbon backbone structure move to lower energy (longer wavelength absorption) along the series $\mathrm{X}=\mathrm{F}, \mathrm{Cl}, \mathrm{Br}$, to $\mathrm{I}$, reflecting a trend of lower electron affinity of the halogen atom [Calvert et al., 2008]. Absorption by $\mathrm{C}-\mathrm{F}$ and $\mathrm{C}-\mathrm{Cl}$ bonds only occurs at wavelengths below approximately $240 \mathrm{~nm}$. CFCs, HFCs, HCFCs, chlorocarbons, and hydrochlorocarbons do not photolyze in the troposphere as sufficiently short wavelength ultra-violet radiation does not reach the troposphere. In contrast to $\mathrm{C}-\mathrm{F}$ and $\mathrm{C}-\mathrm{Cl}$ bonds, $\mathrm{C}-\mathrm{I}$ bonds absorb strongly at tropospherically relevant wavelengths and iodine-containing haloalkanes have atmospheric lifetime of days, or less, with respect to photolysis in the troposphere (e.g., 4.9 days for $\mathrm{CH}_{3} \mathrm{I}, 4.3$ days for $\mathrm{C}_{2} \mathrm{H}_{5} \mathrm{I}$, 4.9 hours for $\mathrm{CH}_{2} \mathrm{ICl}$, and 4.9 minutes for $\mathrm{CH}_{2} \mathrm{I}_{2}$ ) [Calvert et al., 2008]. Absorption by $\mathrm{C}-\mathrm{Br}$ bonds at tropospherically relevant wavelengths is generally weak but photolysis can contribute to determining the atmospheric lifetime of some bromoalkanes such as $\mathrm{CHBr}_{3}$ [Calvert et al., 2008]. Because of the inherent strength of the $\mathrm{C}-\mathrm{F}$ bond, the PFCs are chemically inert and, are the longest lived of the halocarbons, with lifetimes ranging from about a thousand years to approximately 50,000 years for $\mathrm{CF}_{4}$.

[34] The atmospheric lifetime plays a further role in the determination of the radiative efficiency, because it helps determine the degree of heterogeneity in the distribution of the halogenated molecules in the atmosphere. For molecules with lifetimes of less than a few months, the atmospheric distribution is dependent on where and when the gases are emitted, reflecting the spatial and temporal distribution of $\mathrm{OH}$ radicals which determines the local atmospheric lifetimes. Since the radiative efficiency of a gas depends on its location (in general, a gas at low latitudes is more effective, as more radiative energy is available to be absorbed at high temperatures), a unique radiative efficiency cannot be defined for such short-lived molecules without a detailed knowledge of the spatial and temporal emission pattern. In addition, the vertical profile of a gas is also influenced by the atmospheric lifetime. Mixing processes are most efficient within the troposphere with molecules mixed vertically on the typical timescales of days to weeks. Within the stratosphere the vertical profile of a particular species depends strongly on the relationship between the timescales for transport within the stratosphere and the rate at which the molecule is destroyed. Jain et al. [2000] and Naik et al. [2000] [see also Freckleton et al., 1998] used chemical transport models to simulate the distributions of a range of halocarbons, and quantify the difference in the RE between using these distributions and the assumption that the gases are well mixed. Their results were used by Sihra et al. [2001] to develop a simplistic method to approximately account for the effect of atmospheric lifetime on the radiative efficiency. This will be further discussed in section 3.3.4. (A nonconstant atmospheric profile of a species can also result when the rates of surface emissions are growing rapidly, because of the multi-year timescale for the molecule to reach deep into the stratosphere.)

[35] The products of the reactions that destroy halocarbons could in principle themselves be climatically important gases. However, it is well established that the atmospheric degradation of halocarbons gives oxygenated compounds which have relatively short atmospheric lifetimes and are typically removed by wet and dry deposition on a time scale of days or weeks [Wallington et al., 1994b]. The oxidation products do not accumulate in the atmosphere and do not contribute significantly to radiative forcing of climate change.

\subsection{Climate Impact Metrics}

[36] A key objective of this review is to provide values for the GWP and GTP metrics for the halocarbons. The rationale and challenges in developing climate impact metrics have been reviewed in detail by Fuglestvedt et al. [2010] and so only a relatively brief discussion is given here.

[37] One of the prime drivers of the development of emission metrics is the need for their use in multi-gas climate policies (such as the Kyoto Protocol) where emissions of different compounds must be placed on a common scale, usually referred to as a " $\mathrm{CO}_{2}$-equivalent" scale. There is no unique method of doing this, and the choice of method should be consistent with the climate policy that the metric aims to serve [e.g., Plattner et al., 2009]. The Kyoto Protocol's choice of the GWP(100) has been a matter of much discussion and debate [e.g., Fuglestvedt et al., 2003; Manne and Richels, 2001; O'Neill, 2000; Shine, 2009]. One often cited reason for its original use and retention has been the lack of a widely accepted alternative, and, latterly, the difficulties that might arise within policymaking if the metric (more specifically, the numerical value that converts a given emission to a $\mathrm{CO}_{2}$-equivalent emission) was substantially changed.

[38] There are a number of elements that have to be considered in metric design. What kind of emission is consideredfor example, a pulse or a sustained emission? What "impact" is considered - for example, radiative forcing, surface temperature change, sea-level rise, economic impact, or the rate of change of these quantities? Which indirect effects and feedbacks should be included? Is the impact considered integrated over some time period, or at one particular time? Is the impact given as global mean or with a regional resolution? What time period is considered? And, of significance to their wider acceptability, particularly within the policymaking community, how transparent are the formulations of the metrics? 
[39] Here we present results for two metrics. The GWP (with time horizons of 20, 100 and 500 years) is presented to be consistent with reporting in previous IPCC assessments and its wide usage. The GWP definition we use here is as used in the first IPCC Assessment Report [IPCC, 1990] which itself was based on then-recent studies suggesting ways of intercomparing the climate effect of emissions of different gases [Derwent, 1990; Fisher et al., 1990; Lashof and Ahuja, 1990; Wuebbles, 1989]. The GWP represents the time-integrated radiative forcing due to a pulse emission of a gas. It can be presented as the absolute GWP (AGWP-with units of, for example, $\mathrm{W} \mathrm{m} \mathrm{kg}^{-1}$ year) or, more normally, as a ratio to the AGWP of $\mathrm{CO}_{2}$. One difficulty is that the AGWP of $\mathrm{CO}_{2}$ has been subject to periodic revision in IPCC assessments, as a result of atmospheric changes (the $\mathrm{RE}$ of $\mathrm{CO}_{2}$ decreases as $\mathrm{CO}_{2}$ concentrations increase) and changes in understanding of how long $\mathrm{CO}_{2}$ concentrations remain perturbed following a pulse emission. Hence the GWP of a halocarbon may change solely because of a change in AGWP of $\mathrm{CO}_{2}$ rather than revisions to its own lifetime and radiative efficiency, as happened, for example, in the IPCC Third Assessment Report IPCC [2001]. The precise method used here to determine the AGWPs, and hence the GWPs, will be presented in section 3.5.

[40] The GTP [Shine et al., 2005a] is also chosen for presentation here, partly because it has attracted more attention than other alternative metrics, including at the policymaking level [e.g., Plattner et al., 2009] and partly because it has a quite different basis from, and hence provides an alternative perspective to, the GWP. The GTP represents the temperature change due to a pulse emission of a gas, at some time (here 20,50 and 100 years are chosen) in the future. Hence it is an "end-point" metric (unlike the GWP, which is a time-integrated metric) and hence retains less of a memory of the effect of emissions of short-lived species. It has been suggested that the GTP may be more suitable for targetbased climate policies [e.g., Shine et al., 2007], such as envisaged under the Copenhagen Accord of the UNFCCC, where the aim is to keep surface temperature change, relative to pre-industrial times, below 2 degrees $\mathrm{C}$. The GTP method requires, in addition to the lifetime and radiative efficiency, some model to represent the response of global-mean surface temperature to radiative forcing, and hence requires the specification of additional parameters compared to the GWP. As with the GWP it can be presented as an absolute quantity (with units of, for example, $\mathrm{K} \mathrm{kg}^{-1}$ ) or as a ratio to the absolute global temperature change potential (i.e., AGTP) of $\mathrm{CO}_{2}$.

[41] Since Fuglestvedt et al. [2010], there has been a significant literature on climate emission metrics including discussions of how these "physical" metrics relate to metrics which incorporate, additionally, an economics element [e.g., Boucher, 2012; Johansson, 2012; Tol et al., 2012], the relationship amongst metrics (for example, Peters et al. [2011] discuss the similarities of the GWP with a time-integrated GTP) and evaluations of the sensitivities of GWPs and GTPs to uncertainties in input parameters and background scenarios [e.g., Reisinger et al., 2011; Reisinger et al., 2010].

\section{DATA AND METHOD}

\subsection{Absorption Cross Sections}

\subsubsection{Laboratory Measurements of Infrared Absorption Cross Sections}

[42] Analytical infrared instrumentation usually only covers the mid-infrared region, $4000-400 \mathrm{~cm}^{-1}$, and the majority of available IR absorption spectra - including most of the spectra covered in this review - were measured within this wavenumber range. As will be shown in detail in section 3.3.1, the effectiveness of the absorption in contributing to RE varies strongly with wavenumber, peaking at 300-600 and 750$1000 \mathrm{~cm}^{-1}$, significant at $1100-1300 \mathrm{~cm}^{-1}$, and of minor importance for wavenumbers above $1500 \mathrm{~cm}^{-1}$ [Pinnock et al., 1995].

[43] Infrared spectra are measured in transmittance, which is defined as the ratio of spectral intensity transmitted through the sample at a given wavenumber $\widetilde{v}, I_{\text {tr }}(\widetilde{v})$, to the incoming spectral intensity, $I_{0}(\widetilde{v})$. Transmittance is related to the wavenumber and temperature dependent absorption cross section, $\sigma(\widetilde{v}, T)$, through the BeerLambert-Bouguer law:

$$
\frac{I_{t r}(\widetilde{v})}{I_{0}(\widetilde{v})}=e^{-\sigma(\widetilde{v}, T) n l}
$$

where $n$ is the molecule concentration (molecule $\mathrm{cm}^{-3}$ ) and $l$ is the sample optical path length $(\mathrm{cm})$. The absorption cross section $\left(\mathrm{cm}^{2}\right.$ molecule $\left.{ }^{-1}\right)$ is then given by

$$
\sigma(\widetilde{v}, T)=\frac{1}{n \cdot l} \cdot \ln \left\{\frac{I_{0}(\widetilde{v})}{I_{t r}(\widetilde{v})}\right\}=\frac{\ln (10)}{n \cdot l} \cdot \lg \left\{\frac{I_{0}(\widetilde{v})}{I_{t r}(\widetilde{v})}\right\}
$$

where $\ln$ is the napierian logarithm and $\lg$ is the common decadic logarithm.

[44] The strength of an absorption band is given by the integral

$$
S\left(\widetilde{v}_{1}, \widetilde{v}_{2}, T\right)=\int_{\widetilde{v}_{1}}^{\widetilde{v}_{2}} \sigma(\widetilde{v}, T) \cdot d \widetilde{v},
$$

where $S\left(\widetilde{v}_{1}, \widetilde{v}_{2}, T\right)$ is the integrated absorption intensity (in units of $\mathrm{cm}^{2}$ molecule $\mathrm{cm}^{-1}$ ) over the wavenumber range $\widetilde{v}_{1}$ to $\widetilde{v}_{2}$.

[45] The absorption cross section depends on temperature for several reasons. First, infrared absorption occurs from a range of rotational energy levels, and the relative populations of these levels are strongly temperature dependent. Secondly, and particularly for molecules containing heavier atoms and in bending vibrations, absorption will not only occur from the vibrational ground state but also from vibrationally excited states - so called hot bands. Since populations depend on the temperature, so will the measured net absorption. Further, molecules often have several stable conformations with different energies and slightly different infrared spectra. The conformational equilibrium and, consequently, the absorption spectrum of such molecules will therefore vary with temperature. While the infrared absorption bands of halocarbons narrow with decreasing 
temperature there is no significant change in the integrated infrared absorption over the atmospherically relevant range [Ballard et al., 2000b; Le Bris et al., 2011; Orlando et al., 1992]. Changes in temperature over the atmospherically relevant range result in narrowing of the absorption bands by a few $\mathrm{cm}^{-1}$ [Orlando et al., 1992]. The error that results from the use of a single infrared spectrum measured at, or near, room temperature to calculate the $\mathrm{RE}$ of a molecule in the whole atmosphere is comparable to, or smaller than, the uncertainties in a single measurement [Ballard et al., $2000 \mathrm{~b}$ ] and so the temperature dependence is often ignored in RE calculations.

\subsubsection{Theoretical Calculations of Infrared Absorption Cross Sections}

[46] Theoretical calculations can be used to provide estimates of infrared vibrational band positions and the intensity of the transitions. The theory underpinning such calculations and their computational intricacies lie outside the scope of this review, but an introduction to the background can be found in Atkins and Friedman [2010]. Despite the complexities of the calculational methods, modern software packages are such that the non-specialist can use them and take advantage of the insights that theoretical calculations offer. Calculations are carried out using a combination of a calculational method and a basis set. Researchers have used traditional molecular orbital ab initio calculations using the 2nd-order Møller-Plesset (MP2) perturbation method, and more recently, the Density Functional Theory (DFT) method. The DFT method is becoming increasingly common, as it provides comparable accuracy to MP2, but at a considerably reduced computational cost. A commonly used DFT method is the Becke, 3-parameter, Lee-Yang-Parr method, commonly known as B3LYP. The basis sets used in modern calculations are comprised of Gaussian-type orbitals, which have characteristics similar to s-, p-, d-, etc. hydrogenic atomic orbitals. Basis sets are described with specific notation; common examples are, in order of increasing basis set size, 6-31G, 6-31G* and 6-31G**. A calculation might be described as B3LYP/6$31 \mathrm{G}^{* *}$, which would mean that the calculation had been carried out using the B3LYP method combined with the $6-31 \mathrm{G}^{* *}$ basis set. There is always a tension between achieving the most accurate description of a molecule which requires a large basis set-and the need to reduce the computational cost of the calculation-which requires a small basis set.

[47] In principle, calculations should be carried out for all possible conformers of a compound, with the final spectrum being a weighted sum of the spectra of the individual conformers. The contribution of each conformer to the overall spectrum is determined by its relative population, which is calculated using the Boltzmann distribution. Bravo et al. [2010b] have tested the importance of including the contribution of conformers to the overall spectrum for $n-\mathrm{C}_{4} \mathrm{~F}_{10}$. They concluded that the change to the RE of including the higher energy conformers was less than 1\%; most calculations use the lowest energy conformer to generate the spectrum used for RE calculations.
[48] Theoretical calculations are subject to quite significant errors, with contributions arising from the method used and the limited size of the basis set. Fortunately, the outputs from the calculations generally provide an estimate of the positions of vibrational bands that differ in a systematic way from the experimentally observed band positions [Scott and Radom, 1996]. The extent to which these differences have a significant impact on radiative forcing efficiency calculations depends on the region of the spectrum where the transitions occur. For example, compounds containing $\mathrm{C}-\mathrm{F}$ bonds have strong absorptions at around $1250 \mathrm{~cm}^{-1}$. In this region of the spectrum, the radiative efficiency function changes rapidly with wavenumber (see section 3.3.1) and so small errors in the band position can have a relatively large impact on calculated REs [Bravo et al., 2010b]. Different researchers have dealt with the systematic errors in different ways; the errors are sometimes ignored [Blowers and Hollingshead, 2009], accounted for by using a generic correction formula [Shine et al., 2005b], or corrected using methods specific to the particular class of compounds under consideration [Bravo et al., 2010b]. Integrated cross sections (over the appropriate wavenumber range) are generally in good agreement (within 5\%) with those determined experimentally [Bravo et al., 2010b].

[49] The output from calculations differs from experimental measurements in that rather than providing an absorption cross section as a function of wavenumber, an integrated absorption cross section (IAC) is calculated for each vibrational band. Conversion to a cross section can be achieved simply by dividing by the appropriate wavenumber interval to get an average cross section over that interval; for example, Pinnock et al. [1995] calculate REs using a $10 \mathrm{~cm}^{-1}$ interval, so IACs are simply divided by $10 \mathrm{~cm}^{-1}$ to get the average cross section over this interval for use in their calculations [Bravo et al., 2010b]. An alternative approach is to "spread" some of the absorption into neighboring wavenumber intervals. Bravo et al. [2010b] showed that spreading $50 \%$ of absorption equally into regions above and below the central interval did not have a significant effect on calculated radiative forcing efficiencies for a number of PFCs using the Pinnock method. However, the impact is likely to be more significant if a narrower wavenumber interval is chosen for the calculations.

[50] For comparison with experiment, the integrated absorption cross sections can be used to simulate spectra assuming the vibrational bands are Gaussian in shape. Figure 4 shows an experimentally determined spectrum of $n-\mathrm{C}_{4} \mathrm{~F}_{10}$ from Bravo et al. [2010b] along with spectra calculated using the B3LYP and MP2 methods. The calculated spectra have been corrected for the systematic errors discussed earlier. The agreement between theory and experiment is very good, particularly for calculations carried out using the B3LYP method. The spectra generated in this way can also be used to calculate radiative forcing efficiencies in the normal way. Again, using the Pinnock method with a $10 \mathrm{~cm}^{-1}$ interval, Bravo et al. [2010b] found that converting the IACs to spectra in this way had only a modest impact on the calculated RE. 


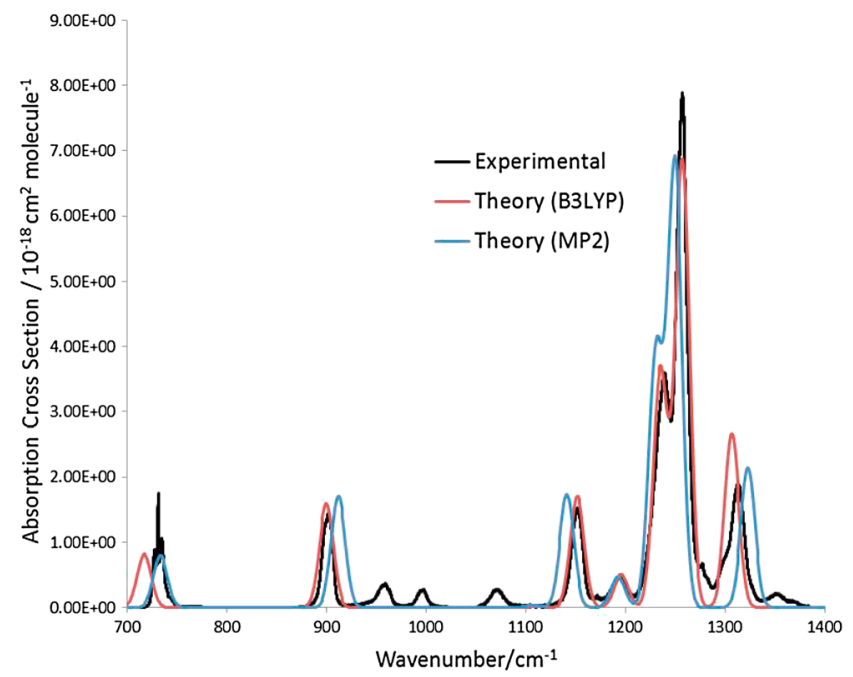

Figure 4. Comparison of experimental and theoretical (B3LYP/6-31G**, MP2/6-31G**) spectra for $n-\mathrm{C}_{4} \mathrm{~F}_{10}$. The theoretical spectra were modeled using Gaussian functions of $14 \mathrm{~cm}^{-1}$ full width. Data taken from Bravo et al. [2010b].

\subsubsection{Database and Sources of Cross-Section Data}

[51] The main sources of experimental infrared absorption cross sections are Ford Motor Company [e.g., Sihra et al., 2001], the SWAGG project (Spectroscopy and Warming potentials of Atmospheric Greenhouse Gases) [Ballard et al., 2000c; Highwood and Shine, 2000], and the two databases HITRAN-2008 (High Resolution Transmission) [Rothman et al., 2009] and GEISA-2009 (which is now referred to as GEISA-2011 on the GEISA website) (Gestion et Etude des Informations Spectroscopiques Atmosphériques) [JacquinetHusson et al., 2011]. Theoretical absorption data from ab initio calculations [Bravo et al., 2011a, 2010b] have also been included here.

[52] The HITRAN-2008 database includes IR cross sections of 31 different gases, many of which are measured at a range of temperatures and pressures. Updates since the previous edition, HITRAN-2004, have been described in detail in Rothman et al. [2009]. In GEISA-2009, IR spectra of 39 different gases are included, again for a wide range of temperatures and pressures. Some of the spectra in GEISA-2009 are from the same source as in HITRAN2008, and when this is the case we disregard the spectrum from GEISA-2009 to avoid duplicates. Jacquinet-Husson et al. [2011] describes the GEISA-2009 database and the updates that have taken place since the 2003 edition.

[53] The absorption cross sections available in the literature have been summarized (Tables 2, 4, 6, 8, 10, 12 and 14) and the spectra which have been used in the calculation of new best estimate REs are highlighted. Each available spectrum has been evaluated and if several cross sections exist from the same laboratory group, only the latest published spectrum has been used in our calculations. In particular, spectra from Sihra et al. [2001] supersede those from Pinnock et al. [1995] and Christidis et al. [1997] since the methodology of the Ford laboratory measurements improved over time. Furthermore, cross sections from laboratory measurements are favored over theoretical calculations, but the latter have been used if experimental spectra are not available for a compound and when significant differences in experimental data exist. The spectrum that was recorded nearest room temperature and atmospheric pressure was used when more than one spectrum was available from a source, as described further in section 3.6.1. The format of theoretical $a b$ initio data differ from experimentally measured infrared spectra; theoretical data consist of values of the central wavenumber and the strength at the vibrational band center. To calculate the radiative efficiencies from these data, they were spread to the $1 \mathrm{~cm}^{-1}$ bin size of our spectrally varying radiative efficiency data (see section 3.3.1). All the cross sections used in this study have been converted to the same format as in HITRAN (more information about this format can be obtained at the HITRAN web site at http://www.cfa.harvard.edu/hitran), and many of the cross sections are available in the supporting information.

\subsection{Atmospheric Lifetimes}

[54] The processes that remove halocarbons from the atmosphere have been described recently [WMO, 2011]; this publication included a discussion of the rationale for recent changes to the recommendations for the lifetimes of a number of species. It is outside of the scope of this review to re-examine these recommendations; we confine ourselves to a summary of the major atmospheric loss processes for halocarbons, which include chemical reaction and photolysis, as well as uptake by the oceans and terrestrial ecosystems. In addition, there are examples of compounds-e.g., $\mathrm{SF}_{5} \mathrm{CF}_{3}$-where dissociative electron attachment may also be important [Takahashi et al., 2002].

[55] The global atmospheric lifetime of a gas was defined in section 2.4 as its burden divided by its loss rate. Under locally defined conditions, lifetimes can be determined as the inverse of a (pseudo-)first-order loss process. For loss of compound $Y$ by reaction with $\mathrm{X}$, we can write the loss rate as:

$$
-\frac{\mathrm{d}[\mathrm{Y}]}{\mathrm{dt}}=\mathrm{k}_{\mathrm{X}}[\mathrm{Y}][\mathrm{X}]
$$

[56] In this process, the pseudo-first-order rate constant for the loss of $\mathrm{Y}$ is equal to $k_{\mathrm{X}}[\mathrm{X}]$, and the lifetime of $\mathrm{Y}$ with respect to reaction with $\mathrm{X}, \tau_{\mathrm{X}}$, is $1 /\left(k_{\mathrm{X}}[\mathrm{X}]\right)=1 / k_{\mathrm{X}}^{\prime}$, with an assumption (or approximation) that $[\mathrm{X}]$ is constant. Integration over space and time yields a global and annual average lifetime of $\mathrm{Y}$ with respect to reaction with $\mathrm{X}$. In the troposphere, the dominant oxidant is the hydroxyl radical, $\mathrm{OH}$. For well-mixed compounds (lifetimes greater than a few months) lifetimes with respect to $\mathrm{OH}$ are determined relative to the lifetime of methyl chloroform, $\mathrm{CH}_{3} \mathrm{CCl}_{3}$. The lifetime of a gas is given as the product of the $\mathrm{CH}_{3} \mathrm{CCl}_{3}$ lifetime and its rate constant for reaction with $\mathrm{OH}$ divided by the $\mathrm{OH}$ rate constant of the gas; see WMO [2011], Prather and Spivakovsky [1990], Spivakovsky et al. [2000] and Montzka et al. [2011] for further detailed discussion.

[57] For photolytic processes, a photolysis rate constant, $J$, is defined with units of $\mathrm{s}^{-1}$, and is given by the expression: 


$$
J=\int_{\lambda_{1}}^{\lambda_{2}} I(\lambda, z) \sigma(\lambda, T) \phi(\lambda, T) \mathrm{d} \lambda,
$$

where $I(\lambda, z)$ is the wavelength-dependent intensity of solar radiation at altitude $z$ (sometimes known as the actinic flux), $\sigma(\lambda, T)$ is the wavelength- and temperature-dependent ultraviolet/visible absorption cross section of the molecule of interest, $\phi(\lambda, T)$ is the wavelength- and temperature-dependent photolysis quantum yield, and $\lambda_{1}$ and $\lambda_{2}$ define the wavelength range over which the calculation is carried out. Integration over space and time yields a global and annual average lifetime with respect to photolysis, $\tau_{J}$.

[58] For a molecule destroyed by both chemical reaction and photolysis (and other processes), the overall global atmospheric lifetime, $\tau_{\text {total }}$ can be written as a combination of the global and annual average lifetimes with respect to the various loss processes:

$$
1 / \tau_{\text {total }}=1 / \tau_{X}+1 / \tau_{J}\left(+1 / \tau_{\text {other }}\right) .
$$

[59] As discussed in section 2.4, loss by chemical reaction within the troposphere is dominated by the reactivity of the hydroxyl radical, OH. For water soluble compounds such as perfluorinated esters, uptake by the oceans may also be important [Kutsuna et al., 2005]. Compounds with lifetimes with respect to reaction with $\mathrm{OH}$ that are greater than a few years will reach the stratosphere, where destruction via photolysis and reaction with $\mathrm{O}\left({ }^{1} \mathrm{D}\right)$ may also contribute. Fully fluorinated compounds have lifetimes typically of several thousands of years and their loss is dominated by photolysis in the mesosphere and thermosphere, while CFCs have lifetimes in the range 50-1000 years and are degraded by photolysis and reaction with $\mathrm{O}\left({ }^{1} \mathrm{D}\right)$ in the stratosphere [Ravishankara et al., 1993].

[60] The calculation of atmospheric lifetimes is complicated. Concentrations of reacting species show strong temporal and spatial variability, and it may be difficult to be confident of the absolute concentrations of these species. The intensity of solar radiation varies strongly with altitude, and the absorption cross sections and quantum yields may show significant dependence on temperature. There are also chemical feedbacks which can affect the lifetime. Given the spatial and temporal variability of reaction partners and photolysis and the potential for chemical feedbacks, it is necessary to use atmospheric models to accurately determine lifetimes, which adds significantly to the complexity of the lifetime determination [Prather, 2007]. There are no unique lifetimes for the shorter lived gases, as their lifetimes depend on the location of emissions and the chemical and physical conditions of the atmosphere. As discussed in section 3.6.3, there are often significant uncertainties associated with atmospheric lifetimes.

\subsection{Radiative Forcing Efficiency}

\subsubsection{Spectrally Varying Radiative Efficiency}

[61] The radiative efficiency calculations carried out here are based on the simple method outlined by Pinnock et al.
[1995] in which a radiative transfer code is used to derive a wavelength-dependent RE for a unit absorption cross section. With this method the instantaneous REs can be estimated directly from the absorption spectrum of a molecule without using a radiative transfer model, as explained in section 2.3. Pinnock et al. [1995] showed that results from their simple method agreed to within $0.3 \%$ with results from a narrowband model. This virtually eliminates the computational time needed and makes it straightforward to perform RE calculations for a large number of compounds. Additionally, when comparing the calculated REs between different compounds, uncertainties related to the absorption spectra are the only factor affecting the comparison, as uncertainties related to the use of different radiative transfer models can be ruled out. The Pinnock method is derived assuming the molecule causing the forcing to be well mixed in the atmosphere. The resulting RE has to be modified to take into account any non-uniformity in the horizontal and vertical distribution; the method by which this is done here is described in sections 3.3.3 and 3.3.4, and is particularly important for emissions of short-lived gases. In principle, the RE should be calculated (in a similar manner to the lifetime, as discussed in section 3.2) by calculating the forcing locally and averaging in space and time to yield the global and annual average RE.

[62] The method proposed by Pinnock et al. [1995] (plus the lifetime correction) is applicable for all compounds with low atmospheric concentrations and therefore weak absorption, such as the halogenated compounds considered here. When this requirement is met, the compound's radiative forcing per spectral interval is proportional to the product of its absorption cross section and its number column density. Pinnock et al. [1995] included a weak absorber with the same cross section at all wavelengths in a narrowband model to calculate the instantaneous, cloudy-sky, RF per unit cross section as a function of wavenumber.

[63] We present here a revised calculation of the instantaneous, cloudy-sky, RF per unit cross section to reflect improvements in the radiative transfer calculations in the period since the Pinnock et al. [1995] curve was derived. Figure 5 illustrates the progression from the original to our final revised Pinnock curve. First we employ the same radiative transfer code (the Reading Narrow Band Model (NBM)) as used in Pinnock et al. [1995] to reproduce the original Pinnock curve, using the (rather dated) globalmean atmospheric profile presented in that paper-the specification of cloud amount was especially crude. We then recalculated the Pinnock curve, incorporating many minor updates to the NBM and in particular the use of a more modern global-mean atmosphere, based on European Centre for Medium-Range Weather Forecasts (ECWMF) and International Satellite Cloud Climatology Project (ISCCP) data [Freckleton et al., 1998]. Figure 5 (top) shows in particular a decrease in the Pinnock curve in the $800-1200 \mathrm{~cm}^{-1}$ region, which mostly reflects an improved characterization of cloud (the longwave cloud forcing increased from 12 to $21 \mathrm{~W} \mathrm{~m}^{-2}$ between the old and the new global-mean atmosphere). At other wavenumbers, the new and old Pinnock 
(a)

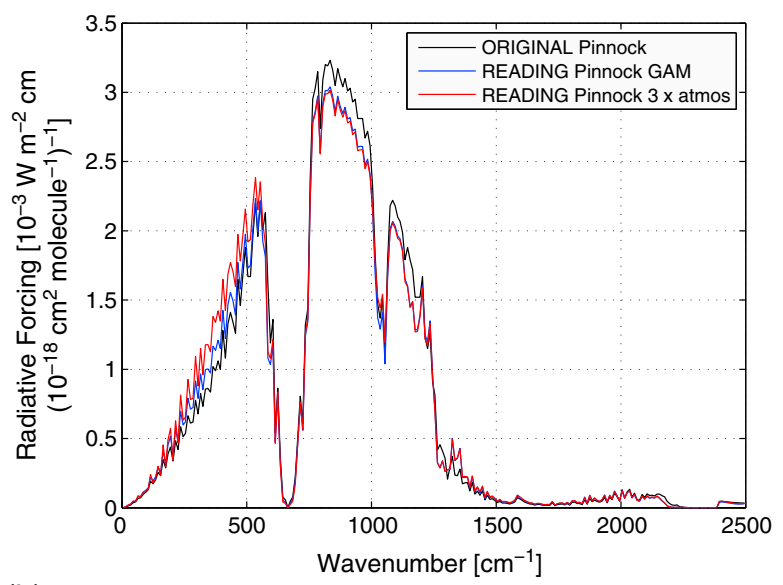

(b)

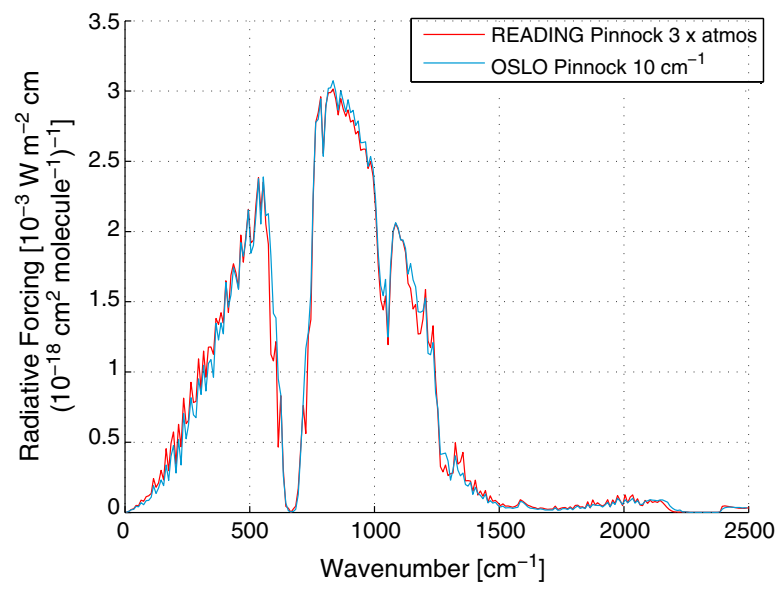

(c)

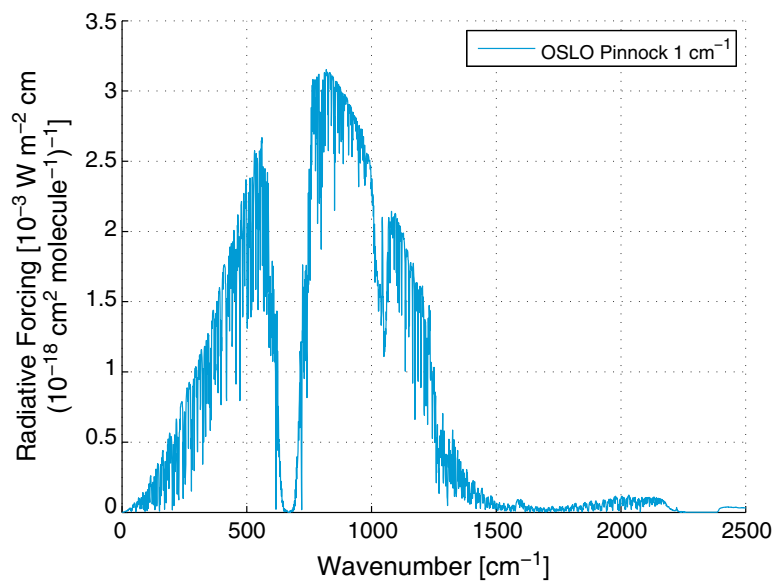

Figure 5. Radiative forcing efficiency (for a $0-1 \mathrm{ppb}$ increase in mixing ratio) per unit cross section compared between the Pinnock et al. [1995] study and this study. The top panel shows the progression from the original Pinnock plot (using the Reading Narrow Band Model (NBM)) on incorporating an updated global-annual mean atmosphere (GAM) and then incorporating three atmospheres representing the tropics and extra-tropics, all at a resolution of $10 \mathrm{~cm}^{-1}$. The middle panel shows a comparison of the Reading NBM and the Oslo Line-by-Line (LBL) model averaged to $10 \mathrm{~cm}^{-1}$ resolution, using atmospheres representing the tropics and extra-tropics. The bottom panel shows the results from the Oslo LBL model at a resolution of $1 \mathrm{~cm}^{-1}$. curves agree well. Next, we recalculated the Pinnock curve using area-weighted results using one tropical and two extratropical profiles [Freckleton et al., 1998], rather than a single global-mean profile. The most marked effect (see red curve on Figure 5 (top)) of using the new profiles is an increase in the Pinnock curve between 100 and $500 \mathrm{~cm}^{-1}$, which reflects the fact that the extratropical profiles are cooler (moving the peak of the Planck function to lower wavenumbers) and drier. At wavenumbers greater than $800 \mathrm{~cm}^{-1}$ there are only small differences between the single and three atmosphere curves. Mixing ratios of other well-mixed gases used in the NBM were $389 \mathrm{ppm}$ for $\mathrm{CO}_{2}, 1800 \mathrm{ppb}$ for $\mathrm{CH}_{4}$ and $323 \mathrm{ppb}$ for $\mathrm{N}_{2} \mathrm{O}$, reflecting contemporary values.

[64] Since we wanted our new Pinnock curve to be based on a LBL code (as it is inherently more accurate and also at higher spectral resolution than the original $\left(10 \mathrm{~cm}^{-1}\right)$ curve) we next generated a Pinnock curve using the Oslo LBL model [Myhre et al., 2006], employing their two (tropical/ extratropical) atmosphere approach. Figure 5 (middle) shows a comparison of the NBM and LBL (averaged to $10 \mathrm{~cm}^{-1}$ resolution) Pinnock curves-there is excellent agreement between the two models. Figure 5 (bottom) shows the final Pinnock curve, using the LBL but now averaged to $1 \mathrm{~cm}^{-1}$ resolution. The effect of using the improved spectral resolution was found to have a negligible impact $(<1-2 \%)$ on the RE calculations for most of the compounds presented in section 4. However, for a few compounds, this effect was stronger, as illustrated in Figure 6. The largest effect was for $\mathrm{CF}_{4}$ because its main absorption band is at the edge of the atmospheric window. For this compound the RE was underestimated by about $8 \%$ when using $10 \mathrm{~cm}^{-1}$ resolution compared to $1 \mathrm{~cm}^{-1}$ resolution of the LBL Pinnock curve.

[65] An Excel spreadsheet with both the updated 1 and $10 \mathrm{~cm}^{-1}$ resolution LBL Pinnock curves is available in the supporting information.

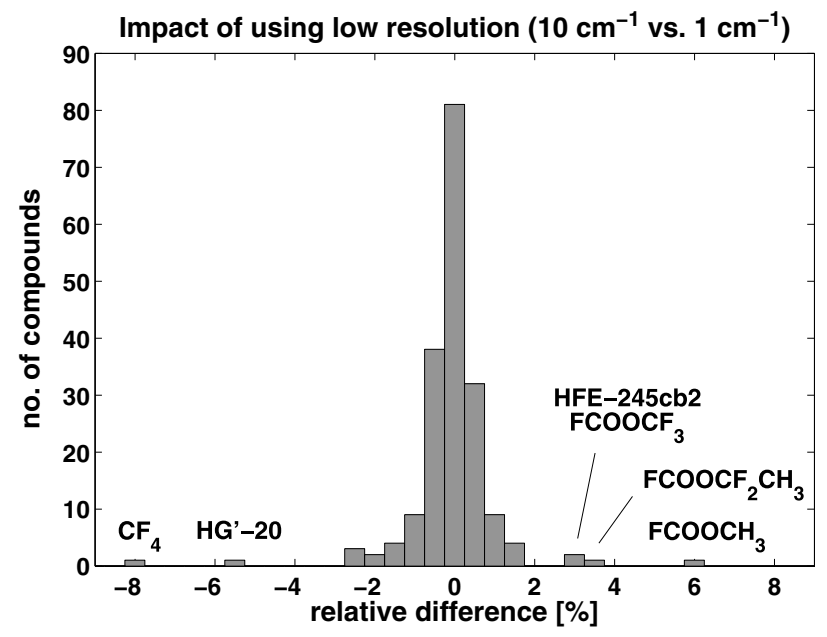

Figure 6. Relative difference in calculation of RE using $1 \mathrm{~cm}^{-1}$ and $10 \mathrm{~cm}^{-1}$ with the Pinnock plot shown in Figure 5 of the compounds investigated in this study. The original LBL calculations are performed with $0.2 \mathrm{~cm}^{-1}$ and then converted to $1 \mathrm{~cm}^{-1}$ and $10 \mathrm{~cm}^{-1}$. 


\subsubsection{Stratospheric Temperature Adjustment}

[66] Generally, halocarbons warm the lower part of the stratosphere because their strongest absorption bands normally occur in the atmospheric window region. For these wavelengths, in the stratosphere, the extra absorption of upwelling radiation by the halocarbon from the surface and troposphere exceeds the amount of extra radiation emitted by the halocarbon. Hence, there will be an increased heating rate of the stratosphere. When stratospheric temperature adjustment is applied, the increased heating rate leads to a warming of the stratosphere. In the new equilibrium state, the higher stratospheric temperatures lead to an increase in the amount of radiation emitted downwards into the troposphere so that the stratosphere-adjusted forcing is higher than the instantaneous forcing. (The reverse is true for $\mathrm{CO}_{2}$ forcing, since it acts to cool the stratosphere so that the stratosphere-adjusted forcing is smaller than the instantaneous forcing.).

[67] Since the Pinnock et al. function used for calculating REs in this study does not take into account the stratospheric temperature adjustment, we have applied a factor to convert from instantaneous to adjusted forcing. Based on several studies [Forster et al., 2005; Jain et al., 2000; Myhre and Stordal, 1997; Naik et al., 2000; Pinnock et al., 1995], we have increased the calculated instantaneous RE for most compounds by $10 \%$ to account for stratospheric temperature adjustment. It should be kept in mind that the effect of stratospheric temperature adjustment can be quite variable for each compound [e.g., Pinnock et al., 1995], particularly for gases which absorb outside the atmospheric window. For a few selected gases (CFC-11, CFC-12, HFC-41 and $\mathrm{CF}_{4}$ ) we have carried out explicit calculations, using the Oslo LBL model, to estimate the ratio between the RE including stratospheric temperature adjustment and the instantaneous RE. For CFC-11 and CFC-12, which have their main absorption bands in the atmospheric window region, the REs were $9.1 \%$ and $10.5 \%$ higher, respectively, when taking the stratospheric temperature adjustment into account. HFC-41 is a special case because its main absorption band overlaps strongly with ozone and our result from the LBL calculation shows a decrease in RE of 5.0\% when accounting for stratospheric temperature adjustment (some of the radiation which would have been absorbed by ozone in the stratosphere is instead trapped by $\mathrm{CH}_{3} \mathrm{~F}$ in the troposphere leading to a cooling of the stratosphere). As stated in section 3.3.1, $\mathrm{CF}_{4}$ absorbs strongly at the edge of the atmospheric window (near $1300 \mathrm{~cm}^{-1}$ ), and our results show an increase in $\mathrm{RE}$ of $10.5 \%$ due to stratospheric temperature adjustment for this compound. Based on these results and on previous literature [e.g., Myhre and Stordal, 1997; Pinnock et al., 1995] we consider a 10\% increase a good approximation for most gases.

\subsubsection{Simulations of Atmospheric Distributions and Lifetimes}

[68] The effect of non-uniform vertical profiles on radiative forcing has been investigated in several studies [e.g., Freckleton et al., 1998; Jain et al., 2000; Naik et al., 2000; Sihra et al., 2001], and is described in section 2.4. To further investigate and reduce the uncertainties associated with the correction factors for compounds which are mainly lost in the troposphere through reaction with $\mathrm{OH}$, and normally have a relatively short lifetime, a number of simulations have been carried out with a 3-D Chemistry-Transport Model (CTM) in combination with a radiative transfer model. The models chosen for this purpose are the global offline Oslo CTM2 model [Berglen et al., 2004; Søvde et al., 2008] and the Oslo broadband radiative transfer model [Myhre and Stordal, 1997].

[69] The setup of the CTM simulations is similar to the studies of Acerboni et al. [2001] and Sellevag et al. [2004b] where a total of 6 short-lived halocarbons were implemented in the Oslo CTM2. Here we have implemented the following 9 halocarbons in the model, which were chosen to represent a range of atmospheric lifetimes ( $\sim 10$ days to 5.2 years): $\mathrm{HFC}-1234 \mathrm{yf}\left(\mathrm{CF}_{3} \mathrm{CF}=\mathrm{CH}_{2}\right), \mathrm{HFE}-356 \mathrm{mmz} 1$ $\left(\mathrm{CH}_{3} \mathrm{OCH}\left(\mathrm{CF}_{3}\right)_{2}\right)$, HFE-254eb2 $\left(\mathrm{CH}_{3} \mathrm{OCHFCF}_{3}\right), \mathrm{HFC}-161$ $\left(\mathrm{CH}_{3} \mathrm{CH}_{2} \mathrm{~F}\right), \mathrm{CH}_{3} \mathrm{Br}, \mathrm{HCFC}-123 \quad\left(\mathrm{CF}_{3} \mathrm{CCl}_{2} \mathrm{H}\right), \mathrm{HFC}-152 \mathrm{a}$ $\left(\mathrm{CH}_{3} \mathrm{CHF}_{2}\right)$, HFC-143 $\left(\mathrm{CH}_{2} \mathrm{FCHF}_{2}\right)$ and HFC-32 $\left(\mathrm{CH}_{2} \mathrm{~F}_{2}\right)$. The compounds were assumed to only react with the hydroxyl radical $(\mathrm{OH})$, which is the main loss for most short-lived halocarbons, and their reaction rate coefficients were taken from the NASA/JPL database [Sander et al., 2010]. In a reference simulation, the geographical distribution of the emissions was the same as for CFC-11 [McCulloch et al., 1994], while in a sensitivity simulation the emission distribution was set the same as for black carbon (BC) [Bond et al., 2004; van der Werf et al., 2006] with the purpose of studying the impact of having a larger share of the emissions occurring at lower latitudes near the equator. It should be kept in mind that the sensitivity simulation is considered a rather extreme case as halocarbons are industrial chemicals and their emission distribution is more likely to follow that for other industrial compounds, such as CFC-11, than for species like black carbon which has significant non-industry related sources. In both cases, the anthropogenic emissions of other compounds were taken from the RETRO [2006] database for year 2000. The model was run repeatedly for the meteorological year 2000 with uniform annual emissions, and a sufficient amount of spin-up time was allowed to obtain chemical steady-state at levels that yield globally averaged surface mixing ratios of approximately $1 \mathrm{ppb}$. The model has been driven by meteorological forecast data from the ECMWF IFS model cycle 36, as explained by Søvde et al. [2011], and run at a horizontal resolution of approximately $2.8^{\circ} \times 2.8^{\circ}(\mathrm{T} 42)$ and 60 vertical layers distributed from the surface to $0.1 \mathrm{hPa}$.

[70] Figure 7 shows the calculated atmospheric distribution of HFC-161, which has a lifetime with respect to $\mathrm{OH}$ of 84 days in the reference simulation. In the sensitivity simulation with a "BC-like" emission distribution, the global burden is smaller, and hence the lifetime is shorter (71 days), due to the higher concentrations of $\mathrm{OH}$ found near the tropics. Due to the relatively short lifetime of HFC-161, the distribution of surface concentrations reflects the regions of emissions quite well (Figure 7, top). The reference simulation reveals large concentrations in the northern hemisphere, and particularly over the industrial areas in US and Europe, while the 
(a)

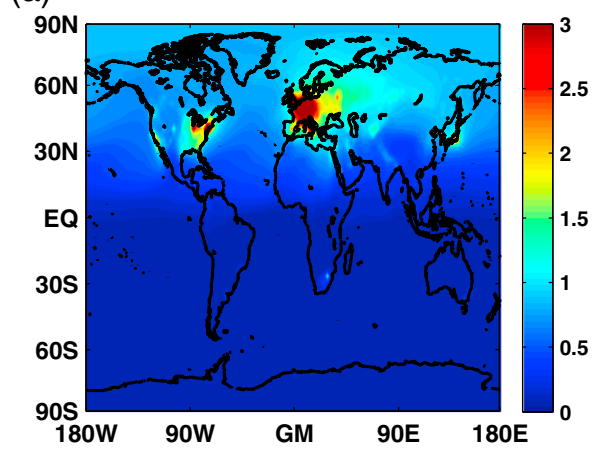

(c)

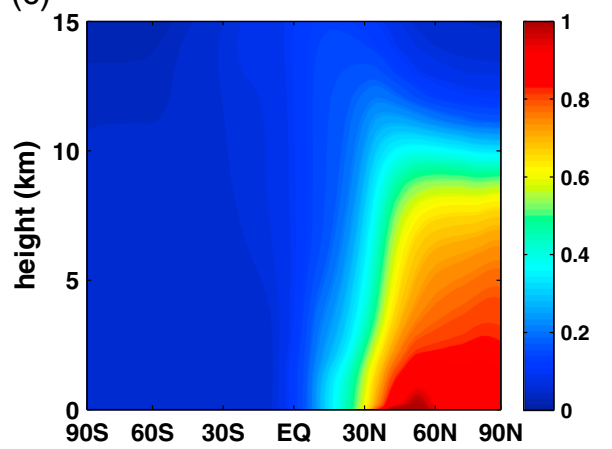

(b)

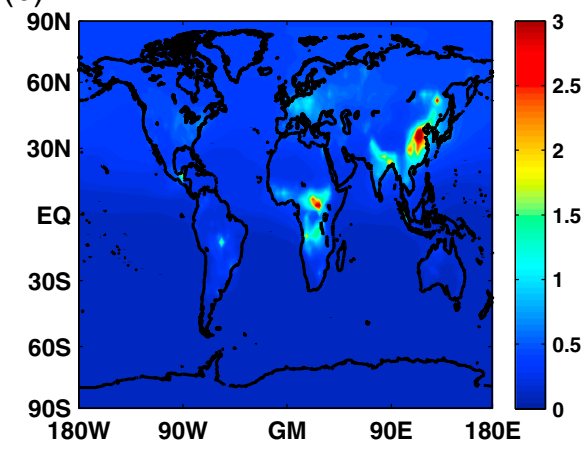

(d)

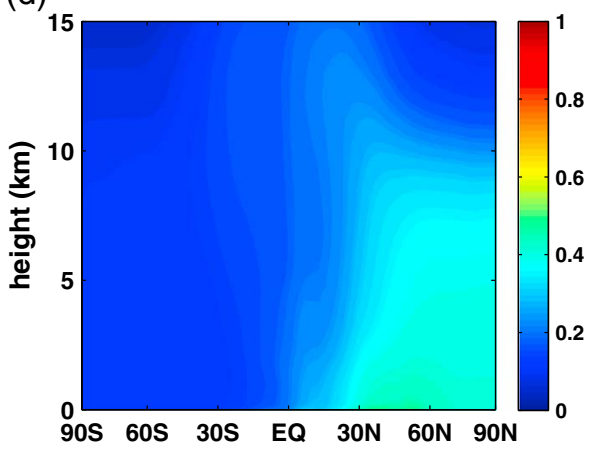

Figure 7. Annual average distribution of HFC-161 mixing ratio (ppb) at the surface (top panels) and averaged zonally (bottom) for the reference simulation with emission distribution as for CFC-11 (left) and the sensitivity simulation with emission distribution as for $\mathrm{BC}$ (right) calculated with the Oslo CTM2 model (see text for details).

sensitivity simulation shows a weaker gradient between the hemispheres, and with surface maxima over Southeast Asia and the biomass burning regions in Africa. Furthermore, the vertical profile is different between the two runs with a stronger decay of mixing ratios with altitude in the simulation with "CFC-11-like" emission distribution compared to the simulation with "BC-like" emission distribution.

[71] The Oslo CTM2 simulated distributions of the halocarbons have been used for RF calculations with the Oslo broadband model [Myhre and Stordal, 1997]. In the radiative transfer calculations we also use 60-layer meteorological data from the ECMWF-IFS model, but with a reduced horizontal resolution of $5.6^{\circ} \times 5.6^{\circ}(\mathrm{T} 21)$. Annual mean cloudy-sky RF (with stratospheric temperature adjustment included) has been calculated using the radiative transfer model (based on monthly mean data), which has been run both with a constant global and annual mean vertical profile (so that the global and annual mean surface mixing ratio is used at all heights, latitudes, longitudes and times), and with the monthly mean atmospheric distribution calculated by Oslo CTM2. A quantification of the importance of using realistic vertical profiles rather than constant profiles was then obtained by calculating the fractional difference between the resulting RF from the two radiative transfer simulations.

[72] In addition to the model runs explained above, simulations were carried out with the Oslo LBL model to quantify the effect of a non-uniform vertical profile for compounds which are mainly lost by photolysis in the stratosphere. Such compounds (i.e., mainly CFCs and halons) are well-mixed in the troposphere but their mixing ratios decay with increasing altitude in the stratosphere. Hence, they have a different vertical profile, and their atmospheric concentrations are also much less influenced by the horizontal distribution of emissions, than the compounds with lifetimes governed by $\mathrm{OH}$ destruction. The three compounds Halon-1211, CFC-11 and CFC-12 were chosen for the LBL model experiments because they span a relatively wide range of lifetimes (16 to 100 years) [WMO, 2011], and because vertical profiles of these compounds were available from CTM simulations. The vertical profiles of the two CFCs were taken from Myhre and Stordal [1997] while the Halon-1211 profiles were fit to the annual mean output from Oslo CTM2, averaged separately over the tropics and the extra-tropics. For all three compounds the mixing ratios were assumed to decrease exponentially above the tropopause in the radiation code.

[73] To validate the vertical profiles of CFC-11 mixing ratio used in the Oslo radiative transfer model (results presented in section 3.3.4), we have compared these data with a recently derived climatology from the MIPAS satellite instrument [Hoffmann et al., 2008] in Figure 8. This MIPAS data set has been thoroughly validated against several other satellite observations, as well as airborne and ground-based measurements [Hoffmann et al., 2008]. For comparison the CFC-11 vertical profiles from the Oslo CTM2 simulations are also included in Figure 8, although 

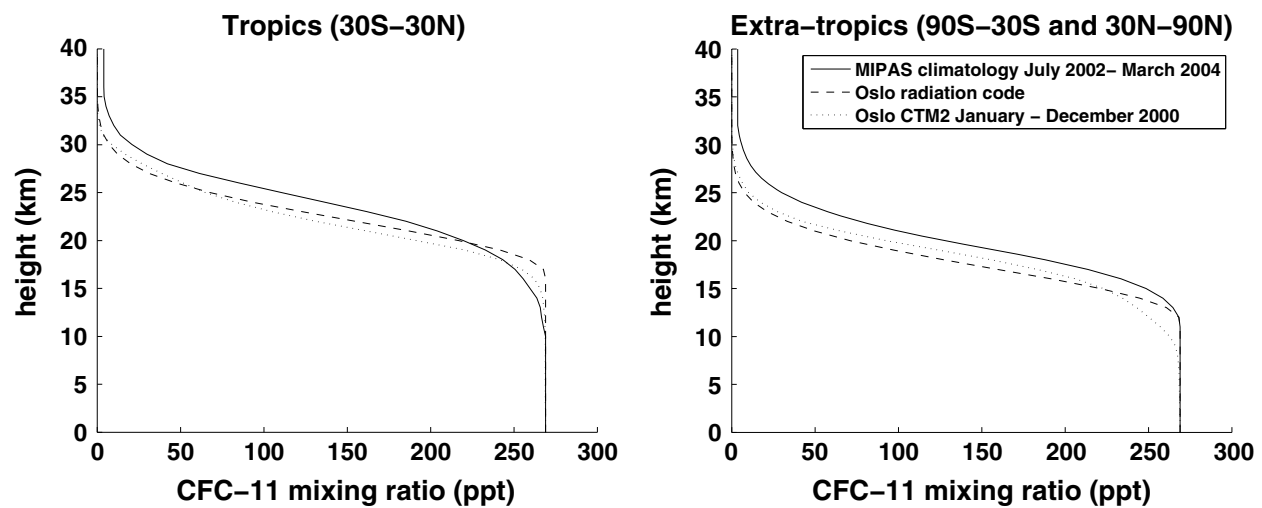

Figure 8. Vertical profiles of CFC-11 mixing ratio (ppt) in the tropics (left) and the extra-tropics (right) from MIPAS observations [Hoffmann et al., 2008], the Oslo radiation code, and the Oslo CTM2 model. The profiles have been scaled to the year 1994 tropospheric mixing ratio of $269 \mathrm{ppt}$ as in Minschwaner et al. [2012].

these results are not used here directly (only the Halon-1211 profiles were used, as explained above). It should be noted that the mixing ratios of CFC-11 calculated by Oslo CTM2 are largely governed by the top and bottom boundary conditions taken from the Oslo 2-D stratospheric chemistry model
[Stordal et al., 1985] which is based on WMO recommendations. CFC-11 has a relatively long lifetime of about 45 years $[W M O, 2011]$ and its main loss is photolysis in the stratosphere. As a consequence, CFC-11 is wellmixed throughout the troposphere, while its concentration

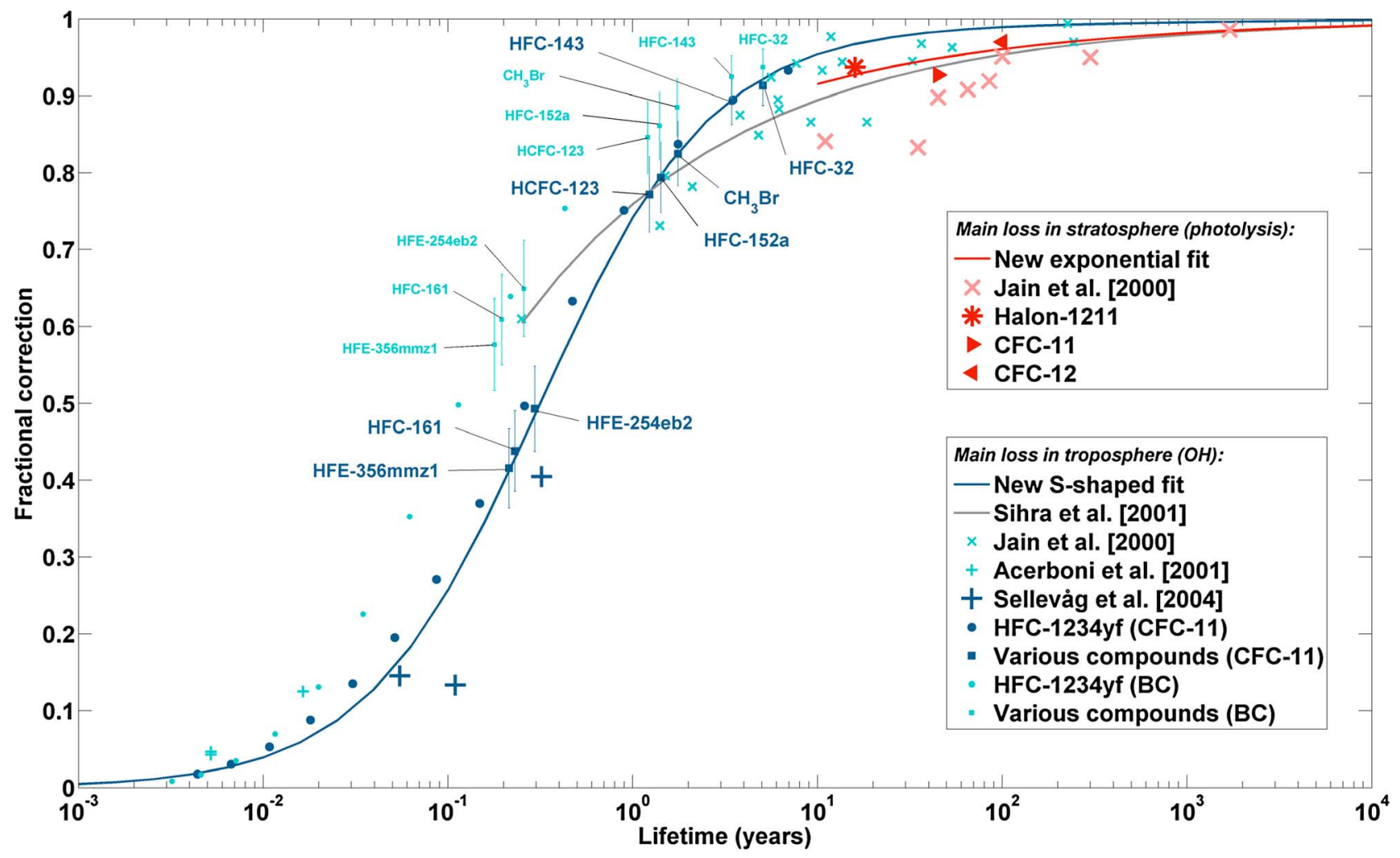

Figure 9. Factor needed to correct RE to account for non-uniform vertical and horizontal distribution versus atmospheric lifetime. The red symbols are for compounds whose main loss mechanism is stratospheric photolysis, while the blue symbols are for compounds which are mainly lost in the troposphere by reaction with $\mathrm{OH}$. Dark blue symbols have been used in the calculation of the $S$-shaped fit, and dark red symbols have been used in the calculation of the exponential fit. Light blue and light red symbols are shown for comparison. The curve from Sihra et al. [2001] represents an empirical least squares fit to the fractional correction factors from Jain et al. [2000]. The parentheses designate whether the results are from the simulations with "CFC-11-like" or "BC-like" emission distribution. For the compounds where several different absorption bands have been used in the RF calculations, both the mean and the standard deviation of the fractional corrections are shown. 
decreases with height in the stratosphere. This reduction with height has a major impact on the compound's radiative forcing [e.g., Freckleton et al., 1998], and it is therefore important that the models include realistic vertical profiles. The comparison between the Oslo radiation code and the Oslo CTM2 model shows that the assumption of an exponential decay of CFC-11 mixing ratios above the tropopause in the radiation code works relatively well (Figure 8). Furthermore, the CFC-11 vertical profiles employed in both models are in relatively good agreement with the climatology derived from MIPAS observations. Some discrepancies can be seen, especially near the tropical tropopause region, but it should be noted that differences between climatologies derived from satellite observations are also evident [Hoffmann et al., 2008] (their Figure 11), and that tropical stratospheric measurements of CFC-11 is a major source of uncertainty [Minschwaner et al., 2012] (see also their Figure 6). The vertical profiles are shown separately for the tropics $\left(30^{\circ} \mathrm{S}-30^{\circ} \mathrm{N}\right)$ and the extra-tropics $\left(90^{\circ} \mathrm{S}-30^{\circ} \mathrm{S}\right.$ and $30^{\circ} \mathrm{N}-90^{\circ} \mathrm{N}$ ) in Figure 8 due to the different tropopause heights. These two regions are also the same as used in the two-atmosphere setup of the Oslo radiation code.

\subsubsection{Fractional Correction Versus Lifetime}

[74] Results from the experiments described in section 3.3.3 are shown in Figure 9 together with results from previous studies [Acerboni et al., 2001; Jain et al., 2000; Sellevag et al., 2004b]. Our calculations differ from previous studies in three important respects. First, a number of hypothetical "HFC-1234yf-like" molecules were studied. These compounds all had the infrared spectrum of HFC-1234yf but had different atmospheric lifetimes ranging from approximately 1 day to 7 years. Variation of the lifetime within the model was achieved by assuming rate coefficients for reaction with $\mathrm{OH}$ radicals in the range of $4.3 \times 10^{-15}$ to $3.5 \times 10^{-11} \mathrm{~cm}^{3}$ molecule ${ }^{-1} \mathrm{~s}^{-1}$. The results are shown by the filled circles in Figure 9. Second, the literature values for the rate coefficients for reactions of $\mathrm{OH}$ radicals with the remaining 8 compounds were used, but this time we did not use the actual absorption spectra for the compound for the radiative transfer calculations. Instead, we chose to span the vertical axis, representing the fractional correction, by repeating the RE calculation 6 times for each gas, using different absorption bands which were either within or at the borders of the atmospheric window region. More specifically, these bands were centered at wavenumbers of 631 (absorption band of $\left.\mathrm{CF}_{4}\right), 714\left(\mathrm{C}_{2} \mathrm{~F}_{6}\right), 948\left(\mathrm{SF}_{6}\right)$, $1116\left(\mathrm{C}_{2} \mathrm{~F}_{6}\right), 1250\left(\mathrm{C}_{2} \mathrm{~F}_{6}\right)$, and $1283\left(\mathrm{CF}_{4}\right) \mathrm{cm}^{-1}$. Figure 9 shows the fractional correction for the mean (filled squares) and standard deviation (vertical lines) of these 6 bands for each of the 8 gases. It should be noted that the fractional correction depends primarily on lifetime, but to some extent also on the position of the absorption bands; absorption bands inside the atmospheric window region has the weakest correction. Third, the correction factors for compounds with stratospheric photolysis as the primary loss mechanism have been calculated using a two-atmosphere approach, and are shown by the red symbols in Figure 9.
[75] Several interesting features can be seen in Figure 9. The lifetimes calculated by the Oslo CTM2 are shorter when the geographical distribution of emissions was "BC-like" rather than "CFC-11-like," especially for lifetimes shorter than approximately 0.5 years. This is not surprising as the levels of $\mathrm{OH}$ are highest near the tropics (where a large share of the "BC-like" emissions takes place) because of higher humidity and more incoming solar radiation at low latitudes. Another interesting feature is that the fractional correction is weaker (i.e., closer to 1) in the run with "BC-like" emissions than the reference run with "CFC-11-like" emissions for lifetimes longer than about 0.003 years, or 1 day, while it is stronger for lifetimes shorter than 1 day. One reason for this is the higher RF for well-mixed greenhouse gases near the equator than at higher latitudes, because of higher temperatures [Shine and Forster, 1999].

[76] For the compounds with similar lifetimes as in Jain et al. [2000], the fractional corrections in our reference simulation roughly agree with their corrections, except for the compound in Jain et al. [2000] that has a lifetime of 0.25 years and a fractional correction of 0.61 , which is closer to our results from the simulation with "BC-like" emission distribution. Part of the reason is probably that Jain et al. [2000] used a 2-D model with geographically constant surface mixing ratios, while we use a 3-D model with an assumed (and likely more realistic) emission distribution. In fact, another Oslo CTM2 sensitivity simulation with surface mixing ratios fixed at $1 \mathrm{ppb}$ globally (results not shown) gives a very similar vertical profile and fractional correction factor as the simulation with "BC-like" emission distribution. Interestingly, the three compounds studied in Sellevag et al. [2004b] have smaller fractional correction factors than our results, and they do not always show an increase of fractional correction proportional with the lifetime. As the models and simulation setup are quite similar to this study, the differences can probably be attributed to the absorption spectra, which are different for the various compounds. Figure 9 shows that the spectral position has some influence on the fractional correction and causes a maximum deviation from the mean of $\pm 10 \%$. On the other hand, the results from Acerboni et al. [2001] show slightly higher fractional correction factors than in our study, presumably because they used a constant surface mixing ratio all over the globe instead of an assumed emission distribution.

[77] Sihra et al. [2001] derived an empirical curve fit (see grey curve in Figure 9) to the values in Jain et al. [2000] and this has been used in later studies [e.g., Bravo et al., 2011a; Gohar et al., 2004]. Their fit is given by $f(\tau)=1-0.241 \tau^{-0.358}$, where $f$ is the fractional correction and $\tau$ is the lifetime in years for lifetimes greater than 0.25 years. Here we have derived two new empirical curve fits, one for compounds dominated by loss in the troposphere through $\mathrm{OH}$ reaction, and one for compounds dominated by loss through stratospheric photolysis. In the latter case we have used a similar approach as Sihra et al. [2001] and derived an exponential fit, but this time only results from explicit LBL calculations discussed in section 3.3.3 have been used. We further assumed that $f=1$ for very long lifetimes. The resulting exponential function is given by 


$$
f(\tau)=1-0.1826 \tau^{-0.3339}
$$

and is shown in Figure 9 by the red curve for $10<\tau<<10,000$ years. Equation (1) has been used to calculate lifetimecorrected RE for some of the compounds presented in section 4. In the case for compounds dominated by tropospheric $\mathrm{OH}$ loss, the empirical fit was restricted to results from 3-D model experiments where a "CFC-11-like" emission distribution was assumed. This means that the results from Acerboni et al. [2001] and the 2-D model of Jain et al. [2000] were not considered when deriving the fit (but still shown in Figure 9 for comparison), while the results of Sellevag et al. [2004b] were included along with results from the present study. As we now want to include compounds with very short lifetimes, the empirical curve fit was constrained to form an $S$-shaped curve in Figure 9 with the following formula:

$$
f(\tau)=\frac{a \tau^{b}}{1+c \tau^{d}},
$$

where $a, b, c$ and $d$ are constants with values of 2.962 , $0.9312,2.994$, and 0.9302 , respectively. The curve was further constrained to give $f=0$ for very short lifetimes and $f=1$ for very long lifetimes. The resulting $S$-shaped function is shown in Figure 9 by the dark blue curve for $10^{-4}<\tau<10^{4}$ years, and has been used to calculate lifetime corrected RE values for most of the compounds presented in section 4 .

\subsection{Discussion of Impact of Functional Groups on Spectra/Radiative Forcing}

[78] The infrared spectra of polyatomic molecules are made up of a number of vibrational bands, each containing rotational fine structure that may, or may not, be resolved. For a nonlinear molecule containing $\mathrm{N}$ atoms, there are $3 \mathrm{~N}-6$ normal vibrations, although this number of bands may not be visible in the spectrum. Bands may overlap with each other, may lie outside of the spectral range of the measurements, may be forbidden or the vibrational mode may be degenerate. For example, the tetrahedral molecule, $\mathrm{CF}_{4}$ has a total of 9 normal vibrations, but only one band is observed in its infrared spectrum (as illustrated in Figure 3). The molecule has stretching and a variety of bending vibrations, but the bending vibrations occur at lower wavenumber (ca. $400 \mathrm{~cm}^{-1}$ ) than can usually be observed in an infrared measurement. At the same time, as it contains four $\mathrm{C}-\mathrm{F}$ bonds, it is expected to have four stretching normal vibrations. A simple analysis of the symmetry properties of the stretching modes shows that one is the totally symmetric $\left(\mathrm{A}_{1}\right)$ stretch, which cannot be accessed in an allowed infrared transition. The other three vibrations turn out to be three-fold degenerate (symmetry species $\mathrm{T}_{2}$ ) and give rise to a single allowed transition at around $1280 \mathrm{~cm}^{-1}$. Molecules with lower symmetry will exhibit more bands, as degenerate vibrations are less likely to occur.

[79] In the case of $\mathrm{CF}_{4}$, it is clearly possible to identify the $\mathrm{T}_{2}$ vibration as a C-F stretching vibration, which is a specific example of a group vibration. In general, a normal mode of vibration involves movement of all the atoms in a molecule and it is not always possible to assign transitions to particular group vibrations. From the perspective of determining radiative efficiencies, the majority of spectral features of importance occur in the region between 1500 and $500 \mathrm{~cm}^{-1}$. This region is called the fingerprint region and usually contains a complicated series of absorptions, and it is often difficult to clearly identify group vibrations within this region. Nevertheless, some features may be identified. Molecules containing $\mathrm{H}$ atoms will have $\mathrm{C}-\mathrm{H}$ stretching vibrations that produce transitions in the $3000 \mathrm{~cm}^{-1}$ region of the spectrum, well outside of the region of interest here. On the other hand, $\mathrm{C}-\mathrm{H}$ bending vibrations are expected at around $1400 \mathrm{~cm}^{-1}$ and are a common feature of many HFCs [e.g., Sihra et al., 2001]. We have already seen that C-F stretching gives rise to a band at $1280 \mathrm{~cm}^{-1}$, and bands in this region are observed in a wide range of fluorinecontaining compounds [e.g., Bravo et al., 2010b; Sihra et al., 2001]. However, it should be noted that the electronwithdrawing properties of neighboring groups can have a significant influence on band position. While molecules with a relatively high fluorine content show a $\mathrm{C}-\mathrm{F}$ stretching feature at around $1200-1300 \mathrm{~cm}^{-1}$, HFC-41 $\left(\mathrm{CH}_{3} \mathrm{~F}\right)$ shows only a feature at $1000-1100 \mathrm{~cm}^{-1}$, which corresponds to the expected position for a $\mathrm{C}-\mathrm{F}$ group vibration given in standard spectroscopy textbooks such as Hollas [2004]. For this reason, care must be used when assigning observed bands to individual group vibrations in the spectra of heavily halogenated molecules.

\subsection{Description of Metrics}

[80] The motivation for the choice of metrics adopted here (GWP and GTP) was given in section 2.5.

\subsubsection{The Global Warming Potential (GWP)}

[81] The Global Warming Potential (GWP) is based on the time-integrated radiative forcing due to a pulse emission of a unit mass of gas. It can be given as an absolute GWP for gas $i\left(\mathrm{AGWP}_{\mathrm{i}}\right)$ (usually in $\mathrm{W} \mathrm{m} \mathrm{m}^{-2} \mathrm{~kg}^{-1}$ year) or as a dimensionless value by dividing the $\mathrm{AGWP}_{\mathrm{i}}$ by the AGWP of a reference gas, normally $\mathrm{CO}_{2}$. Thus, the GWP is defined as:

$$
G W P_{i}(H)=\frac{\int_{0}^{H} R F_{i}(t) d t}{\int_{0}^{H} R F_{C O_{2}}(t) d t}=\frac{A G W P_{i}(H)}{A G W P_{C_{2}}(H)} .
$$

[82] A user choice is the time horizon $(H)$ over which the integration is performed. IPCC has usually presented GWP for 20, 100 and 500 years and the Kyoto Protocol has adopted GWPs for a time horizon of 100 years.

[83] For a gas $i$, if $A_{i}$ is the RE, $\tau_{i}$ is the lifetime (and assuming its removal from the atmosphere can be represented by exponential decay), and $H$ is the time horizon, then the integrated RF up to $\mathrm{H}$ is given by:

$$
A G W P_{i}(H)=A_{i} \tau\left(1-\exp \left(-\frac{H}{\tau}\right)\right)
$$

[84] This is an approximation that holds for long-lived gases but is less accurate for shorter lived gases whose 


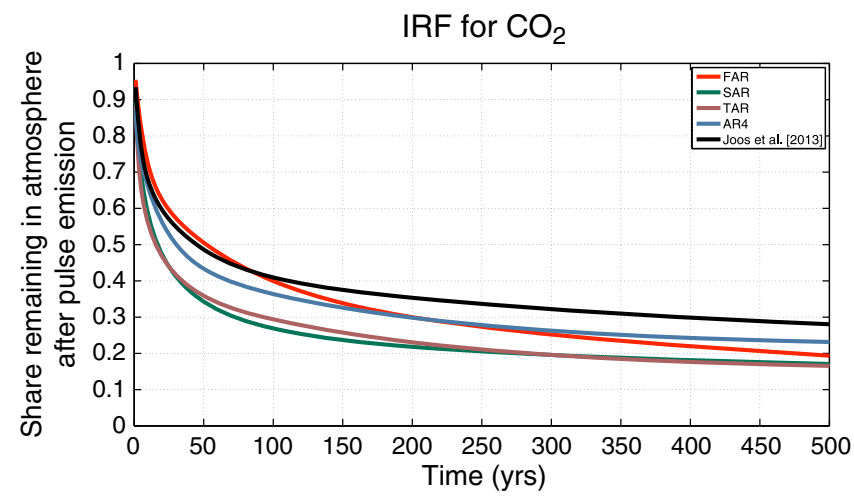

Figure 10. Impulse response functions from the four IPCC assessments and from the recent multi-model study of Joos et al. [2013]. Note that the IRF from FAR [IPCC, 1990] and SAR [IPCC, 1995] did not include climate-carbon cycle feedbacks, while these are included in IRFs from TAR [IPCC, 2001], AR4 [IPCC, 2007], and Joos et al. [2013].

lifetimes depend on location of emissions and physical and chemical conditions of the atmosphere. Prather [2007] developed a concept of atmospheric chemistry as a coupled system across different trace species with transport between different regions and radiative feedbacks. Due to these processes a perturbation to one species in one location will lead to a global response on a wide range of time scales, often involving many other chemical components. The chemistrytransport system can be linearized and represented by eigenvalue decomposition [Prather, 2007] that are perturbation patterns of trace gas abundances, also known as chemical modes. Any perturbation to atmospheric composition can be expressed as a sum of chemical modes, each with a fixed decay term.

[85] The AGWP for $\mathrm{CO}_{2}$ is more complicated, because its atmospheric response time (or lifetime of a perturbation) cannot be represented by a simple exponential decay. This situation arises because $\mathrm{CO}_{2}$ is absorbed into the various regions of the oceans (surface water, thermocline, deep ocean) on a range of different timescales. As a consequence, following a pulse emission of $\mathrm{CO}_{2}$ the perturbation of the atmospheric concentration of $\mathrm{CO}_{2}$ remains significant ( $>20 \%$ ) even after 1000 years. The decay of a perturbation of atmospheric $\mathrm{CO}_{2}$ following a pulse emission at time $t$ is usually approximated by Joos et al. [2013]:

$$
\operatorname{IRF}(t)=a_{0}+\sum_{i=1}^{3} a_{i} \exp \left(-\frac{t}{\alpha_{i}}\right)
$$

where the parameter values are $a_{0}=0.2173, a_{1}=0.2240$, $a_{2}=0.2824, a_{3}=0.2763, \alpha_{1}=394.4$ years, $\alpha_{2}=36.54$ years and $\alpha_{3}=4.304$ years. The parameter values for the impulse response function (IRF) are based on a recent multi-model study [Joos et al., 2013], and these values have been used here. For comparison the parameter values from Forster et al. [2007] were $a_{0}=0.217, a_{1}=0.259, a_{2}=0.338$, $a_{3}=0.186, \alpha_{1}=172.9$ years, $\alpha_{2}=18.51$ years and $\alpha_{3}=1.186$ years (see footnote a, Table 2.14 in Forster et al. [2007]).
[86] Then the $\mathrm{AGWP}_{\mathrm{CO} 2}$ can be given as:

$$
\begin{aligned}
& A G W P_{\mathrm{CO}_{2}}(H) \\
& =A_{\mathrm{CO}_{2}}\left\{a_{0} H+\sum_{i=1}^{3} a_{\mathrm{i}} \alpha_{\mathrm{i}}\left(1-\exp \left(-\frac{H}{\alpha_{i}}\right)\right)\right\}
\end{aligned}
$$

[87] Note that the parameters used in calculating the AGWP are dependent on the choice of background state, but it is convention to use present-day conditions. While the models used to calulate IRF for $\mathrm{CO}_{2}$ usually include climate-carbon cycle feedbacks, usually no climate feedbacks are included for the non- $\mathrm{CO}_{2}$ gases.

\subsubsection{The Global Temperature Change Potential (GTP)}

[88] GTP is presented as an alternative to the GWP and uses the change in global mean temperature for a chosen point in time as the impact parameter. While GWP is a metric integrative in time, the GTP is based on the temperature change per unit emissions for a selected year, $t$. As for the GWP, the impact of $\mathrm{CO}_{2}$ is normally used as reference, thus,

$$
G T P(t)_{i}=A G T P(t)_{i} / A G T P(t)_{C O 2}=\Delta T(t)_{i} / \Delta T(t)_{C O 2},
$$

where AGTP $\left(\mathrm{K} \mathrm{kg}^{-1}\right)$ is the absolute GTP. The assumed lifetime of $\mathrm{CO}_{2}$ is the same as that given for the GWP in section 3.5.1.

[89] In the calculations here, we represent the thermal inertia of the climate system following the method used by Fuglestvedt et al. [2010]. This includes a representation of the deep ocean as well as the ocean mixed layer based on a temperature response function with two time-constants derived from climate model results [Boucher and Reddy, 2008]. The derived GTPs are dependent on the assumed value of climate sensitivity [Shine et al., 2005a; Shine et al., 2007], which is implicit in the Boucher and Reddy response functions, and is equal to about $1 \mathrm{~K}\left(\mathrm{~W} \mathrm{~m}^{-2}\right)^{-1}$.

\subsubsection{The Reference Gas $\mathrm{CO}_{2}$}

[90] The metric values need updating due to new scientific knowledge about various properties, but also due to changes in lifetimes and radiative efficiencies caused by changing atmospheric background conditions.

[91] For the reference gas $\mathrm{CO}_{2}$, such changes (i.e., in $\mathrm{AGWP}_{\mathrm{CO} 2}$ and $\mathrm{AGTP}_{\mathrm{CO} 2}$ ) will affect all the other gases. With increasing $\mathrm{CO}_{2}$ levels in the atmosphere the marginal radiative forcing is reduced, while at the same time the ocean uptake is reduced and airborne fraction increased. These changes (working in opposite directions) lead to changes in $\mathrm{AGWP}_{\mathrm{CO} 2}$ and $\mathrm{AGTP}_{\mathrm{CO} 2}$. Updates to $\mathrm{AGWP}_{\mathrm{CO} 2}$ are often presented in IPCC and WMO Ozone assessments.

[92] The radiative forcing for a change in atmospheric mixing ratio of $\mathrm{CO}_{2}, \Delta C$, can be approximated using the expression based on radiative transfer models [Myhre et al., 1998]:

$R F=\alpha \ln \left(\left(C_{0}+\Delta C\right) / C_{0}\right)$,

where $\alpha=5.35 \mathrm{~W} \mathrm{~m}^{-2}$ and $C_{0}$ is the atmospheric mixing ratio of $\mathrm{CO}_{2}$. The radiative efficiency of $\mathrm{CO}_{2}$ at this value of $C_{0}$ can then be approximated using this expression for 
small $\Delta C$. The $\mathrm{RE}$ of $\mathrm{CO}_{2}$ changed from $0.0147 \mathrm{~W} \mathrm{~m}^{-2}$ $\mathrm{ppm}^{-1}$ to $0.0141 \mathrm{~W} \mathrm{~m}^{-2} \mathrm{ppm}^{-1}$ when atmospheric $\mathrm{CO}_{2}$ levels increased from 364 to $378 \mathrm{ppm}$, as used by IPCC Third Assessment Report (TAR) [IPCC, 2001] and IPCC Fourth Assessment Report (AR4) [IPCC, 2007], respectively. At current $\mathrm{CO}_{2}$ levels of $\sim 391 \mathrm{ppm}[W M O / G A W, 2012]$, a $1 \mathrm{ppm}$ change in the $\mathrm{CO}_{2}$ concentration $(\Delta \mathrm{C}=1 \mathrm{ppm})$ gives a radiative efficiency for $\mathrm{CO}_{2}$ of $0.013665 \mathrm{~W} \mathrm{~m}^{-2} \mathrm{ppm}^{-1}$.

[93] The airborne fraction and the impulse response function have also been updated and Figure 10 shows the IRFs from the four IPCC assessment reports together with the updated IRF from Joos et al. [2013]. In this review we have updated the $\mathrm{AGWP}_{\mathrm{CO} 2}$ and $\mathrm{AGTP}_{\mathrm{CO} 2}$ values based on the new IRF and RE of $\mathrm{CO}_{2}$. The latter value is converted from per ppb to per kg by multiplying with $\left(M_{\mathrm{A}} / M_{\mathrm{CO} 2}\right) \times\left(10^{9} /\right.$ $T_{\mathrm{M}}$ ), where $M_{\mathrm{A}}$ and $M_{\mathrm{CO} 2}$ are the molecular weight of dry air $\left(28.97 \mathrm{~g} \mathrm{~mol}^{-1}\right)$ and $\mathrm{CO}_{2}\left(44.01 \mathrm{~g} \mathrm{~mol}^{-1}\right)$, respectively, and $T_{\mathrm{M}}$ is the mean dry mass of the atmosphere $(5.135 \times$ $10^{18} \mathrm{~kg}$ ) [Trenberth and Smith, 2005]. The RE of $\mathrm{CO}_{2}$ given per mass is then $1.75 \times 10^{-15} \mathrm{~W} \mathrm{~m}^{-2} \mathrm{~kg}^{-1}$, and the resulting AGWPs for $\mathrm{CO}_{2}$ (using equation (3)) are $2.495 \times 10^{-14}$, $9.171 \times 10^{-14}$ and $32.17 \times 10^{-14} \mathrm{~W} \mathrm{~m}^{-2} \mathrm{yr}\left(\mathrm{kgCO}_{2}\right)^{-1}$ for time horizons of 20,100 and 500 years, respectively. These values are higher than the $\mathrm{AGWP}_{\mathrm{CO} 2}$ used in AR4 (calculated based on the IRF and RE of $\mathrm{CO}_{2}$ given in AR4) by approximately $1.4,6.0$ and $13 \%$, respectively, mainly due to the change in IRF. As a consequence the $\mathrm{GWP}_{100}$ values presented for all compounds in section 4 will be about $6 \%$ lower than if the $\mathrm{AGWP}_{\mathrm{CO} 2}$ from $\mathrm{AR} 4$ was used. The $\mathrm{AGTP}_{\mathrm{CO} 2}$ values used in the calculations of GTPs in section 4.2, have been updated (using equation (A3) in Fuglestvedt et al. [2010]) to $6.841 \times 10^{-16}, 6.167 \times$

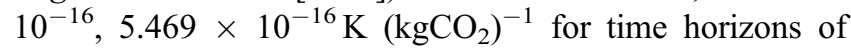
20, 50 and 100 years, respectively. As for $\mathrm{AGWP}_{\mathrm{CO} 2}$ the new $\mathrm{AGTP}_{\mathrm{CO} 2}$ values take into account the updated IRF and radiative efficiency of $\mathrm{CO}_{2}$, while the remaining parameters are taken from Fuglestvedt et al. [2010].

\subsection{Uncertainty-Sensitivity to Assumptions \\ 3.6.1. Absorption Cross Sections}

[94] Uncertainties related to the measurements of IR absorption spectra are dependent on many factors, and can differ for each compound. Some compounds have been subject to extensive laboratory measurements by several groups, such as for HCFC-22 [Ballard et al., 2000b] and HFC-134a [Forster et al., 2005], while others may lack reliable experimental cross-section data. Typical sources of uncertainties related to spectra include, but are not limited to, temperature and pressure for the measurement and in the sample, spectral range and resolution in the measurement, purity of sample, spectrometer and methods used, and noise in the measurements. A comprehensive intercomparison of laboratory measurements of absorption spectra was reported by Ballard et al. [2000b] for HCFC-22. They examined a range of sources of uncertainties and identified a limited set of aspects, related both to sample and photometric uncertainty sources, which should be given special attention when measuring other molecules. Overall, the total error in the absorption cross-section measurements for each of the five laboratory groups considered by Ballard et al. [2000b] were generally less than $5 \%$ and for the most part in the range of $3-5 \%$.

[95] Integrated absorption cross sections from theoretical calculations are often in good agreement with experimentally determined values; for example, Bravo et al. [2010b] report theoretical integrated absorption cross sections for a range of PFCs that are within $5 \%$ of the experimentally determined values. Because band overlap often makes it difficult to compare individual vibrational bands, agreement at this level may be somewhat worse than for the total integrated cross sections. As discussed in section 3.1.2, theoretical calculations generally provide infrared absorption band positions that differ systematically from those observed experimentally. These differences are wavenumber dependent and are usually only a few percent, but because band position is so important in determining radiative efficiencies, corrections for these differences are usually made.

[96] The absorption spectra used in this study have for the most part been used as reported in the literature when performing the radiative forcing calculations. However, each spectrum has been the subject of a visual inspection and in some cases it was necessary to remove noise around the baseline. As the noise often does not average out to precisely zero, inclusion of noise occurring outside the absorption bands may lead to biases in the RE calculations. Furthermore, for some compounds measurements were often available for a number of different temperatures and pressures, particularly for the HITRAN and GEISA databases. When this was the case, we used the data for which temperature and pressure were closest to room temperature, $296 \mathrm{~K}$, and surface pressure, 760 Torr. Forster et al. [2005] have shown that variation of the diluent pressure over the range of $0-740$ Torr and temperature over the range of 190-296 K has no discernible $(<5 \%)$ effect on the integrated absorption band intensities of HFC-134a. To sum up, we estimate an uncertainty of 5 and $10 \%$ for the experimental and ab initio absorption cross sections, respectively.

\subsubsection{Radiative Forcing Calculations}

[97] Past studies estimating halocarbon radiative forcings have differed significantly for some compounds. For instance, a recent $\mathrm{RE}$ estimate of the very potent greenhouse gas sulfur hexafluoride $\left(\mathrm{SF}_{6}\right)\left(0.68 \mathrm{~W} \mathrm{~m}^{-2} \mathrm{ppb}^{-1}\right)$ [Zhang et al., 2011a] was more than $30 \%$ higher than the IPCC AR4 estimate $\left(0.52 \mathrm{~W} \mathrm{~m}^{-2} \mathrm{ppb}^{-1}\right)$. As noted in section 3.6.1, differences can arise due to uncertainties related to the absorption cross sections, but a large part of the uncertainties is usually related to the radiative forcing calculations.

[98] Multi-model studies have proved particularly useful in assessing and reducing uncertainties in the RF calculations. Forster et al. [2005] applied six detailed radiative transfer models (four line-by-line models and two narrowband models) and reduced the uncertainty in the radiative forcing of HFC-134a, a compound with a RE estimate that had differed significantly in the previous studies. They also concluded that for this compound the uncertainties arising from the RF calculations were larger than those caused by 
using different absorption cross sections - up to 10 and 7\%, respectively. Similarly, Gohar et al. [2004] obtained differences of less than $12 \%$ when using two different radiative transfer models to calculate REs of four compounds which had differed significantly in the past literature.

[99] The assumptions related to RF calculations include the choice of radiation scheme, temporal and spatial averaging, cloud data, background temperature and concentrations, tropopause height, stratospheric temperature adjustment, and accounting for non-uniform vertical profile. A wide range of radiative transfer schemes exist, each varying in complexity. Broadband schemes are among the simplest and are often used in General Circulation Models (GCMs) due to the heavy computational requirements of such models. The intercomparison study of Collins et al. [2006] showed that there are often large differences in the calculated radiative forcing by well-mixed greenhouse gases between the various GCM schemes, and between the GCM schemes and the much more detailed and computationally expensive line-by-line (LBL) codes. However, the LBL codes were in excellent agreement with each other, and this type of code has previously been found to agree well with observations, at least in the spectral region between 800 and $2600 \mathrm{~cm}^{-1}$ [Tjemkes et al., 2003], which covers the whole atmospheric window. Similarly, Forster et al. [2011] generally found agreement within 5\% for four longwave LBL codes (slightly larger range for shortwave LBL codes) in an intercomparison study under clear-sky conditions for various cases with changes in GHG concentrations, whereas differences were substantially larger for radiative transfer codes used in GCMs. One exception for the agreement between the LBL codes was for changes in stratospheric water vapor [Maycock and Shine, 2012]. In a recent study by Oreopoulos et al. [2012], a LBL model was validated against several high-resolution spectral measurements and used as reference when comparing a number of different LBL and GCM radiative transfer codes. They concluded that the longwave radiative transfer schemes were generally in agreement with the reference results, and that the current generation schemes perform better than the GCMs from two decades ago [Ellingson and Fouquart, 1991]. The fact that we apply a detailed LBL model, should lead to less uncertainty compared to if a narrowband or broadband code was used. In Forster et al. [2005], the estimated contribution to total RF uncertainty for HFC-134a due to radiative transfer scheme was taken to be $3 \%$. Here, we consider this value to be too optimistic and estimate an uncertainty of $\sim 5 \%$. We underscore that this uncertainty is for detailed radiative transfer codes and codes which have been through careful validation in intercomparison studies such as Forster et al. [2005] and does not apply to radiative transfer codes traditionally used in GCMs.

[100] Different methodologies in how clouds are treated lead to additional uncertainties in radiative transfer models [e.g., Gohar et al., 2004]. Clouds lead to reduced upward irradiance and therefore the cloudy-sky radiative forcing is normally about $25-35 \%$ lower than the clear-sky RF [Jain et al., 2000]. Inter-model differences of up to $10 \%$ in the cloud radiative effects were found by Oreopoulos et al.
[2012], while Forster et al. [2005] estimated an additional uncertainty of about $5 \%$ in the RE of HFC-134a due to the inclusion of clouds. The detailed radiative transfer codes used in Forster et al. [2005] all had a global-mean outgoing longwave radiative flux at the top of the atmosphere close to observations and they span the range of realistic longwave cloud radiative effects [Kiehl and Trenberth, 1997; Trenberth et al., 2009].

[101] The effect of spectral overlap is important, including in the atmospheric window where most of the halocarbons absorb. Spectral overlap with $\mathrm{H}_{2} \mathrm{O}$ is the most important for most compounds, and according to Pinnock et al. [1995] and Jain et al. [2000], removing all water vapor lead to increases in cloudy-sky instantaneous RF typically in the range of $\sim 10-30 \%$. However, there is less than $1 \%$ increase when reducing the water vapor by $10 \%$ [Pinnock et al., 1995], indicating that the uncertainty induced by spectral overlap is negligible. On the other hand, omitting $\mathrm{N}_{2} \mathrm{O}$ and $\mathrm{CH}_{4}$, which was common in some models, could lead to substantially larger errors as they increase the instantaneous RF by about $10 \%$ for some compounds [Pinnock et al., 1995]. In Forster et al. [2005], one model was used to test the effect of a $0.2 \mathrm{~K}$ uncertainty in surface temperature and of using two different climatologies for water vapor and pressure, and found approximately 1 and $2 \%$ differences in the radiative forcings, respectively. Previous studies have also assessed uncertainties associated with spectroscopic measurements in new releases of HITRAN data of the greenhouse gases $\mathrm{H}_{2} \mathrm{O}, \mathrm{CO}_{2}, \mathrm{O}_{3}, \mathrm{~N}_{2} \mathrm{O}$, and $\mathrm{CH}_{4}$ [Kratz, 2008; Pinnock and Shine, 1998]. In general, they found that improvements in absorption spectra for these compounds during the preceding couple of decades had a relatively small impact on radiative forcing estimates.

[102] Another factor influencing the radiative forcing estimates is the definition of the tropopause (recall from section 2.2 that the radiative forcing is normally defined at the tropopause). Previous studies have highlighted the role of choosing an appropriate tropopause height, and found differences up to $10 \%$ in the global mean instantaneous RF when testing various tropopause definitions [Forster et al., 2005; Freckleton et al., 1998; Myhre and Stordal, 1997]. The error when using more than one vertical profile to represent the global atmosphere is lower, and we have estimated this uncertainty to be $\sim 5 \%$. Furthermore, the effect of global and annual averaging may lead to additional errors due to non-linearities in the radiative forcing calculations. For well-mixed gases, Myhre and Stordal [1997] found only small differences (less than 1\%) in RF due to temporal averaging, while spatial averaging to one global mean profile induced errors up to $10 \%$, partly due to the strong sensitivity to tropopause height for the halocarbons. However, the use of three profiles representing the tropics and the extratropics of each hemisphere was found sufficient by Freckleton et al. [1998]. The RF calculations presented in this study use two or three profiles, representing the tropics and the extra-tropics (see section 3.3.1).

[103] As explained in section 3.3.2, stratospheric temperature adjustment typically leads to an increase in cloudy-sky 
TABLE 1. Estimated Contributions to the Total Radiative Forcing Uncertainty

\begin{tabular}{|c|c|c|}
\hline Source of Uncertainty & $\begin{array}{l}\text { Estimated Contribution to } \\
\text { Total RF Uncertainty }\end{array}$ & References Used as Basis for Uncertainty Estimates \\
\hline Absorption cross-sections & $\begin{array}{l}\sim 5 \% \text { for experimentally determined spectra, } \\
\sim 10 \% \text { for ab initio spectra }\end{array}$ & $\begin{array}{c}\text { [Ballard et al., 2000b; Bravo et al., 2010b; } \\
\text { Forster et al., 2005] }\end{array}$ \\
\hline Radiation scheme & $\sim 5 \%$ & $\begin{array}{c}\text { [Collins et al., 2006; Forster et al., 2005; } \\
\text { Oreopoulos et al., 2012] }\end{array}$ \\
\hline Clouds & $\sim 5 \%$ & [Forster et al., 2005; Gohar et al., 2004] \\
\hline Spectral overlap and water vapor distribution & $\sim 3 \%$ & $\begin{array}{c}\text { [Forster et al., 2005; Jain et al., 2000; } \\
\text { Pinnock et al., 1995] }\end{array}$ \\
\hline $\begin{array}{l}\text { Surface temperature and atmospheric } \\
\text { temperature }\end{array}$ & $\sim 3 \%$ & [Forster et al., 2005] \\
\hline Tropopause level & $\sim 5 \%$ & $\begin{array}{c}\text { [Forster et al., 2005; Freckleton et al., 1998; Myhre } \\
\text { and Stordal, 1997] }\end{array}$ \\
\hline Temporal and spatial averaging & $\sim 1 \%$ & [Freckleton et al., 1998; Myhre and Stordal, 1997] \\
\hline Stratospheric temperature adjustment & $\sim 4 \%$ & [Forster et al., 2005; Gohar et al., 2004] \\
\hline Non-uniform vertical profile & $\begin{array}{l}\sim 5 \% \text { for lifetimes }>\sim 5 \text { years, } \\
\sim 20 \% \text { for lifetimes }<\sim 5 \text { years }\end{array}$ & {$[$ Sihra et al., 2001] + this study } \\
\hline Total (RSS) (experimental) & $\begin{array}{l}\sim 13 \% \text { for lifetimes }>\sim 5 \text { years } \\
\sim 23 \% \text { for lifetimes }<\sim 5 \text { years }\end{array}$ & \\
\hline Total (RSS) (ab initio) & $\sim 15 \%$ for lifetimes $>\sim 5$ years & \\
\hline
\end{tabular}

RF for the halocarbons of typically about $10 \%$. Forster et al. [2005] have provided an estimate of the contribution to the RF uncertainty arising from this factor, namely $\sim 4 \%$, based on the results of four different radiative transfer models. The two models in Gohar et al. [2004] differed by a maximum of 3 percentage points when calculating the increase in RF due to stratospheric temperature adjustment for four different HFCs.

[104] One of the largest sources of uncertainties in RF estimates is the effect of a non-uniform vertical profile caused mainly by reaction with $\mathrm{OH}$ in the troposphere and photolysis in the stratosphere (section 3.3.4). Sihra et al. [2001] estimated this uncertainty to be in the order of $5-10 \%$, while we note from Figure 9 that this number is dependent on the lifetime. The fractional correction factors for compounds that are reasonably well-mixed in the atmosphere, with lifetimes typically longer than about 5 years, show less spread than the compounds with shorter lifetimes. One reason for the larger spread is differences caused by the various absorption bands, but is also due to uncertainties related to the geographical distribution of emissions which influence both the fractional correction and the atmospheric lifetime. However, it should be stressed here that the sensitivity simulation using the "BC-like" emission distribution (section 3.3.3) is considered an extreme case and should be given less weight. Based on previous literature and the new simulations performed in this study, we estimate an uncertainty of $\sim 5 \%$ for compounds with lifetimes longer than about 5 years and $\sim 20 \%$ for compounds with shorter lifetimes.

[105] Each source of uncertainty and their estimated contribution to the total RE uncertainty is listed in Table 1. The uncertainty estimates are based on available published studies and on subjective judgment, as discussed above. Using the root-sum-square (RSS) method, we find an overall uncertainty due to radiative forcing calculations (including uncertainties in the experimental absorption spectra described in section 3.6.1) of approximately $13 \%$ for compounds with lifetimes longer than around 5 years. When using properly corrected theoretical absorption spectra the total uncertainty increases to around $15 \%$. We estimate the overall uncertainty to be valid for a 5 to $95 \%(90 \%)$ confidence range, which is the same confidence range used for the radiative forcing values in IPCC AR4. Our estimate of 13\% (valid for experimental cross sections) is only slightly larger than the $10 \%$ uncertainty reported for long-lived greenhouse gases in AR4. Due to the large uncertainties in the fractional correction, the total RF uncertainty increases to $\sim 23 \%$ for compounds with lifetimes shorter than around 5 years. It should also be noted that the radiation schemes used to produce our updated "Pinnock curve" is a detailed LBL code and therefore has less uncertainties than models with coarser spectral resolution, such as broadband models.

\subsubsection{Atmospheric Lifetimes}

[106] Uncertainties in atmospheric lifetimes arise from a range of factors. For short-lived compounds, accurate determinations of the temperature-dependent rate coefficients for reactions with $\mathrm{OH}$ are needed. The NASA Data Evaluation Panel [Chemical Kinetics and Photochemical Data for Use in Atmospheric Studies Evaluation Number 17 NASA Panel for Data Evaluation:2011] indicates uncertainties in $\mathrm{OH}$ rate constants at room temperature of up to about $20 \%$ for the compounds considered here. Combined with uncertainties in the temperature dependence gives an overall uncertainty of about $30 \%$ in the rate coefficient of the reactions at tropospheric temperatures. It is also important to note that lifetimes with respect to reaction with $\mathrm{OH}$ are determined relative to the lifetime of methyl chloroform, which in turn is dependent on the global $\mathrm{OH}$ field (see section 3.4). As an example, Prather et al. [2012] have used a recently published analysis of methyl chloroform data [Montzka et al., 2011] to estimate a total lifetime for HFC-134a of $14.2 \mathrm{yr}$ as against the WMO [WMO, 2011] recommendation of $13.4 \mathrm{yr}$. While this change is within our stated uncertainty, the important point is that changes in 
our understanding of the methyl chloroform lifetime can have an impact on the lifetimes of a great many compounds.

[107] For some longer-lived compounds, photolysis in the stratosphere is the dominant loss process. Estimates of lifetimes for such compounds can be made from their ultraviolet absorption cross sections and quantum yields, and the altitude-dependent actinic flux. The NASA Data Evaluation Panel provides combined cross section/quantum yield uncertainties for some of the compounds considered here. For well-studied CFCs (CFC-11 and CFC-12) these uncertainties are well-constrained and are quoted at $10 \%$, while for halons, uncertainties of a factor of two are quoted. Combined with uncertainties in the actinic flux, it is clear that there can be very significant uncertainties in photolysis lifetimes. This can be particularly true when considering very long-lived compounds such as the PFCs [Ravishankara et al., 1993]. However, it should be noted that for such longlived species, GWPs on a one hundred year time horizon are insensitive to atmospheric lifetimes. Uncertainties in other processes such as deposition can be very large, but as Prather et al. [2012] point out, these uncertainties often have a relatively small impact on total lifetimes. In general, uncertainties in lifetimes are large compared to uncertainties in other parameters such as cross sections. A follow up study could assess the uncertainties in lifetimes and the combined effect of RE and lifetimes uncertainties on GWP and GTP.

\subsubsection{GWP}

[108] Some studies have investigated uncertainty in GWP and GTP values [Boucher, 2012; Olivié and Peters, 2012; Reisinger et al., 2010; Wuebbles et al., 1995] and they have been either based on model comparisons or Monte-Carlo approaches. Uncertainty can also be assessed using standard methods of uncertainty propagation. For a general function, $f$, with two independent variables, $x$ and $y$, the uncertainty in $f$ can be approximated as

$$
\Delta \mathrm{f}=\sqrt{\left(\frac{\partial f}{\partial x}\right)^{2} \Delta x^{2}+\left(\frac{\partial f}{\partial y}\right)^{2} \Delta y^{2}}
$$

[109] This allows combination of different pieces of information on uncertainty (e.g., from independent studies) to assess the importance of the different components of metrics (e.g., RE versus lifetime). We use this approach for two chosen gases as examples (HFC-134a and CFC-11) and use uncertainties in RE obtained in this study with uncertainties in lifetimes from the literature. Based on equation (4) the uncertainty for AGWP is given by

$$
\Delta \mathrm{AGWP}=\sqrt{\left(\frac{\partial A G W P}{\partial R E}\right)^{2} \Delta \mathrm{R} E^{2}+\left(\frac{\partial A G W P}{\partial \tau}\right)^{2} \Delta \tau^{2}}
$$

assuming Gaussian distributions and no correlation between $\mathrm{RE}$ and $\tau$. The derivatives of AGWP with respect to RE and $\tau$ were obtained analytically. For HFC-134a, the relative uncertainty (for the 5-95\% (90\%) confidence range) is estimated to be $\pm 18 \%$ for $\tau$ [Prather et al., 2012] and $\pm 13 \%$ for RE (from Table 1). Using equation (5) with these uncertainties, the total uncertainty for $\mathrm{AGWP}_{\mathrm{HFC}-134 \mathrm{a}}$ is $\pm 16 \%$ for a 20 year time horizon, $\pm 22 \%$ for 100 years, and $\pm 22 \%$ for 500 years. For CFC-11, the relative uncertainty is estimated to be $\pm 33 \%$ for $\tau$ [Minschwaner et al., 2012] and $\pm 13 \%$ for $\mathrm{RE}$ (from Table 1). Note that uncertainties related to indirect effects caused by e.g., the influence of CFC-11 on stratospheric ozone, are not taken into account here. The total uncertainty for $\mathrm{AGWP}_{\mathrm{CFC}-11}$ is then $\pm 15 \%$ for a 20 year time horizon, $\pm 28 \%$ for 100 years, and $\pm 36 \%$ for 500 years.

[110] The uncertainty in the $\mathrm{AGWP}_{\mathrm{CO} 2}$ can be obtained using the $\pm 10 \%$ estimated uncertainty in RE [IPCC, 2007] and uncertainty in the time-integrated $\mathrm{IRF}_{\mathrm{CO} 2}$ (see definition of $\mathrm{IRF}_{\mathrm{CO} 2}$ in section 3.5 .1 ) of $\pm 15 \%, \pm 25 \%$, and $\pm 28 \%$ for a 20, 100, and 500 year time horizon [Joos et al., 2013]. The uncertainty for the product $\mathrm{RE}_{\mathrm{CO}_{2}} \times \int I R \mathrm{~F}_{\mathrm{CO}_{2}}$, i.e., the uncertainty in $\mathrm{AGWP}_{\mathrm{CO} 2}$, is given by

$$
\frac{\Delta \mathrm{AGWP}_{\mathrm{CO} 2}}{\mathrm{AGWP} P_{\mathrm{CO} 2}}=\sqrt{\left(\frac{\Delta \mathrm{R} E_{\mathrm{CO}_{2}}}{R E_{\mathrm{CO}_{2}}}\right)^{2}+\left(\frac{\Delta \int I R F_{\mathrm{CO}_{2}}}{\int I R F_{\mathrm{CO}_{2}}}\right)^{2}},
$$

leading to an uncertainty of $\mathrm{AGWP}_{\mathrm{CO} 2}$ of $\pm 18 \%, \pm 26 \%$, and $\pm 30 \%$, respectively, with the uncertainty dominated by the uncertainty in the integrated $\mathrm{IRF}_{\mathrm{CO} 2}$. These estimates are different from those given by IPCC AR4 where it was stated that AGWP for $\mathrm{CO}_{2}$ is estimated to be $\pm 15 \%$, with equal contributions from the $\mathrm{CO}_{2}$ response function and the RF calculation [IPCC, 2007]. The main reason for the difference is the new uncertainty range in the IRF for $\mathrm{CO}_{2}$ based on a multi model study [Joos et al., 2013]. Combining the uncertainty in the AGWP values for HFC-134a and CFC-11 with $\mathrm{AGWP}_{\mathrm{CO} 2}$ (using the sum of the squares uncertainty propagation), the uncertainty in $\mathrm{GWP}_{\mathrm{HFC}-134 \mathrm{a}}$ is estimated to $\pm 24 \%, \pm 34 \%$, and $\pm 37 \%$ for a 20,100 , and 500 year time horizon. For CFC-11 the GWP uncertainties are $\pm 23 \%$, $\pm 38 \%$ and $\pm 47 \%$ for a 20,100 , and 500 year time horizon.

[111] IPCC [2007] gives GWP uncertainties of $\pm 35 \%$ for the 5 to $95 \%(90 \%)$ confidence range which is based on earlier IPCC assessments; i.e., the Second and Third Assessment reports [IPCC, 1995; 2001].

[112] The stated uncertainties for HFC-134a and CFC-11 are probably representative of those for most other CFCs, HCFCs, HFCs and perfluorocarbons with similar or longer lifetimes and with experimentally determined absorption cross sections. For shorter-lived gases ( $\tau$ less than 5 years), the uncertainties will be considerably greater (we estimate AGWP uncertainties about at least a factor of 2 larger than those given above), and the assumption that there is no correlation between $\mathrm{RE}$ and $\tau$ will be less valid. In addition, for the shorter-lived gases, both RE and $\tau$ will depend on the location (and time) of emission, and the validity of presenting a single globally representative value of GWPs is more questionable. 


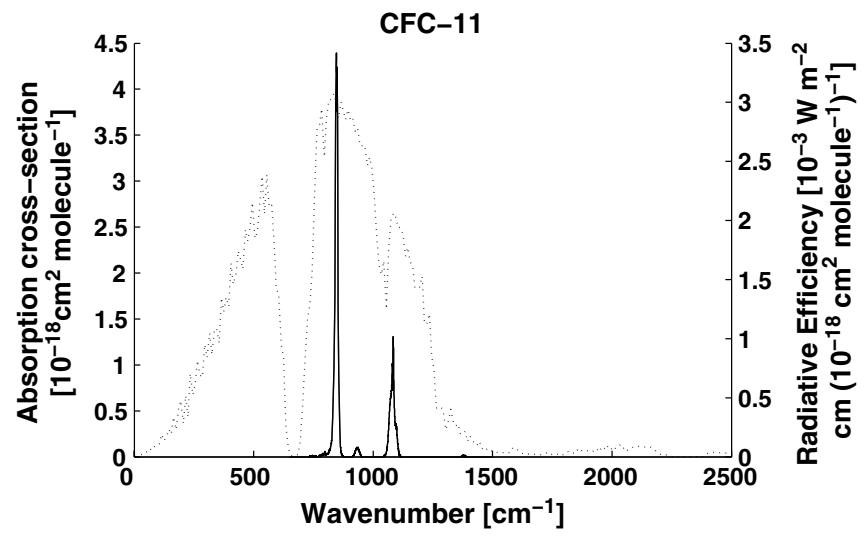

Figure 11. Absorption spectrum of CFC-11 at $296 \mathrm{~K}$ in $933 \mathrm{hPa}$ (700 Torr) air diluent from Sihra et al. [2001] (solid line) and Oslo simulation of Pinnock curve (dotted line).

\section{RESULTS AND DISCUSSION}

\subsection{Infrared Spectra, REs, and GWPs}

[113] Absorption cross sections and radiative efficiency estimates in the literature are reviewed in this section. In addition, we present new calculations of REs and GWPs for a large number of gases based on published absorption cross sections and the updated Pinnock curve described in section 3.3. All the REs are given for cloudy-sky and with stratospheric temperature adjustment included (see definition of $\mathrm{RE}$ in section 2.2), unless explicitly noted in the text. When the atmospheric lifetime is available, a correction for nonhomogeneous (vertical and horizontal) distribution is applied to the calculated REs, following the methods described in section 3.3.4. Each available spectrum has been evaluated, and the most reliable spectra have been used in the calculations of new best estimate REs, as explained in section 3.1.3.

[114] For each compound, our results are compared to the values presented in AR4. In a few cases, the best estimate RE from AR4 has been retained when new calculations were not carried out due to unavailability of reliable absorption cross-section data. Best estimate RE and GWP for each compound are indicated in bold in the tables. Additionally, we provide best estimate REs and GWPs for a number of compounds which were not included in AR4, but where absorption cross sections were available or where RE values have been published. The atmospheric lifetimes necessary for the GWP calculations have been taken from WMO [2011] unless stated otherwise in the text. Note that indirect effects caused by, e.g., the influence of CFCs on stratospheric ozone have not been studied here but are covered elsewhere [e. g., Daniel et al., 1995; WMO, 2011]. In the following, a brief discussion is given for each compound in each of the categories: chlorofluorocarbons, hydrochlorofluorocarbons, hydrofluorocarbons, chlorocarbons, bromocarbons and halons, fully fluorinated species, and halogenated alcohols and ethers. Additional information, such as the REs reported in each of the individual studies, and the calculated REs of all available spectra, is given in Tables $\mathrm{S} 1-\mathrm{S} 7$ in the supporting information. Tables S1-S7 also provide more significant figures, which are necessary to reproduce the GWP(100) values given in the section 4 tables, where the best estimate REs are rounded to two decimal places.

[115] In the following, when we refer to IPCC AR4 [IPCC, 2007], it should be noted that a number of compounds were inadvertently omitted in the printed version of AR4 WGI Table 2.14; we have used the erratum to this table which is available at http://www.ipcc.ch/publications_and_data/ar4/ wg1/en/errataserrata-errata.html\#table214.

\subsubsection{Chlorofluorocarbons (CFCs)}

[116] CFCs are long-lived compounds which are mainly removed in the stratosphere by UV photolysis or reaction with excited oxygen atoms, $\mathrm{O}\left({ }^{1} \mathrm{D}\right)$. Their GWPs are generally high due to long lifetimes, and despite substantial emission reductions of CFCs during the past couple of decades, their radiative forcing of climate will remain large for many decades [WMO, 2011]. The CFCs are relatively homogeneously distributed in the troposphere, but due to photolysis their mixing ratios decrease with increasing altitude in the stratosphere. The IR absorption by the CFCs occurs to a large extent in the "atmospheric window" from 800 to $1200 \mathrm{~cm}^{-1}$, as illustrated for CFC11 in Figure 11. Previously published absorption cross sections are listed in Table 2, while updated atmospheric lifetimes, REs, and GWP(100) values for CFCs are presented in Table 3 and discussed below. Unless stated otherwise, the exponential fit from section 3.3.4 (equation (1) and red curve in Figure 9) has been used to account for a non-uniform vertical profile for the compounds presented in this subsection.

\subsubsection{CFC-11 $\left(\mathrm{CCl}_{3} \mathrm{~F}\right)$}

[117] Several studies have calculated the RE of CFC-11 [Christidis et al., 1997; Fisher et al., 1990; Good et al., 1998; Hansen et al., 1997; Heathfield et al., 1998; Jain et al., 2000; Myhre and Stordal, 1997; Myhre et al., 1998; Naik et al., 2000; Ninomiya et al., 2000; Pinnock et al., 1995; Sihra et al., 2001]. Many of these studies report RE equal to, or close to, $0.25 \mathrm{~W} \mathrm{~m}^{-2} \mathrm{ppb}^{-1}$, (range: $0.22-0.29 \mathrm{~W} \mathrm{~m}^{-2} \mathrm{ppb}^{-1}$, mean: $0.25 \mathrm{~W} \mathrm{~m}^{-2} \mathrm{ppb}^{-1}$ ), which is the value that was used in AR4. (It should be noted that the RE values for all compounds reported by Fisher et al. [1990] were given relative to CFC11 in IPCC [1990], assuming a RE of $0.22 \mathrm{~W} \mathrm{~m}^{-2} \mathrm{ppb}^{-1}$ for CFC-11. WMO [1999] scaled the REs from Fisher et al. [1990] by a factor 1.14 to account for the change in the recommended forcing for CFC-11 (from 0.22 to $0.25 \mathrm{~W} \mathrm{~m}^{-2}$ $\mathrm{ppb}^{-1}$ ), and these values were then adopted in subsequent IPCC assessments.) Good et al. [1998] estimated a value of RE using vibrational integrated absorption cross sections calculated using $\mathrm{ab}$ initio methods and obtained a value some $18 \%$ larger than those experimentally derived band strengths.

[118] In the present study, we have used absorption spectra from several sources [Heathfield et al., 1998; Imasu et al., 1995; Li and Varanasi, 1994; Orkin et al., 2003; Sihra et al., 2001] and calculated the RE of CFC-11, assuming it to be well mixed, to be in the range of $0.27-0.29 \mathrm{~W} \mathrm{~m}^{-2} \mathrm{ppb}^{-1}$ (mean: $0.28 \mathrm{~W} \mathrm{~m}^{-2} \mathrm{ppb}^{-1}$ ) (see Tables 2 and 3). For CFC-11, we have carried out explicit simulations using the Oslo LBL model and derived factors to account for stratospheric temperature 
TABLE 2. Integrated Absorption Cross Sections (S) for Chlorofluorocarbons (CFCs) ${ }^{\mathrm{a}}$

\begin{tabular}{|c|c|c|c|c|c|c|c|c|c|}
\hline Name & CAS\# & Acronym & Formula I & Data $^{\mathrm{b}}$ & $T / \mathrm{K}$ & $\begin{array}{c}\text { Wn. } \\
\text { Range } / \mathrm{cm}^{-1}\end{array}$ & $S^{\mathrm{c}}$ & Reference & Database $^{\mathrm{d}}$ \\
\hline \multirow[t]{17}{*}{ Trichlorofluoromethane } & \multirow[t]{17}{*}{$75-69-4$} & \multirow[t]{17}{*}{ CFC-11 } & \multirow[t]{17}{*}{$\mathrm{CCl}_{3} \mathrm{~F}$} & $\mathrm{E}$ & 295 & $820-1120$ & 9.3 & [Orkin et al., 2003] & \multirow{6}{*}{$\mathrm{H}$} \\
\hline & & & & $\mathrm{E}$ & 296 & $650-1500$ & 9.3 & [Sihra et al., 2001] & \\
\hline & & & & $\mathrm{E}$ & & & & [Naik et al., 2000] & \\
\hline & & & & $\mathrm{E}$ & & & & [Ninomiya et al., 2000] & \\
\hline & & & & $\mathrm{E}$ & 296 & $810-1120$ & 9.5 & $\begin{array}{l}\text { [Varanasi, personal } \\
\text { communication, 2000] }\end{array}$ & \\
\hline & & & & A & & & & [Good et al., 1998] & \\
\hline & & & & $\mathrm{E}$ & 298 & $800-1120$ & 9.4 & [Heathfield et al., 1998] & G \\
\hline & & & & $\mathrm{E}$ & 296 & $810-1120$ & 9.0 & [Christidis et al., 1997] & $\mathrm{G}$ \\
\hline & & & & $\mathrm{E}$ & 296 & $700-1500$ & 9.8 & [Imasu et al., 1995] & \\
\hline & & & & $\mathrm{E}$ & 296 & $810-1120$ & 9.5 & [Li and Varanasi, 1994] & $\mathrm{G}$ \\
\hline & & & & $\mathrm{E}$ & 293 & $800-1120$ & 9.2 & [McDaniel et al., 1991] & \\
\hline & & & & $\mathrm{E}$ & & $810-1120$ & 8.9 & [Fisher et al., 1990] & \\
\hline & & & & $\mathrm{E}$ & & $800-1120$ & 9.8 & $\begin{array}{c}\text { [Varanasi and } \\
\text { Chudamani, 1988a] }\end{array}$ & \\
\hline & & & & $\mathrm{E}$ & & $800-1120$ & 8.4 & [Massie et al., 1985] & \\
\hline & & & & $\mathrm{E}$ & & $800-1120$ & 10.3 & [Kagann et al., 1983] & \\
\hline & & & & $\mathrm{E}$ & & $800-1120$ & 8.9 & [Nanes et al., 1980] & \\
\hline & & & & $\mathrm{E}$ & & $800-1120$ & 8.9 & [Varanasi and Ko, 1977] & \\
\hline \multirow[t]{16}{*}{ Dichlorodifluoromethane } & \multirow[t]{16}{*}{$75-71-8$} & \multirow[t]{16}{*}{ CFC-12 } & \multirow[t]{16}{*}{$\mathrm{CCl}_{2} \mathrm{~F}_{2}$} & $\mathrm{E}$ & 295 & $850-1190$ & 13.5 & [Myhre et al., 2006] & \multirow{4}{*}{ G } \\
\hline & & & & $\mathrm{E}$ & 296 & $640-1200$ & 12.2 & [Hurley, personal communication, 2003] & \\
\hline & & & & $\mathrm{E}$ & 295 & $850-1190$ & 12.9 & [Orkin et al., 2003] & \\
\hline & & & & $\mathrm{E}$ & 296 & $500-1500$ & 12.2 & [Sihra et al., 2001] & \\
\hline & & & & $\mathrm{E}$ & 296 & $850-1200$ & 13.6 & [Varanasi, personal communication, 2000] & \multirow[t]{2}{*}{$\mathrm{H}$} \\
\hline & & & & A & & & & [Good et al., 1998] & \\
\hline & & & & $\mathrm{E}$ & 296 & $850-1200$ & 13.6 & $\begin{array}{c}\text { [Varanasi and Nemtchinov, } \\
1994]\end{array}$ & G \\
\hline & & & & $\mathrm{E}$ & 287 & $850-1190$ & 13.5 & [Clerbaux et al., 1993] & \multirow[t]{9}{*}{$\mathrm{G}$} \\
\hline & & & & $\mathrm{E}$ & 293 & $850-1190$ & 12.6 & [McDaniel et al., 1991] & \\
\hline & & & & $\mathrm{E}$ & 296 & $850-1190$ & 12.1 & [Fisher et al., 1990] & \\
\hline & & & & $\mathrm{E}$ & 300 & $850-1190$ & 13.4 & $\begin{array}{c}{[\text { Varanasi and }} \\
\text { Chudamani, 1988a] }\end{array}$ & \\
\hline & & & & $\mathrm{E}$ & 298 & $800-1200$ & 12.7 & [Vanthanh et al., 1986] & \\
\hline & & & & $\mathrm{E}$ & 296 & $850-1190$ & 13.3 & [Massie et al., 1985] & \\
\hline & & & & $\mathrm{E}$ & 296 & $850-1190$ & 13.6 & [Kagann et al., 1983] & \\
\hline & & & & $\mathrm{E}$ & 300 & $850-1190$ & 12.9 & [Varanasi and Ko, 1977] & \\
\hline & & & & $\mathrm{E}$ & & & & [Morcillo et al., 1966] & \\
\hline \multirow[t]{3}{*}{ Chlorotrifluoromethane } & \multirow[t]{3}{*}{$75-72-9$} & \multirow[t]{3}{*}{ CFC-13 } & \multirow[t]{3}{*}{$\mathrm{CClF}_{3}$} & $\mathrm{E}$ & 293 & $765-1235$ & 14.8 & [McDaniel et al., 1991] & \multirow[t]{3}{*}{$\mathrm{H}$} \\
\hline & & & & $\mathrm{E}$ & & $1050-1291$ & 16.3 & $\begin{array}{c}\text { [Varanasi and } \\
\text { Chudamani, 1988b] }\end{array}$ & \\
\hline & & & & $\mathrm{E}$ & & $755-1291$ & 16.1 & [Golden et al., 1978] & \\
\hline \multirow[t]{5}{*}{ 1,1,2-Trichloro-1,2,2-trifluoroethane } & \multirow[t]{5}{*}{$76-13-1$} & \multirow{5}{*}{\multicolumn{2}{|c|}{$\mathrm{CFC}-113 \mathrm{CCl}_{2} \mathrm{FCClF}_{2}$}} & E & 283 & $600-1250$ & 13.7 & [Le Bris et al., 2011] & \\
\hline & & & & $\mathrm{E}$ & 293 & $780-1232$ & 12.7 & [McDaniel et al., 1991] & $\mathrm{H}$ \\
\hline & & & & $\mathrm{E}$ & & $618-1397$ & 12.7 & [Fisher et al., 1990] & \\
\hline & & & & $\mathrm{E}$ & & $780-1235$ & 19.4 & [Rogers and Stephens, 1988] & \\
\hline & & & & $\mathrm{E}$ & & $780-1235$ & 14.1 & $\begin{array}{c}\text { [Varanasi and } \\
\text { Chudamani, 1988b] }\end{array}$ & \\
\hline 1,2-Dichloro-1,1,2,2-tetrafluoroethane & $76-14-2$ & CFC-114C & $\mathrm{CClF}_{2} \mathrm{CClF}_{2}$ & $\mathrm{E}$ & 293 & $815-1285$ & 15.2 & [McDaniel et al., 1991] & $\mathrm{H}$ \\
\hline & & & & $\mathrm{E}$ & & $555-1397$ & 15.4 & [Fisher et al., 1990] & \\
\hline & & & & $\mathrm{E}$ & & $820-1310$ & 23.9 & [Rogers and Stephens, 1988] & \\
\hline & & & & $\mathrm{E}$ & & $820-1310$ & 15.8 & $\begin{array}{c}\text { [Varanasi and } \\
\text { Chudamani, 1988b] }\end{array}$ & \\
\hline & & & & $\mathrm{E}$ & & $1025-1310$ & 12.0 & [Massie et al., 1985] & \\
\hline 1-Chloro-1,1,2,2,2-pentafluoroethane & $76-15-3$ & CFC-115 & $\mathrm{CClF}_{2} \mathrm{CF}_{3}$ & $\mathrm{E}$ & 293 & $955-1260$ & 12.1 & [McDaniel et al., 1991] & $\mathrm{H}$ \\
\hline & & & & $\mathrm{E}$ & & $618-1397$ & 17.4 & [Fisher et al., 1990] & \\
\hline
\end{tabular}

${ }^{\mathrm{a}}$ Spectra used in RE calculations in the present study are indicated in bold.

${ }^{\mathrm{b}}$ Type of data: E, Experimental; A, Ab initio.

Integrated absorption cross-section in units of $10^{-17} \mathrm{~cm}^{2}$ molecule ${ }^{-1} \mathrm{~cm}^{-1}$ for the wavenumber interval specified.

${ }^{\mathrm{d}}$ Database: H, HITRAN 2008; G, GEISA 2009.

adjustment and lifetime adjustment (see sections 3.3.3 and 3.3.4 for details and validation against satellite observations of CFC11). The stratospheric adjustment, which is accounted for in the mean value of $0.28 \mathrm{~W} \mathrm{~m}^{-2} \mathrm{ppb}^{-1}$, is assumed to increase the forcing by $9.1 \%$, while the lifetime correction reduces this value by $7.3 \%$. Our final value, $0.26 \mathrm{~W} \mathrm{~m}^{-2} \mathrm{ppb}^{-1}$ is in relatively good agreement with AR4. As noted above, the RE in some studies is given relative to the RE of CFC-11 and has been scaled in previous assessments to the former recommended CFC-11 RE of $0.25 \mathrm{~W} \mathrm{~m}^{-2} \mathrm{ppb}^{-1}$. Here we choose to list the absolute REs of these studies [mainly Fisher et al., 1990; Imasu et al., 1995] as scaled to our new recommended CFC-11 RE of $0.26 \mathrm{~W} \mathrm{~m}^{-2} \mathrm{ppb}^{-1}$.

[119] A significant source of uncertainty related to the GWP of CFC-11 is the lifetime. In recent assessments [IPCC, 2007; $W M O, 2011]$, the lifetime has been estimated as 45 years, based 
HODNEBROG ET AL.: HALOCARBON REVIEW

TABLE 3. Lifetimes, Radiative Efficiencies, and Direct GWPs (Relative to $\mathrm{CO}_{2}$ ) for Chlorofluorocarbons (CFCs)

\begin{tabular}{|c|c|c|c|c|c|c|c|}
\hline \multirow[b]{2}{*}{ Acronym } & \multirow[b]{2}{*}{ Formula } & \multirow[b]{2}{*}{ Lifetime (yr) } & \multicolumn{3}{|c|}{ Radiative Efficiency $\left(\mathrm{W} \mathrm{m}{ }^{-2} \mathrm{ppb}^{-1}\right)$} & \multicolumn{2}{|r|}{ GWP 100 year } \\
\hline & & & AR4 & This study-const. profile & This study-lifetime corr. & AR4 & This study_lifetime corr. \\
\hline CFC-11 & $\mathrm{CCl}_{3} \mathrm{~F}$ & 45 & 0.25 & 0.28 & 0.26 & 4,750 & 4,660 \\
\hline CFC-12 & $\mathrm{CCl}_{2} \mathrm{~F}_{2}$ & 100 & 0.32 & 0.33 & 0.32 & 10,900 & 10,200 \\
\hline CFC-13 & $\mathrm{CClF}_{3}$ & 640 & 0.25 & 0.26 & 0.25 & 14,400 & 13,900 \\
\hline CFC-113 & $\mathrm{CCl}_{2} \mathrm{FCClF}_{2}$ & 85 & 0.30 & 0.31 & $\mathbf{0 . 3 0}$ & 6,130 & 5,820 \\
\hline CFC-114 & $\mathrm{CClF}_{2} \mathrm{CClF}_{2}$ & 190 & 0.31 & 0.32 & 0.31 & 10,000 & 8,590 \\
\hline CFC-115 & $\mathrm{CClF}_{2} \mathrm{CF}_{3}$ & 1,020 & 0.18 & 0.21 & 0.20 & 7,370 & 7,670 \\
\hline
\end{tabular}

${ }^{\mathrm{a} C}$ Compounds in bold either have significant current atmospheric concentrations or a clear potential for future emissions. Recommended RE and GWP 100 year values are indicated in bold. Lifetimes are from WMO [2011].

on observational studies [Cunnold et al., 1997; Volk et al., 1997] and model studies [WMO, 1999]. However, new studies, based on both models and observations, suggest a longer lifetime for CFC-11. Douglass et al. [2008] estimated a CFC-11 lifetime of 56-64 years using models that have realistic age of air and reproduce the observed relationship between the mean age and the fractional release. In Wuebbles et al. [2009], the lifetime was estimated to be 54 and 57 years, using a 3-D and a 2-D atmospheric chemistry model, respectively. Recent studies based on satellite and ground-based observations have estimated a CFC-11 lifetime of 50 years (range: 34-67 years) [Minschwaner et al., 2012], 52 years (range: 40-66 years) [Rigby et al., 2013], and 59 years (range: 53-66 years) [Laube et al., 2012]. In Table 2, we choose to keep the lifetime of 45 years from $W M O$ [2011] as our best estimate.

\subsubsection{CFC-12 $\left(\mathrm{CCl}_{2} \mathrm{~F}_{2}\right)$}

[120] Literature values for the RE of CFC-12 [Fisher et al., 1990; Good et al., 1998; Hansen et al., 1997; Jain et al., 2000; Myhre and Stordal, 1997; Myhre et al., 1998; Myhre et al., 2006; Orkin et al., 2003; Sihra et al., 2001] provide results in the range of $0.30-0.33 \mathrm{~W} \mathrm{~m}^{-2} \mathrm{ppb}^{-1}$ with a mean of $0.32 \mathrm{~W}$ $\mathrm{m}^{-2} \mathrm{ppb}^{-1}$, while a value of $0.32 \mathrm{~W} \mathrm{~m}^{-2} \mathrm{ppb}^{-1}$ was used in AR4 (based on Myhre and Stordal [1997]). Differences are caused by differing impact of clouds, absorption crosssection data, and the vertical profile of decay of the mixing ratio in the stratosphere [IPCC, 2001]. Detailed LBL calculations were performed by Myhre et al. [2006] who calculated a $\mathrm{RE}$ of $0.33 \mathrm{~W} \mathrm{~m}^{-2} \mathrm{ppb}^{-1}$. Here we have used absorption cross sections from several sources [Clerbaux et al., 1993; Myhre et al., 2006; Orkin et al., 2003; Sihra et al., 2001; Varanasi and Nemtchinov, 1994] to calculate an average RE due to CFC-12 of $0.32 \mathrm{~W} \mathrm{~m}^{-2} \mathrm{ppb}^{-1}$ (range: $0.29-0.33 \mathrm{~W} \mathrm{~m}^{-2}$ $\mathrm{ppb}^{-1}$ ) (Tables 2 and 3). As for CFC-11, we have carried out explicit simulations of CFC-12 using the Oslo LBL model and derived factors to account for stratospheric temperature adjustment and lifetime adjustment. The instantaneous $\mathrm{RE}$ is increased by $10.5 \%$ when stratospheric temperature adjustment is taken into account, while the lifetime correction reduces the RE by $3.0 \%$. Our final estimate $\left(0.32 \mathrm{~W} \mathrm{~m}^{-2} \mathrm{ppb}^{-1}\right)$ is in excellent agreement with that used in AR4. In contrast to CFC-11, the atmospheric lifetimes of CFC-12 derived in the new model study by Douglass et al. [2008] are in good agreement with those used in previous IPCC and WMO assessments, and we here adopt the lifetime of 100 years which has been used since the assessment of $W M O$ [1999].

\subsubsection{3. $\mathrm{CFC}-13\left(\mathrm{CClF}_{3}\right)$}

[121] A value of $0.25 \mathrm{~W} \mathrm{~m}^{-2} \mathrm{ppb}^{-1}$ for the RE of CFC-13 has been used in the previous IPCC and WMO assessments and is from Myhre and Stordal [1997] who used a broadband model. The same value was calculated with a narrowband model in Jain et al. [2000] and was obtained in this study using absorption cross-section data from McDaniel et al. [1991].

\subsubsection{4. $\mathrm{CFC}-113\left(\mathrm{CCl}_{2} \mathrm{FCCIF}_{2}\right)$}

[122] Literature measurements of the RE of CFC-113 fall in the range of $0.28-0.33 \mathrm{~W} \mathrm{~m}^{-2} \mathrm{ppb}^{-1}$ with a mean of $0.31 \mathrm{~W} \mathrm{~m}^{-2} \mathrm{ppb}^{-1}$ [Fisher et al., 1990; Jain et al., 2000; Myhre and Stordal, 1997], while AR4 used a value of 0.30 $\mathrm{W} \mathrm{m} \mathrm{mpb}^{-1}$ (based on Myhre and Stordal [1997]). We have used absorption cross sections from a recent study by Le Bris et al. [2011] and from McDaniel et al. [1991] to obtain values of 0.31 and $0.29 \mathrm{~W} \mathrm{~m}^{-2} \mathrm{ppb}^{-1}$, respectively. Our average $\mathrm{RE}\left(0.30 \mathrm{~W} \mathrm{~m}^{-2} \mathrm{ppb}^{-1}\right)$ is in excellent agreement with AR4.

\subsubsection{5. $\mathrm{CFC}-114\left(\mathrm{CCIF}_{2} \mathrm{CClF}_{2}\right)$}

[123] Literature measurements of the RE of CFC-114 are in the range of $0.29-0.38 \mathrm{~W} \mathrm{~m}^{-2} \mathrm{ppb}^{-1}$ (mean: $0.33 \mathrm{~W} \mathrm{~m}^{-2} \mathrm{ppb}^{-1}$ ) [Fisher et al., 1990; Jain et al., 2000; Myhre and Stordal, 1997]. AR4 reports a RE of $0.31 \mathrm{~W} \mathrm{~m}^{-2} \mathrm{ppb}^{-1}$ (based on Myhre and Stordal [1997]) which is the same as calculated here using absorption cross section from McDaniel et al. [1991]. Although our RE estimate is in excellent agreement with AR4, the best estimate GWP of CFC-114 is about $15 \%$ lower (Table 3 ) due to the shorter lifetime and higher $\mathrm{AGWP}_{\mathrm{CO} 2}$ used here. We have used the lifetime from WMO [2011] of 190 years, which is based on new model calculations by Prather and Hsu [2008; 2010], and is approximately 40\% shorter than the AR4 estimate of 300 years..

\subsubsection{6. $\mathrm{CFC}-115\left(\mathrm{CCIF}_{2} \mathrm{CF}_{3}\right)$}

[124] Literature reports of the RE of CFC-115 fall in the range of $0.20 \mathrm{~W} \mathrm{~m}^{-2} \mathrm{ppb}^{-1}$ to $0.30 \mathrm{~W} \mathrm{~m}^{-2} \mathrm{ppb}^{-1}$ (mean: $0.24 \mathrm{~W} \mathrm{~m}^{-2} \mathrm{ppb}^{-1}$ ) [Fisher et al., 1990; Jain et al., 2000; Myhre and Stordal, 1997], while the latest assessments (since IPCC [2001]) have used the instantaneous forcing of $0.18 \mathrm{~W} \mathrm{~m}^{-2} \mathrm{ppb}^{-1}$ from Myhre and Stordal [1997] (note that the value from AR4 falls outside the range quoted for the range of literature values because they reported the instantaneous RE while we consider the RE from Myhre and Stordal [1997]). The much higher RE of CFC-115 calculated by Fisher et al. [1990] compared to Myhre and Stordal [1997] and Jain et al. [2000] is most likely caused 


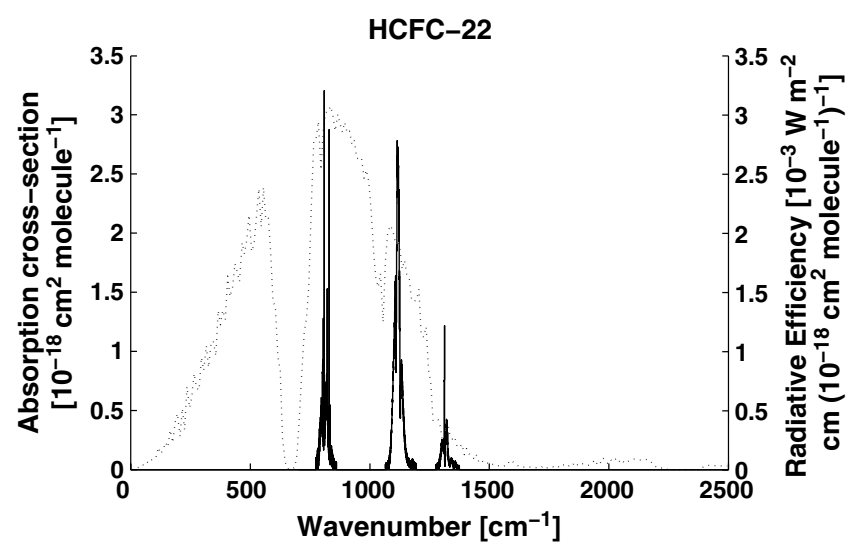

Figure 12. Absorption spectrum of HCFC-22 at $293 \mathrm{~K}$ in $800 \mathrm{hPa}$ air diluent from Ballard et al. [2000b] (solid line) and Oslo simulation of Pinnock curve (dotted line).

by the much higher integrated absorption cross section in the first study compared to the work of McDaniel et al. [1991] which has been used in the two latter studies (Table 2). We calculate a RE value of $0.20 \mathrm{~W} \mathrm{~m}^{-2} \mathrm{ppb}^{-1}$, which is in agreement with Myhre and Stordal [1997] and close to the RE of $0.21 \mathrm{~W} \mathrm{~m}^{-2} \mathrm{ppb}^{-1}$ estimated by Jain et al. [2000]. As for CFC-114, new model calculations [Prather and Hsu, 2008; 2010] suggested a significantly shorter lifetime of 1,020 years for CFC-115 (compared to 1,700 years in AR4). Nevertheless, the GWP(100) of CFC-115 is still $\sim 4 \%$ higher than in AR4 due to the higher RE of CFC-115 calculated here (Table 3).

\subsubsection{Hydrochlorofluorocarbons (HCFCs)}

[125] HCFCs are controlled by the Montreal Protocol, but they have been common substitutes for CFCs due to their lower potential for ozone depletion. As a consequence, atmospheric concentrations of some HCFCs have grown rapidly over the last decade, as illustrated for HCFC-22 in Figure 1. The atmospheric lifetimes of HCFCs are generally lower than for CFCs, but some of these compounds still have sufficiently long lifetimes to yield significant global warming potentials. The absorption cross section of one of the most well-studied gases, HCFC-22, is shown in Figure 12. Similarly to the CFCs, most of the absorption from HCFCs occurs in the atmospheric window region $\left(800-1200 \mathrm{~cm}^{-1}\right)$. Previously published absorption cross sections are listed in Table 4, while best estimate lifetimes, radiative efficiencies, and GWP(100) values for HCFCs are given in Table 5 and discussed below. Since the main loss mechanism for HCFCs is through reaction with $\mathrm{OH}$ in the troposphere, the $S$-shaped fit from section 3.3.4 (equation (2) and dark blue curve in Figure 9) has been used to account for the non-uniform vertical profile and horizontal distribution of all compounds presented in this subsection.

\subsubsection{1. $\mathrm{HCFC}-21\left(\mathrm{CHCl}_{2} \mathrm{~F}\right)$}

[126] REs of $0.19 \mathrm{~W} \mathrm{~m}^{-2} \mathrm{ppb}^{-1}$ [Christidis et al., 1997] and $0.14 \mathrm{~W} \mathrm{~m}^{-2} \mathrm{ppb}^{-1}$ [Sihra et al., 2001] have been reported for HCFC-21. The difference in the results between the studies reflects different vertical profile assumptions; Christidis et al. [1997] assumed a constant vertical profile, while Sihra et al. [2001] accounted for the fall-off in concentration of this relatively short-lived species $(1.7$ years atmospheric lifetime) above the troposphere. The RE from Sihra et al. [2001] is used for the recommended RE in AR4, and the cross section from that study has been used in our RE and GWP calculations. Both the HITRAN 2008 and GEISA 2009 databases include the spectrum from Massie et al. [1985], but this spectrum contains only one of the absorption bands $\left(785-840 \mathrm{~cm}^{-1}\right)$ and has therefore not been employed in our calculations. Our estimate of $0.15 \mathrm{~W} \mathrm{~m}^{-2} \mathrm{ppb}^{-1}$ is in good agreement $(3.8 \%$ higher prior to rounding) with the AR4 (see Table 5).

\subsubsection{2. $\mathrm{HCFC}-22\left(\mathrm{CHClF}_{2}\right)$}

[127] HCFC-22 is one of the most well-studied compounds with $\mathrm{RE}$ estimates in the literature ranging from 0.18 to $0.23 \mathrm{~W} \mathrm{~m}^{-2} \mathrm{ppb}^{-1}$ (mean: $0.21 \mathrm{~W} \mathrm{~m}^{-2} \mathrm{ppb}^{-1}$ ) [Fisher et al., 1990; Good et al., 1998; Highwood and Shine, 2000; Jain et al., 2000; Myhre and Stordal, 1997; Naik et al., 2000; Orkin et al., 2003; Pinnock et al., 1995; Sihra et al., 2001]. Papasavva et al. [1997] used an ab initio spectrum which is approximately $10 \%$ more intense than the experimentally derived spectra (Table 4) and consequently report a $\mathrm{RE}$ of $0.23 \mathrm{~W} \mathrm{~m}^{-2} \mathrm{ppb}^{-1}$ which is $10 \%$ higher than the average from the experimental studies. AR4 reports a RE of $0.20 \mathrm{~W} \mathrm{~m}^{-2} \mathrm{ppb}^{-1}$ which is taken from Highwood and Shine [2000]. We have based our calculations on the spectrum from Ballard et al. [2000b] which is a composite of measurements from five laboratory groups, and is in good agreement with other reported experimental spectra (see Table 4). Our calculations yield a RE value of $0.20 \mathrm{~W} \mathrm{~m}^{-2} \mathrm{ppb}^{-1}$, which is the same as recommended by AR4. We note that calculated RE values using absorption cross sections available from other studies [Clerbaux et al., 1993; Highwood and Shine, 2000; Orkin et al., 2003; Pinnock et al., 1995; Sihra et al., 2001] (see Table S2 in the supporting information for individual results) agree to within $4 \%$ of the RE value calculated using the spectrum from Ballard et al. [2000b], indicating that the uncertainty in the HCFC-22 spectrum is rather small (the spectrum reported by Varanasi et al. [1994] was not included in this comparison because one of the absorption bands was missing).

\subsubsection{3. $\mathrm{HCFC}-122\left(\mathrm{CHCl}_{2} \mathrm{CF}_{2} \mathrm{Cl}\right)$}

[128] One study has estimated the instantaneous RE of HCFC-122 with a value $0.23 \mathrm{~W} \mathrm{~m}^{-2} \mathrm{ppb}^{-1}$ [Orkin et al., 2003] (scaled to our recommended CFC-11 RE of $\left.0.26 \mathrm{~W} \mathrm{~m}^{-2} \mathrm{ppb}^{-1}\right)$. We have used their absorption spectrum and calculated a RE value of $0.17 \mathrm{~W} \mathrm{~m}^{-2} \mathrm{ppb}^{-1}$. The main reasons for the lower value calculated here are probably that Orkin et al. [2003] used a simplified approach which was not based on radiative transfer calculations, and that they did not account for stratospheric temperature adjustment and inhomogeneous distribution in the troposphere. The lifetime of 1.0 year is taken from Orkin et al. [2003].

\subsubsection{4. $\left.\mathrm{HCFC}-122 \mathrm{a}(\mathrm{CHFClCFCl})_{2}\right)$}

[129] One study has estimated instantaneous RE due to HCFC-122a, with a value $0.24 \mathrm{~W} \mathrm{~m}^{-2} \mathrm{ppb}^{-1}$ [Orkin 
TABLE 4. Integrated Absorption Cross Sections $(S)$ for Hydrochlorofluorocarbons (HCFCs) ${ }^{\mathrm{a}}$

\begin{tabular}{|c|c|c|c|c|c|c|c|c|c|}
\hline Name & CAS\# & Acronym & Formula & Data $^{\mathrm{b}}$ & $T / \mathrm{K}$ & $\begin{array}{l}\text { Wn. } \\
\text { Range } / \mathrm{cm}^{-1}\end{array}$ & $S^{\mathrm{c}}$ & Reference & Database $^{\mathrm{d}}$ \\
\hline \multirow[t]{3}{*}{ Dichlorofluoromethane } & $75-43-4$ & HCFC-21 & $\mathrm{CHCl}_{2} \mathrm{~F}$ & $\mathrm{E}$ & 296 & $600-1500$ & 7.4 & [Sihra et al., 2001] & \\
\hline & & & & $\mathrm{E}$ & 296 & $450-2000$ & 6.8 & [Christidis et al., 1997] & \\
\hline & & & & $\mathrm{E}$ & 296 & $785-840$ & 2.7 & [Massie et al., 1985] & $\mathrm{H}$ \\
\hline \multirow[t]{14}{*}{ Chlorodifluoromethane } & $75-45-6$ & HCFC-22 & $\mathrm{CHClF}_{2}$ & $\mathrm{E}$ & 295 & $750-1380$ & 10.0 & [Orkin et al., 2003] & \\
\hline & & & & $\mathrm{E}$ & 296 & $700-1400$ & 10.1 & [Sihra et al., 2001] & \\
\hline & & & & $\mathrm{E}$ & 293 & $775-1375$ & 10.1 & [Ballard et al., 2000b] & G \\
\hline & & & & $\mathrm{E}$ & 273 & $750-1400$ & 10.2 & $\begin{array}{c}\text { [Highwood and Shine, } \\
\text { 2000] }\end{array}$ & \\
\hline & & & & $\mathrm{E}$ & & & & [Naik et al., 2000] & \\
\hline & & & & A & & $600-1500$ & 11.6 & [Papasavva et al., 1997] & \\
\hline & & & & $\mathrm{E}$ & 296 & $765-1390$ & 10.2 & [Pinnock et al., 1995] & G \\
\hline & & & & $\mathrm{E}$ & 296 & $735-1380$ & 9.7 & [Anastasi et al., 1994] & \\
\hline & & & & $\mathrm{E}$ & 296 & $1070-1195$ & 6.9 & [Varanasi et al., 1994] & G \\
\hline & & & & $\mathrm{E}$ & 287 & $765-1380$ & 10.3 & [Clerbaux et al., 1993] & $\mathrm{H}$ \\
\hline & & & & $\mathrm{E}$ & 293 & $755-1390$ & 10.3 & $\begin{array}{c}\text { [Cappellani and Restelli, } \\
\text { 1992] }\end{array}$ & \\
\hline & & & & $\mathrm{E}$ & 293 & $775-1375$ & 9.0 & [McDaniel et al., 1991] & \\
\hline & & & & $\mathrm{E}$ & & $775-1397$ & 9.5 & [Fisher et al., 1990] & \\
\hline & & & & $\mathrm{E}$ & & $775-1170$ & 9.4 & $\begin{array}{c}\text { [Varanasi and } \\
\text { Chudamani, 1988b] }\end{array}$ & \\
\hline $\begin{array}{l}\text { 1,1,2-Trichloro-2,2- } \\
\text { difluoroethane }\end{array}$ & $354-21-2$ & $\mathrm{HCFC}-122$ & $\mathrm{CHCl}_{2} \mathrm{CF}_{2} \mathrm{Cl}$ & $\mathrm{E}$ & 295 & $560-1360$ & 10.4 & [Orkin et al., 2003] & \\
\hline $\begin{array}{l}\text { 1,1,2-Trichloro-1,2- } \\
\text { difluoroethane }\end{array}$ & $354-15-4$ & HCFC-122a & $\mathrm{CHFClCFCl}_{2}$ & $\mathrm{E}$ & 295 & $590-1380$ & 9.9 & [Orkin et al., 2003] & \\
\hline \multirow{8}{*}{$\begin{array}{l}\text { 2,2-Dichloro-1,1,1- } \\
\text { trifluoroethane }\end{array}$} & $306-83-2$ & HCFC-123 & $\mathrm{CHCl}_{2} \mathrm{CF}_{3}$ & $\mathrm{E}$ & 295 & $480-1430$ & 13.1 & [Orkin et al., 2003] & \\
\hline & & & & $\begin{array}{l}\mathrm{E} \\
\mathrm{E}\end{array}$ & 296 & $700-1500$ & 11.9 & $\begin{array}{l}\text { [Sihra et al., 2001] } \\
{[\text { Naik et al., 2000] }}\end{array}$ & \\
\hline & & & & A & & $600-1500$ & 14.1 & [Papasavva et al., 1997] & \\
\hline & & & & $\mathrm{E}$ & 296 & $700-1400$ & 12.0 & [Pinnock et al., 1995] & $\mathrm{G}$ \\
\hline & & & & $\mathrm{E}$ & & $480-1430$ & 12.7 & [Olliff and Fischer, 1994] & \\
\hline & & & & $\mathrm{E}$ & 287 & $740-1450$ & 12.9 & [Clerbaux et al., 1993] & $\mathrm{H}$ \\
\hline & & & & $\mathrm{E}$ & 293 & $648-1440$ & 12.7 & $\begin{array}{c}\text { [Cappellani and Restelli, } \\
\text { 1992] }\end{array}$ & \\
\hline & & & & $\mathrm{E}$ & & 649-1307 & 10.6 & [Fisher et al., 1990] & \\
\hline $\begin{array}{l}\text { 1,2-Dichloro-1,1,2- } \\
\text { trifluoroethane }\end{array}$ & $354-23-4$ & HCFC-123a & $\mathrm{CHClFCF}_{2} \mathrm{Cl}$ & $\mathrm{E}$ & 295 & $450-1400$ & 12.3 & [Orkin et al., 2003] & \\
\hline \multirow{6}{*}{$\begin{array}{l}\text { 2-Chloro-1,1,1,2- } \\
\text { tetrafluoroethane }\end{array}$} & $2837-89-0$ & $\mathrm{HCFC}-124$ & $\mathrm{CHClFCF}_{3}$ & $\mathrm{E}$ & 296 & $700-1500$ & 13.4 & [Sihra et al., 2001] & \\
\hline & & & & $\mathrm{E}$ & & & & [Naik et al., 2000] & \\
\hline & & & & A & & $600-1500$ & 15.7 & [Papasavva et al., 1997] & \\
\hline & & & & $\mathrm{E}$ & 296 & $670-1435$ & 13.8 & [Pinnock et al., 1995] & $\mathrm{G}$ \\
\hline & & & & $\mathrm{E}$ & 287 & $675-1430$ & 14.4 & [Clerbaux et al., 1993] & $\mathrm{H}$ \\
\hline & & & & $\mathrm{E}$ & & $440-1420$ & 15.0 & [Fisher et al., 1990] & \\
\hline $\begin{array}{l}\text { 1,1-Dichloro-1,2- } \\
\text { difluoroethane }\end{array}$ & $1842-05-3$ & $\mathrm{HCFC}-132 \mathrm{c}$ & $\mathrm{CH}_{2} \mathrm{FCFCl}_{2}$ & $\mathrm{E}$ & 295 & $425-1490$ & 8.4 & [Orkin et al., 2003] & \\
\hline \multirow[t]{10}{*}{ 1,1-Dichloro-1-fluoroethane } & $1717-00-6$ & HCFC-141b & $\mathrm{CH}_{3} \mathrm{CCl}_{2} \mathrm{~F}$ & $\mathrm{E}$ & 283 & $570-3100$ & 8.1 & [Le Bris et al., 2012] & \\
\hline & & & & $\mathrm{E}$ & 295 & $540-1540$ & 8.0 & [Orkin et al., 2003] & \\
\hline & & & & $\mathrm{E}$ & 296 & $700-1500$ & 7.1 & [Sihra et al., 2001] & \\
\hline & & & & $\mathrm{E}$ & & & & [Naik et al., 2000] & \\
\hline & & & & A & & $600-1500$ & 9.1 & [Papasavva et al., 1997] & \\
\hline & & & & $\mathrm{E}$ & 296 & $700-1500$ & 8.3 & [Imasu et al., 1995] & \\
\hline & & & & $\mathrm{E}$ & 296 & $700-1470$ & 7.2 & [Pinnock et al., 1995] & G \\
\hline & & & & $\mathrm{E}$ & & $540-1480$ & 7.6 & [Olliff and Fischer, 1994] & \\
\hline & & & & $\mathrm{E}$ & 287 & $710-1470$ & 7.8 & [Clerbaux et al., 1993] & $\mathrm{H}$ \\
\hline & & & & $\mathrm{E}$ & & $555-1420$ & 7.1 & [Fisher et al., 1990] & \\
\hline \multirow[t]{8}{*}{ 1-Chloro-1,1-difluoroethane } & $75-68-3$ & $\mathrm{HCFC}-142 b$ & $\mathrm{CH}_{3} \mathrm{CClF}_{2}$ & $\mathrm{E}$ & 283 & $650-3500$ & 10.8 & $\begin{array}{c}\text { [Le Bris and Strong, } \\
2010]\end{array}$ & \\
\hline & & & & $\mathrm{E}$ & 296 & $700-1500$ & 9.6 & [Sihra et al., 2001] & \\
\hline & & & & $\mathrm{E}$ & & & & [Naik et al., 2000] & \\
\hline & & & & A & & $600-1500$ & 11.8 & [Papasavva et al., 1997] & \\
\hline & & & & $\mathrm{E}$ & 296 & $650-1425$ & 10.1 & [Pinnock et al., 1995] & $\mathrm{G}$ \\
\hline & & & & $\mathrm{E}$ & 287 & $650-1469$ & 11.1 & [Clerbaux et al., 1993] & $\mathrm{H}$ \\
\hline & & & & $\mathrm{E}$ & 293 & $647-1485$ & 10.7 & $\begin{array}{c}\text { [Cappellani and Restelli, } \\
\text { 1992] }\end{array}$ & \\
\hline & & & & $\mathrm{E}$ & & $649-1397$ & 9.6 & [Fisher et al., 1990] & \\
\hline \multirow{3}{*}{$\begin{array}{l}\text { 3,3-Dichloro-1,1,1,2,2- } \\
\text { pentafluoropropane }\end{array}$} & $422-56-0$ & HCFC-225ca & $\mathrm{CHCl}_{2} \mathrm{CF}_{2} \mathrm{CF}_{3}$ & $\mathrm{E}$ & 296 & $700-1400$ & 18.0 & [Sihra et al., 2001] & \\
\hline & & & & $\mathrm{E}$ & & & & [Naik et al., 2000] & \\
\hline & & & & $\mathrm{E}$ & 296 & $700-1400$ & 14.6 & [Pinnock et al., 1995] & \\
\hline
\end{tabular}


TABLE 4. (Continued)

\begin{tabular}{|c|c|c|c|c|c|c|c|c|c|}
\hline Name & CAS\# & Acronym & Formula & Data $^{\mathrm{b}}$ & $T / \mathrm{K}$ & $\begin{array}{c}\text { Wn. } \\
\text { Range } / \mathrm{cm}^{-1}\end{array}$ & $S^{\mathrm{c}}$ & Reference & Database $^{\mathrm{d}}$ \\
\hline \multirow{6}{*}{$\begin{array}{l}\text { 1,3-Dichloro-1,1,2,2,3- } \\
\text { pentafluoropropane }\end{array}$} & & & & $\mathrm{E}$ & 287 & $695-1420$ & 17.7 & [Clerbaux et al., 1993] & $\mathrm{H}$ \\
\hline & $507-55-1$ & HCFC-225cb & $\mathrm{CHClFCF}_{2} \mathrm{CClF}_{2}$ & $2 \mathrm{E}$ & 296 & $700-1400$ & 15.2 & [Sihra et al., 2001] & \\
\hline & & & & E & & & & [Naik et al., 2000] & \\
\hline & & & & E & 296 & $700-1500$ & 16.6 & [Imasu et al., 1995] & \\
\hline & & & & E & 296 & $700-1400$ & 15.1 & [Pinnock et al., 1995] & \\
\hline & & & & E & 287 & $715-1375$ & 15.6 & [Clerbaux et al., 1993] & $\mathrm{H}$ \\
\hline (E)-1-Chloro-3,3,3- & $102687-65-0$ & & $\begin{array}{l}\text { trans- } \\
\mathrm{CF}_{2} \mathrm{CH}=\mathrm{CHCl}\end{array}$ & $\mathrm{E}$ & 295 & $600-1800$ & 17.4 & [Andersen et al., 2008] & \\
\hline
\end{tabular}

et al., 2003] (scaled to our recommended CFC-11 RE of $\left.0.26 \mathrm{~W} \mathrm{~m}^{-2} \mathrm{ppb}^{-1}\right)$. We calculate a $\mathrm{RE}$ value of $0.21 \mathrm{~W}$ $\mathrm{m}^{-2} \mathrm{ppb}^{-1}$ when using their absorption cross section and lifetime estimate of 3.4 years.

\subsubsection{5. $\mathrm{HCFC}-123\left(\mathrm{CHCl}_{2} \mathrm{CF}_{3}\right)$}

[130] Literature estimations of the RE of HCFC-123 derived from experimental measurements of the IR spectrum lie in the range of $0.14-0.22 \mathrm{~W} \mathrm{~m}^{-2} \mathrm{ppb}^{-1}$ (mean: $0.18 \mathrm{~W}$ $\mathrm{m}^{-2} \mathrm{ppb}^{-1}$ ) [Fisher et al., 1990; Jain et al., 2000; Naik et al., 2000; Orkin et al., 2003; Pinnock et al., 1995; Sihra et al., 2001]. As seen from Table 4, the infrared spectrum reported in the ab initio study of Papasavva et al. [1997] is more intense than measured in the experimental studies and consequently the instantaneous $\mathrm{RE}$ of $0.22 \mathrm{~W} \mathrm{~m}^{-2} \mathrm{ppb}^{-1}$ is higher than those determined in the experimental studies. AR4 report a RE of $0.14 \mathrm{~W} \mathrm{~m}^{-2} \mathrm{ppb}^{-1}$ which is based on both Sihra et al. [2001] and Jain et al. [2000]. We calculate a slightly higher RE value of $0.15 \mathrm{~W} \mathrm{~m}^{-2} \mathrm{ppb}^{-1}$ for all three sources of absorption spectra [Clerbaux et al., 1993; Orkin et al., 2003; Sihra et al., 2001] (Tables 4 and 5). It should be noted here that for this compound we have applied a correction for stratospheric temperature adjustment of $6.5 \%$ (the average of the values found by Jain et al. [2000] (5\%) and Pinnock et al. [1995] (8\%)) rather than the generic $10 \%$ correction used elsewhere in section 4.1.2.

\subsubsection{6. $\mathrm{HCFC}-123 \mathrm{a}\left(\mathrm{CHCIFCF}_{2} \mathrm{Cl}\right)$}

[131] One study has estimated instantaneous RE of HCFC-123a with a value $0.25 \mathrm{~W} \mathrm{~m}^{-2} \mathrm{ppb}^{-1}$ [Orkin et al., 2003] (scaled to our recommended CFC-11 RE of $0.26 \mathrm{~W}$ $\mathrm{m}^{-2} \mathrm{ppb}^{-1}$ ). We have used their absorption spectrum and calculated a slightly lower RE value of $0.23 \mathrm{~W} \mathrm{~m}^{-2} \mathrm{ppb}^{-1}$.

\subsubsection{HCFC-124 ( $\left.\mathrm{CHCIFCF}_{3}\right)$}

[132] Previous studies of RE due to HCFC-124 are in relatively good agreement with a range of $0.19-0.23 \mathrm{~W}$ $\mathrm{m}^{-2} \mathrm{ppb}^{-1}$ (mean: $0.21 \mathrm{~W} \mathrm{~m}^{-2} \mathrm{ppb}^{-1}$ ) [Fisher et al., 1990; Jain et al., 2000; Naik et al., 2000; Pinnock et al., 1995; Sihra et al., 2001]. As for HCFC-123, Papasavva et al. [1997] calculated a higher RE of $0.23 \mathrm{~W} \mathrm{~m}^{-2} \mathrm{ppb}^{-1}$ (instantaneous RE) based upon an ab initio absorption cross section. IPCC AR4 report a RE of $0.22 \mathrm{~W} \mathrm{~m}^{-2} \mathrm{ppb}^{-1}$ which is taken from Fisher et al. [1990] (note that AR4 scaled the RE value from Fisher et al. [1990] to the previously recommended CFC-11 RE of $0.25 \mathrm{~W} \mathrm{~m}^{-2}$ $\mathrm{ppb}^{-1}$ - see the discussion concerning CFC-11 in section 4.1.1-while we refer to the Fisher et al. [1990] value as scaled to our recommended CFC-11 RE of $0.26 \mathrm{~W} \mathrm{~m}^{-2}$

TABLE 5. Lifetimes, Radiative Efficiencies, and Direct GWPs (Relative to $\mathrm{CO}_{2}$ ) for Hydrochlorofluorocarbons (HCFCs)

\begin{tabular}{|c|c|c|c|c|c|c|c|}
\hline \multirow[b]{2}{*}{ Acronym / name } & \multirow[b]{2}{*}{ Formula } & \multirow[b]{2}{*}{$\begin{array}{l}\text { Lifetime } \\
\text { (yr) }\end{array}$} & \multicolumn{3}{|c|}{ Radiative Efficiency $\left(\mathrm{W} \mathrm{m}^{-2} \mathrm{ppb}^{-1}\right)$} & \multicolumn{2}{|c|}{ GWP 100 year } \\
\hline & & & AR4 & $\begin{array}{l}\text { This study- } \\
\text { const. profile }\end{array}$ & $\begin{array}{l}\text { This study- } \\
\text { lifetime corr. }\end{array}$ & AR4 & $\begin{array}{l}\text { This study- } \\
\text { lifetime corr. }\end{array}$ \\
\hline HCFC-21 & $\mathrm{CHCl}_{2} \mathrm{~F}$ & 1.7 & 0.14 & 0.18 & 0.15 & 151 & 148 \\
\hline HCFC-22 & $\mathrm{CHClF}_{2}$ & 11.9 & 0.20 & 0.22 & 0.21 & 1,810 & 1,760 \\
\hline HCFC-122 & $\mathrm{CHCl}_{2} \mathrm{CF}_{2} \mathrm{Cl}$ & 1.0 & & 0.23 & 0.17 & & 59 \\
\hline HCFC-122a & $\mathrm{CHFClCFCl}_{2}$ & 3.4 & & 0.23 & 0.21 & & 258 \\
\hline HCFC-123 & $\mathrm{CHCl}_{2} \mathrm{CF}_{3}$ & 1.3 & 0.14 & 0.19 & 0.15 & 77 & 79 \\
\hline HCFC-123a & $\mathrm{CHClFCF}_{2} \mathrm{Cl}$ & 4.0 & & 0.25 & 0.23 & & 370 \\
\hline HCFC-124 & $\mathrm{CHClFCF}_{3}$ & 5.9 & 0.22 & 0.21 & 0.20 & 609 & 527 \\
\hline HCFC-132c & $\mathrm{CH}_{2} \mathrm{FCFCl}_{2}$ & 4.3 & & 0.19 & 0.17 & & 338 \\
\hline HCFC-141b & $\mathrm{CH}_{3} \mathrm{CCl}_{2} \mathrm{~F}$ & 9.2 & 0.14 & 0.17 & 0.16 & 725 & 782 \\
\hline HCFC-142b & $\mathrm{CH}_{3} \mathrm{CClF}_{2}$ & 17.2 & 0.20 & 0.19 & 0.19 & 2,310 & 1,980 \\
\hline HCFC-225ca & $\mathrm{CHCl}_{2} \mathrm{CF}_{2} \mathrm{CF}_{3}$ & 1.9 & 0.20 & 0.26 & 0.22 & 122 & 127 \\
\hline HCFC-225cb & $\mathrm{CHClFCF}_{2} \mathrm{CClF}_{2}$ & 5.9 & 0.32 & 0.32 & 0.29 & 595 & 525 \\
\hline $\begin{array}{l}\text { (E)-1-Chloro-3,3,3- } \\
\text { trifluoroprop-1-ene }\end{array}$ & trans- $\mathrm{CF}_{3} \mathrm{CH}=\mathrm{CHCl}$ & 26.0 days & & 0.22 & 0.04 & & 1 \\
\hline
\end{tabular}

${ }^{\mathrm{a} C o m p o u n d s}$ in bold either have significant current atmospheric concentrations or a clear potential for future emissions. Recommended RE and GWP 100 year values are indicated in bold. Lifetimes are from $W M O$ [2011] except those in italics (see text for details). 


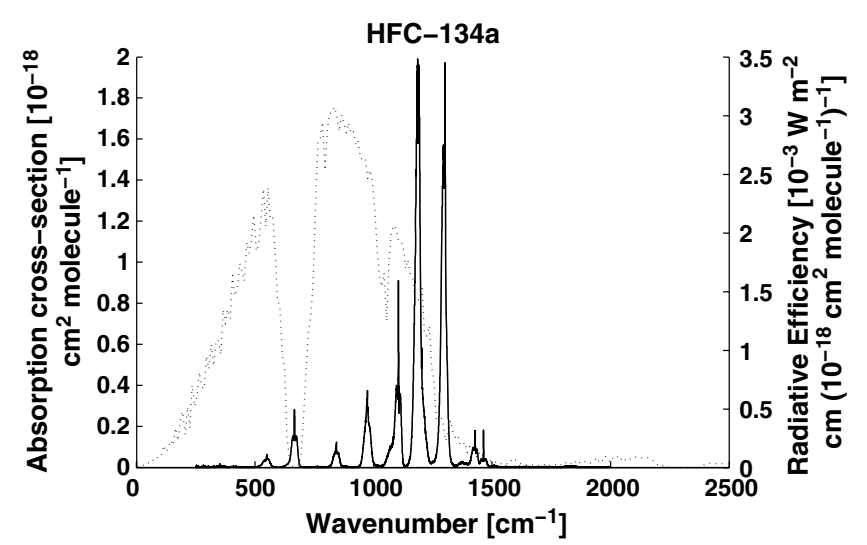

Figure 13. Absorption cross section of HFC-134a from Forster et al. [2005] (solid line) and Oslo simulation of Pinnock curve (dotted line). The spectrum is a composite of measurements from five laboratory groups and has been measured under various temperatures and diluent gas pressures.

$\mathrm{ppb}^{-1}$ ). We have used absorption cross sections from Sihra et al. [2001] and Clerbaux et al. [1993] to calculate a mean RE value of $0.20 \mathrm{~W} \mathrm{~m}^{-2} \mathrm{ppb}^{-1}$ (range: $0.19-0.20 \mathrm{~W} \mathrm{~m}^{-2} \mathrm{ppb}^{-1}$ ) (Tables 4 and 5), which is lower than in Fisher et al. [1990]. However, our calculated RE is in agreement with the newer studies of Sihra et al. [2001], Jain et al. [2000] and Naik et al. [2000], most likely due to the higher integrated absorption cross section of Fisher et al. [1990] (Table 4).

\subsubsection{8. $\mathrm{HCFC}-132 \mathrm{c}\left(\mathrm{CH}_{2} \mathrm{FCFCl}_{2}\right)$}

[133] One study has estimated instantaneous RE due to HCFC-132c, with a value $0.19 \mathrm{~W} \mathrm{~m}^{-2} \mathrm{ppb}^{-1}$ [Orkin et al., 2003] (scaled to our recommended CFC-11 RE of $0.26 \mathrm{~W}$ $\mathrm{m}^{-2} \mathrm{ppb}^{-1}$ ). We calculate a RE value of $0.17 \mathrm{~W} \mathrm{~m}^{-2} \mathrm{ppb}^{-1}$ when using their absorption cross section and lifetime estimate of 4.3 years.

\subsubsection{9. $\mathrm{HCFC}-141 \mathrm{~b}\left(\mathrm{CH}_{3} \mathrm{CCl}_{2} \mathrm{~F}\right)$}

[134] Radiative efficiencies for HCFC-141b reported in the published literature are in the range of $0.12-0.18 \mathrm{~W} \mathrm{~m}^{-2}$ $\mathrm{ppb}^{-1}$ (mean: $0.15 \mathrm{~W} \mathrm{~m}^{-2} \mathrm{ppb}^{-1}$ ) [Fisher et al., 1990; Imasu et al., 1995; Jain et al., 2000; Naik et al., 2000; Orkin et al., 2003; Pinnock et al., 1995; Sihra et al., 2001], and the value of $0.14 \mathrm{~W} \mathrm{~m}^{-2} \mathrm{ppb}^{-1}$ from Fisher et al. [1990] has been used by AR4 (scaled to the previously recommended CFC-11 RE of $\left.0.25 \mathrm{~W} \mathrm{~m}^{-2} \mathrm{ppb}^{-1}\right)$. Papasavva et al. [1997] calculated a much higher RE (instantaneous RE of $0.21 \mathrm{~W} \mathrm{~m}^{-2} \mathrm{ppb}^{-1}$ ) using an ab initio absorption spectrum. We calculate a slightly higher RE than AR4 with a mean value of $0.16 \mathrm{~W} \mathrm{~m}^{-2} \mathrm{ppb}^{-1}$ (range: $0.15-0.17 \mathrm{~W} \mathrm{~m}^{-2} \mathrm{ppb}^{-1}$ ) when using absorption cross sections from several sources [Clerbaux et al., 1993; Imasu et al., 1995; Orkin et al., 2003; Sihra et al., 2001]. We note that the value of $0.14 \mathrm{~W} \mathrm{~m}^{-2} \mathrm{ppb}^{-1}$ from Fisher et al. [1990] has been scaled by AR4 to account for changes in the recommended RE of CFC-11 (from $0.22 \mathrm{~W} \mathrm{~m}^{-2} \mathrm{ppb}^{-1}$ in Fisher et al. [1990] to $0.25 \mathrm{~W} \mathrm{~m}^{-2} \mathrm{ppb}^{-1}$ in AR4), and that a scaling to our recommended CFC-11 forcing of $0.26 \mathrm{~W} \mathrm{~m}^{-2}$ $\mathrm{ppb}^{-1}$ results in a RE of $0.15 \mathrm{~W} \mathrm{~m}^{-2} \mathrm{ppb}^{-1}$ from Fisher et al. [1990] - in better agreement with our calculations.

\subsubsection{0. $\mathrm{HCFC}-142 \mathrm{~b}\left(\mathrm{CH}_{3} \mathrm{CClF}_{2}\right)$}

[135] Previous reports of RE of HCFC-142b are in the range of $0.16-0.21 \mathrm{~W} \mathrm{~m}^{-2} \mathrm{ppb}^{-1}$ (mean: $0.18 \mathrm{~W} \mathrm{~m}^{-2} \mathrm{ppb}^{-1}$ ) [Fisher et al., 1990; Jain et al., 2000; Naik et al., 2000; Pinnock et al., 1995; Sihra et al., 2001]. Again, the ab initio study of Papasavva et al. [1997] is at the higher end of the range based on experimental studies as they calculate an instantaneous RE of $0.20 \mathrm{~W} \mathrm{~m}^{-2} \mathrm{ppb}^{-1}$. AR4 report a RE of $0.20 \mathrm{~W} \mathrm{~m}^{-2} \mathrm{ppb}^{-1}$ which is taken from Fisher et al. [1990]. We calculate a mean RE value of $0.19 \mathrm{~W} \mathrm{~m}^{-2} \mathrm{ppb}^{-1}$ (range: $0.18-0.20 \mathrm{~W} \mathrm{~m}^{-2} \mathrm{ppb}^{-1}$ ) when using absorption cross sections from Sihra et al. [2001] and Clerbaux et al. [1993] (Tables 4 and 5). Our estimate is lower than Fisher et al. [1990] and Pinnock et al. [1995] but higher than the more recent studies [Jain et al., 2000; Naik et al., 2000; Sihra et al., 2001].

\subsubsection{1. $\mathrm{HCFC}-225 \mathrm{Ca}\left(\mathrm{CHCl}_{2} \mathrm{CF}_{2} \mathrm{CF}_{3}\right)$}

[136] A range of $0.20-0.27 \mathrm{~W} \mathrm{~m}^{-2} \mathrm{ppb}^{-1}$ (mean: $0.22 \mathrm{~W}$ $\mathrm{m}^{-2} \mathrm{ppb}^{-1}$ ) for the RE of HCFC-225ca has been reported in the literature [Jain et al., 2000; Naik et al., 2000; Pinnock et al., 1995; Sihra et al., 2001]. Three of the studies are in good agreement $(<3 \%$ difference) while Pinnock et al. [1995] is an outlier with a value of $0.27 \mathrm{~W} \mathrm{~m}^{-2} \mathrm{ppb}^{-1}$, despite the lower integrated absorption cross section in their study (Table 4). The reason is that Pinnock et al. [1995] did not take into account the non-uniform tropospheric distribution, which gives a reduction in the $\mathrm{RE}$ of $16 \%$ when using our fractional correction method described in section 3.3.4 and a lifetime of 1.9 years [WMO, 2011]. AR4 has based their RE recommendation of $0.20 \mathrm{~W}$ $\mathrm{m}^{-2} \mathrm{ppb}^{-1}$ on Sihra et al. [2001] and Jain et al. [2000]. We calculate a mean RE value of $0.22 \mathrm{~W} \mathrm{~m}^{-2} \mathrm{ppb}^{-1}$ (range: $0.22-0.23 \mathrm{~W} \mathrm{~m}^{-2} \mathrm{ppb}^{-1}$ ) when using absorption cross sections from Sihra et al. [2001] and Clerbaux et al. [1993] (Tables 4 and 5).

\subsubsection{2. $\mathrm{HCFC}-225 \mathrm{cb}\left(\mathrm{CHClFCF}_{2} \mathrm{CClF}_{2}\right)$}

[137] The RE of HCFC-225cb has differed considerably in the past literature with a range of $0.25-0.35 \mathrm{~W} \mathrm{~m}^{-2} \mathrm{ppb}^{-1}$ (mean: $0.29 \mathrm{~W} \mathrm{~m}^{-2} \mathrm{ppb}^{-1}$ ) [Imasu et al., 1995; Jain et al., 2000; Naik et al., 2000; Pinnock et al., 1995; Sihra et al., 2001]. A value of $0.32 \mathrm{~W} \mathrm{~m}^{-2} \mathrm{ppb}^{-1}$ has been used in previous assessments and is based on Granier (personal communication, 1994) [IPCC, 1994]. We calculate a mean RE value of $0.29 \mathrm{~W} \mathrm{~m}^{-2} \mathrm{ppb}^{-1}$ (range: $0.28-0.31 \mathrm{~W} \mathrm{~m}^{-2} \mathrm{ppb}^{-1}$ ) when using absorption cross sections from Sihra et al. [2001], Clerbaux et al. [1993] and Imasu et al. [1995] (Tables 4 and 5). Our result differs by almost $10 \%$ from the AR 4 recommendation. As the AR4 value is not based on published literature, it is difficult to assess why our estimate is significantly lower than their value, but we note that our estimate is in agreement with the mean of published values and close to the most recent published RE estimate of HCFC-225cb of $0.28 \mathrm{~W} \mathrm{~m}^{-2} \mathrm{ppb}^{-1}$ [Sihra et al., 2001].

\subsubsection{3. (E)-1-Chloro-3,3,3-trifluoroprop-1-ene $\left(\mathrm{CF}_{3}\right.$} $\mathrm{CH}=\mathrm{CHCl}(\mathrm{E}))$

[138] The radiative efficiency of (E)-1-chloro-3,3,3trifluoroprop-1-ene has not been assessed in AR4 but was estimated by Andersen et al. [2008]. They used the original 
HODNEBROG ET AL.: HALOCARBON REVIEW

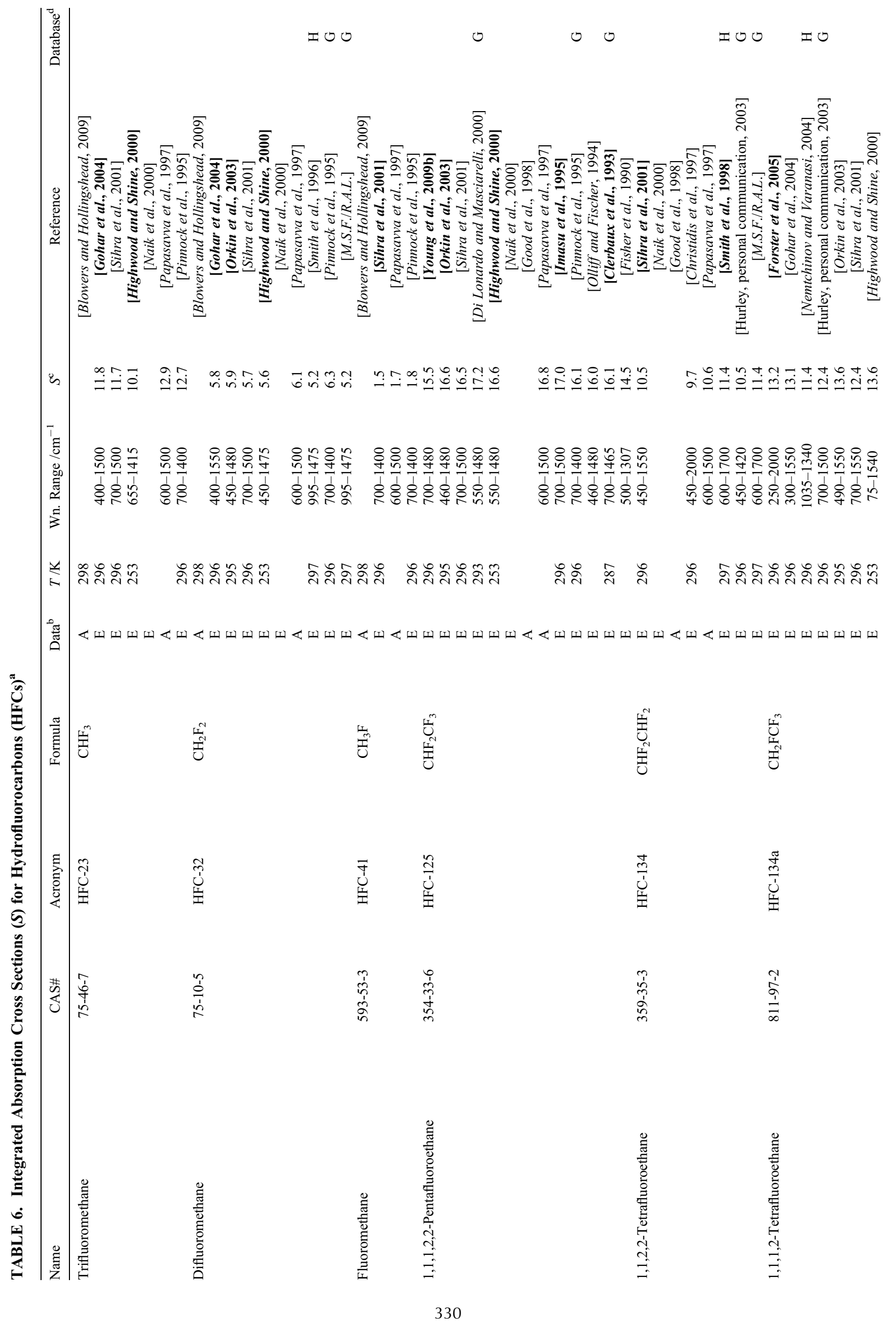


HODNEBROG ET AL.: HALOCARBON REVIEW

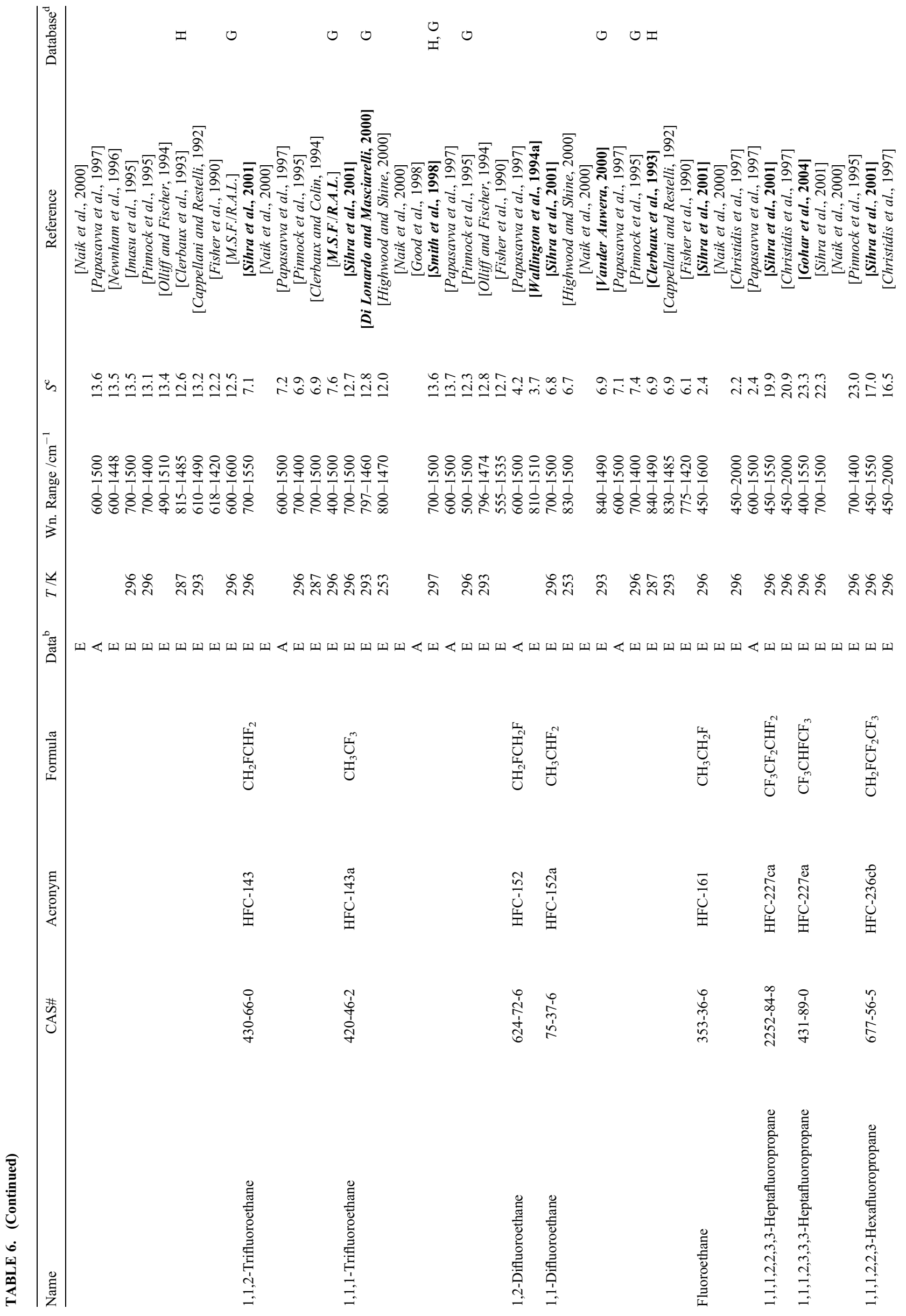


HODNEBROG ET AL.: HALOCARBON REVIEW

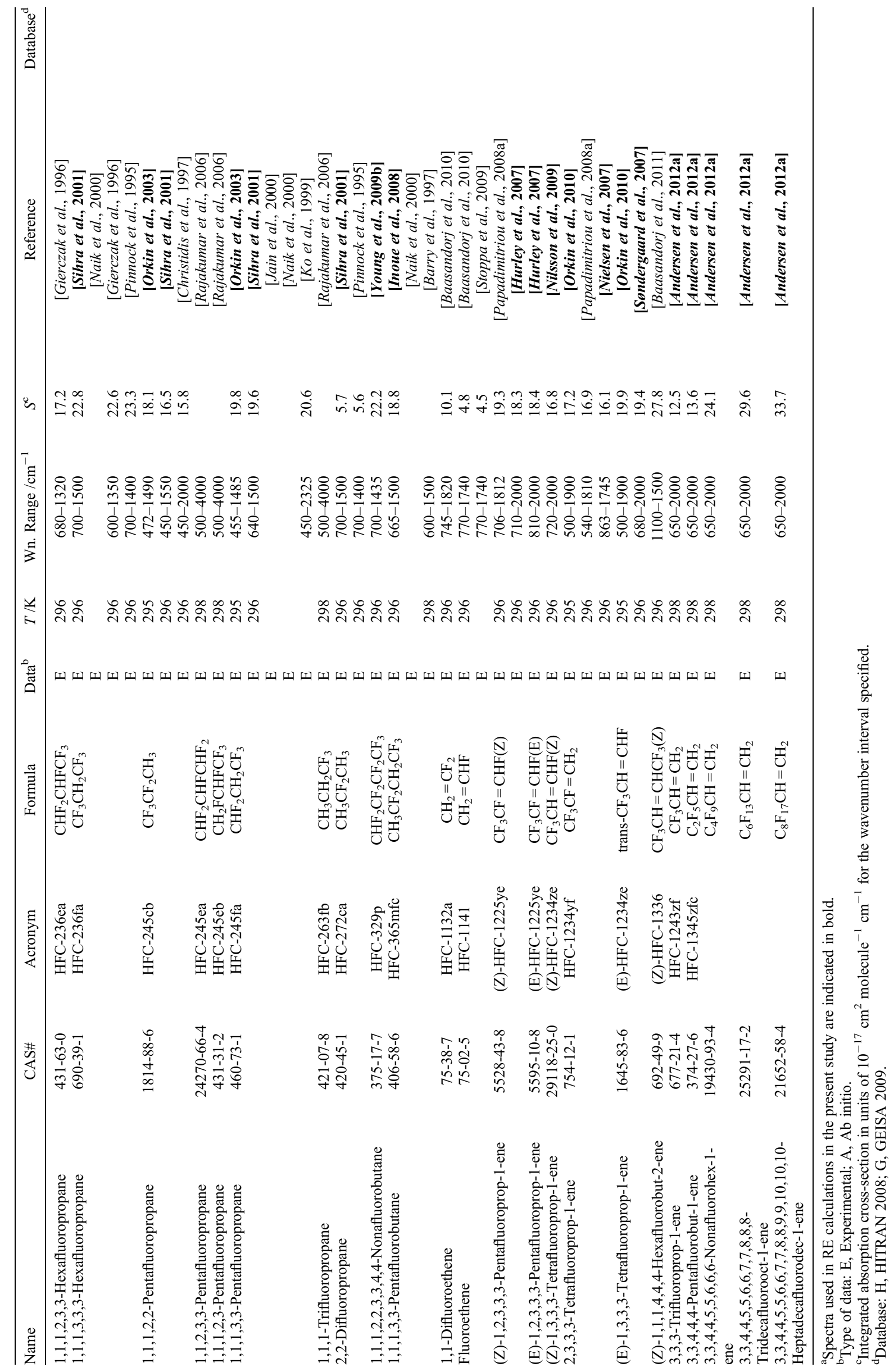


TABLE 7. Lifetimes, Radiative Efficiencies, and Direct GWPs (Relative to $\mathrm{CO}_{2}$ ) for Hydrofluorocarbons (HFCs) ${ }^{\mathrm{a}}$

\begin{tabular}{|c|c|c|c|c|c|c|c|}
\hline \multirow[b]{2}{*}{ Acronym / name } & \multirow[b]{2}{*}{ Formula } & \multirow[b]{2}{*}{ Lifetime (yr) } & \multicolumn{3}{|c|}{ Radiative Efficiency $\left(\mathrm{W} \mathrm{m}^{-2} \mathrm{ppb}^{-1}\right)$} & \multicolumn{2}{|c|}{ GWP 100 year } \\
\hline & & & AR4 & $\begin{array}{l}\text { This study- } \\
\text { const. profile }\end{array}$ & $\begin{array}{l}\text { This study- } \\
\text { lifetime corr. }\end{array}$ & AR4 & $\begin{array}{l}\text { This study- } \\
\text { lifetime corr. }\end{array}$ \\
\hline HFC-23 & $\mathrm{CHF}_{3}$ & 222.0 & 0.19 & 0.18 & 0.18 & 14,800 & 12,400 \\
\hline HFC-32 & $\mathrm{CH}_{2} \mathrm{~F}_{2}$ & 5.2 & 0.11 & 0.12 & 0.11 & 675 & 677 \\
\hline HFC-41 & $\mathrm{CH}_{3} \mathrm{~F}$ & 2.8 & 0.02 & 0.03 & 0.02 & 92 & 116 \\
\hline HFC-125 & $\mathrm{CHF}_{2} \mathrm{CF}_{3}$ & 28.2 & 0.23 & 0.23 & 0.23 & 3,500 & 3,170 \\
\hline HFC-134 & $\mathrm{CHF}_{2} \mathrm{CHF}_{2}$ & 9.7 & 0.18 & 0.20 & 0.19 & 1,100 & 1,120 \\
\hline HFC-134a & $\mathrm{CH}_{2} \mathrm{FCF}_{3}$ & 13.4 & 0.16 & 0.17 & 0.16 & 1,430 & 1,300 \\
\hline HFC-143 & $\mathrm{CH}_{2} \mathrm{FCHF}_{2}$ & 3.5 & 0.13 & 0.14 & 0.13 & 353 & 328 \\
\hline HFC-143a & $\mathrm{CH}_{3} \mathrm{CF}_{3}$ & 47.1 & 0.13 & 0.16 & 0.16 & 4,470 & 4,800 \\
\hline HFC-152 & $\mathrm{CH}_{2} \mathrm{FCH}_{2} \mathrm{~F}$ & 0.4 & 0.09 & 0.08 & 0.04 & 53 & 16 \\
\hline HFC-152a & $\mathrm{CH}_{3} \mathrm{CHF}_{2}$ & 1.5 & 0.09 & 0.12 & 0.10 & 124 & 138 \\
\hline HFC-161 & $\mathrm{CH}_{3} \mathrm{CH}_{2} \mathrm{~F}$ & 66.0 days & 0.03 & 0.04 & 0.02 & 12 & 4 \\
\hline HFC-227ca & $\mathrm{CF}_{3} \mathrm{CF}_{2} \mathrm{CHF}_{2}$ & 28.2 & & 0.27 & 0.27 & & 2,640 \\
\hline HFC-227ea & $\mathrm{CF}_{3} \mathrm{CHFCF}_{3}$ & 38.9 & 0.26 & 0.26 & 0.26 & 3,220 & $\mathbf{3 , 3 5 0}$ \\
\hline HFC-236cb & $\mathrm{CH}_{2} \mathrm{FCF}_{2} \mathrm{CF}_{3}$ & 13.1 & 0.23 & 0.24 & 0.23 & 1,340 & 1,210 \\
\hline HFC-236еа & $\mathrm{CHF}_{2} \mathrm{CHFCF}_{3}$ & 11.0 & 0.30 & & & 1,370 & 1,330 \\
\hline HFC-236fa & $\mathrm{CF}_{3} \mathrm{CH}_{2} \mathrm{CF}_{3}$ & 242.0 & 0.28 & 0.24 & 0.24 & 9,810 & 8,060 \\
\hline HFC-245ca & $\mathrm{CH}_{2} \mathrm{FCF}_{2} \mathrm{CHF}_{2}$ & 6.5 & 0.23 & & 0.24 & 693 & 716 \\
\hline HFC-245cb & $\mathrm{CF}_{3} \mathrm{CF}_{2} \mathrm{CH}_{3}$ & 47.1 & & 0.25 & 0.24 & & 4,620 \\
\hline HFC-245ea & $\mathrm{CHF}_{2} \mathrm{CHFCHF}_{2}$ & 3.2 & & 0.18 & 0.16 & & 235 \\
\hline HFC-245eb & $\mathrm{CH}_{2} \mathrm{FCHFCF}_{3}$ & 3.1 & & 0.23 & 0.20 & & 290 \\
\hline HFC-245fa & $\mathrm{CHF}_{2} \mathrm{CH}_{2} \mathrm{CF}_{3}$ & 7.7 & 0.28 & 0.26 & 0.24 & 1,030 & 858 \\
\hline HFC-263fb & $\mathrm{CH}_{3} \mathrm{CH}_{2} \mathrm{CF}_{3}$ & 1.2 & & 0.13 & 0.10 & & 76 \\
\hline HFC-272ca & $\mathrm{CH}_{3} \mathrm{CF}_{2} \mathrm{CH}_{3}$ & 2.6 & & 0.08 & 0.07 & & 144 \\
\hline HFC-329p & $\mathrm{CHF}_{2} \mathrm{CF}_{2} \mathrm{CF}_{2} \mathrm{CF}_{3}$ & 28.4 & & 0.31 & 0.31 & & 2,360 \\
\hline HFC-365mfc & $\mathrm{CH}_{3} \mathrm{CF}_{2} \mathrm{CH}_{2} \mathrm{CF}_{3}$ & 8.7 & 0.21 & 0.23 & 0.22 & 794 & 804 \\
\hline HFC-43-10mee & $\mathrm{CF}_{3} \mathrm{CHFCHFCF}_{2} \mathrm{CF}_{3}$ & 16.1 & 0.40 & & 0.42 & 1,640 & 1,650 \\
\hline HFC-1132a & $\mathrm{CH}_{2}=\mathrm{CF}_{2}$ & 4.0 days & & 0.10 & 0.00 & & $<1$ \\
\hline HFC-1141 & $\mathrm{CH}_{2}=\mathrm{CHF}$ & 2.1 days & & 0.09 & 0.00 & & $<1$ \\
\hline (Z)-HFC-1225ye & $\mathrm{CF}_{3} \mathrm{CF}=\mathrm{CHF}(\mathrm{Z})$ & 8.5 days & & 0.26 & 0.02 & & $<1$ \\
\hline (E)-HFC-1225ye & $\mathrm{CF}_{3} \mathrm{CF}=\mathrm{CHF}(\mathrm{E})$ & 4.9 days & & 0.25 & 0.01 & & $<1$ \\
\hline (Z)-HFC-1234ze & $\mathrm{CF}_{3} \mathrm{CH}=\mathrm{CHF}(\mathrm{Z})$ & 10.0 days & & 0.20 & 0.02 & & $<1$ \\
\hline HFC-1234yf & $\mathrm{CF}_{3} \mathrm{CF}=\mathrm{CH}_{2}$ & 10.5 days & & 0.23 & 0.02 & & $<1$ \\
\hline (E)-HFC-1234ze & trans $-\mathrm{CF}_{3} \mathrm{CH}=\mathrm{CHF}$ & 16.4 days & & 0.28 & 0.04 & & $<\mathbf{1}$ \\
\hline (Z)-HFC-1336 & $\mathrm{CF}_{3} \mathrm{CH}=\mathrm{CHCF}_{3}(\mathrm{Z})$ & 22.0 days & & 0.42 & 0.07 & & 2 \\
\hline HFC-1243zf & $\mathrm{CF}_{3} \mathrm{CH}=\mathrm{CH}_{2}$ & 7.0 days & & 0.17 & 0.01 & & $<1$ \\
\hline HFC-1345zfc & $\mathrm{C}_{2} \mathrm{~F}_{5} \mathrm{CH}=\mathrm{CH}_{2}$ & 7.6 days & & 0.19 & 0.01 & & $<1$ \\
\hline $3,3,4,4,5,5,6,6,6-$ & & & & & & & \\
\hline Nonafluorohex-1-ene & $\mathrm{C}_{4} \mathrm{~F}_{9} \mathrm{CH}=\mathrm{CH}_{2}$ & 7.6 days & & 0.35 & 0.03 & & $<1$ \\
\hline $3,3,4,4,5,5,6,6,7,7,8,8,8-$ & & & & & & & \\
\hline $\begin{array}{l}\text { Tridecafluorooct-1-ene } \\
3,3,4,4,5,5,6,6,7,7,8\end{array}$ & $\mathrm{C}_{6} \mathrm{~F}_{13} \mathrm{CH}=\mathrm{CH}_{2}$ & 7.6 days & & 0.39 & 0.03 & & $<1$ \\
\hline $8,9,9,10,10,10$ & & & & & & & \\
\hline Heptadecafluorodec-1-ene & $\mathrm{C}_{8} \mathrm{~F}_{17} \mathrm{CH}=\mathrm{CH}_{2}$ & 7.6 days & & 0.44 & 0.03 & & $<1$ \\
\hline
\end{tabular}

${ }^{a}$ Compounds in bold either have significant current atmospheric concentrations or a clear potential for future emissions. Recommended RE and GWP 100 year values are indicated in bold. Lifetimes are from WMO [2011] except those in italics (see text for details). RE and GWP values in italics are based on previous publications (see text for details).

Pinnock et al. [1995] method and calculated an instantaneous RE of $0.21 \mathrm{~W} \mathrm{~m}^{-2} \mathrm{ppb}^{-1}$. Their absorption cross section has been used in this study to calculate a lifetimecorrected RE of $0.04 \mathrm{~W} \mathrm{~m}^{-2} \mathrm{ppb}^{-1}$ (Table 5). The short lifetime of 26 days $[W M O, 2011]$ for this compound leads to a strong effect of the fractional correction factor which has been applied to account for non-uniform mixing (vertical and horizontal). It should be noted here that the uncertainties associated with this correction factor are very large on a percentage basis for such short-lived species (see Figure 9 and associated discussion in section 3.3.4), and we further note that our calculated RE is in good agreement with Andersen et al. [2008] if we assume uniform mixing.

\subsubsection{Hydrofluorocarbons (HFCs)}

[139] HFCs do not destroy stratospheric ozone [Ravishankara et al., 1994; Wallington et al., 1995] and have emerged as important replacements for ozone-depleting substances such as the CFCs. The main removal mechanism for the HFCs is through reaction with $\mathrm{OH}$. The atmospheric lifetime of HFCs depends on their reactivity towards $\mathrm{OH}$ radicals and ranges from 2.1 days for $\mathrm{CH}_{2}=\mathrm{CHF}$ to 242 years for $\mathrm{CF}_{2} \mathrm{CH}_{2} \mathrm{CF}_{3}$ (HFC-236fa). Compounds with lifetimes greater than a decade tend to be well mixed in the troposphere. Compounds with lifetimes less than a year are not well mixed and have an inhomogeneous distribution within the troposphere and needs to be accounted for in RE estimates. HFCs have strong absorption bands within the atmospheric window region $\left(800-1200 \mathrm{~cm}^{-1}\right)$ and hence have the potential to be potent greenhouse gases, especially for long-lived gases such as HFC-23 and HFC-236fa which have lifetimes greater than 200 years. At the other extreme, fluorinated alkenes such as $\mathrm{CF}_{3} \mathrm{CF}=\mathrm{CH}_{2}$ (HFC-1234yf) have very short atmospheric 
lifetimes (1-2 weeks) and are not significant greenhouse gases. HFC-134a $\left(\mathrm{CF}_{3} \mathrm{CFH}_{2}\right)$ is the most abundant HFC in the atmosphere and is currently present at a concentration of approximately $60 \mathrm{ppt}$ (Figure 1). HFC-134a has a lifetime of 13.4 years, and its potency as a greenhouse gas lies between those of the long-lived and short-lived HFCs. Figure 13 shows the absorption spectrum of HFC-134a which, because of its industrial importance, has been studied extensively and is perhaps the best established of all the HFCs. Published absorption cross sections for HFCs are listed in Table 6, atmospheric lifetimes, radiative efficiencies, and GWP(100) values for HFCs are presented in Table 7 and discussed below. The $S$-shaped fit from section 3.3.4 (equation (2) and dark blue curve in Figure 9) has been used to account for a non-uniform vertical profile and geographic distribution for all compounds presented in this subsection.

\subsubsection{HFC-23 $\left(\mathrm{CHF}_{3}\right)$}

[140] Published estimates of the RE of HFC-23 span the range $0.16-0.27 \mathrm{~W} \mathrm{~m}^{-2} \mathrm{ppb}^{-1}$ (mean: $0.21 \mathrm{~W} \mathrm{~m}^{-2} \mathrm{ppb}^{-1}$ ) [Gohar et al., 2004; Highwood and Shine, 2000; Jain et al., 2000; Naik et al., 2000; Pinnock et al., 1995; Sihra et al., 2001]. AR4 adopted the value of $0.19 \mathrm{~W} \mathrm{~m}^{-2} \mathrm{ppb}^{-1}$ from Gohar et al. [2004], who used two different radiative transfer methods to estimate forcings of 0.18 and $0.19 \mathrm{~W}$ $\mathrm{m}^{-2} \mathrm{ppb}^{-1}$. The small differences between results from the two models used by Gohar et al. [2004] were attributed to slight differences in the treatment of clouds in the models. The large difference between the results of Gohar et al. [2004] and those of Jain et al. [2000] $\left(0.248 \mathrm{~W} \mathrm{~m}^{-2} \mathrm{ppb}^{-1}\right)$ and Naik et al. [2000] $\left(0.271 \mathrm{~W} \mathrm{~m}^{-2} \mathrm{ppb}^{-1}\right)$ is difficult to explain because all three studies used essentially the same IR spectrum. Two studies have used ab initio methods to estimate HFC-23 RE to be $0.18 \mathrm{~W} \mathrm{~m}^{-2} \mathrm{ppb}^{-1}$ [Blowers and Hollingshead, 2009] and $0.19 \mathrm{~W} \mathrm{~m}^{-2} \mathrm{ppb}^{-1}$ [Papasavva et al., 1997], but these are instantaneous REs and must be increased by approximately $11 \%$ [Gohar et al., 2004] to be comparable with the RE values (including stratospheric temperature adjustment) reported by Gohar et al. [2004]. We have used absorption cross sections from Gohar et al. [2004] and Highwood and Shine [2000] to calculate RE values of 0.19 and $0.16 \mathrm{~W} \mathrm{~m}^{-2} \mathrm{ppb}^{-1}$, respectively, which are in excellent agreement with the REs reported in each of the two individual studies. The mean of our calculated REs $\left(0.18 \mathrm{~W} \mathrm{~m}^{-2} \mathrm{ppb}^{-1}\right)$ is slightly more than $5 \%$ lower than the AR4 recommendation. The relatively large range in the integrated absorption cross sections for HFC-23 (Table 6), and subsequent large range of REs in our calculations, indicates that there are uncertainties related to the measurements of the absorption cross section for this compound (the absorption band below $700 \mathrm{~cm}^{-1}$, which is only taken into account in Gohar et al. [2004], has only a negligible contribution to the integrated absorption cross section).

\subsubsection{2. $\mathrm{HFC}-32\left(\mathrm{CH}_{2} \mathrm{~F}_{2}\right)$}

[141] Estimates for the RE of HFC-32 based on experimental absorption cross sections range from 0.09 to $0.16 \mathrm{~W} \mathrm{~m}^{-2} \mathrm{ppb}^{-1}$ (mean: $0.12 \mathrm{~W} \mathrm{~m}^{-2} \mathrm{ppb}^{-1}$ ) [Gohar et al., 2004; Highwood and Shine, 2000; Jain et al., 2000; Naik et al., 2000; Orkin et al.,
2003; Pinnock et al., 1995; Sihra et al., 2001; Zhang et al., 2011b], while estimates based on absorption cross sections from $\mathrm{ab}$ initio studies are in the range of $0.12-0.13 \mathrm{~W} \mathrm{~m}^{-2} \mathrm{ppb}^{-1}$ (instantaneous RE) [Blowers and Hollingshead, 2009; Papasavva et al., 1997]. As for HFC-23, the results of Gohar et al. [2004] were used in AR4 with a value of $0.11 \mathrm{~W}$ $\mathrm{m}^{-2} \mathrm{ppb}^{-1}$. We have used absorption spectra from Gohar et al. [2004], Highwood and Shine [2000] and Orkin et al. [2003] and derived a RE of HFC-32 of $0.11 \mathrm{~W} \mathrm{~m}^{-2} \mathrm{ppb}^{-1}$ for all these spectra, in excellent agreement with AR4. It should be noted that additional absorption cross sections are available, e.g., through the HITRAN and GEISA databases (Table 6), but have not been included to avoid double-counting of absorption cross sections from the same laboratory groups (e.g., both Highwood and Shine [2000] and Smith et al. [1996] are based on spectra from the Molecular Spectroscopy Facility/Rutherford Appleton Laboratory [M.S.F./R.A.L.]). The combination of a change in the recommended lifetime for this compound (5.2 years in $W M O$ [2011] compared to 4.9 years in AR4) and the higher $\mathrm{AGWP}_{\mathrm{CO} 2}$ used here result in a $\operatorname{GWP}(100)$ value which is about the same as in AR4 (see Table 7).

\subsubsection{HFC-41 $\left(\mathrm{CH}_{3} \mathrm{~F}\right)$}

[142] A radiative efficiency for HFC-41 of $0.02 \mathrm{~W} \mathrm{~m}^{-2}$ $\mathrm{ppb}^{-1}$ has been used in previous assessments and is taken from Pinnock et al. [1995] (note that stratospheric decay was accounted for in the assessments but not in the original study). A range of $0.02-0.03 \mathrm{~W} \mathrm{~m}^{-2} \mathrm{ppb}^{-1}$ (mean: $0.03 \mathrm{~W} \mathrm{~m}^{-2} \mathrm{ppb}^{-1}$ ) has been reported from studies using measured absorption cross sections [Pinnock et al., 1995; Sihra et al., 2001]. The ab initio studies have the same range and mean, but they have only reported instantaneous RE [Blowers and Hollingshead, 2009; Papasavva et al., 1997]. We used the absorption spectrum from Sihra et al. [2001] and derived a RE value of $0.02 \mathrm{~W} \mathrm{~m}^{-2} \mathrm{ppb}^{-1}$, which is in excellent agreement with AR4. It should be noted that stratospheric temperature adjustment normally leads to a stronger forcing compared to instantaneous RE (recall from section 3.3.2 that we apply a $10 \%$ increase for most compounds), while for HFC41 , it leads to a weakening due to the strong overlap with the absorption spectrum of ozone [Pinnock et al., 1995]. We have carried out explicit LBL model calculations and estimated a $5.0 \%$ decrease for the stratospheric temperature adjustment for HFC-41 (see section 3.3.2), and this result has been used (instead of the $10 \%$ increase) to calculate the $\mathrm{RE}$ of $0.02 \mathrm{~W} \mathrm{~m}^{-2} \mathrm{ppb}^{-1}$ above. Due to a change in the recommended lifetime for this compound (2.8 years in $W M O$ [2011] compared to 2.4 years in AR4), our recommended GWP value is higher than in AR4 (see Table 7).

\subsubsection{4. $\mathrm{HFC}-125\left(\mathrm{CHF}_{2} \mathrm{CF}_{3}\right)$}

[143] Previous studies have reported a fairly wide range of RE values for HFC-125: $0.21-0.30 \mathrm{~W} \mathrm{~m}^{-2} \mathrm{ppb}^{-1}$ (mean: $0.25 \mathrm{~W} \mathrm{~m}^{-2} \mathrm{ppb}^{-1}$ ) [Fisher et al., 1990; Highwood and Shine, 2000; Imasu et al., 1995; Jain et al., 2000; Naik et al., 2000; Orkin et al., 2003; Pinnock et al., 1995; Sihra et al., 2001; Young et al., 2009b; Zhang et al., 2011b]. $\mathrm{Ab}$ initio studies for this compound have calculated REs that are at the high end of the range of experimental studies with 
instantaneous RE of $0.24 \mathrm{~W} \mathrm{~m}^{-2} \mathrm{ppb}^{-1}$ [Papasavva et al., 1997] and RE of $0.28 \mathrm{~W} \mathrm{~m}^{-2} \mathrm{ppb}^{-1}$ [Good et al., 1998]. The recent study by Zhang et al. [2011b] is an outlier with a value of $0.30 \mathrm{~W} \mathrm{~m}^{-2} \mathrm{ppb}^{-1}$, but they did not identify any clear reason for the large difference between their result and the results from all other studies. Zhang et al. [2011b] calculate their RE from a combination of forcings from three standard atmospheres; they do not show to what extent this combination is representative of a true global-mean atmosphere, nor do they show how their outgoing longwave radiation or cloud forcing, using this combination of atmospheres, compare with satellite observed values, which is an important diagnostic of model behavior [e.g., Forster et al., 2005]. Recent assessments have used the value of $0.23 \mathrm{~W} \mathrm{~m}^{-2} \mathrm{ppb}^{-1}$ estimated in Highwood and Shine [2000]. We have used absorption cross sections from several sources [Clerbaux et al., 1993; Highwood and Shine, 2000; Imasu et al., 1995; Orkin et al., 2003; Young et al., 2009b] (see also Table 6; note that the spectrum from Young et al. [2009b] supersede that of Sihra et al. [2001]) and calculated a mean RE value of $0.23 \mathrm{~W} \mathrm{~m}^{-2} \mathrm{ppb}^{-1}$ (range: $0.21-0.24 \mathrm{~W} \mathrm{~m}^{-2} \mathrm{ppb}^{-1}$ ) (Table 7), which is in excellent agreement with AR4 (note that our use of a lifetime of 28.2 years recommended by [WMO, 2011] is shorter than that of 29 years used in AR4, but this does not affect the GWP(100) value significantly).

\subsubsection{HFC-134 $\left(\mathrm{CHF}_{2} \mathrm{CHF}_{2}\right)$}

[144] Studies of the radiative efficiency of HFC-134 have reported values in the range of $0.18-0.27 \mathrm{~W} \mathrm{~m}^{-2} \mathrm{ppb}^{-1}$ (mean: $0.20 \mathrm{~W} \mathrm{~m}^{-2} \mathrm{ppb}^{-1}$ ) [Christidis et al., 1997; Jain et al., 2000; Naik et al., 2000; Sihra et al., 2001; Zhang et al., 2011b]. Again, Zhang et al. [2011b] is an outlier with a RE value of $0.27 \mathrm{~W} \mathrm{~m}^{-2} \mathrm{ppb}^{-1}$, which is more than $30 \%$ higher than reported in any of the other studies (see also the HFC-125 section above for a discussion of Zhang et al. [2011b]). The ab initio studies are in good agreement with the mean of experimental studies for this compound as both Papasavva et al. [1997] and Good et al. [1998] calculated REs of $0.20 \mathrm{~W} \mathrm{~m}^{-2} \mathrm{ppb}^{-1}$ (the first study calculated instantaneous RE). Previous assessments have used the value of $0.18 \mathrm{~W} \mathrm{~m}^{-2} \mathrm{ppb}^{-1}$ based on Christidis et al. [1997] (a scaling factor to account for decreased concentrations in the stratosphere was applied). We calculate a mean RE value of $0.19 \mathrm{~W}$ $\mathrm{m}^{-2} \mathrm{ppb}^{-1}$ (range: $0.18-0.20 \mathrm{~W} \mathrm{~m}^{-2} \mathrm{ppb}^{-1}$ ) when using absorption cross sections from two sources [Sihra et al., 2001; Smith et al., 1998]. Our GWP(100) estimate is similar to AR4 due to the combination of a slightly higher RE, a slightly longer lifetime, and a higher $\mathrm{AGWP}_{\mathrm{CO} 2}$ used here.

\subsubsection{6. $\mathrm{HFC}-134 \mathrm{a}\left(\mathrm{CH}_{2} \mathrm{FCF}_{3}\right)$}

[145] Calculations of the RE of HFC-134a are in the range of 0.15-0.22 $\mathrm{W} \mathrm{m}^{-2} \mathrm{ppb}^{-1}$ (mean: $0.18 \mathrm{~W} \mathrm{~m}^{-2} \mathrm{ppb}^{-1}$ ) [Fisher et al., 1990; Forster et al., 2005; Gohar et al., 2004; Highwood and Shine, 2000; Imasu et al., 1995; Jain et al., 2000; Naik et al., 2000; Orkin et al., 2003; Pinnock et al., 1995; Sihra et al., 2001; Zhang et al., 2011b], while one ab initio study estimated an instantaneous RE of $0.14 \mathrm{~W} \mathrm{~m}^{-2} \mathrm{ppb}^{-1}$ Papasavva et al. [1997]. AR4 adopted a value of $0.16 \mathrm{~W} \mathrm{~m}^{-2}$ $\mathrm{ppb}^{-1}$ based on the multi-model studies of Gohar et al.
[2004] and Forster et al. [2005]. Particularly, Forster et al. [2005] derived a "recommended" absorption cross section and applied four radiative transfer models to yield an average RE with relatively low uncertainty $\left(0.16 \pm 0.02 \mathrm{~W} \mathrm{~m}^{-2} \mathrm{ppb}^{-1}\right)$, and attributed most of the uncertainty to the radiative forcing calculation rather than the absorption cross section. In this study we have used the recommended absorption spectrum from Forster et al. [2005] (Table 6), which is based on measurements from six different laboratory groups, and calculated a radiative forcing of $0.16 \mathrm{~W} \mathrm{~m}^{-2} \mathrm{ppb}^{-1}$, the same as used in AR4 (Table 7). The lifetime has been updated to 13.4 years from $W M O$ [2011] compared to the 14 years used in AR4.

\subsubsection{7. $\mathrm{HFC}-143\left(\mathrm{CH}_{2} \mathrm{FCHF}_{2}\right)$}

[146] The average RE of HFC-143 reported in the literature based on experimentally measured absorption spectra is $0.12 \mathrm{~W}$ $\mathrm{m}^{-2} \mathrm{ppb}^{-1}$ (range: $0.11-0.14 \mathrm{~W} \mathrm{~m}^{-2} \mathrm{ppb}^{-1}$ ) [Clerbaux and Colin, 1994; Jain et al., 2000; Naik et al., 2000; Pinnock et al., 1995; Sihra et al. 2001], while the ab initio study of Papasavva et al. [1997] estimated an instantaneous RE of $0.14 \mathrm{~W} \mathrm{~m}^{-2} \mathrm{ppb}^{-1}$. AR4 used $0.13 \mathrm{~W} \mathrm{~m}^{-2} \mathrm{ppb}^{-1}$ taken from Clerbaux and Colin [1994]. We calculate the same mean RE value (range: $0.12-0.13 \mathrm{~W} \mathrm{~m}^{-2} \mathrm{ppb}^{-1}$ ) using absorption cross sections from two sources [M.S.F./R.A.L.; Sihra et al., 2001].

\subsubsection{8. $\mathrm{HFC}-143 \mathrm{a}\left(\mathrm{CH}_{3} \mathrm{CF}_{3}\right)$}

[147] The estimated RE of HFC-143a ranges from 0.13 to $0.22 \mathrm{~W} \mathrm{~m}^{-2} \mathrm{ppb}^{-1}$ (mean: $0.16 \mathrm{~W} \mathrm{~m}^{-2} \mathrm{ppb}^{-1}$ ) in previous studies [Fisher et al., 1990; Highwood and Shine, 2000; Jain et al., 2000; Naik et al., 2000; Pinnock et al., 1995; Sihra et al., 2001; Zhang et al., 2011b]. Ab initio studies have calculated RE of $0.15 \mathrm{~W} \mathrm{~m}^{-2} \mathrm{ppb}^{-1}$ [Good et al., 1998] and instantaneous RE of $0.16 \mathrm{~W} \mathrm{~m}^{-2} \mathrm{ppb}^{-1}$ [Papasavva et al., 1997]. AR4 adopted the value from Highwood and Shine [2000] of $0.13 \mathrm{~W} \mathrm{~m}^{-2} \mathrm{ppb}^{-1}$, which is at the lower end of this range. The recent study of Zhang et al. [2011b] calculated almost $70 \%$ higher RE $\left(0.22 \mathrm{~W} \mathrm{~m}^{-2} \mathrm{ppb}^{-1}\right)$ than in AR4, but they did not provide adequate reasons for these discrepancies (see also discussion of HFC-125). By using absorption cross sections from three different sources [Di Lonardo and Masciarelli, 2000; Sihra et al., 2001; Smith et al., 1998], we calculate a mean RE value of $0.16 \mathrm{~W} \mathrm{~m}^{-2} \mathrm{ppb}^{-1}$ (range: $0.15-0.17 \mathrm{~W} \mathrm{~m}^{-2} \mathrm{ppb}^{-1}$ ), which is $22 \%$ higher than the AR4 value, but in line with the mean of estimates from literature measurements. The low value of RE in the AR4 reflects the use of the infrared spectrum from Highwood and Shine [2000] which has an integrated absorption cross section which is significantly lower than in any of the other studies (Table 6). We did not include the Highwood and Shine [2000] spectrum here as this was taken from a lower temperature $(253 \mathrm{~K})$ pure gas measurement of Di Lonardo and Masciarelli [2000] who note that their lower temperature measurements may be more inaccurate if they fail to properly resolve the sharper spectral features at the lower temperature. Another contribution to the discrepancy is the use of different factors to correct for a non-uniform vertical profile. Whereas we use a fractional correction factor of 0.98 based on the method in section 3.3.4 and a lifetime of 47.1 years, Highwood and Shine [2000] used the crude factor of 0.95 based on Freckleton et al. [1998]. 


\subsubsection{9. $\mathrm{HFC}-152\left(\mathrm{CH}_{2} \mathrm{FCH}_{2} \mathrm{~F}\right)$}

[148] The ab initio study by Papasavva et al. [1997] is the only published investigation of the RE for HFC-152. An instantaneous RE value of $0.09 \mathrm{~W} \mathrm{~m}^{-2} \mathrm{ppb}^{-1}$ was reported, and this value has been used in previous IPCC assessments. Using experimentally determined absorption cross sections from Wallington et al. [1994a] (Tables 6 and 7) and accounting for the non-uniform distribution, we calculate a much lower $\mathrm{RE}$ value of $0.04 \mathrm{~W} \mathrm{~m}^{-2} \mathrm{ppb}^{-1}$. The large difference is mainly due to the short lifetime of 146 days for HFC$152[W M O, 2011]$ which leads to a reduction from 0.08 to $0.04 \mathrm{~W} \mathrm{~m}^{-2} \mathrm{ppb}^{-1}$ when taking into account the nonuniform distribution (Table 7). Recommended RE and GWP values are updated based on our calculations.

\subsubsection{HFC-152a $\left(\mathrm{CH}_{3} \mathrm{CHF}_{2}\right)$}

[149] Literature calculations of the RE of HFC-152a, using measured cross sections, lie in the range of $0.09-0.14 \mathrm{~W}$ $\mathrm{m}^{-2} \mathrm{ppb}^{-1}$ (mean: $0.11 \mathrm{~W} \mathrm{~m}^{-2} \mathrm{ppb}^{-1}$ ) [Fisher et al., 1990; Highwood and Shine, 2000; Jain et al., 2000; Naik et al., 2000; Pinnock et al., 1995; Sihra et al., 2001; Zhang et al., 2011b], while the ab initio study of Papasavva et al. [1997] estimated an instantaneous RE of $0.11 \mathrm{~W} \mathrm{~m}^{-2} \mathrm{ppb}^{-1}$. AR4 reports a RE of $0.09 \mathrm{~W} \mathrm{~m}^{-2} \mathrm{ppb}^{-1}$ which is taken from Highwood and Shine [2000]. We calculated a slightly higher $\mathrm{RE}$ value of $0.10 \mathrm{~W} \mathrm{~m}^{-2} \mathrm{ppb}^{-1}$ when using absorption cross sections from either of the three different sources [Clerbaux et al., 1993; Sihra et al., 2001; Vander Auwera, 2000], showing that the uncertainty associated with measurements of the HFC-152a spectrum is low. The higher GWP value calculated here reflects the higher RE value, a longer lifetime estimate in the latest review by $W M O$ [2011] (1.5 years) compared to that used in AR4 (1.4 years), and an updated $\mathrm{AGWP}_{\mathrm{CO} 2}$ value used here.

\subsubsection{1. $\mathrm{HFC}-161\left(\mathrm{CH}_{3} \mathrm{CH}_{2} \mathrm{~F}\right)$}

[150] Values of $0.02-0.04 \mathrm{~W} \mathrm{~m}^{-2} \mathrm{ppb}^{-1}$ have been reported for RE of HFC-161 (mean: $0.03 \mathrm{~W} \mathrm{~m}^{-2} \mathrm{ppb}^{-1}$ ) [Christidis et al., 1997; Jain et al., 2000; Naik et al., 2000; Sihra et al., 2001]. The ab initio study of Papasavva et al. [1997] is at the high end of this range with an instantaneous $\mathrm{RE}$ of $0.04 \mathrm{~W} \mathrm{~m}^{-2} \mathrm{ppb}^{-1}$. A value of $0.03 \mathrm{~W} \mathrm{~m}^{-2} \mathrm{ppb}^{-1}$ has been used in previous IPCC assessments and is based on Christidis et al. [1997] (a scaling factor of 0.8 based on Freckleton et al. [1998] was applied to account for decreased concentrations in the stratosphere). We calculate a RE value of $0.02 \mathrm{~W} \mathrm{~m}^{-2} \mathrm{ppb}^{-1}$ when using the absorption cross sections from Sihra et al. [2001]. The lower RE in our study compared to that in AR4 is explained by the different lifetime correction factors used as we use a factor of 0.37 to account for the non-homogeneous mixing while a factor 0.8 was applied to the Christidis et al. [1997] result.

\subsubsection{HFC-227 ca $\left(\mathrm{CF}_{3} \mathrm{CF}_{2} \mathrm{CHF}_{2}\right)$}

[151] The radiative efficiency of HFC-227ca has not been assessed in AR4. Values in the range of $0.25-0.33 \mathrm{~W} \mathrm{~m}^{-2}$ $\mathrm{ppb}^{-1}$ (mean: $0.29 \mathrm{~W} \mathrm{~m}^{-2} \mathrm{ppb}^{-1}$ ) are available for this compound [Christidis et al., 1997; Sihra et al., 2001]. We have used the absorption cross section from Sihra et al. [2001] to calculate a RE value of $0.27 \mathrm{~W} \mathrm{~m}^{-2} \mathrm{ppb}^{-1}$, which is slightly higher than the RE of $0.25 \mathrm{~W} \mathrm{~m}^{-2} \mathrm{ppb}^{-1}$ calculated in their study. The lifetime of 28.2 years is taken from Christidis et al. [1997].

\subsubsection{HFC-227ea $\left(\mathrm{CF}_{3} \mathrm{CHFCF}_{3}\right)$}

[152] Published values of the RE of HFC-227ea lie in the range of 0.26 to $0.32 \mathrm{~W} \mathrm{~m}^{-2} \mathrm{ppb}^{-1}$ (mean: $0.28 \mathrm{~W} \mathrm{~m}^{-2} \mathrm{ppb}^{-1}$ ) [Gohar et al., 2004; Jain et al., 2000; Naik et al., 2000; Pinnock et al., 1995; Sihra et al., 2001]. AR4 used a RE value of $0.26 \mathrm{~W} \mathrm{~m}^{-2} \mathrm{ppb}^{-1}$ which is an average derived from the two models used in Gohar et al. [2004]. The absorption cross section from that study has been used here to calculate a RE value of $0.26 \mathrm{~W} \mathrm{~m}^{-2} \mathrm{ppb}^{-1}$, in agreement with that in AR4 (Tables 6 and 7). Our best estimate GWP value is higher than that in AR4 reflecting the latest information on the atmospheric lifetime of HFC-227ea [WMO, 2011].

\subsubsection{4. $\mathrm{HFC}-236 \mathrm{cb}\left(\mathrm{CH}_{2} \mathrm{FCF}_{2} \mathrm{CF}_{3}\right)$}

[153] Two studies have been conducted to determine the RE of HFC-236cb. The average of results from the two studies is $0.24 \mathrm{~W} \mathrm{~m}^{-2} \mathrm{ppb}^{-1}$ (range: $0.22-0.26 \mathrm{~W} \mathrm{~m}^{-2} \mathrm{ppb}^{-1}$ ) [Christidis et al., 1997; Sihra et al., 2001]. Previous assessments have adopted the value of $0.23 \mathrm{~W} \mathrm{~m}^{-2} \mathrm{ppb}^{-1}$ based on Christidis et al. [1997] (a scaling factor to account for decreased concentrations in the stratosphere was applied). We calculate the same RE value of $0.23 \mathrm{~W} \mathrm{~m}^{-2} \mathrm{ppb}^{-1}$ when using the absorption cross section from Sihra et al. [2001] (Tables 6 and 7).

\subsubsection{HFC-236ea $\left(\mathrm{CHF}_{2} \mathrm{CHFCF}_{3}\right)$}

[154] Previous IPCC and WMO assessments have used a value of $0.30 \mathrm{~W} \mathrm{~m}^{-2} \mathrm{ppb}^{-1}$ based on Gierczak et al. [1996] (a factor 0.8 was applied to yield cloudy-sky adjusted forcing from their clear-sky instantaneous forcing), which is the only study that have estimated RE due to HFC-236ea. No new calculations have been carried out here for this compound, thus we retain the RE from AR4 as our best estimate. The GWP(100) value has been updated, however, to account for the change in $\mathrm{AGWP}_{\mathrm{CO} 2}$ and the updated lifetime (11.0years in WMO [2011] compared to 10.7 years in AR4).

\subsubsection{6. $\mathrm{HFC}-236 \mathrm{fa}\left(\mathrm{CF}_{3} \mathrm{CH}_{2} \mathrm{CF}_{3}\right)$}

[155] Literature estimates of the RE of HFC-236fa range from 0.23 to $0.29 \mathrm{~W} \mathrm{~m}^{-2} \mathrm{ppb}^{-1}$ (mean: $0.26 \mathrm{~W} \mathrm{~m}^{-2} \mathrm{ppb}^{-1}$ ) [Gierczak et al., 1996; Jain et al., 2000; Naik et al., 2000; Pinnock et al., 1995; Sihra et al., 2001] (note that the upper estimate of $0.29 \mathrm{~W} \mathrm{~m}^{-2} \mathrm{ppb}^{-1}$ from Gierczak et al. [1996] has been scaled by a factor 0.8 to convert from clear-sky instantaneous forcing to cloudy-sky stratospheric temperature adjusted forcing following $W M O$ [1999]). In previous assessments, an average of the results from Pinnock et al. [1995] and Gierczak et al. [1996] of $0.28 \mathrm{~W} \mathrm{~m}^{-2} \mathrm{ppb}^{-1}$ has been used. Using the absorption spectrum from Sihra et al. [2001], we calculate a RE value of $0.24 \mathrm{~W} \mathrm{~m}^{-2} \mathrm{ppb}^{-1}, 13 \%$ lower than the AR4 value (Tables 6 and 7). We note that the estimate of Gierczak et al. [1996] was crudely scaled to account for clouds and stratospheric temperature adjustment, and that the resulting RE is at the higher end of the range of REs from the literature. Furthermore, the difference between our RE estimate and the calculation of Pinnock et al. [1995] $\left(0.27 \mathrm{~W} \mathrm{~m}^{-2} \mathrm{ppb}^{-1}\right)$ can be partly explained by the higher integrated absorption cross section in their study (Table 6). 


\subsubsection{7. $\mathrm{HFC}-245 \mathrm{ca}\left(\mathrm{CH}_{2} \mathrm{FCF}_{2} \mathrm{CHF}_{2}\right)$}

[156] An RE estimate of $0.23 \mathrm{~W} \mathrm{~m}^{-2} \mathrm{ppb}^{-1}$ for HFC-245ca has been used in all IPCC and WMO assessments since IPCC [1994] and is based on Fisher (personal communication, 1994) (original value was $0.20 \mathrm{~W} \mathrm{~m}^{-2} \mathrm{ppb}^{-1}$, but it was scaled to $0.23 \mathrm{~W} \mathrm{~m}^{-2} \mathrm{ppb}^{-1}$ in $W M O$ [1999] because of a change in the recommended forcing of CFC-11 - see the discussion of CFC-11 in section 4.1.1), and no newer estimates were found in the literature. No new calculations have been carried out here for this compound, thus we retain the RE from AR4 as our best estimate, except that we scale the value by a factor $0.26 / 0.25=1.04$ to account for the update in our recommended RE of CFC-11. Our recommended RE of HFC-245ca is then $0.24 \mathrm{~W} \mathrm{~m}^{-2} \mathrm{ppb}^{-1}$. Also, the GWP(100) value has been updated to account for the change in $\mathrm{AGWP}_{\mathrm{CO} 2}$ and the updated lifetime (6.5 years in $W M O$ [2011] compared to 6.2 years in AR4).

\subsubsection{8. $\mathrm{HFC}-245 \mathrm{cb}\left(\mathrm{CF}_{3} \mathrm{CF}_{2} \mathrm{CH}_{3}\right)$}

[157] The radiative efficiency of HFC-245cb was not assessed in AR4. Published studies give RE in the range of $\quad 0.25-0.28 \mathrm{~W} \mathrm{~m}^{-2} \mathrm{ppb}^{-1}$ (mean: $0.27 \mathrm{~W} \mathrm{~m}^{-2} \mathrm{ppb}^{-1}$ ) [Christidis et al., 1997; Sihra et al., 2001]. We used the absorption spectrum from two sources [Orkin et al., 2003; Sihra et al., 2001] and calculated a mean $\mathrm{RE}$ value of $0.24 \mathrm{~W} \mathrm{~m}^{-2}$ $\mathrm{ppb}^{-1}$ (range: $0.23-0.25 \mathrm{~W} \mathrm{~m}^{-2} \mathrm{ppb}^{-1}$ ) (Tables 6 and 7), which is slightly lower than the $0.25 \mathrm{~W} \mathrm{~m}^{-2} \mathrm{ppb}^{-1}$ reported by Sihra et al. [2001]. However, they assumed a constant vertical profile for this compound, and we note that our RE estimate when assuming a constant vertical profile $(0.25 \mathrm{~W}$ $\mathrm{m}^{-2} \mathrm{ppb}^{-1}$ ) is consistent with their result. The lifetime of 47.1 years is taken from Christidis et al. [1997] who assumed the same lifetime as HFC-143a, based on the similar molecular structure of the two compounds.

\subsubsection{HFC-245ea $\left(\mathrm{CHF}_{2} \mathrm{CHFCHF}_{2}\right)$, $\mathrm{HFC}-245 \mathrm{eb}$} $\left(\mathrm{CH}_{2} \mathrm{FCHFCF}_{3}\right)$, and HFC-263fb $\left(\mathrm{CH}_{3} \mathrm{CH}_{2} \mathrm{CF}_{3}\right)$

[158] The REs of HFC-245ea, HFC-245eb, and HFC$263 \mathrm{fb}$ have not been assessed in AR4, but Rajakumar et al. [2006] used a LBL model to calculate REs of 0.18, 0.23 , and $0.13 \mathrm{~W} \mathrm{~m}^{-2} \mathrm{ppb}^{-1}$, respectively. Clouds and stratospheric temperature adjustment were included in their study, but they did not include the effect of a nonhomogeneous vertical profile. When using lifetimes from $W M O$ [2011] and our method described in section 3.3.4, the lifetime-corrected REs from Rajakumar et al. [2006] are $0.16,0.20$, and $0.10 \mathrm{~W} \mathrm{~m}^{-2} \mathrm{ppb}^{-1}$ for HFC-245ea, HFC-245eb, and HFC-263fb, respectively. Using these REs, we derive the recommended GWPs given in Table 7.

\subsubsection{HFC-245fa $\left(\mathrm{CHF}_{2} \mathrm{CH}_{2} \mathrm{CF}_{3}\right)$}

[159] Published estimates of the RE of HFC-245fa lie in the range of $0.24-0.29 \mathrm{~W} \mathrm{~m}^{-2} \mathrm{ppb}^{-1}$ (mean: $0.27 \mathrm{~W} \mathrm{~m}^{-2}$ $\mathrm{ppb}^{-1}$ ) [Jain et al., 2000; Ko et al., 1999; Naik et al., 2000; Orkin et al., 2003; Sihra et al., 2001], and the value of $0.28 \mathrm{~W} \mathrm{~m}^{-2} \mathrm{ppb}^{-1}$ from Ko et al. [1999] has been used in recent assessments. We calculate a lower mean RE value of $0.24 \mathrm{~W} \mathrm{~m}^{-2} \mathrm{ppb}^{-1}$ (range: $0.24-0.25 \mathrm{~W} \mathrm{~m}^{-2} \mathrm{ppb}^{-1}$ ) when using the absorption cross sections from Sihra et al. [2001] and Orkin et al. [2003] (Tables 6 and 7). Part of the reason for the weaker RE in this study is the lower integrated absorption cross section in Sihra et al. [2001] compared to Ko et al. [1999] (Table 6), but it could also be related to differences in how the non-homogeneous distribution is accounted for. We note further that the RE estimate of $K o$ et al. [1999] is at the high end of the range of literature REs and that our estimate is in agreement with the $0.24 \mathrm{~W}$ $\mathrm{m}^{-2} \mathrm{ppb}^{-1}$ calculated by Sihra et al. [2001]. Our RE estimate of $0.24 \mathrm{~W} \mathrm{~m}^{-2} \mathrm{ppb}^{-1}$ is approximately $13 \%$ lower than the value of $0.28 \mathrm{~W} \mathrm{~m}^{-2} \mathrm{ppb}^{-1}$ used in AR4 (see Table 7).

\subsubsection{1. $\mathrm{HFC}-272 \mathrm{ca}\left(\mathrm{CH}_{3} \mathrm{CF}_{2} \mathrm{CH}_{3}\right)$}

[160] Previous studies of RE due to HFC-272ca are in the range of $0.08-0.09 \mathrm{~W} \mathrm{~m}^{-2} \mathrm{ppb}^{-1}$ (mean: $0.09 \mathrm{~W} \mathrm{~m}^{-2} \mathrm{ppb}^{-1}$ ) [Pinnock et al., 1995; Sihra et al., 2001]. We calculate a RE value of $0.08 \mathrm{~W} \mathrm{~m}^{-2} \mathrm{ppb}^{-1}$ using the absorption spectrum from Sihra et al. [2001] (Tables 6 and 7). While there is no lifetime estimate for $\mathrm{CH}_{3} \mathrm{CF}_{2} \mathrm{CH}_{3}$ in the literature, using the structure activity relationship developed by Calvert et al. [2008] with $k\left(-\mathrm{CH}_{3}\right)=1.35 \times 10^{-13}$ and $\mathrm{F}$ $\left(-\mathrm{CF}_{2}{ }^{-}\right)=0.045$, we estimate $k\left(\mathrm{OH}+\mathrm{CH}_{3} \mathrm{CF}_{2} \mathrm{CH}_{3}\right)=1.21$ $\times 10^{-14} \mathrm{~cm}^{3}$ molecule ${ }^{-1} \mathrm{~s}^{-1}$ at $298 \mathrm{~K}$. Combining this rate coefficient with an average tropospheric $\mathrm{OH}$ concentration of $1 \times 10^{6} \mathrm{~cm}^{-3}$ provides an estimate for the atmospheric lifetime of 2.6 years. Using this estimated lifetime, we derive the GWP value given in Table 7 .

\subsubsection{2. $\mathrm{HFC}-329 \mathrm{p}\left(\mathrm{CHF}_{2} \mathrm{CF}_{2} \mathrm{CF}_{2} \mathrm{CF}_{3}\right)$}

[161] The RE of HFC-329p has not been assessed by AR4 but was estimated to $0.31 \mathrm{~W} \mathrm{~m}^{-2} \mathrm{ppb}^{-1}$ (instantaneous RE) by Young et al. [2009b] who used the original Pinnock et al. [1995] method. We have used the absorption cross section from Young et al. [2009b] and calculated the same RE value of $0.31 \mathrm{~W} \mathrm{~m}^{-2} \mathrm{ppb}^{-1}$ (Tables 6 and 7).

\subsubsection{HFC-365mfc $\left(\mathrm{CH}_{3} \mathrm{CF}_{2} \mathrm{CH}_{2} \mathrm{CF}_{3}\right)$}

[162] A range of $0.21-0.23 \mathrm{~W} \mathrm{~m}^{-2} \mathrm{ppb}^{-1}$ (mean: $0.22 \mathrm{~W}$ $\mathrm{m}^{-2} \mathrm{ppb}^{-1}$ ) is available from literature estimations of the RE of HFC-365mfc [Barry et al., 1997; Inoue et al., 2008; Naik et al., 2000]. AR4 adopted the value of $0.21 \mathrm{~W} \mathrm{~m}^{-2}$ $\mathrm{ppb}^{-1}$ from Barry et al. [1997], while WMO [2011] used an average of the results from Barry et al. [1997] and the more recent study of Inoue et al. [2008]. The latter study calculated a slightly higher RE of $0.23 \mathrm{~W} \mathrm{~m}^{-2} \mathrm{ppb}^{-1}$ (instantaneous RE) reflecting an approximately $10 \%$ more intense infrared absorption spectrum reported by Inoue et al. [2008]. A precise comparison of the spectra recorded by Barry et al. [1997] and Inoue et al. [2008] is not possible because Barry et al. [1997] did not report an integrated absorption cross section. Here we have used the better documented absorption cross section from Inoue et al. [2008] to calculate a radiative forcing of $0.22 \mathrm{~W} \mathrm{~m}^{-2} \mathrm{ppb}^{-1}$. Our RE estimate is approximately $6 \%$ higher (prior to rounding) than the value used in AR4 (see Table 7).

\subsubsection{HFC-43-10mee $\left(\mathrm{CF}_{3} \mathrm{CHFCHFCF}_{2} \mathrm{CF}_{3}\right)$}

[163] AR4 reports a RE of HFC-43-10mee of $0.40 \mathrm{~W} \mathrm{~m}^{-2}$ $\mathrm{ppb}^{-1}$ which is based on Fisher (personal communication) [IPCC, 1994] (original value was scaled in WMO [1999] because of a change in the recommended forcing of CFC11 - see the discussion of CFC-11 in section 4.1.1). No published estimates of the RE of this compound exist, and no 


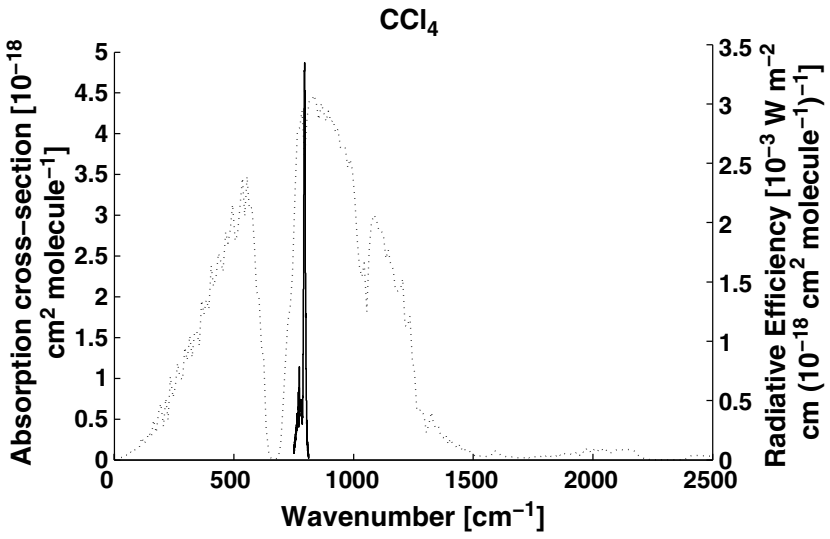

Figure 14. Absorption spectrum of $\mathrm{CCl}_{4}$ at $296 \mathrm{~K}$ from Nemtchinov and Varanasi [2003] (solid line) and Oslo simulation of Pinnock curve (dotted line).

new calculations have been carried out here; thus, we retain the RE from AR4 as our best estimate, except that we scale the value by a factor $0.26 / 0.25=1.04$ to account for the update in our recommended RE of CFC-11. Our recommended RE of HFC-43-10mee is then $0.42 \mathrm{~W} \mathrm{~m}^{-2} \mathrm{ppb}^{-1}$. Also, the GWP (100) value has been updated to account for the change in $\mathrm{AGWP}_{\mathrm{CO} 2}$ and the updated lifetime (16.1 years in $W M O$ [2011] compared to 15.9 years in AR4).

4.1.3.25. HFC-1132a $\left(\mathrm{CH} 2=\mathrm{CF}_{2}\right)$, $\mathrm{HFC}-1141 \quad\left(\mathrm{CH}_{2}=\right.$ $\mathrm{CHF})$ and $(\mathrm{Z})$-HFC-1336 $\left(\mathrm{CF}_{3} \mathrm{CH}=\mathrm{CHCF}_{3}(\mathrm{Z})\right)$

[164] The REs of HFC-1132a, HFC-1141, and (Z)-HFC1336 were not assessed in AR4. Baasandorj et al. [2010] have estimated the radiative efficiencies of HFC-1132a and HFC1141 to be 0.09 and $0.08 \mathrm{~W} \mathrm{~m}^{-2} \mathrm{ppb}^{-1}$, respectively. Baasandorj et al. [2011] estimated the radiative efficiency of (Z)-HFC-1336 to be $0.38 \mathrm{~W} \mathrm{~m}^{-2} \mathrm{ppb}^{-1}$. The RE values from both studies are instantaneous REs derived using the original Pinnock et al. [1995] method for the forcing calculations. We apply a $10 \%$ increase to account for stratospheric temperature adjustment and an additional correction factor to account for the non-homogeneous mixing (see section 3.3.4) to derive recommended REs of $0.004,0.002$, and $0.074 \mathrm{~W}$ $\mathrm{m}^{-2} \mathrm{ppb}^{-1}$ for HFC-1132a, HFC-1141, and (Z)-HFC-1336, respectively. Lifetimes necessary for the RE lifetime correction and GWP calculation were taken from $W M O$ [2011] for HFC-1132a and HFC-1141, and from Baasandorj et al. [2011] for (Z)-HFC-1336.

\subsubsection{6. (Z)-HFC-1225ye $\left(\mathrm{CF}_{3} \mathrm{CF}=\mathrm{CHF}(\mathrm{Z})\right)$}

[165] Literature values of the RE of (Z)-HFC-1225ye are in close agreement with a range of 0.25 $0.26 \mathrm{~W} \mathrm{~m}^{-2} \mathrm{ppb}^{-1}$ (mean: $0.26 \mathrm{~W} \mathrm{~m}^{-2} \mathrm{ppb}^{-1}$ ) [Hurley et al., 2007; Papadimitriou et al., 2008a]. Our RE calculation using the absorption spectrum from Hurley et al. [2007] and assuming homogeneous mixing throughout the troposphere is $0.26 \mathrm{~W}$ $\mathrm{m}^{-2} \mathrm{ppb}^{-1}$, in good agreement with the literature data. However, when we account for the substantially nonhomogeneous mixing of this short-lived species, we arrive at the much lower RE value of $0.02 \mathrm{~W} \mathrm{~m}^{-2} \mathrm{ppb}^{-1}$ (Table 7). Neither of the two literature studies account for the nonhomogeneous mixing of $\mathrm{CF}_{3} \mathrm{CF}=\mathrm{CHF}$ in the troposphere. Our recommended RE and GWP values are given in Table 7 .

\subsubsection{7. (E)-HFC-1225ye $\left(\mathrm{CF}_{3} \mathrm{CF}=\mathrm{CHF}(\mathrm{E})\right)$}

[166] There has been one published study of the RE of (E)HFC-1225ye which gave a value $0.24 \mathrm{~W} \mathrm{~m}^{-2} \mathrm{ppb}^{-1}$ [Hurley et al., 2007]. We have used the absorption spectrum from Hurley et al. [2007] and calculated a RE value of $0.01 \mathrm{~W}$ $\mathrm{m}^{-2} \mathrm{ppb}^{-1}$ (Tables 6 and 7). As for the (Z)-HFC-1225ye compound discussed above, our RE estimate is in close agreement with the published value when we assume homogeneous mixing of (E)-HFC-1225ye.

\subsubsection{8. (Z)-HFC-1234ze $\left(\mathrm{CF}_{3} \mathrm{CH}=\mathrm{CHF}(\mathrm{Z})\right)$}

[167] There has been one published study of the RE of (Z)HFC-1234ze which gave a value $0.20 \mathrm{~W} \mathrm{~m}^{-2} \mathrm{ppb}^{-1}$ [Nilsson et al., 2009]. We calculate a RE value of $0.02 \mathrm{~W}$ $\mathrm{m}^{-2} \mathrm{ppb}^{-1}$ using absorption spectrum from Nilsson et al.

TABLE 8. Integrated Absorption Cross Sections $(S)$ for Chlorocarbons and Hydrochlorocarbons ${ }^{\mathrm{a}}$

\begin{tabular}{|c|c|c|c|c|c|c|c|c|c|}
\hline Name & CAS\# & Trivial Name & Formula & Data $^{\mathrm{b}}$ & $T / \mathrm{K}$ & $\begin{array}{c}\text { Wn. } \\
\text { Range / } \\
\mathrm{cm}^{-1}\end{array}$ & $S^{\mathrm{c}}$ & Reference & Database $^{\mathrm{d}}$ \\
\hline \multirow[t]{3}{*}{ 1,1,1-Trichloroethane } & \multirow{3}{*}{\multicolumn{2}{|c|}{ 71-55-6 Methyl chloroform }} & $\mathrm{CH}_{3} \mathrm{CCl}_{3}$ & $\mathrm{E}$ & 295 & $480-1490$ & 5.1 & [Orkin et al., 2003] & \\
\hline & & & & $\mathrm{E}$ & 296 & $700-1500$ & 5.0 & [Imasu et al., 1995] & \\
\hline & & & & $\mathrm{E}$ & & $669-1397$ & 4.5 & [Fisher et al., 1990] & \\
\hline \multirow[t]{6}{*}{$\begin{array}{l}\text { Perchloromethane, } \\
\text { tetrachloromethane }\end{array}$} & \multirow[t]{6}{*}{$56-23-5$} & \multirow[t]{6}{*}{$\begin{array}{l}\text { Carbon } \\
\text { tetrachloride }\end{array}$} & \multirow[t]{6}{*}{$\mathrm{CCl}_{4}$} & $\mathrm{E}$ & 297 & $750-812$ & 6.2 & [Nemtchinov and Varanasi, 2003] & $\mathrm{G}$ \\
\hline & & & & $\mathrm{E}$ & 297 & $750-812$ & 6.2 & $\begin{array}{l}\text { [Varanasi, personal communication, } \\
\text { 2000] }\end{array}$ & $\mathrm{H}$ \\
\hline & & & & $\mathrm{E}$ & 298 & $730-825$ & 5.9 & [Orlando et al., 1992] & \\
\hline & & & & $\mathrm{E}$ & 298 & $773-802$ & 3.7 & [Brown et al., 1987] & \\
\hline & & & & $\mathrm{E}$ & 298 & $786-806$ & 3.6 & [Massie et al., 1985] & \\
\hline & & & & $\mathrm{E}$ & & $616-934$ & 4.5 & [Fisher et al., 1990] & \\
\hline Chloromethane & $74-87-3$ & Methyl chloride & $\mathrm{CH}_{3} \mathrm{Cl}$ & $\mathrm{E}$ & & $661-1646$ & 1.4 & [Grossman et al., 1997] & \\
\hline Dichloromethane & $75-09-2$ & $\begin{array}{l}\text { Methylene } \\
\text { chloride }\end{array}$ & $\mathrm{CH}_{2} \mathrm{Cl}_{2}$ & A & & $250-3300$ & 3.3 & [Bera et al., 2009] & \\
\hline Trichloromethane & $67-66-3$ & Chloroform & $\mathrm{CHCl}_{3}$ & $\mathrm{E}$ & 295 & $540-1600$ & 5.6 & [McPheat and Duxbury, 2000] & \\
\hline 1,2-Dichloroethane & $107-06-2$ & & $\mathrm{CH}_{2} \mathrm{ClCH}_{2} \mathrm{Cl}$ & $1 \mathrm{E}$ & 293 & $600-1700$ & 2.1 & [Vander Auwera, 2000] & \\
\hline
\end{tabular}

${ }^{\mathrm{a}}$ Spectra used in RE calculations in the present study are indicated in bold.

${ }^{\mathrm{b}}$ Type of data: E, Experimental; A, Ab initio.

Integrated absorption cross-section in units of $10^{-17} \mathrm{~cm}^{2}$ molecule $\mathrm{cm}^{-1}$ for the wavenumber interval specified.

dDatabase: H, HITRAN 2008; G, GEISA 2009. 
TABLE 9. Lifetimes, Radiative Efficiencies, and Direct GWPs (Relative to $\mathrm{CO}_{2}$ ) for Chlorocarbons and Hydrochlorocarbons ${ }^{\mathrm{a}}$

\begin{tabular}{|c|c|c|c|c|c|c|c|}
\hline \multirow[b]{2}{*}{ Acronym / name } & \multirow[b]{2}{*}{ Formula } & \multirow[b]{2}{*}{ Lifetime (yr) } & \multicolumn{3}{|c|}{ Radiative Efficiency $\left(\mathrm{W} \mathrm{m}{ }^{-2} \mathrm{ppb}^{-1}\right)$} & \multicolumn{2}{|c|}{ GWP 100 year } \\
\hline & & & AR4 & $\begin{array}{l}\text { This study- } \\
\text { const. profile }\end{array}$ & $\begin{array}{l}\text { This study- } \\
\text { lifetime corr. }\end{array}$ & AR4 & $\begin{array}{l}\text { This study- } \\
\text { lifetime corr. }\end{array}$ \\
\hline Methyl chloroform & $\mathrm{CH}_{3} \mathrm{CCl}_{3}$ & 5.0 & 0.06 & 0.08 & 0.07 & 146 & 160 \\
\hline Carbon tetrachloride & $\mathrm{CCl}_{4}$ & 26.0 & 0.13 & 0.18 & 0.17 & 1,400 & 1,730 \\
\hline Methyl chloride & $\mathrm{CH}_{3} \mathrm{Cl}$ & 1.0 & 0.01 & & & 13 & 12 \\
\hline Methylene chloride & $\mathrm{CH}_{2} \mathrm{Cl}_{2}$ & 0.4 & 0.03 & & & 9 & 9 \\
\hline Chloroform & $\mathrm{CHCl}_{3}$ & 0.4 & 0.11 & 0.14 & 0.08 & 31 & 16 \\
\hline 1,2-Dichloroethane & $\mathrm{CH}_{2} \mathrm{ClCH}_{2} \mathrm{Cl}$ & 65.0 days & & 0.02 & 0.01 & & $<\mathbf{1}$ \\
\hline
\end{tabular}

${ }^{\mathrm{a}}$ Compounds in bold either have significant current atmospheric concentrations or a clear potential for future emissions. Recommended RE and GWP 100 year values are indicated in bold. Lifetimes are from WMO [2011].

[2009] (Tables 6 and 7). The RE value estimated here is in good agreement with the published value when homogeneous distribution is assumed. The lifetime of 10 days is taken from Nilsson et al. [2009].

\subsubsection{HFC-1234yf $\left(\mathrm{CF}_{3} \mathrm{CF}=\mathrm{CH}_{2}\right)$}

[168] Literature values for the RE of HFC-1234yf fall in the range of $0.22-0.24 \mathrm{~W} \mathrm{~m}^{-2} \mathrm{ppb}^{-1}$ (mean: $0.23 \mathrm{~W} \mathrm{~m}^{-2} \mathrm{ppb}^{-1}$ ) [Nielsen et al., 2007; Orkin et al., 2010; Papadimitriou et al., 2008a]. We calculate a mean RE value of $0.02 \mathrm{~W} \mathrm{~m}^{-2}$ $\mathrm{ppb}^{-1}$ both when using the absorption cross section from Orkin et al. [2010] and from Nielsen et al. [2007] (Tables 6 and 7). Neither of the previous studies accounted for the non-homogeneous mixing of this short-lived compound and we note that our estimate is in excellent agreement with the mean of published RE values when we assume uniform mixing of HFC-1234yf.

\subsubsection{0. (E)-HFC-1234ze (trans- $\mathrm{CF}_{3} \mathrm{CH}=\mathrm{CHF}$ )}

[169] Results from the published studies of the RE of (E)HFC-1234ze lie in the range of $0.24-0.27 \mathrm{~W} \mathrm{~m}^{-2} \mathrm{ppb}^{-1}$ (mean: $0.26 \mathrm{~W} \mathrm{~m}^{-2} \mathrm{ppb}^{-1}$ ) [Orkin et al., 2010; Søndergaard et al., 2007]. We calculate a RE value of $0.04 \mathrm{~W} \mathrm{~m}^{-2} \mathrm{ppb}^{-1}$ when using absorption cross sections from both of these studies (Tables 6 and 7). The non-homogeneous mixing of this short-lived compound was not accounted for in the two studies; our estimate of RE is consistent with the published values if we assume uniform mixing.

4.1.3.31. HFC-1243zf, HFC-1345zfc, 3,3,4,4,5,5,6,6,6nonafluorohex-1-ene, 3,3,4,4,5,5,6,6,7,7,8,8,8-tridecafluo rooct-1-ene and 3,3,4,4,5,5,6,6,7,7,8,8,9,9,10,10,10-hepta decafluorodec-1-ene $\left(\mathrm{C}_{\mathrm{x}} \mathrm{F}_{2 \mathrm{x}+1} \mathrm{CH}=\mathrm{CH}_{2}(x=1,2,4,6\right.$, and 8))

[170] In the recent study by Andersen et al. [2012a], REs were calculated for five compounds that have not been included in previous assessments. They used the original Pinnock et al. [1995] method to calculate instantaneous REs of $0.16,0.18,0.34,0.38$, and $0.42 \mathrm{~W} \mathrm{~m}^{-2} \mathrm{ppb}^{-1}$ for HFC-1243zf, HFC-1345zfc, 3,3,4,4,5,5,6,6,6-nonafluorohex1-ene, 3,3,4,4,5,5,6,6,7,7,8,8,8-tridecafluorooct-1-ene, and 3,3,4,4,5,5,6,6,7,7,8,8,9,9,10,10,10-heptadecafluorodec-1-ene, respectively, assuming uniform mixing of these gases. As can be seen in Table 7, the corresponding REs calculated in this study are in close agreement to Andersen et al. [2012a], while they are substantially lower-in the range of $0.01-0.03 \mathrm{~W} \mathrm{~m}^{-2} \mathrm{ppb}^{-1}$ - when accounting for nonhomogeneous mixing. It should be noted here that the uncertainties associated with the lifetime correction factor are very large on a percentage basis for such short-lived species (see Figure 9 and associated discussion in section 3.3.4). The absorption cross sections used here are from $\mathrm{An}$ dersen et al. [2012a] (Table 6), and the lifetimes necessary for the fractional correction and GWP calculation have been taken from Andersen et al. [2005].

\subsubsection{Chlorocarbons and Hydrochlorocarbons}

[171] Chlorocarbons and hydrochlorocarbons are ozonedepleting substances and are therefore controlled under the Montreal Protocol. Lifetimes for the chlorocarbons and hydrochlorocarbons considered here range from less than a year for $\mathrm{CH}_{2} \mathrm{ClCH}_{2} \mathrm{Cl}$ to 26 years for $\mathrm{CCl}_{4}$ (carbon tetrachloride). Figure 1 shows the contrasting time-histories of the atmospheric concentrations of the most abundant chlorocarbon $\left(\mathrm{CCl}_{4}\right)$ and hydrochlorocarbon $\left(\mathrm{CH}_{3} \mathrm{CCl}_{3}\right.$, methyl chloroform). Methyl chloroform concentrations fell rapidly after implementation of the Montreal Protocol, due to a combination of rapidly decreasing emissions and its short ( 5 year) lifetime. By contrast, due to continued emissions of carbon tetrachloride it remains the fourth most abundant of the compounds considered here (about $90 \mathrm{ppt}$ ), with concentrations decreasing only rather slowly (at a rate of about $1.2 \mathrm{pptyear}{ }^{-1}$ ) [WMO, 2011]. Figure 14 shows the absorption spectrum of carbon tetrachloride - the symmetry of this molecule results in a quite simple spectrum, with most of the absorption concentrated in the $750-800 \mathrm{~cm}^{-1}$ spectral region. Previously published absorption cross sections are listed in Table 8, while updated atmospheric lifetimes, radiative efficiencies, and 100-year GWP values for chlorocarbons and hydrochlorocarbons are presented in Table 9 and discussed below. With the exception of carbon tetrachloride, which is mainly lost by photolysis [WMO, 2011], the $S$-shaped fit from section 3.3.4 (equation (2) and dark blue curve in Figure 9) has been used to account for a non-uniform vertical profile and geographic distribution for all compounds presented in this subsection.

\subsubsection{Methyl chloroform $\left(\mathrm{CH}_{3} \mathrm{CCl}_{3}\right)$}

[172] The studies that have calculated RE of methyl chloroform present values in the range of $0.06-0.10 \mathrm{~W} \mathrm{~m}^{-2} \mathrm{ppb}^{-1}$ (mean: $0.07 \mathrm{~W} \mathrm{~m}^{-2} \mathrm{ppb}^{-1}$ ) [Fisher et al., 1990; Imasu et al., 1995; Jain et al., 2000; Orkin et al., 2003]. Both Fisher et al. [1990] and Jain et al. [2000] used the same absorption cross section [Fisher et al., 1990]. Orkin et al. [2003] 


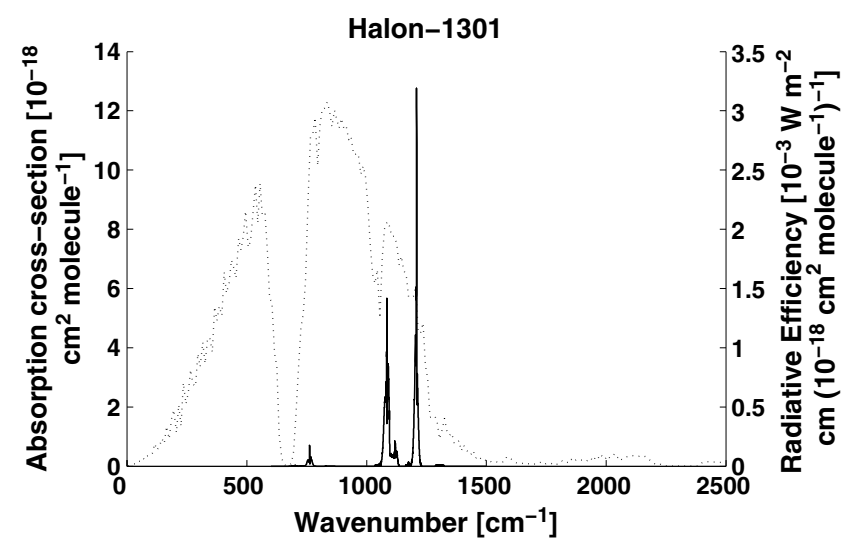

Figure 15. Absorption spectrum of Halon-1301 at $296 \mathrm{~K}$ in $933 \mathrm{hPa}$ (700 Torr) air diluent from Sihra et al. [2001] (solid line) and Oslo simulation of Pinnock curve (dotted line).

presented a $9 \%$ larger absorption cross section and, based on the measured spectrum of the Earth's outgoing radiation obtained by NIMBUS 4 [Kunde et al., 1974], a relative RE to CFC-11 of 0.38 . AR4 adopted the RE value of $0.06 \mathrm{~W} \mathrm{~m}^{-2}$ $\mathrm{ppb}^{-1}$ from Fisher et al. [1990]. We have used the absorption cross sections from two sources [Imasu et al., 1995; Orkin et al., 2003] and calculated a slightly higher RE value of $0.07 \mathrm{~W} \mathrm{~m}^{-2} \mathrm{ppb}^{-1}$ for both spectra.

\subsubsection{Carbon Tetrachloride $\left(\mathrm{CCl}_{4}\right)$}

[173] Previous studies of carbon tetrachloride RE present values in the range of $0.09-0.13 \mathrm{~W} \mathrm{~m}^{-2} \mathrm{ppb}^{-1}$ (mean: $0.11 \mathrm{~W}$ $\mathrm{m}^{-2} \mathrm{ppb}^{-1}$ ) [Fisher et al., 1990; Jain et al., 2000; Myhre and Stordal, 1997]; Fisher et al. [1990] and Jain et al. [2000] based their calculations on the absorption cross section presented by Fisher et al. [1990], while Myhre and Stordal [1997] employed the absorption cross section of Massie et al. [1985]. AR4 adopted the RE of $0.13 \mathrm{~W} \mathrm{~m}^{-2} \mathrm{ppb}^{-1}$ from Jain et al. [2000]. We have used the more recent absorption cross section from the study of Nemtchinov and Varanasi [2003], which includes temperature and pressure dependency and an inter-comparison of all previous data, and derive a $\mathrm{RE}$ value of $0.17 \mathrm{~W} \mathrm{~m}^{-2} \mathrm{ppb}^{-1}$. This is significantly higher (35\% higher) than the AR4 value (Table 9) and entirely due to the higher integrated absorption cross section of the newer data (Table 8) than that was used in the RE calculation of Jain et al. [2000]. In contrast to the other compounds listed in this section, carbon tetrachloride is mainly lost by photolysis rather than reaction with $\mathrm{OH}[W M O, 2011]$. Hence, we have used the exponential fit from section 3.3.4 (equation (1) and red curve in Figure 9) instead of the $S$-shaped fit to account for a non-uniform vertical profile, although this has only a small impact on the RE because this compound is relatively wellmixed in the atmosphere (lifetime of 26.0 years).

TABLE 10. Integrated Absorption Cross Sections (S) for Bromocarbons, Hydrobromocarbons, and Halons ${ }^{\text {a }}$

\begin{tabular}{|c|c|c|c|c|c|c|c|c|}
\hline Name & CAS\# & $\begin{array}{l}\text { Acronym / trivial } \\
\text { name }\end{array}$ & Formula I & Data $^{\mathrm{b}}$ & $T / \mathrm{K}$ & $\begin{array}{c}\mathrm{Wn} . \\
\text { range } / \mathrm{cm}^{-1}\end{array}$ & $S^{\mathrm{c}}$ & Database $^{\mathrm{d}}$ \\
\hline \multirow[t]{4}{*}{ Bromomethane } & \multirow[t]{4}{*}{$74-83-9$} & \multirow[t]{4}{*}{ Methyl bromide } & \multirow[t]{4}{*}{$\mathrm{CH}_{3} \mathrm{Br}$} & $\mathrm{E}$ & 296 & $450-2000$ & 0.7 & [Sihra et al., 2001] \\
\hline & & & & $\mathrm{E}$ & 296 & $450-2000$ & 0.8 & [Christidis et al., 1997] \\
\hline & & & & $\mathrm{E}$ & & $550-1600$ & 1.2 & [Grossman et al., 1997] \\
\hline & & & & $\mathrm{E}$ & & & & [Graner, 1981] \\
\hline \multirow[t]{2}{*}{ Dibromomethane } & \multirow[t]{2}{*}{$74-95-3$} & \multirow[t]{2}{*}{ Methylene bromide } & \multirow[t]{2}{*}{$\mathrm{CH}_{2} \mathrm{Br}_{2}$} & $\mathrm{E}$ & 296 & $450-2000$ & 2.1 & [Sihra et al., 2001] \\
\hline & & & & $\mathrm{E}$ & 296 & $450-2000$ & 2.0 & [Christidis et al., 1997] \\
\hline \multirow[t]{4}{*}{ Bromodifluoromethane } & \multirow[t]{4}{*}{$1511-62-2$} & \multirow[t]{4}{*}{ Halon-1201 } & \multirow[t]{4}{*}{$\mathrm{CHBrF}_{2}$} & E,A & 298 & $530-1460$ & 10.2 & [Charmet et al., 2010] \\
\hline & & & & $\mathrm{E}$ & 295 & $530-1400$ & 10.1 & [Orkin et al., 2003] \\
\hline & & & & $\mathrm{E}$ & 296 & $450-2000$ & 10.0 & [Sihra et al., 2001] \\
\hline & & & & $\mathrm{E}$ & 296 & $450-2000$ & 9.9 & [Christidis et al., 1997] \\
\hline Dibromodifluoromethane & $75-61-6$ & Halon-1202 & $\mathrm{CBr}_{2} \mathrm{~F}_{2}$ & $\mathrm{E}$ & 295 & $400-1600$ & 11.8 & [Orkin et al., 2003] \\
\hline \multirow[t]{2}{*}{ Bromochlorodifluoromethane } & \multirow[t]{2}{*}{$353-59-3$} & \multirow[t]{2}{*}{ Halon-1211 } & \multirow[t]{2}{*}{$\mathrm{CBrClF}_{2}$} & $\mathrm{E}$ & 296 & $450-2000$ & 12.4 & [Sihra et al., 2001] \\
\hline & & & & $\mathrm{E}$ & 296 & $450-2000$ & 11.5 & [Christidis et al., 1997] \\
\hline \multirow[t]{7}{*}{ Bromotrifluoromethane } & \multirow[t]{7}{*}{$75-63-8$} & \multirow[t]{7}{*}{ Halon-1301 } & \multirow[t]{7}{*}{$\mathrm{CBrF}_{3}$} & $\mathrm{E}$ & 298 & $461-2500$ & 16.7 & [Charmet et al., 2008] \\
\hline & & & & $\mathrm{E}$ & 298 & $720-1250$ & 15.4 & [Drage et al., 2006] \\
\hline & & & & $\mathrm{E}$ & 295 & $720-1250$ & 16.4 & [Orkin et al., 2003] \\
\hline & & & & $\mathrm{E}$ & 296 & $450-2000$ & 17.0 & [Sihra et al., 2001] \\
\hline & & & & $\mathrm{E}$ & & $1040-1250$ & 16.0 & $\begin{array}{c}\text { [Varanasi and } \\
\text { Chudamani, } 1988 \mathrm{~b}]\end{array}$ \\
\hline & & & & $\mathrm{E}$ & & $1040-1250$ & 16.1 & $\begin{array}{c}\text { [Ramanathan et al., } \\
1985]\end{array}$ \\
\hline & & & & $\mathrm{E}$ & & $720-1250$ & 15.9 & [Person and Polo, 1961] \\
\hline 2-Bromo-1,1,1-trifluoroethane & $421-06-7$ & Halon-2301 & $\mathrm{CH}_{2} \mathrm{BrCF}_{3}$ & $\mathrm{E}$ & 295 & $590-1510$ & 12.8 & [Orkin et al., 2003] \\
\hline \multirow[t]{2}{*}{$\begin{array}{l}\text { 2-Bromo-2-chloro-1,1,1- } \\
\text { trifluoroethane }\end{array}$} & \multirow[t]{2}{*}{$151-67-7$} & \multirow[t]{2}{*}{$\begin{array}{c}\text { Halon-2311 / } \\
\text { Halothane }\end{array}$} & \multirow[t]{2}{*}{$\mathrm{CHBrClCF}_{3}$} & $3 \mathrm{E}$ & 298 & $650-1500$ & 12.2 & [Andersen et al., 2012b] \\
\hline & & & & $\mathrm{E}$ & 295 & $480-1370$ & 13.0 & [Orkin et al., 2003] \\
\hline $\begin{array}{l}\text { 2-Bromo-1,1,1,2- } \\
\text { tetrafluoroethane }\end{array}$ & $124-72-1$ & Halon-2401 & $\mathrm{CHFBrCF}_{3}$ & $\mathrm{E}$ & 295 & $490-1480$ & 14.6 & [Orkin et al., 2003] \\
\hline $\begin{array}{l}\text { 1,2-Dibromo-1,1,2,2- } \\
\text { tetrafluoroethane }\end{array}$ & $124-73-2$ & Halon-2402 & $\mathrm{CBrF}_{2} \mathrm{CBrF}_{2}$ & $2 \mathrm{E}$ & 296 & $450-2000$ & 15.4 & [Sihra et al., 2001] \\
\hline
\end{tabular}

\footnotetext{
${ }^{\mathrm{a}}$ Spectra used in RE calculations in the present study are indicated in bold.

${ }^{\mathrm{b}}$ Type of data: E, Experimental; A, Ab initio.

Integrated absorption cross-section in units of $10^{-17} \mathrm{~cm}^{2}$ molecule $\mathrm{cm}^{-1}$ for the wavenumber interval specified.

${ }^{\mathrm{d}}$ Database: H, HITRAN 2008; G, GEISA 2009.
} 
TABLE 11. Lifetimes, Radiative Efficiencies, and Direct GWPs (Relative to $\mathrm{CO}_{2}$ ) for Bromocarbons, Hydrobromocarbons, and Halons ${ }^{\text {a }}$

\begin{tabular}{|c|c|c|c|c|c|c|c|}
\hline \multirow[b]{2}{*}{ Acronym / name } & \multirow[b]{2}{*}{ Formula } & \multirow[b]{2}{*}{ Lifetime (yr) } & \multicolumn{3}{|c|}{ Radiative Efficiency $\left(\mathrm{W} \mathrm{m}^{-2} \mathrm{ppb}^{-1}\right)$} & \multicolumn{2}{|c|}{ GWP 100 year } \\
\hline & & & AR4 & $\begin{array}{l}\text { This study- } \\
\text { const. profile }\end{array}$ & $\begin{array}{l}\text { This study- } \\
\text { lifetime corr. }\end{array}$ & AR4 & $\begin{array}{l}\text { This study- } \\
\text { lifetime corr. }\end{array}$ \\
\hline Methyl bromide & $\mathrm{CH}_{3} \mathrm{Br}$ & 0.8 & 0.01 & 0.01 & 0.00 & 5 & 2 \\
\hline Methylene bromide & $\mathrm{CH}_{2} \mathrm{Br}_{2}$ & 0.3 & 0.01 & 0.02 & 0.01 & 2 & 1 \\
\hline Halon-1201 & $\mathrm{CHBrF}_{2}$ & 5.2 & 0.14 & 0.17 & 0.15 & 404 & 376 \\
\hline Halon-1202 & $\mathrm{CBr}_{2} \mathrm{~F}_{2}$ & 2.9 & & 0.31 & 0.27 & & 231 \\
\hline Halon-1211 & $\mathrm{CBrClF}_{2}$ & 16.0 & 0.30 & 0.31 & 0.29 & 1,890 & 1,750 \\
\hline Halon-1301 & $\mathrm{CBrF}_{3}$ & 65.0 & 0.32 & 0.31 & 0.30 & 7,140 & 6,290 \\
\hline Halon-2301 & $\mathrm{CH}_{2} \mathrm{BrCF}_{3}$ & 3.4 & & 0.15 & 0.14 & & 173 \\
\hline Halon-2311 / Halothane & $\mathrm{CHBrClCF}_{3}$ & 1.0 & & 0.18 & 0.13 & & 41 \\
\hline Halon-2401 & $\mathrm{CHFBrCF}_{3}$ & 2.9 & & 0.21 & 0.19 & & 184 \\
\hline Halon-2402 & $\mathrm{CBrF}_{2} \mathrm{CBrF}_{2}$ & 20.0 & 0.33 & 0.34 & 0.31 & 1,640 & 1,470 \\
\hline
\end{tabular}

${ }^{a}$ Compounds in bold either have significant current atmospheric concentrations or a clear potential for future emissions. Recommended RE and GWP 100 year values are indicated in bold. Lifetimes are from WMO [2011] except those in italics (see text for details).

\subsubsection{Methyl Chloride $\left(\mathrm{CH}_{3} \mathrm{Cl}\right)$}

[174] Only one study has estimated the methyl chloride RE presenting a value of $0.01 \mathrm{~W} \mathrm{~m}^{-2} \mathrm{ppb}^{-1}$ [Grossman et al., 1997], which is also the value that has been used in the AR4 assessment. Grossman and co-workers employed a combination of absorption cross sections from Brown et al. [1987] and HITRAN. No new calculations have been carried out here for this compound; thus, we retain the RE from AR4 as our best estimate. The GWP(100) value has, however, been updated to account for the change in $\mathrm{AGWP}_{\mathrm{CO} 2}$.

\subsubsection{Methylene chloride $\left(\mathrm{CH}_{2} \mathrm{Cl}_{2}\right)$}

[175] No estimate of the methylene chloride $\mathrm{RE}$ has been found in the published literature. AR4 reports a RE of $0.03 \mathrm{~W}$ $\mathrm{m}^{-2} \mathrm{ppb}^{-1}$ that has been used in all assessments since IPCC [1994] and is based on Fisher (pers. comm.) (scaled to the previously recommended CFC-11 RE of $0.25 \mathrm{~W} \mathrm{~m}^{-2} \mathrm{ppb}^{-1}$ ). No new calculations have been carried out here for this compound; thus, we retain the RE and GWP(100) from AR4 as our best estimate (the GWP(100) for this compound rounds to 9 after updating the $\mathrm{AGWP}_{\mathrm{CO} 2}$ value).

\subsubsection{Chloroform $\left(\mathrm{CHCl}_{3}\right)$}

[176] The two previous reports on chloroform $\mathrm{RE}$ are in the range of $0.09-0.11 \mathrm{~W} \mathrm{~m}^{-2} \mathrm{ppb}^{-1}$ (mean: $0.10 \mathrm{~W} \mathrm{~m}^{-2} \mathrm{ppb}^{-1}$ ) [Highwood and Shine, 2000; Sihra et al., 2001] and are both based on the spectroscopic data from McPheat and Duxbury [2000]. AR4 has adopted the RE of $0.11 \mathrm{~W} \mathrm{~m}^{-2} \mathrm{ppb}^{-1}$ from Highwood and Shine [2000]. We have employed the absorption cross section from McPheat and Duxbury [2000], but we derive a substantially lower RE value of $0.08 \mathrm{~W} \mathrm{~m}^{-2} \mathrm{ppb}^{-1}$ (Tables 8 and 9). The reason for the $\sim 30 \%$ lower value in the present study is linked to the different methods correcting for the nonhomogeneous mixing of this short-lived species. Highwood and Shine [2000] used a factor of 0.8 from Freckleton et al. [1998] while we use a fractional correction factor of 0.55 based on the method described in section 3.3.4 and a lifetime of 0.4 years [WMO, 2011]. Recommended RE and GWP values, based on our calculations, are presented in Table 9 .

\subsubsection{1,2-Dichloroethane $\left(\mathrm{CH}_{2} \mathrm{ClCH}_{2} \mathrm{Cl}\right)$}

[177] 1,2-dichloroethane has a relatively low $\mathrm{RE}$ with estimates of $0.02 \mathrm{~W} \mathrm{~m}^{-2} \mathrm{ppb}^{-1}$ in the literature [Highwood and Shine, 2000; Sihra et al., 2001]; both studies use the absorption cross section of Vander Auwera [2000]. The present calculations, employing the same spectroscopic data, yield a RE about half the magnitude, $0.01 \mathrm{~W} \mathrm{~m}^{-2} \mathrm{ppb}^{-1}$ (Tables 8 and 9). As for chloroform, the calculated RE value is consistent with the previous studies when a homogeneous distribution is assumed.

\subsubsection{Bromocarbons, Hydrobromocarbons, and Halons}

[178] The bromocarbons, hydrobromocarbons, and halons are ozone-depleting substances on account of both presences of bromine, and in some compounds, also chlorine. They are controlled under the Montreal Protocol. Lifetimes for the compounds considered here range from less than a year in the case of methylene bromide $\left(\mathrm{CH}_{2} \mathrm{Br}_{2}\right)$ to 65 years in the case of Halon-1301 $\left(\mathrm{CBrF}_{3}\right)$. The most abundant hydrobromocarbon in the atmosphere is methyl bromide (about $7.5 \mathrm{ppt}$, decreasing at 0.2 pptyear $^{-1}$ ) [WMO, 2011] and the most abundant halon is Halon-1211 (about $4.2 \mathrm{ppt}$, decreasing at 0.05 ppt year $^{-1}$ ) [WMO, 2011]. Figure 15 shows the absorption spectrum of Halon-1301 $\left(\mathrm{CBrF}_{3}\right)$ - the relatively simple structure of this molecule is reflected in an absorption spectrum where most of the intensity is concentrated in two narrow bands between 1,000 and $1,200 \mathrm{~cm}^{-1}$.

[179] Previously published absorption cross sections are listed in Table 10, while updated atmospheric lifetimes, radiative efficiencies, and GWP(100) values for bromocarbons, hydrobromocarbons, and halons are presented in Table 11 and discussed below. Three of the compounds are mainly lost by photolysis in the stratosphere (Halon-1211, Halon1301, and Halon-2402) [WMO, 2011], and we have therefore used the exponential fit from section 3.3.4 (equation (1) and red curve in Figure 9) to account for a non-uniform vertical profile for these compounds. The remaining compounds are mainly lost through reaction with $\mathrm{OH}$, and we have therefore used the $S$-shaped fit from section 3.3.4 (equation (2) and dark blue curve in Figure 9) to account for a non-uniform vertical profile and geographic distribution for these compounds.

\subsubsection{Methyl Bromide $\left(\mathrm{CH}_{3} \mathrm{Br}\right)$}

[180] The RE of methyl bromide is low with a mean of $0.006 \mathrm{~W} \mathrm{~m}^{-2} \mathrm{ppb}^{-1}$ (range: $0.005-0.007 \mathrm{~W} \mathrm{~m}^{-2} \mathrm{ppb}^{-1}$ ) from published estimates [Christidis et al., 1997; 


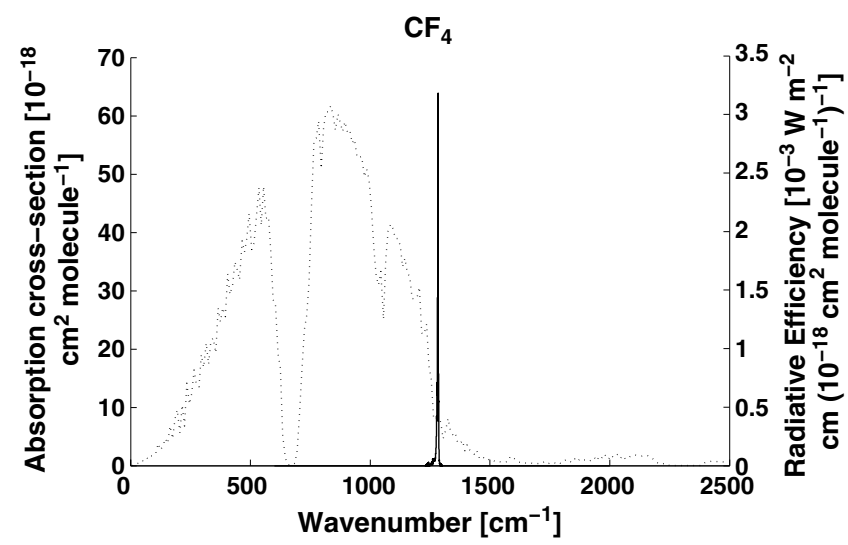

Figure 16. Absorption spectrum of $\mathrm{CF}_{4}$ at $296 \mathrm{~K}$ in 933 hPa (700 Torr) air diluent from Sihra et al. [2001] (solid line) and Oslo simulation of Pinnock curve (dotted line).

Grossman et al., 1997; Jain et al., 2000; Sihra et al., 2001]. AR4 has adopted a RE of $0.01 \mathrm{~W} \mathrm{~m}^{-2} \mathrm{ppb}^{-1}$ based on the results of Grossman et al. [1997] and Christidis et al. [1997] (rounded to two decimals). Grossman et al. [1997] used the molecular parameters of Anttila et al. [1983] and Graner and Blass [1975] to model the $\mathrm{CH}_{3} \mathrm{Br}$ spectrum. We have used the absorption cross section from Sihra et al. [2001] and derive $\mathrm{RE}=0.004 \mathrm{~W} \mathrm{~m}^{-2} \mathrm{ppb}^{-1}$ (Tables 10 and 11), which is lower than the AR4 value $\left(0.006 \mathrm{~W} \mathrm{~m}^{-2} \mathrm{ppb}^{-1}\right)$. The reason is that the previous studies assumed a constant vertical profile, while we applied a lifetime correction factor of 0.70 using the method described in section 3.3.4 and a lifetime of 0.8 years [WMO, 2011]. The present calculations are in excellent agreement with the $0.007 \mathrm{~W} \mathrm{~m}^{-2} \mathrm{ppb}^{-1}$ calculated by Christidis et al. [1997] when a constant vertical profile of methyl bromide is assumed. The best estimate RE and GWP are shown in Table 11.

\subsubsection{Methylene Bromide $\left(\mathrm{CH}_{2} \mathrm{Br}_{2}\right)$}

[181] Previous studies of RE due to methylene bromide are in the range of $0.011-0.021 \mathrm{~W} \mathrm{~m}^{-2} \mathrm{ppb}^{-1}$ (mean: $0.017 \mathrm{~W} \mathrm{~m}^{-2} \mathrm{ppb}^{-1}$ ) [Christidis et al., 1997; Jain et al., 2000; Sihra et al., 2001]; AR4 recommends RE of $0.01 \mathrm{~W}$ $\mathrm{m}^{-2} \mathrm{ppb}^{-1}$ (rounded to two decimals) from Christidis et al. [1997] (note that AR4 accounted for stratospheric decay [WMO, 1999]). When using the absorption cross section from Sihra et al. [2001], we calculate a RE value of $0.008 \mathrm{~W}$ $\mathrm{m}^{-2} \mathrm{ppb}^{-1}$, which leads to a new recommended GWP(100) value of 1 (Tables 10 and 11).

\subsubsection{Halon-1201 $\left(\mathrm{CHBrF}_{2}\right)$}

[182] Literature reports of Halon-1201 RE are in the range of $\quad 0.15-0.18 \mathrm{~W} \mathrm{~m}^{-2} \mathrm{ppb}^{-1} \quad$ (mean: $0.17 \mathrm{~W} \mathrm{~m}^{-2} \mathrm{ppb}^{-1}$ ) [Christidis et al., 1997; Jain et al., 2000; Orkin et al., 2003; Sihra et al., 2001]; AR4 adopted a RE of $0.14 \mathrm{~W} \mathrm{~m}^{-2} \mathrm{ppb}^{-1}$ which is taken from Christidis et al. [1997] (note that AR4 accounted for stratospheric decay [WMO, 1999]). We derive a mean $\mathrm{RE}$ of $0.15 \mathrm{~W} \mathrm{~m}^{-2} \mathrm{ppb}^{-1}$ (range: $0.15-0.16 \mathrm{~W} \mathrm{~m}^{-2}$ $\mathrm{ppb}^{-1}$ ) when using the absorption cross sections from Sihra et al. [2001], Orkin et al. [2003] and the recent study by
Charmet et al. [2010] (Tables 10 and 11). Our RE estimate is in agreement with the value from Sihra et al. [2001], but it is more than 5\% higher than the AR4 estimate (Table 11). Despite the higher RE, our recommended GWP(100) value is lower than in AR4 due to the shorter lifetime recommended by $W M O$ [2011] (5.2 years compared to 5.8 years in AR4) and the higher $\mathrm{AGWP}_{\mathrm{CO} 2}$ used here.

\subsubsection{Halon-1202 $\left(\mathrm{CBr}_{2} \mathrm{~F}_{2}\right)$}

[183] One study has estimated RE due to Halon-1202 with a value $0.29 \mathrm{~W} \mathrm{~m}^{-2} \mathrm{ppb}^{-1}$ [Orkin et al., 2003] (when scaled to our recommended CFC-11 RE of $0.26 \mathrm{~W}$ $\left.\mathrm{m}^{-2} \mathrm{ppb}^{-1}\right)$. We have used the absorption cross section from the same study and calculated a slightly lower RE of $0.27 \mathrm{~W} \mathrm{~m}^{-2} \mathrm{ppb}^{-1}$. It should be noted that the recent study by Papanastasiou et al. [2013] suggests a lifetime of 2.52 years, which is shorter than the 2.9 years [ $W M O$, 2011] used here.

\subsubsection{Halon-1211 ( $\left.\mathrm{CBrClF}_{2}\right)$}

[184] Previous reports of the RE of Halon-1211 are in the range of $0.25-0.33 \mathrm{~W} \mathrm{~m}^{-2} \mathrm{ppb}^{-1}$ (mean: $0.28 \mathrm{~W} \mathrm{~m}^{-2} \mathrm{ppb}^{-1}$ ) [Christidis et al., 1997; Jain et al., 2000; Sihra et al., 2001]. AR4 reports a RE of $0.30 \mathrm{~W} \mathrm{~m}^{-2} \mathrm{ppb}^{-1}$, which is based on the results of Christidis et al. [1997] (note that AR4 accounted for stratospheric decay [WMO, 1999]). We have used the absorption cross section from Sihra et al. [2001] and calculated a RE value of $0.29 \mathrm{~W} \mathrm{~m}^{-2} \mathrm{ppb}^{-1}$, which is consistent (within 5\% difference) with the AR4 value (Tables 10 and 11). For Halon-1211 we have carried out explicit simulations using the Oslo LBL model and derived a factor of 0.937 to account for the non-uniform vertical profile induced by loss through photolysis in the stratosphere (see section 3.3.4 for details), and this factor has been used to derive the RE of $0.29 \mathrm{~W} \mathrm{~m}^{-2} \mathrm{ppb}^{-1}$. It should be noted that Papanastasiou et al. [2013] have recently suggested a slightly longer lifetime of 16.4 years compared to the 16.0 years [ $W M O, 2011]$ which have been used here.

\subsubsection{Halon-1301 $\left(\mathrm{CBrF}_{3}\right)$}

[185] Estimates of the RE of Halon-1301 in the literatures range from 0.27 to $0.33 \mathrm{~W} \mathrm{~m}^{-2} \mathrm{ppb}^{-1}$ (mean: $0.30 \mathrm{~W} \mathrm{~m}^{-2}$ $\mathrm{ppb}^{-1}$ ) [Charmet et al., 2008; Drage et al., 2006; Jain et al., 2000; Orkin et al., 2003; Ramanathan et al., 1985; Sihra et al., 2001]. AR4 used a RE of $0.32 \mathrm{~W} \mathrm{~m}^{-2} \mathrm{ppb}^{-1}$ taken from Ramanathan et al. [1985]. We have used absorption cross sections from three sources [Charmet et al., 2008; Orkin et al., 2003; Sihra et al., 2001] and calculated a mean $\mathrm{RE}$ value of $0.30 \mathrm{~W} \mathrm{~m}^{-2} \mathrm{ppb}^{-1}$ (range: $0.29-0.31 \mathrm{~W} \mathrm{~m}^{-2}$ $\mathrm{ppb}^{-1}$ ), about $6 \%$ lower than AR4.

\subsubsection{Halon-2301 $\left(\mathrm{CH}_{2} \mathrm{BrCF}_{3}\right)$}

[186] One study has estimated RE due to Halon-2301 with a value $0.17 \mathrm{~W} \mathrm{~m}^{-2} \mathrm{ppb}^{-1}$ [Orkin et al., 2003] (scaled to our recommended CFC-11 RE of $0.26 \mathrm{~W} \mathrm{~m}^{-2} \mathrm{ppb}^{-1}$ ). We have used their absorption cross section and calculated a lower $\mathrm{RE}$ value of $0.14 \mathrm{~W} \mathrm{~m}^{-2} \mathrm{ppb}^{-1}$. Our value includes corrections for stratospheric temperature adjustment and nonhomogeneous mixing, which were not accounted for in the published estimate. The lifetime of 3.4 years is taken from Orkin et al. [2003]. 
HODNEBROG ET AL.: HALOCARBON REVIEW

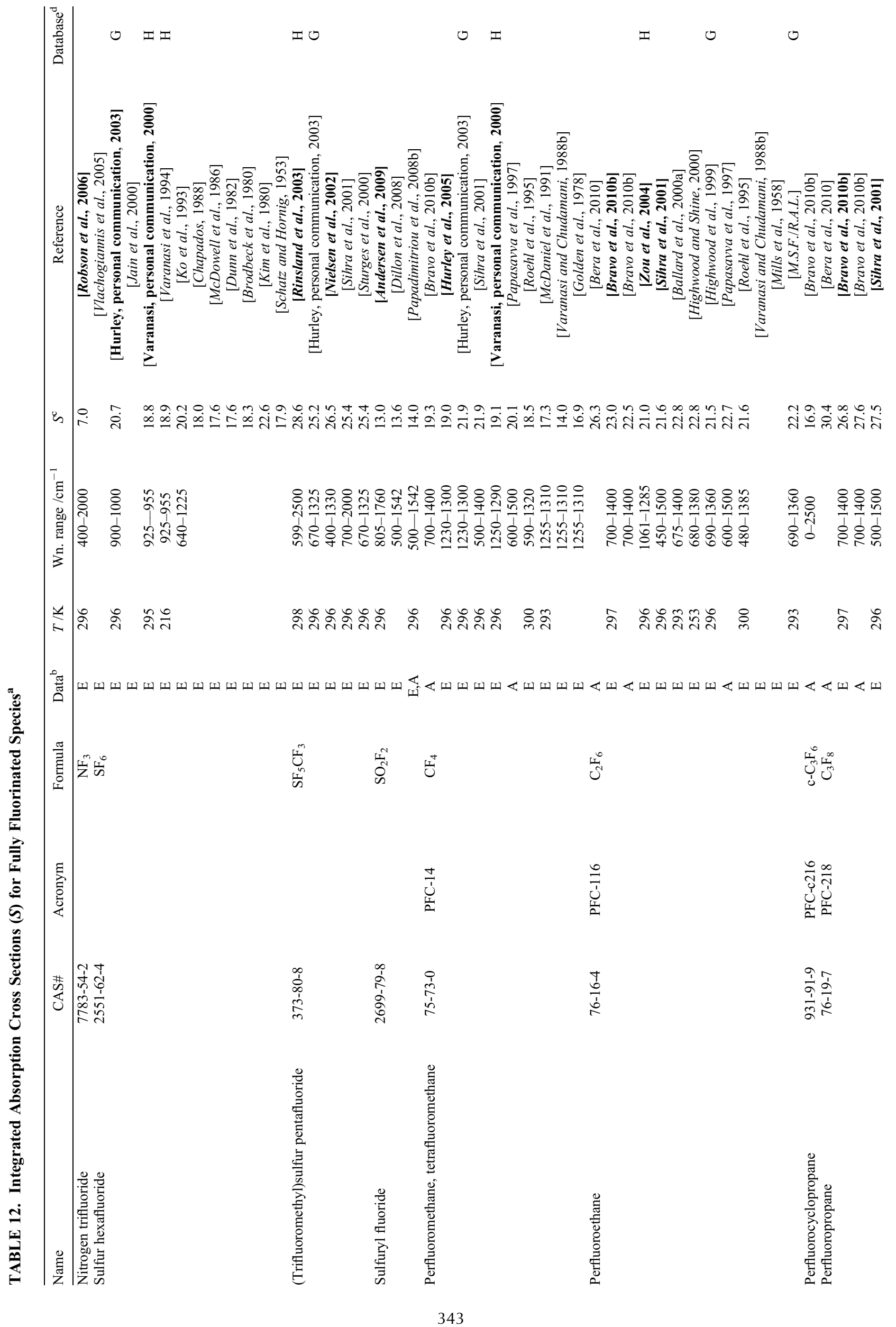


HODNEBROG ET AL.: HALOCARBON REVIEW

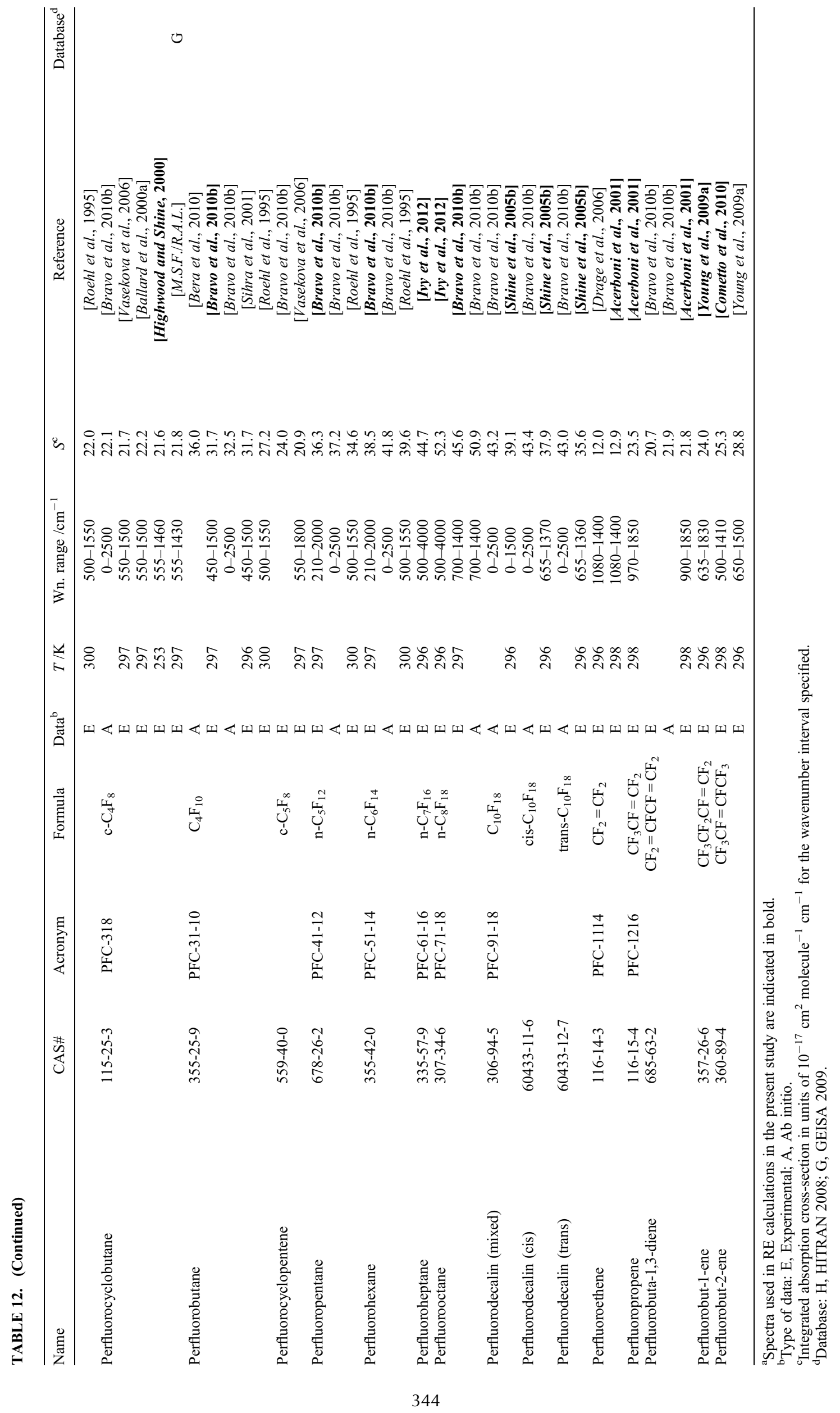


TABLE 13. Lifetimes, Radiative Efficiencies, and Direct GWPs (Relative to $\mathrm{CO}_{2}$ ) for Fully Fluorinated Species ${ }^{\mathrm{a}}$

\begin{tabular}{|c|c|c|c|c|c|c|c|}
\hline \multirow[b]{2}{*}{ Acronym / name } & \multirow[b]{2}{*}{ Formula } & \multirow[b]{2}{*}{ Lifetime (yr) } & \multicolumn{3}{|c|}{ Radiative Efficiency $\left(\mathrm{W} \mathrm{m}^{-2} \mathrm{ppb}^{-1}\right)$} & \multicolumn{2}{|c|}{ GWP 100 year } \\
\hline & & & AR4 & $\begin{array}{l}\text { This study } \\
\text { const. profile }\end{array}$ & $\begin{array}{l}\text { This study } \\
\text { - lifetime corr. }\end{array}$ & AR4 & $\begin{array}{c}\text { This study } \\
\text { - lifetime corr. }\end{array}$ \\
\hline Nitrogen trifluoride & $\mathrm{NF}_{3}$ & 500.0 & 0.21 & 0.21 & 0.20 & 17,200 & 16,100 \\
\hline Sulfur hexafluoride & $\mathrm{SF}_{6}$ & $3,200.0$ & 0.52 & 0.57 & 0.57 & 22,800 & $\mathbf{2 3 , 5 0 0}$ \\
\hline (Trifluoromethyl)sulfur pentafluoride & $\mathrm{SF}_{5} \mathrm{CF}_{3}$ & 800.0 & 0.57 & 0.60 & 0.59 & 17,700 & 17,400 \\
\hline Sulfuryl fluoride & $\mathrm{SO}_{2} \mathrm{~F}_{2}$ & 36.0 & & 0.21 & 0.20 & & 4,090 \\
\hline PFC-14 & $\mathrm{CF}_{4}$ & $50,000.0$ & 0.10 & 0.09 & 0.09 & 7,390 & 6,630 \\
\hline PFC-116 & $\mathrm{C}_{2} \mathrm{~F}_{6}$ & $10,000.0$ & 0.26 & 0.25 & 0.25 & 12,200 & 11,100 \\
\hline PFC-c216 & $\mathrm{c}-\mathrm{C}_{3} \mathrm{~F}_{6}$ & $3,000.0$ & 0.42 & 0.23 & 0.23 & 17,300 & 9,200 \\
\hline PFC-218 & $\mathrm{C}_{3} \mathrm{~F}_{8}$ & $2,600.0$ & 0.26 & 0.28 & 0.28 & 8,830 & 8,900 \\
\hline PFC-318 & $\mathrm{c}-\mathrm{C}_{4} \mathrm{~F}_{8}$ & $3,200.0$ & 0.32 & 0.32 & 0.32 & 10,300 & 9,540 \\
\hline PFC-31-10 & $\mathrm{C}_{4} \mathrm{~F}_{10}$ & $2,600.0$ & 0.33 & 0.37 & 0.36 & 8,860 & 9,200 \\
\hline Perfluorocyclopentene & $\mathrm{c}-\mathrm{C}_{5} \mathrm{~F}_{8}$ & 31.0 days & & 0.33 & 0.08 & & 2 \\
\hline PFC-41-12 & $\mathrm{n}-\mathrm{C}_{5} \mathrm{~F}_{12}$ & $4,100.0$ & 0.41 & 0.41 & 0.41 & 9,160 & 8,550 \\
\hline PFC-51-14 & $\mathrm{n}-\mathrm{C}_{6} \mathrm{~F}_{14}$ & $3,100.0$ & 0.49 & 0.45 & 0.44 & 9,300 & 7,910 \\
\hline PFC-61-16 & $\mathrm{n}-\mathrm{C}_{7} \mathrm{~F}_{16}$ & $3,000.0$ & & 0.51 & 0.50 & & 7,820 \\
\hline PFC-71-18 & $\mathrm{C}_{8} \mathrm{~F}_{18}$ & $3,000.0$ & & 0.56 & 0.55 & & 7,620 \\
\hline Perfluorodecalin (mixed) & $\mathrm{C}_{10} \mathrm{~F}_{18}$ & $2,000.0$ & 0.56 & 0.56 & 0.55 & 7,500 & 7,190 \\
\hline Perfluorodecalin (cis) & cis- $\mathrm{C}_{10} \mathrm{~F}_{18}$ & $2,000.0$ & & 0.57 & 0.56 & & 7,240 \\
\hline Perfluorodecalin (trans) & trans- $\mathrm{C}_{10} \mathrm{~F}_{18}$ & $2,000.0$ & & 0.49 & 0.48 & & 6,290 \\
\hline PFC-1114 & $\mathrm{CF}_{2}=\mathrm{CF}_{2}$ & 1.1 days & & 0.12 & 0.00 & & $<1$ \\
\hline PFC-1216 & $\mathrm{CF}_{3} \mathrm{CF}=\mathrm{CF}_{2}$ & 4.9 days & & 0.25 & 0.01 & & $<\mathbf{1}$ \\
\hline Perfluorobuta-1,3-diene & $\mathrm{CF}_{2}=\mathrm{CFCF}=\mathrm{CF}_{2}$ & 1.1 days & & 0.24 & 0.00 & & $<\mathbf{1}$ \\
\hline Perfluorobut-1-ene & $\mathrm{CF}_{3} \mathrm{CF}_{2} \mathrm{CF}=\mathrm{CF}_{2}$ & 6.0 days & & 0.30 & 0.02 & & $<\mathbf{1}$ \\
\hline Perfluorobut-2-ene & $\mathrm{CF}_{3} \mathrm{CF}=\mathrm{CFCF}_{3}$ & 31.0 days & & 0.29 & 0.07 & & 2 \\
\hline
\end{tabular}

${ }^{\mathrm{a} C}$ Compounds in bold either have significant current atmospheric concentrations or a clear potential for future emissions. Recommended RE and GWP 100 year values are indicated in bold. Lifetimes are from WMO [2011] except those in italics (see text for details). RE and GWP values in italics are based on previous publications (see text for details).

\subsubsection{Halon-2311 / Halothane ( $\left.\mathrm{CHBrClCF}_{3}\right)$}

[187] The RE of Halon-2311 has not been assessed in AR4 but was estimated to be in the range of $0.17-0.21 \mathrm{~W} \mathrm{~m}^{-2}$ $\mathrm{ppb}^{-1}$ (mean: $0.19 \mathrm{~W} \mathrm{~m}^{-2} \mathrm{ppb}^{-1}$ ) in previous studies [Andersen et al., 2012b; Orkin et al., 2003]. Both these studies assumed homogeneous mixing throughout the troposphere and Andersen et al. [2012b] used the original Pinnock et al. [1995] method to calculate the instantaneous RE. We calculate a lower RE with a mean value of $0.13 \mathrm{~W}$ $\mathrm{m}^{-2} \mathrm{ppb}^{-1}$ (range: $0.13-0.14 \mathrm{~W} \mathrm{~m}^{-2} \mathrm{ppb}^{-1}$ ) when using the absorption cross sections from Andersen et al. [2012b] and Orkin et al. [2003] (Tables 10 and 11). The lower value calculated here primarily reflects the correction factor we have applied to account for non-homogeneous mixing, but it is also a result of the difference between the original Pinnock curve and the new curve presented in section 3.3.1, whereas the latter curve generally yields lower REs (in this case $\sim 5 \%$ lower).

\subsubsection{Halon-2401 $\left(\mathrm{CHFBrCF}_{3}\right)$}

[188] Orkin et al. [2003] have estimated the RE due to Halon2401 with a value $0.23 \mathrm{~W} \mathrm{~m}^{-2} \mathrm{ppb}^{-1}$ (when scaled to our recommended CFC-11 RE of $0.26 \mathrm{~W} \mathrm{~m}^{-2} \mathrm{ppb}^{-1}$ ). We have used their absorption cross section and calculated a RE value of $0.19 \mathrm{~W} \mathrm{~m}^{-2} \mathrm{ppb}^{-1}$. Again, the lower value results mainly from the lifetime correction factor applied here to account for non-homogeneous mixing. The lifetime of 2.9 years is taken from Orkin et al. [2003].

\subsubsection{Halon-2402 $\left(\mathrm{CBrF}_{2} \mathrm{CBrF}_{2}\right)$}

[189] Sihra et al. [2001] estimated the RE of Halon-2402 presenting a value of $0.33 \mathrm{~W} \mathrm{~m}^{-2} \mathrm{ppb}^{-1}$, which is also the RE adopted by AR4. We have used the absorption cross section from Sihra et al. [2001] and calculated a RE value of
$0.31 \mathrm{~W} \mathrm{~m}^{-2} \mathrm{ppb}^{-1}$, about $6 \%$ lower than that used in AR4. We have used a lifetime of 20.0 years [WMO, 2011], but we note that the recent study by Papanastasiou et al. [2013] has estimated a significantly longer lifetime of 28.3 years and consequently higher GWP values for this compound.

\subsubsection{Fully Fluorinated Species}

[190] Fully fluorinated compounds are generally longlived compounds removed by photolysis in the stratosphere, although unsaturated compounds may be very short-lived because of their reactivity towards $\mathrm{OH}$ radicals. Perfluorocarbons (PFCs) usually have strong absorption in the $1200-1300 \mathrm{~cm}^{-1}$ region of the spectrum (as illustrated for $\mathrm{CF}_{4}$ in Figure 16) and so are radiatively active in the atmosphere. As a result - and combined with their long lifetimes - saturated PFCs have some of the largest GWPs of any compounds detected in the atmosphere. These compounds are identified within the Kyoto Protocol as gases whose presence in the atmosphere must be controlled, as has sulfur hexafluoride. As noted in section 1, nitrogen trifluoride was added to the basket of greenhouse gases in the second commitment period of the Kyoto Protocol. Published absorption cross sections are listed in Table 12, while updated atmospheric lifetimes, radiative efficiencies, and GWP(100) values for fully fluorinated species are presented in Table 13 and discussed below. For sulfuryl fluoride and six short-lived compounds we have used the $S$-shaped fit from section 3.3.4 (equation (2) and dark blue curve in Figure 9) to account for a non-uniform vertical profile and geographic distribution due to their reactivity towards $\mathrm{OH}$. The remaining compounds have very long lifetimes ( $>500$ years) and are lost by photolysis in the 
stratosphere, hence we have used the exponential fit from section 3.3.4 (equation (1) and red curve in Figure 9) to account for a non-uniform vertical profile for these compounds.

\subsubsection{Nitrogen Trifluoride $\left(\mathrm{NF}_{3}\right)$}

[191] There is one study of the RE for nitrogen trifluoride in the literature. Robson et al. [2006] calculated a cloudy-sky adjusted radiative forcing of $0.21 \mathrm{~W} \mathrm{~m}^{-2} \mathrm{ppb}^{-1}$ by using a combination of line-by-line and narrow band radiative transfer models, and this value has been used in IPCC and WMO assessments (since WMO [2007]). Earlier assessments reported a much lower value of $0.13 \mathrm{~W} \mathrm{~m}^{-2} \mathrm{ppb}^{-1}$ (instantaneous RE), but these calculations were based on incomplete cross-section data. We have used the spectrum from Robson et al. [2006] and calculated a RE value of $0.20 \mathrm{~W} \mathrm{~m}^{-2} \mathrm{ppb}^{-1}$ (Tables 12 and 13), which is consistent (within 5\% difference) with AR4. Since AR4, the lifetime of $\mathrm{NF}_{3}$ has been studied by Prather and Hsu [2008] who suggest a much shorter lifetime of 550 years, partly due to inclusion of the $\mathrm{O}\left({ }^{1} \mathrm{D}\right)+\mathrm{NF}_{3}$ reaction, compared to the 740 years recommended in AR4. WMO [2011] used an updated rate constant for the $\mathrm{O}\left({ }^{1} \mathrm{D}\right)$ reaction to obtain a lifetime of 500 years, which is the value we have used here. It should be noted that a very recent study by Papadimitriou et al. [2013] measured the temperature dependence of the $\mathrm{NF}_{3}$ UV absorption spectrum and suggested a longer lifetime for $\mathrm{NF}_{3}$ of 585 years $( \pm 20 \%)$.

\subsubsection{Sulfur hexafluoride $\left(\mathrm{SF}_{6}\right)$}

[192] Previous studies of the RE for sulfur hexafluoride are in the range of $0.49-0.68 \mathrm{~W} \mathrm{~m}^{-2} \mathrm{ppb}^{-1}$ (mean: $0.56 \mathrm{~W}$ $\mathrm{m}^{-2} \mathrm{ppb}^{-1}$ ) [Jain et al., 2000; Myhre and Stordal, 1997; Zhang et al., 2011a]. Zhang et al. [2011a] estimated a much higher RE than the other studies, and this was also the case for several of the HFCs calculated by Zhang et al. [2011b] (see discussion of HFC-125 in section 4.1.3). AR4 adopted a RE of $0.52 \mathrm{~W} \mathrm{~m}^{-2} \mathrm{ppb}^{-1}$ from Myhre and Stordal [1997], while we calculate a $10 \%$ higher RE value of $0.57 \mathrm{~W}$ $\mathrm{m}^{-2} \mathrm{ppb}^{-1}$ (range: $0.54-0.59 \mathrm{~W} \mathrm{~m}^{-2} \mathrm{ppb}^{-1}$ ) using absorption cross sections from the GEISA and HITRAN databases (Tables 12 and 13).

\subsubsection{3. (Trifluoromethyl)sulfur pentafluoride $\left(\mathrm{SF}_{5} \mathrm{CF}_{3}\right)$}

[193] Previous reports of RE of (trifluoromethyl)sulfur pentafluoride are in the range of $0.57-0.59 \mathrm{~W} \mathrm{~m}^{-2} \mathrm{ppb}^{-1}$ (mean: $0.58 \mathrm{~W} \mathrm{~m}^{-2} \mathrm{ppb}^{-1}$ ) [Nielsen et al., 2002; Sihra et al., 2001; Sturges et al., 2000], and AR4 adopted the $\mathrm{RE}$ of $0.57 \mathrm{~W} \mathrm{~m}^{-2} \mathrm{ppb}^{-1}$ from Sturges et al. [2000]. We calculate a mean $\mathrm{RE}$ value of $0.59 \mathrm{~W} \mathrm{~m}^{-2} \mathrm{ppb}^{-1}$ (range: $0.58-0.61 \mathrm{~W} \mathrm{~m}^{-2} \mathrm{ppb}^{-1}$ ), consistent (within $5 \%$ difference) with the AR4, using absorption cross sections from two sources [Nielsen et al., 2002; Rinsland et al., 2003] (Tables 12 and 13). Both of these spectra include an absorption feature at $612.5 \mathrm{~cm}^{-1}$ which was not included in the measurements of Sturges et al. [2000], and this explains the slightly higher RE calculated here.

\subsubsection{Sulfuryl fluoride $\left(\mathrm{SO}_{2} \mathrm{~F}_{2}\right)$}

[194] Previous reports of RE of sulfuryl fluoride are in the range of $0.20-0.22 \mathrm{~W} \mathrm{~m}^{-2} \mathrm{ppb}^{-1}$ (mean: $0.21 \mathrm{~W} \mathrm{~m}^{-2} \mathrm{ppb}^{-1}$ ) [Andersen et al., 2009; Papadimitriou et al., 2008b]. We calculate a RE value of $0.20 \mathrm{~W} \mathrm{~m}^{-2} \mathrm{ppb}^{-1}$ using the absorption spectrum from Andersen et al. [2009] (Tables 12 and 13) - in good agreement with the previous literature.

\subsubsection{PFC-14 $\left(\mathrm{CF}_{4}\right)$}

[195] Previous reports of the RE of PFC-14 are in the range of $0.08-0.12 \mathrm{~W} \mathrm{~m}^{-2} \mathrm{ppb}^{-1}$ (mean: $0.10 \mathrm{~W} \mathrm{~m}^{-2}$ $\mathrm{ppb}^{-1}$ ) [Bravo et al., 2010b; Hurley et al., 2005; Jain et al., 2000; Myhre and Stordal, 1997; Roehl et al., 1995; Sihra et al., 2001; Zhang et al., 2011a]. Bravo et al. [2010b] report a relatively low RE value of $0.08 \mathrm{~W}$ $\mathrm{m}^{-2} \mathrm{ppb}^{-1}$ (instantaneous RE) from their B3LYP/6$31 \mathrm{G}^{* *}$ calculations, but it should be noted that $\mathrm{CF}_{4}$ was part of the training set used to determine corrections to band positions. AR4 adopted a RE of $0.10 \mathrm{~W} \mathrm{~m}^{-2} \mathrm{ppb}^{-1}$ from Hurley et al. [2005], and we calculate a similar mean $\mathrm{RE}$ of $0.09 \mathrm{~W} \mathrm{~m}^{-2} \mathrm{ppb}^{-1}$ (range: $0.09-0.10 \mathrm{~W} \mathrm{~m}^{-2} \mathrm{ppb}^{-1}$ ) when using absorption data from Hurley et al. [2005] (only the Ford data, and not the M.S.F./R.A.L. data) and from the HITRAN database (Tables 12 and 13). Interestingly, as PFC-14 has a very strong and narrow absorption band centered near $1280 \mathrm{~cm}^{-1}$, which is close to the edge of the atmospheric window region, the spectral resolution is more important for PFC-14 than for other compounds. When using a $10 \mathrm{~cm}^{-1}$ resolution instead of $1 \mathrm{~cm}^{-1}$ in our calculations, the RE of PFC-14 is underestimated by $\sim 8 \%$, as shown in Figure 6 and briefly discussed in section 3.3.1. For PFC-14, we have carried out explicit simulations using the Oslo LBL model and derived a $10.5 \%$ increase to account for stratospheric temperature adjustment (see section 3.3.3 for details), and this value has been used (rather than the generic 10\% increase) in the calculation of the RE value of $0.09 \mathrm{~W} \mathrm{~m}^{-2} \mathrm{ppb}^{-1}$.

\subsubsection{6. $P F C-116\left(\mathrm{C}_{2} \mathrm{~F}_{6}\right)$}

[196] Previous reports of RE of PFC-116 are in the range of $\quad 0.25-0.35 \mathrm{~W} \mathrm{~m}^{-2} \mathrm{ppb}^{-1}$ (mean: $0.27 \mathrm{~W} \mathrm{~m}^{-2} \mathrm{ppb}^{-1}$ ) [Bravo et al., 2010b; Highwood and Shine, 2000; Myhre and Stordal, 1997; Roehl et al., 1995; Sihra et al., 2001; Zhang et al., 2011a]. Bravo et al. [2010b] report a value for RE of $0.23 \mathrm{~W} \mathrm{~m}^{-2} \mathrm{ppb}^{-1}$ (instantaneous RE) from their B3LYP/6-31G** calculations, but it should be noted that $\mathrm{C}_{2} \mathrm{~F}_{6}$ was part the training set used to determine corrections to band positions. Papasavva et al. [1997] obtained an ab initio RE value of $0.33 \mathrm{~W} \mathrm{~m}^{-2} \mathrm{ppb}^{-1}$ using the MP2 with a wavenumber scaling factor of 0.9427 . In AR4, a RE value of $0.26 \mathrm{~W} \mathrm{~m}^{-2} \mathrm{ppb}^{-1}$ was used and is taken from Highwood and Shine [2000]. We calculate a mean RE value of $0.25 \mathrm{~W} \mathrm{~m}^{-2} \mathrm{ppb}^{-1}$ (range: $0.24-0.26 \mathrm{~W} \mathrm{~m}^{-2}$ $\mathrm{ppb}^{-1}$ ), which is in good agreement with AR4, and we have used absorption cross sections from three sources [Bravo et al., 2010b; Sihra et al., 2001; Zou et al., 2004] (Tables 12 and 13). It should be noted here that as both Bravo et al. [2010b] and Highwood and Shine [2000] present absorption data from M.S.F./R.A.L., we here choose the most recent spectrum measurement from Bravo et al. [2010b]. Also note that the Zou et al. [2004] spectrum does not include the absorption band located at $715 \mathrm{~cm}^{-1}$ but this had negligible impact on the RE, thus we keep this spectrum in our calculation. 


\subsubsection{PFC-c216 (c- $\left.\mathrm{C}_{3} \mathrm{~F}_{6}\right)$}

[197] Assessments since $W M O$ [1999] have used a RE for PFC-c216 of $0.42 \mathrm{~W} \mathrm{~m}^{-2} \mathrm{ppb}^{-1}$ which is reported to have been taken from Papasavva et al. [1997]. However, Papasavva et al. [1997] did not report a RE for this compound and so the origin of the value used in AR4 is unclear. The only estimate of the RE for $\mathrm{c}-\mathrm{C}_{3} \mathrm{~F}_{6}$ that we are aware of is from a calculation (B3LYP/6-31 $\left.\mathrm{G}^{* *}\right)$, which gives an instantaneous RE of $0.21 \mathrm{~W} \mathrm{~m}^{-2} \mathrm{ppb}^{-1}$ [Bravo et al., 2010b]. An updated RE (assuming a 10\% increase to account for stratospheric temperature adjustment) and GWP values for PFC-c216 are given in Table 13.

\subsubsection{PFC-218 $\left(\mathrm{C}_{3} \mathrm{~F}_{8}\right)$}

[198] Previous reports of RE of PFC-218 are in the range of $\quad 0.26-0.28 \mathrm{~W} \mathrm{~m}^{-2} \mathrm{ppb}^{-1}$ (mean: $0.27 \mathrm{~W} \mathrm{~m}^{-2} \mathrm{ppb}^{-1}$ ) [Bravo et al., 2010b; Roehl et al., 1995; Sihra et al., 2001]. Bravo et al. [2010b] also report an instantaneous $\mathrm{RE}$ value of $0.27 \mathrm{~W} \mathrm{~m}^{-2} \mathrm{ppb}^{-1}$ from their B3LYP/6-31G** calculations - consistent with their instantaneous RE derived from experimental cross sections. AR4 reports a RE of $0.26 \mathrm{~W} \mathrm{~m}^{-2} \mathrm{ppb}^{-1}$ which is taken from Roehl et al. [1995]. We calculate a slightly higher mean RE value of $0.28 \mathrm{~W} \mathrm{~m}^{-2}$ $\mathrm{ppb}^{-1}$ (range: $0.27-0.28 \mathrm{~W} \mathrm{~m}^{-2} \mathrm{ppb}^{-1}$ ) using experimental absorption cross sections from two sources [Bravo et al., 2010b; Sihra et al., 2001] (Tables 12 and 13). The higher $\mathrm{RE}$ calculated here can be explained by the much lower integrated absorption cross section in the PFC-218 spectrum of Roehl et al. [1995] compared to other studies (see Table 12).

\subsubsection{9. $P F C-318\left(\mathrm{c}-\mathrm{C}_{4} \mathrm{~F}_{8}\right)$}

[199] Previous reports of RE of PFC-318 based on experimentally measured absorption spectra are in the range of $\quad 0.31-0.32 \mathrm{~W} \mathrm{~m}^{-2} \mathrm{ppb}^{-1}$ (mean: $0.31 \mathrm{~W} \mathrm{~m}^{-2} \mathrm{ppb}^{-1}$ ) [Highwood and Shine, 2000; Sihra et al., 2001; Vasekova et al., 2006], while Bravo et al. [2010b] report a value for $\mathrm{RE}$ of $0.30 \mathrm{~W} \mathrm{~m}^{-2} \mathrm{ppb}^{-1}$ from their B3LYP/6-31G** calculations, in good agreement with the values derived from the experimentally measured spectra. AR4 reports a RE of $0.32 \mathrm{~W} \mathrm{~m}^{-2} \mathrm{ppb}^{-1}$ taken from Highwood and Shine [2000]. We have used the absorption spectrum from the same study and our calculations give a RE value of $0.32 \mathrm{~W} \mathrm{~m}^{-2} \mathrm{ppb}^{-1}$ which is in agreement with AR4 (Tables 12 and 13).

\subsubsection{PFC-31-10 $\left(\mathrm{C}_{4} \mathrm{~F}_{10}\right)$}

[200] Previous estimates of the RE for PFC-31-10 based on experimentally measured absorption spectra are in the range of 0.33-0.37 W m mpb $^{-1}$ (mean: $0.36 \mathrm{~W} \mathrm{~m}^{-2} \mathrm{ppb}^{-1}$ ) [Bravo et al., 2010b; Roehl et al., 1995; Sihra et al., 2001]. Bravo et al. [2010b] also report an instantaneous RE of $0.34 \mathrm{~W} \mathrm{~m}^{-2}$ $\mathrm{ppb}^{-1}$ from their B3LYP/6-31G** calculations-consistent with their instantaneous RE derived from experimental cross sections. AR4 report a RE of $0.33 \mathrm{~W} \mathrm{~m}^{-2} \mathrm{ppb}^{-1}$ which is taken from Roehl et al. [1995]. We calculate a higher RE value of $0.36 \mathrm{~W} \mathrm{~m}^{-2} \mathrm{ppb}^{-1}$ when using the experimental absorption cross section from Bravo et al. [2010b] (Tables 12 and 13). As for PFC-218, the higher RE calculated here can be explained by the lower integrated absorption cross section in Roehl et al. [1995] compared to Bravo et al. [2010b]. Updated values of recommended RE and GWP for PFC-31-10 are given in Table 13.

\subsubsection{Perfluorocyclopentene $\left(c-C_{5} F_{8}\right)$}

[201] Previous reports of $\mathrm{RE}$ of perfluorocyclopentene are in the range of $0.22-0.32 \mathrm{~W} \mathrm{~m}^{-2} \mathrm{ppb}^{-1}$ (mean: $0.27 \mathrm{~W}$ $\mathrm{m}^{-2} \mathrm{ppb}^{-1}$ ) [Bravo et al., 2010b; Vasekova et al., 2006]. Part of the reason for the large difference between these two studies is that Vasekova et al. [2006] applied a factor of 0.8 to account for non-homogeneous vertical profile, while Bravo et al. [2010b] assumed a constant vertical profile. No new calculations have been carried out here for this compound, and to provide recommended RE, we therefore use the average of the instantaneous REs reported in the literature $(0.30 \mathrm{~W}$ $\mathrm{m}^{-2} \mathrm{ppb}^{-1}$ ) and account for stratospheric temperature adjustment as well as non-homogeneous mixing (see sections 3.3.2 and 3.3.4) and end up with a RE value of $0.08 \mathrm{~W} \mathrm{~m}^{-2}$ $\mathrm{ppb}^{-1}$. The only lifetime reported in the literature for this compound is 1.0 year from Vasekova et al. [2006] who refer to a non-traceable source. Considering that Cometto et al. [2010] estimated a lifetime of only 31 days for $\mathrm{CF}_{3} \mathrm{CF}=\mathrm{CFCF}_{3}$, we think that the lifetime from Vasekova et al. [2006] may be too long and instead use a value of 31 days when applying the lifetime correction and calculating the GWP value.

\subsubsection{PFC-41-12 (n- $\left.C_{5} F_{12}\right)$}

[202] Previous reports of RE of PFC-41-12 are in the range of $0.40-0.41 \mathrm{~W} \mathrm{~m}^{-2} \mathrm{ppb}^{-1}$ (mean: $0.41 \mathrm{~W} \mathrm{~m}^{-2} \mathrm{ppb}^{-1}$ ) [Bravo et al., 2010b; Roehl et al., 1995]. Bravo et al. [2010b] also report an instantaneous RE of $0.40 \mathrm{~W} \mathrm{~m}^{-2}$ $\mathrm{ppb}^{-1}$ from their B3LYP/6-31G** calculations - in agreement with their instantaneous RE estimate based on experimental absorption cross sections (it should be noted that $\mathrm{C}_{5} \mathrm{~F}_{12}$ was part the training set used to determine corrections to band positions). AR4 has used a value of $0.41 \mathrm{~W} \mathrm{~m}^{-2}$ $\mathrm{ppb}^{-1}$ which is taken from Roehl et al. [1995], and we calculate the exact same RE value when using the experimental absorption cross section from Bravo et al. [2010b] (Tables 12 and 13).

\subsubsection{PFC-51-14 (n- $\left.\mathrm{C}_{6} \mathrm{~F}_{14}\right)$}

[203] Previous reports of RE of PFC-51-14 are in the range of $0.43-0.49 \mathrm{~W} \mathrm{~m}^{-2} \mathrm{ppb}^{-1}$ (mean: $0.46 \mathrm{~W} \mathrm{~m}^{-2} \mathrm{ppb}^{-1}$ ) [Bravo et al., 2010b; Roehl et al., 1995]. Bravo et al. [2010b] also report an instantaneous RE of $0.42 \mathrm{~W} \mathrm{~m}^{-2} \mathrm{ppb}^{-1}$ from their B3LYP/6-31G** calculations, but it should be noted that $\mathrm{C}_{6} \mathrm{~F}_{14}$ was part of the training set used to determine corrections to band positions. AR4 report a RE of $0.49 \mathrm{~W} \mathrm{~m}^{-2} \mathrm{ppb}^{-1}$ which is taken from Roehl et al. [1995]. We calculate a RE value of $0.44 \mathrm{~W} \mathrm{~m}^{-2} \mathrm{ppb}^{-1}$ when using the experimental absorption cross section from Bravo et al. [2010b] (Tables 12 and 13). The lower RE value calculated here is presumably due to the lower integrated absorption cross section in Bravo et al. [2010b] than in Roehl et al. [1995] (Table 12).

\subsubsection{PFC-61-16 (n-C $\left.\mathrm{F}_{\mathbf{1 6}}\right)$}

[204] Ivy et al. [2012] calculated the RE of PFC-61-16 using experimental absorption data and derived a value of $0.48 \mathrm{~W} \mathrm{~m}^{-2} \mathrm{ppb}^{-1}$. Bravo et al. [2010b] reported a value of $0.45 \mathrm{~W} \mathrm{~m}^{-2} \mathrm{ppb}^{-1}$ using absorption data from B3LYP/ $6-31 \mathrm{G}^{* *}$ calculations, in reasonable agreement with the result obtained using experimental absorption data. We have used the absorption spectrum from Ivy et al. [2012] and calculated a RE value of $0.50 \mathrm{~W} \mathrm{~m}^{-2} \mathrm{ppb}^{-1}$ (Tables 12 and 13). 


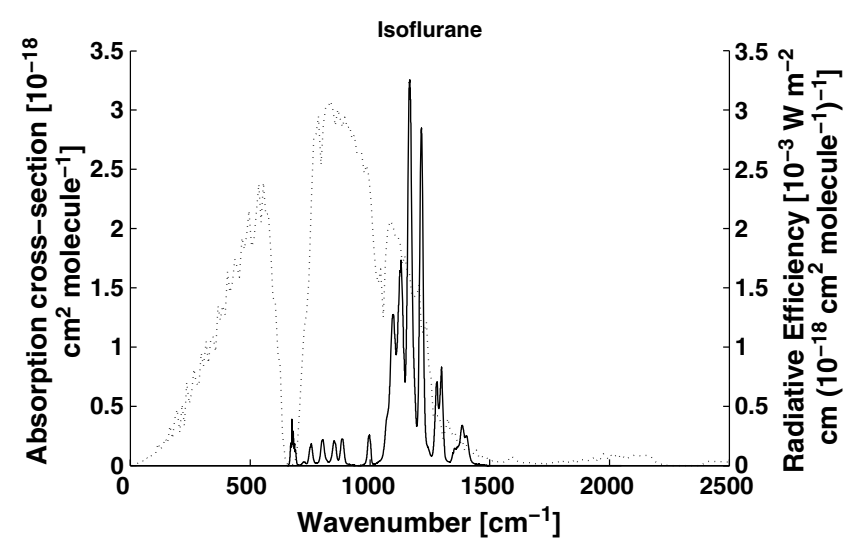

Figure 17. Absorption spectrum of isoflurane at $296 \mathrm{~K}$ in 933 mbar (700 Torr) air diluent from Andersen et al. [2010c] (solid line) and Oslo simulation of Pinnock curve (dotted line).

\subsubsection{PFC-71-18 $\left(\mathrm{C}_{\mathbf{8}} \mathrm{F}_{\mathbf{1 8}}\right)$}

[205] Previous experimental results for RE of PFC-71-18 are in the range of $0.50-0.57 \mathrm{~W} \mathrm{~m}^{-2} \mathrm{ppb}^{-1}$ (mean: $0.53 \mathrm{~W}$ $\mathrm{m}^{-2} \mathrm{ppb}^{-1}$ ) [Bravo et al., 2010b; Ivy et al., 2012]. We calculate a mean $\mathrm{RE}$ value of $0.55 \mathrm{~W} \mathrm{~m}^{-2} \mathrm{ppb}^{-1}$ (range: $0.51-0.59 \mathrm{~W} \mathrm{~m}^{-2} \mathrm{ppb}^{-1}$ ) when using absorption cross sections from both of these studies (Tables 12 and 13). The large range in our calculations is caused by the large difference in the integrated absorption cross sections of Bravo et al. [2010b] and Ivy et al. [2012] (Table 12). The lifetime of 3,000 years is taken from Bravo et al. [2010b], who also report a value for $\mathrm{RE}$ of $0.50 \mathrm{~W} \mathrm{~m}^{-2} \mathrm{ppb}^{-1}$ from their B3LYP/6-31G** calculations, but it should be noted that PFC-71-18 was part of the training set used to determine corrections to band positions.

\subsubsection{Perfluorodecalin (mixed $C_{10} F_{18}, Z-C_{10} F_{18}$, $\mathrm{E}-\mathrm{C}_{\mathbf{1 0}} \mathrm{F}_{\mathbf{1 8}}$ )}

[206] The RE of perfluorodecalin has been reported to be $0.56 \mathrm{~W} \mathrm{~m}^{-2} \mathrm{ppb}^{-1}$ [Shine et al., 2005b], and this value was adopted by AR4. We calculate a RE value of $0.55 \mathrm{~W}$ $\mathrm{m}^{-2} \mathrm{ppb}^{-1}$ using the absorption cross section from Shine et al. [2005b] (Tables 12 and 13), which was derived experimentally in the wavenumber range of $600-1500 \mathrm{~cm}^{-1}$, while the absorption bands were calculated in the lower wavenumber range of $0-600 \mathrm{~cm}^{-1}$. Our calculations for the isomers $Z-\mathrm{C}_{10} \mathrm{~F}_{18}$ and $E-\mathrm{C}_{10} \mathrm{~F}_{18}$ yield REs (in the wavenumber range of $600-1500 \mathrm{~cm}^{-1}$ ) of 0.56 and $0.48 \mathrm{~W}$ $\mathrm{m}^{-2} \mathrm{ppb}^{-1}$, respectively. Bravo et al. [2010b] report instantaneous $\mathrm{RE}$ values of $0.58,0.60$ and $0.56 \mathrm{~W} \mathrm{~m}^{-2} \mathrm{ppb}^{-1}$ for $\mathrm{C}_{10} \mathrm{~F}_{18}$ (mixed), Z- $\mathrm{C}_{10} \mathrm{~F}_{18}, E-\mathrm{C}_{10} \mathrm{~F}_{18}$, respectively, from their B3LYP/6-31G** calculations.

\subsubsection{7. $P F C-1114\left(C_{2}=C_{2}\right)$}

[207] Previous results for RE of PFC-1114 are in the range of $\quad 0.01-0.11 \mathrm{~W} \mathrm{~m}^{-2} \mathrm{ppb}^{-1} \quad$ (mean: $0.06 \mathrm{~W} \mathrm{~m}^{-2} \mathrm{ppb}^{-1}$ ) [Acerboni et al., 2001; Drage et al., 2006]. (Acerboni et al. [2001] used vertical profiles from a CTM distribution, while Drage et al. [2006] assumed a constant profile.) Due to the short lifetime of 1.1 days, we calculate a RE value which rounds to $0.00 \mathrm{~W} \mathrm{~m}^{-2} \mathrm{ppb}^{-1}$ when using the absorption cross section from Acerboni et al. [2001] (Tables 12 and 13) and the correction factor for non-uniform mixing discussed in section 3.3.4.

\subsubsection{8. $P F C-1216\left(\mathrm{CF}_{3} \mathrm{CF}=\mathrm{CF}_{2}\right)$}

[208] Only one study has estimated RE due to PFC-1216, with a value $0.04 \mathrm{~W} \mathrm{~m}^{-2} \mathrm{ppb}^{-1}$ [Acerboni et al., 2001] (vertical profiles from a CTM distribution were used). We have used their spectrum and calculated a $R E$ value of $0.01 \mathrm{~W} \mathrm{~m}^{-2} \mathrm{ppb}^{-1}$ when accounting for the nonhomogeneous vertical profile (Tables 12 and 13).

\subsubsection{Perfluorobuta-1,3-diene $\left(\mathrm{CF}_{2}=\mathrm{CFCF}=\mathrm{CF}_{2}\right)$}

[209] Previous reports of RE of Perfluorobuta-1,3-diene are in the range of $0.01-0.20 \mathrm{~W} \mathrm{~m}^{-2} \mathrm{ppb}^{-1}$ (mean: $0.11 \mathrm{~W}$ $\mathrm{m}^{-2} \mathrm{ppb}^{-1}$ ) [Acerboni et al., 2001; Bravo et al., 2010b]. (Acerboni et al. [2001] used vertical profiles from a CTM distribution while Bravo et al. [2010b] assumed a constant profile.) We calculate a RE value which rounds to $0.00 \mathrm{~W} \mathrm{~m}^{-2} \mathrm{ppb}^{-1}$ when using the absorption cross section from Acerboni et al. [2001] (Tables 12 and 13).

\subsubsection{Perfluorobut-1-ene $\left(\mathrm{CF}_{3} \mathrm{CF}_{2} \mathrm{CF}=\mathrm{CF}_{2}\right)$}

[210] Only one study has estimated RE due to perfluorobut1 -ene, with a value $0.29 \mathrm{~W} \mathrm{~m}^{-2} \mathrm{ppb}^{-1}$ Young et al. [2009a]. We calculate a RE value of $0.02 \mathrm{~W} \mathrm{~m}^{-2} \mathrm{ppb}^{-1}$ when using their absorption cross section, and account for stratospheric temperature adjustment and non-homogeneous distribution. A lifetime of 6 days has been used in the RE and GWP calculation for this compound, assuming that its lifetime is comparable to the lifetime of PFC-1216.

\subsubsection{Perfluorobut-2-ene $\left(\mathrm{CF}_{3} \mathrm{CF}=\mathrm{CFCF}_{3}\right)$}

[211] Previous reports of $\mathrm{RE}$ of perfluorobut-2-ene are in the range of $0.30-0.32 \mathrm{~W} \mathrm{~m}^{-2} \mathrm{ppb}^{-1}$ (mean: $0.31 \mathrm{~W}$ $\mathrm{m}^{-2} \mathrm{ppb}^{-1}$ ) [Cometto et al., 2010; Young et al., 2009a]. We calculate a RE value of $0.07 \mathrm{~W} \mathrm{~m}^{-2} \mathrm{ppb}^{-1}$ when using the absorption spectra and lifetime estimate (31 days) from Cometto et al. [2010], and accounting for stratospheric temperature adjustment and nonhomogeneous distribution.

\subsubsection{Other PFCs}

[212] In the sections above, recommended values of RE have been presented for the range of fully fluorinated compounds considered in AR4, along with a small number of others, where experimental data are available. In addition, Bravo et al. [2010b] report estimates of RE for a range of other PFCs, based on theoretical calculations.

\subsubsection{Halogenated Alcohols and Ethers}

[213] This is a very broad range of compounds with lifetimes stretching from days to centuries. The generally complex structure, compared to other compounds considered here, leads to a rich infrared absorption spectrum-Figure 17 shows the spectrum of isoflurane $\left(\mathrm{CHF}_{2} \mathrm{OCHClCF}\right)$, a molecule used as an inhalation anesthetic, which has absorption bands stretching across much of the infrared.

[214] Previously published absorption cross sections are listed in Table 14, while updated atmospheric lifetimes, radiative efficiencies, and 100 year GWP values for halogenated alcohols and ethers are presented in Table 15 and discussed below. In contrast to sections 4.1.1-4.1.6, not all compounds have their own individual piece of text in this section. For the purpose of presentation quality and brevity, some 
HODNEBROG ET AL.: HALOCARBON REVIEW

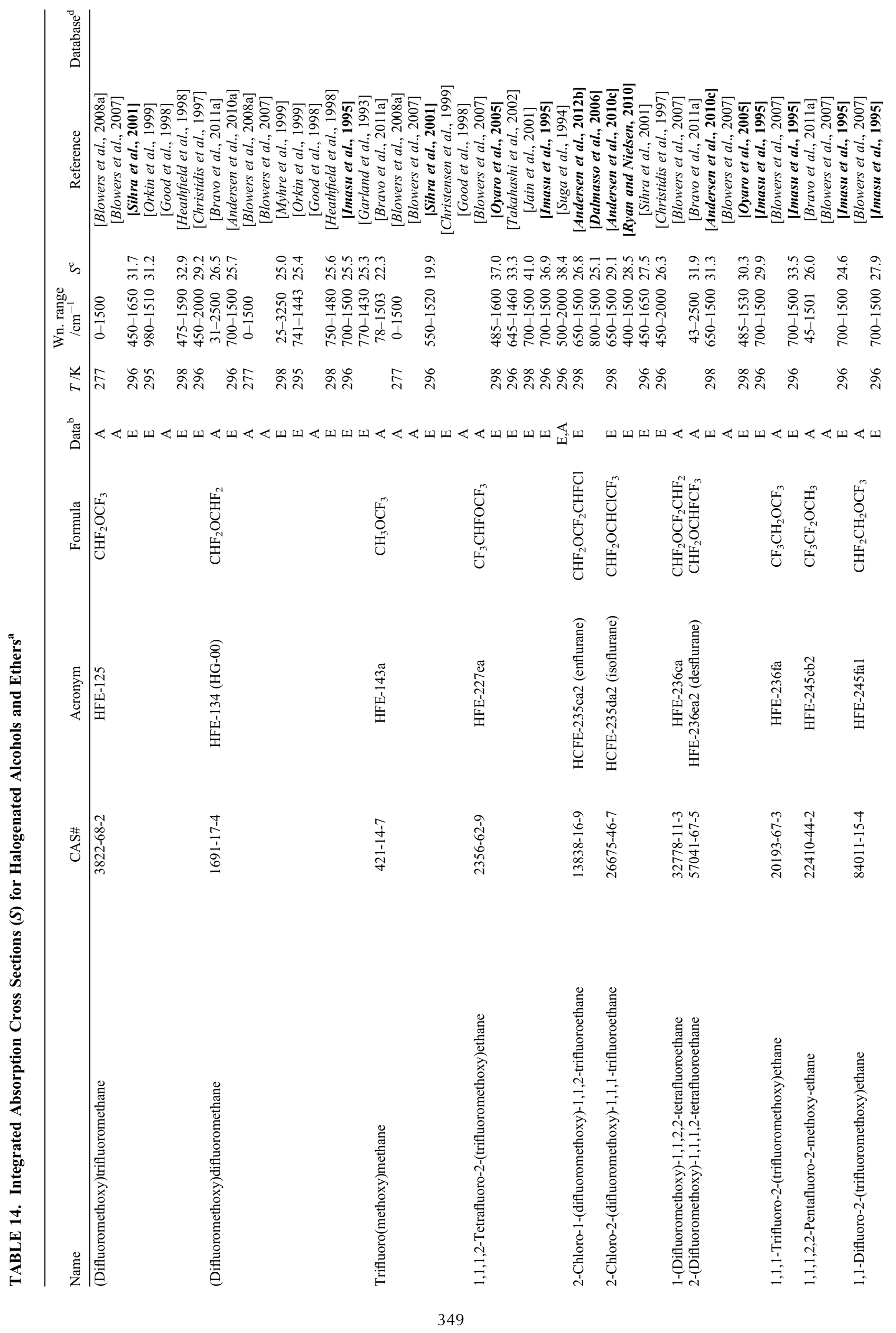


HODNEBROG ET AL.: HALOCARBON REVIEW

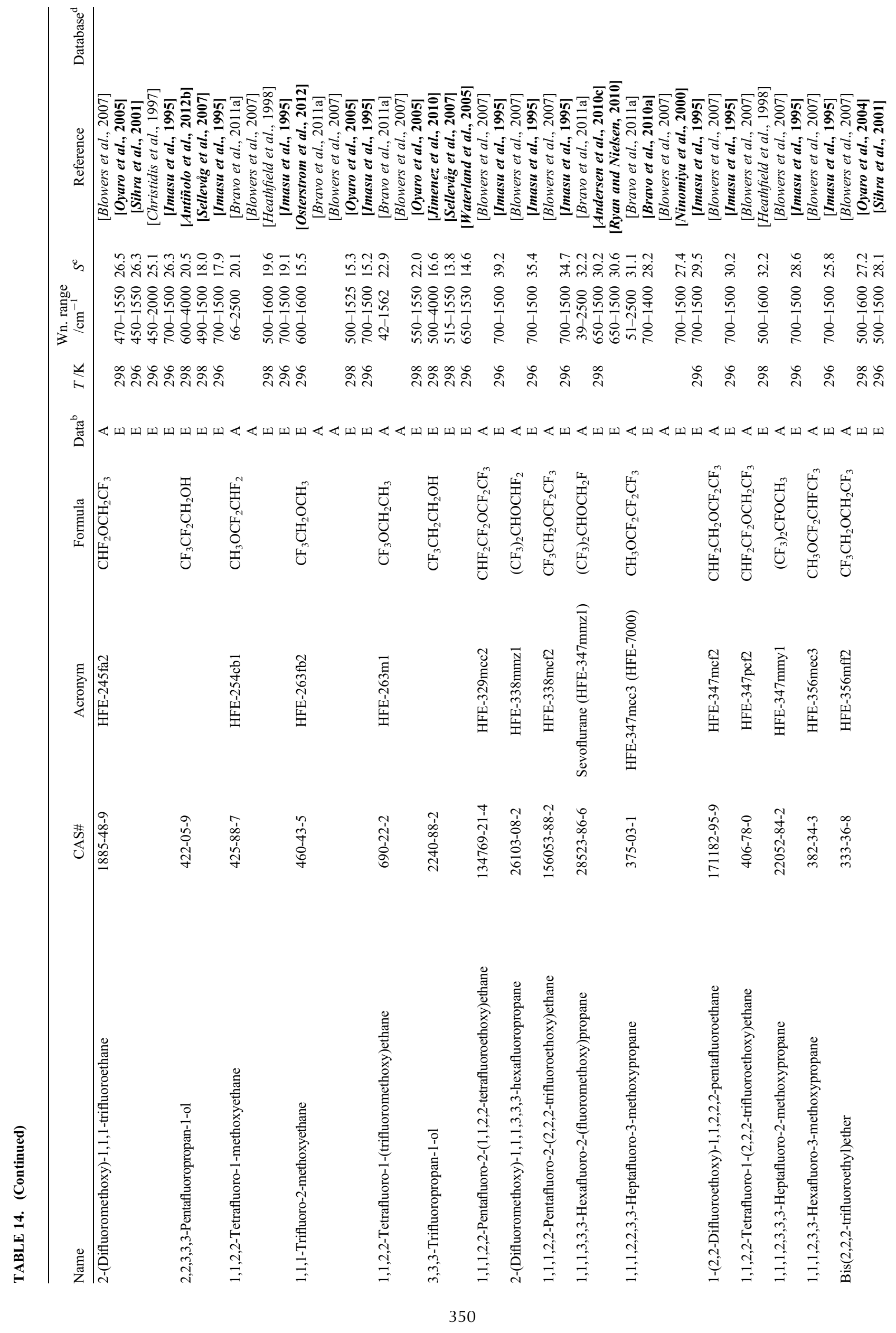


HODNEBROG ET AL.: HALOCARBON REVIEW

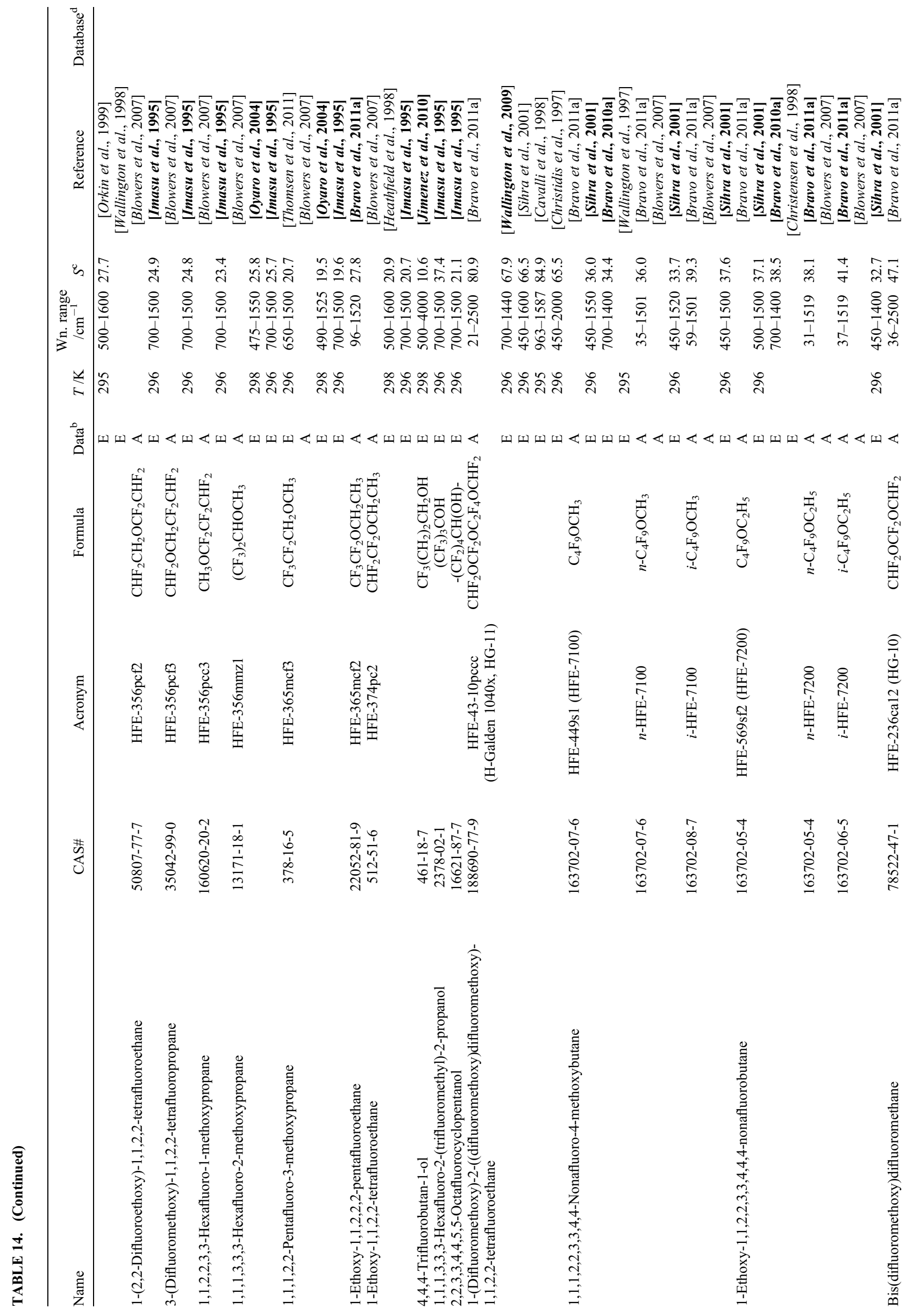


HODNEBROG ET AL.: HALOCARBON REVIEW

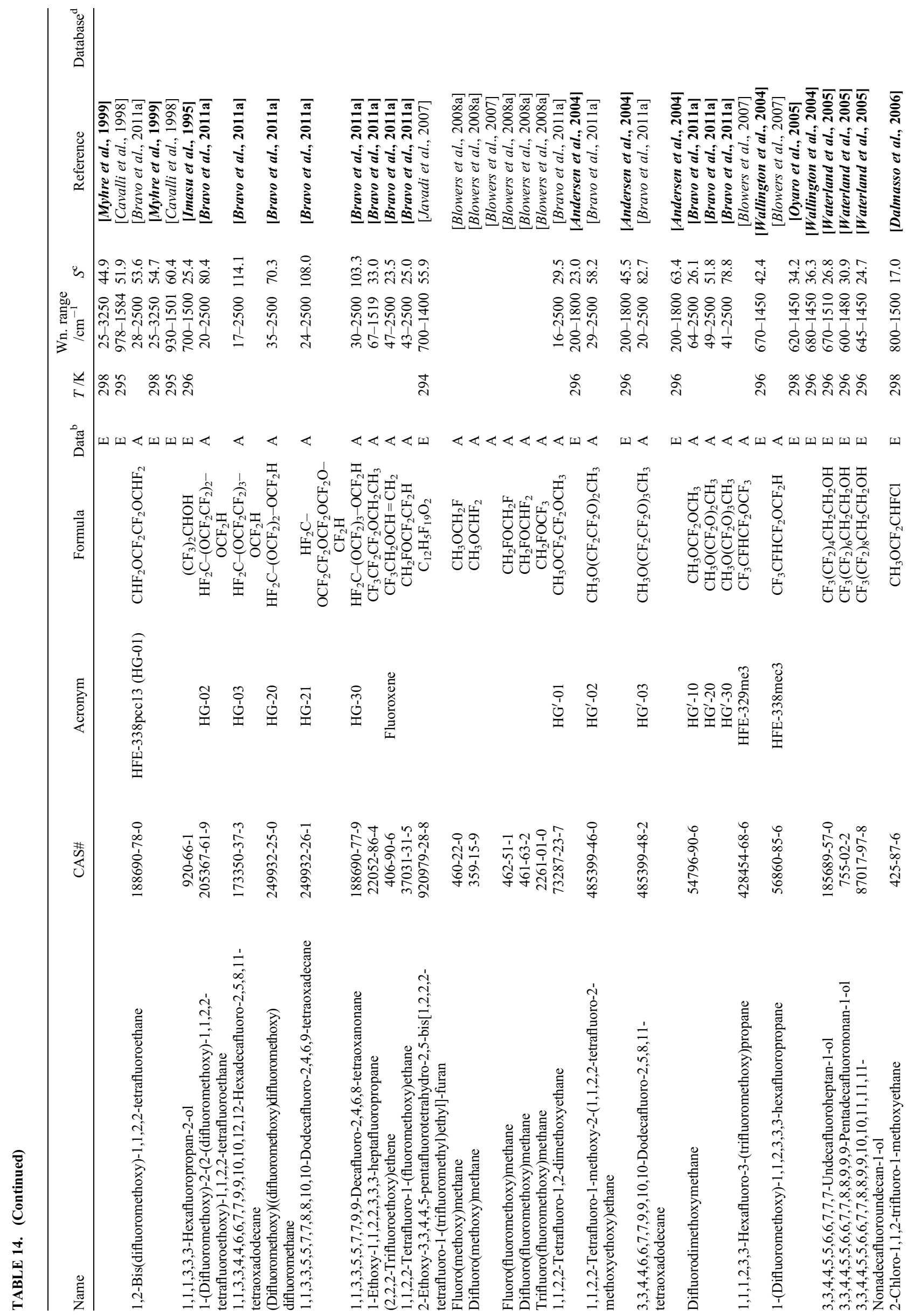


HODNEBROG ET AL.: HALOCARBON REVIEW




HODNEBROG ET AL.: HALOCARBON REVIEW

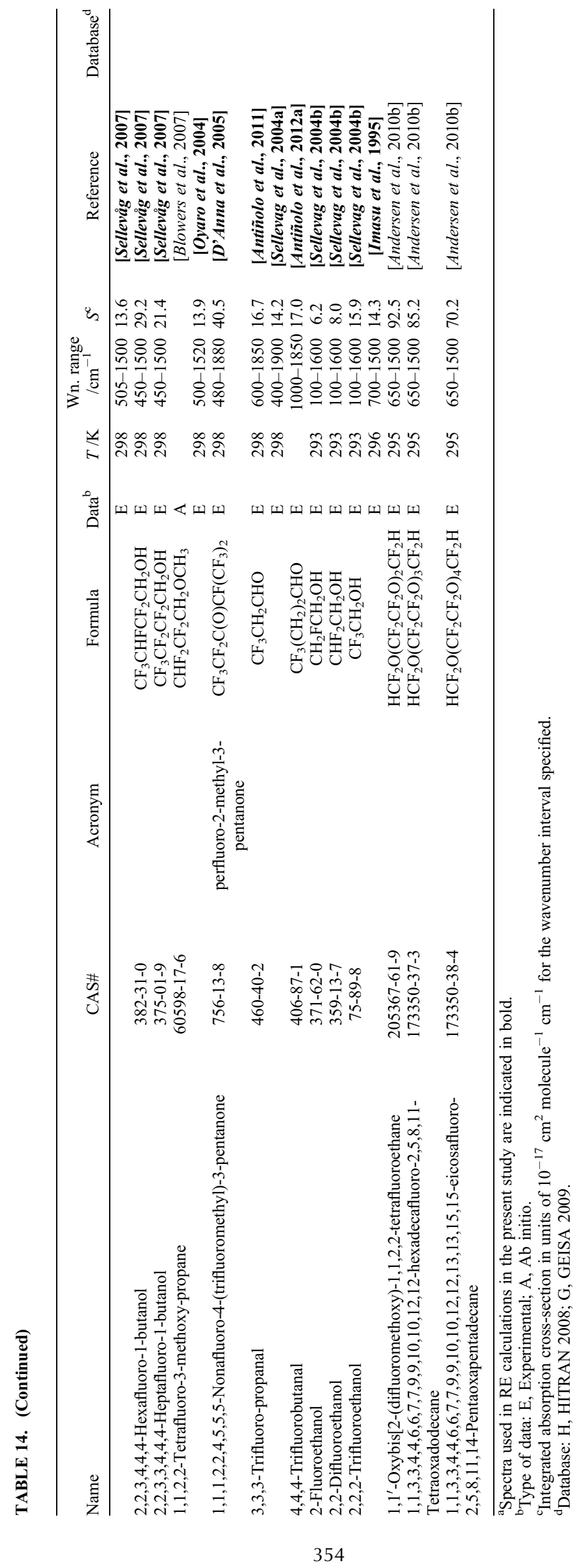




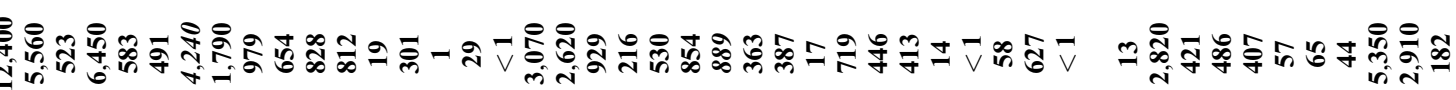

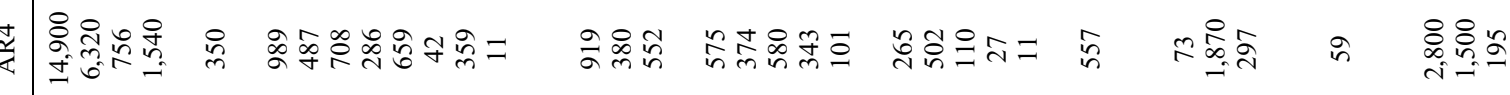

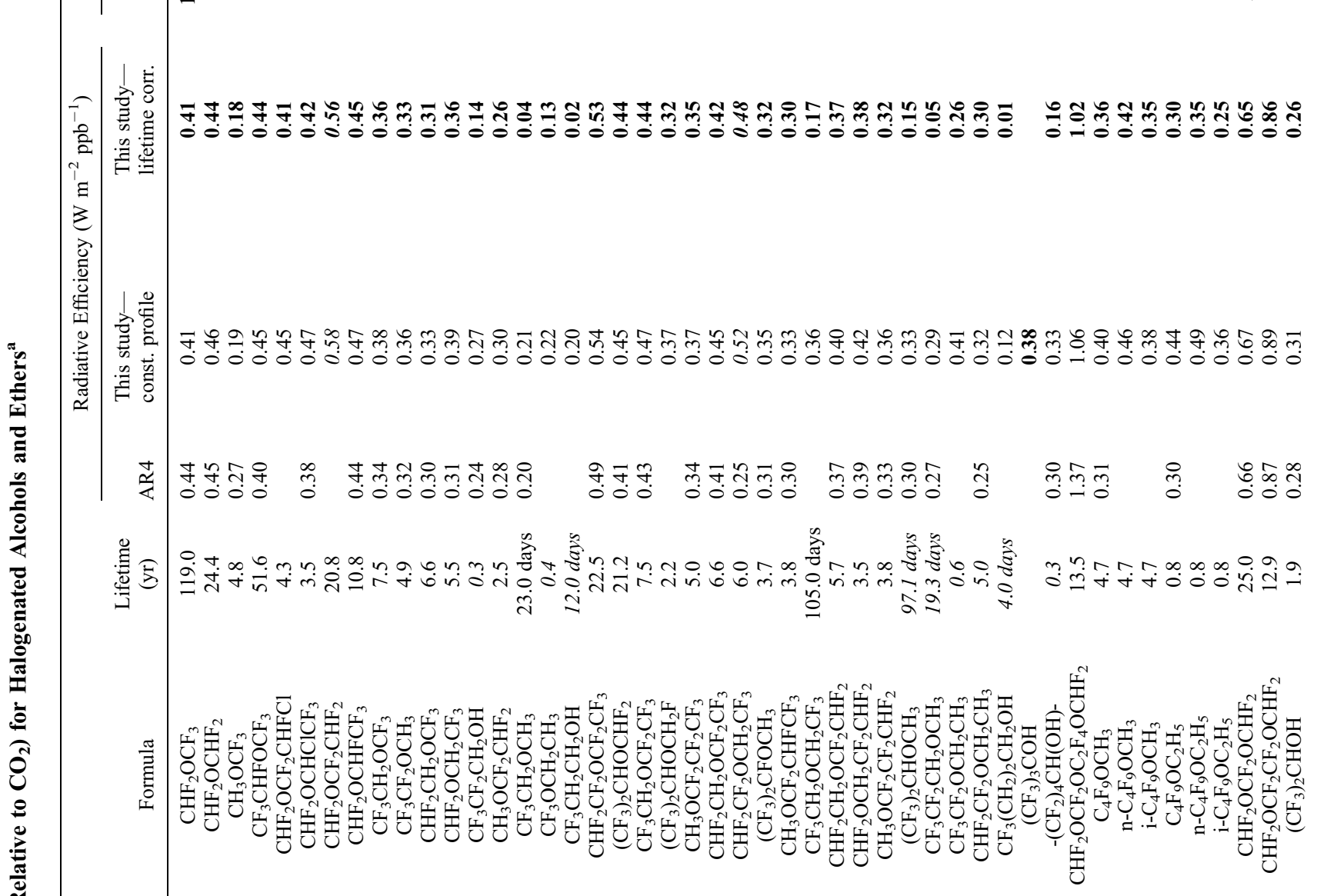

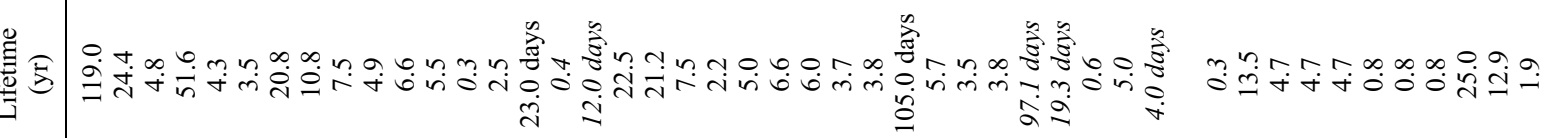

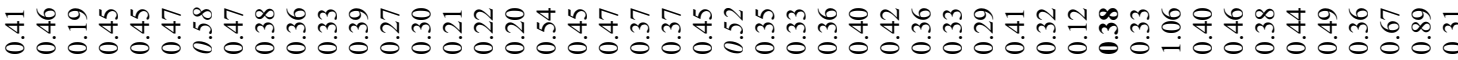


HODNEBROG ET AL.: HALOCARBON REVIEW

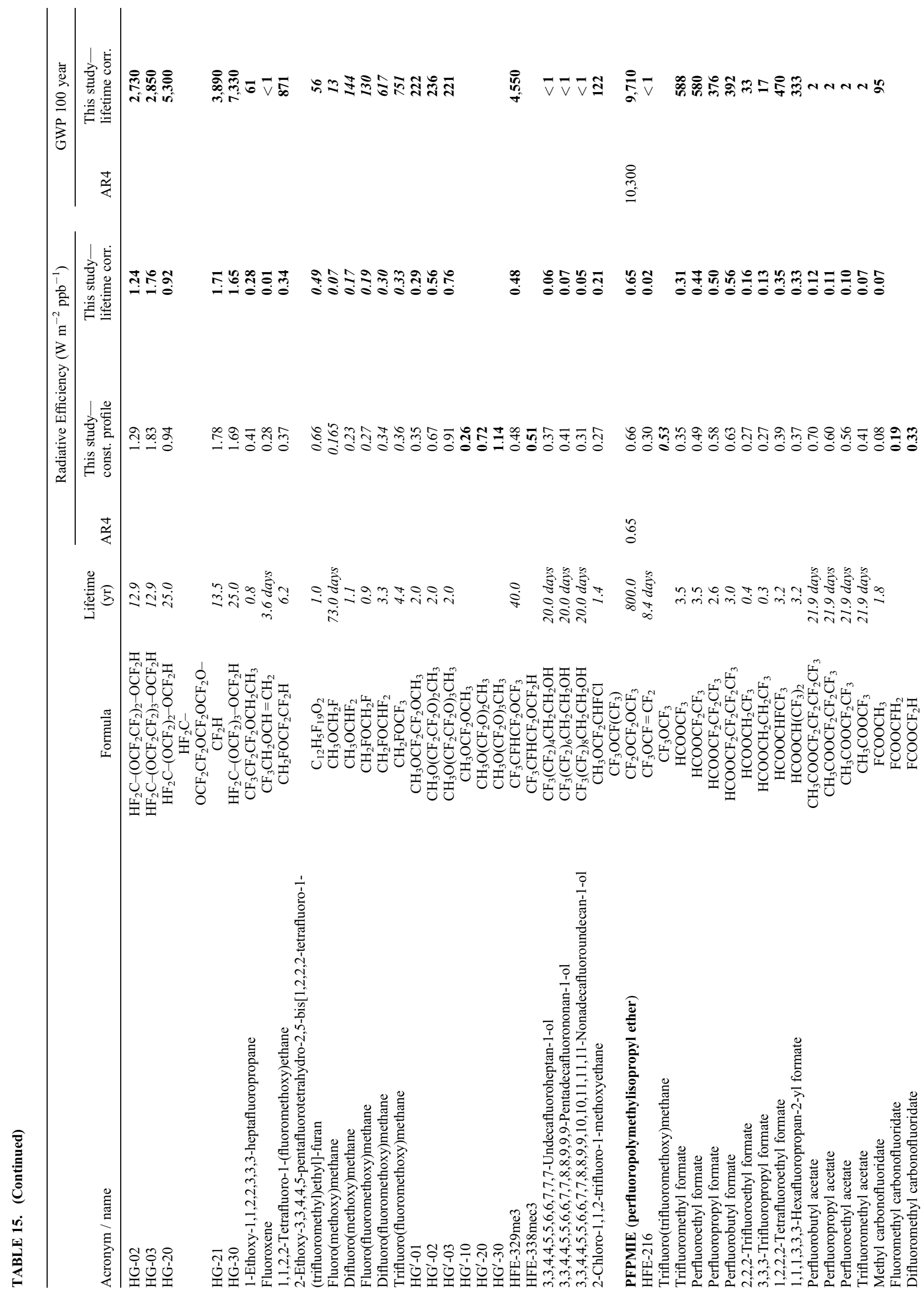


HODNEBROG ET AL.: HALOCARBON REVIEW

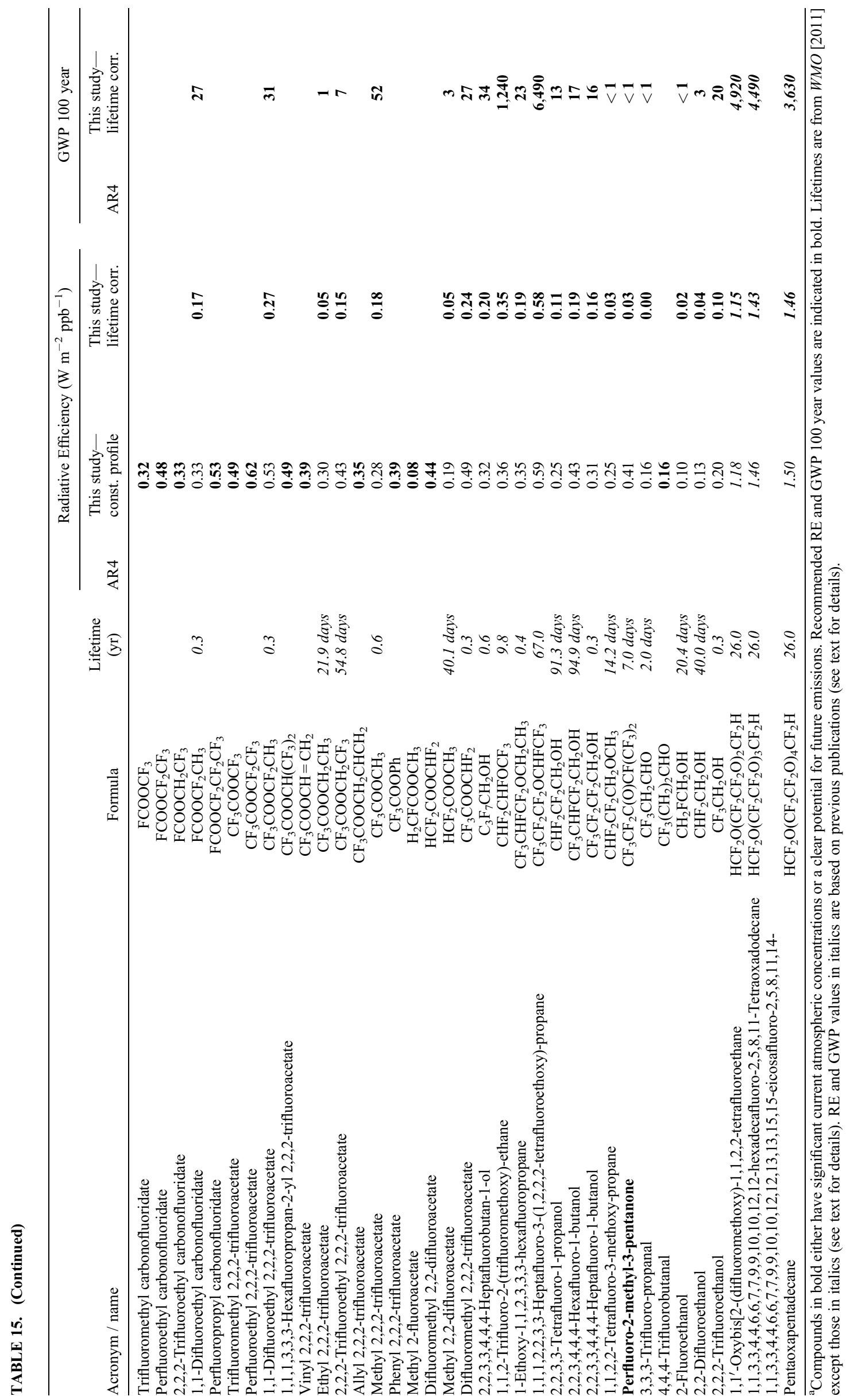


compounds are grouped together where we found it appropriate. However, all the information about previously published estimates (both based on experimental and ab initio absorption spectra) and results from our calculations can be found in Tables 14 and 15, and in Table S7 in the supporting information. With the exception of PFPMIE, which is lost by photolysis in the upper atmosphere [Young et al., 2006], the $S$-shaped fit from section 3.3.4 (equation (2) and dark blue curve in Figure 9) has been used to account for a nonuniform vertical profile and geographic distribution for all compounds presented in this subsection.

[215] In what follows, we focus particularly on the experimental studies. There have been ab initio studies from three groups [Blowers et al., 2007; 2008b; Bravo et al., 2011a; Good et al., 1998]. We can make the following general observations about these studies. The work from the group of Blowers tends to calculate REs that are significantly higher than those obtained from experimentally determined values. Differences are around $25 \%$, but can be as high as $40 \%$. This group does not adjust for atmospheric lifetimes, so the differences can appear greater. The calculations from Bravo et al. [2011a] tend to agree with experimental values within about $10-15 \%$, although the more sophisticated lifetime adjustment applied here can make the differences appear larger. However, REs calculated for the $\mathrm{HG}^{\prime}$ HFPEs are some $35 \%$ higher than experimental values, although it should be noted that only one group has studied these compounds experimentally [Andersen et al., 2004]. Good et al. [1998] examined only three compounds using a narrow band model; they obtain values that are somewhat higher than those using experimentally determined cross sections. In the text below, we do not discuss the ab initio calculations except where they provide the only RE values, or are of special note. Whenever RE values based on $a b$ initio calculations are presented, this has been clearly marked in the text.

[216] A large number of the compounds in this section were examined by Imasu et al. [1995], who reported both laboratory spectroscopy measurements and REs, calculated for a clearsky mid-latitude atmosphere. In $W M O$ [1999] (which became a source for REs used in many subsequent IPCC and WMO Ozone assessments), these were approximately converted to global-mean all-sky adjusted RE by taking their RE relative to Imasu et al's [1995] own CFC-11 calculation and then multiplying by the CFC-11 RE $\left(0.25 \mathrm{~W} \mathrm{~m}^{-2} \mathrm{ppb}^{-1}\right)$ used in $W M O$ [1999] (see footnote i of Table 10-6 of WMO [1999]). Henceforth in this section, we refer to these forcings as "Imasu et al. [1995] as modified by WMO [1999]." When referring to the Imasu et al. [1995] REs we renormalize the $W M O$ [1999] forcings to account for our recommended $4 \%$ increase in the CFC$11 \mathrm{RE}$ (see section 4.1.1).

\subsubsection{HFE-125 $\left(\mathrm{CHF}_{2} \mathrm{OCF}_{3}\right)$}

[217] Previous reports of RE due to HFE-125 are in the range of $0.41-0.44 \mathrm{~W} \mathrm{~m}^{-2} \mathrm{ppb}^{-1}$ (mean: $0.42 \mathrm{~W} \mathrm{~m}^{-2} \mathrm{ppb}^{-1}$ ) [Christidis et al., 1997; Heathfield et al., 1998; Sihra et al., 2001]. IPCC AR4 uses a RE of $0.44 \mathrm{~W} \mathrm{~m}^{-2} \mathrm{ppb}^{-1}$ taken from Christidis et al. [1997], Good et al. [1998] and Heathfield et al. [1998] (the latter two after rescaling as reported in $W M O$ [1999]). We have used the absorption cross sections from Sihra et al. [2001] and calculated a RE of $0.41 \mathrm{~W} \mathrm{~m}^{-2} \mathrm{ppb}^{-1}, 8 \%$ lower than that in AR4.

\subsubsection{HFE-134 (HG-00) $\left(\mathrm{CHF}_{2} \mathrm{OCHF}_{2}\right)$}

[218] Previous reports of RE of HFE-134 (HG-00) are in the range of $0.40-0.44 \mathrm{~W} \mathrm{~m}^{-2} \mathrm{ppb}^{-1}$ (mean: $0.43 \mathrm{~W} \mathrm{~m}^{-2}$ $\mathrm{ppb}^{-1}$ ) [Andersen et al., 2010a; Heathfield et al., 1998; Imasu et al., 1995; Myhre et al., 1999]. IPCC AR4 used a RE value of $0.45 \mathrm{~W} \mathrm{~m}^{-2} \mathrm{ppb}^{-1}$ which is taken from Good et al. [1998] and Heathfield et al. [1998] after rescaling in $W M O$ [1999]. Here we have used the absorption cross section from Imasu et al. [1995] and calculated a RE value of $0.44 \mathrm{~W} \mathrm{~m}^{-2} \mathrm{ppb}^{-1}$, which is in good agreement with AR4. Due to an update in the lifetime for this compound (24.4 years in WMO [2011] compared to 26 years in $\mathrm{AR} 4)$, and a higher $\mathrm{AGWP}_{\mathrm{CO} 2}$ value, the GWP(100) value is significantly lower than that in AR4 (see Table 15).

\subsubsection{HFE-143a $\left(\mathrm{CH}_{3} \mathrm{OCF}_{3}\right)$}

[219] Previous reports of RE of HFE-143a are in the range of $\quad 0.17-0.19 \mathrm{~W} \mathrm{~m}^{-2} \mathrm{ppb}^{-1}$ (mean: $0.18 \mathrm{~W} \mathrm{~m}^{-2} \mathrm{ppb}^{-1}$ ) [Christensen et al., 1999; Sihra et al., 2001]. IPCC AR4 reports a $\mathrm{RE}$ of $0.27 \mathrm{~W} \mathrm{~m}^{-2} \mathrm{ppb}^{-1}$ which is taken from the ab initio study of Good et al. [1998] after rescaling assuming CFC-11 $\mathrm{RE}=0.25 \mathrm{~W} \mathrm{~m}^{-2} \mathrm{ppb}^{-1}$ in $W M O$ [1999]. We calculate a RE value of $0.18 \mathrm{~W} \mathrm{~m}^{-2} \mathrm{ppb}^{-1}$ using absorption cross section from Sihra et al. [2001]. Our estimate is much lower (34\% lower) than the AR4 value, which is based on an ab initio study, but in good agreement with experimental studies.

\subsubsection{HFE-227ea $\left(\mathrm{CF}_{3} \mathrm{CHFOCF}_{3}\right)$}

[220] Previous reports of RE of HFE-227ea are in the range of $0.31-0.42 \mathrm{~W} \mathrm{~m}^{-2} \mathrm{ppb}^{-1}$ (mean: $0.37 \mathrm{~W} \mathrm{~m}^{-2} \mathrm{ppb}^{-1}$ ) [Imasu et al., 1995; Jain et al., 2001; Oyaro et al., 2005; Takahashi et al., 2002]. IPCC AR4 reports a RE of $0.40 \mathrm{~W}$ $\mathrm{m}^{-2} \mathrm{ppb}^{-1}$ which is taken from Imasu et al. [1995] as modified by $W M O$ [1999]. We calculate a RE value of $0.44 \mathrm{~W}$ $\mathrm{m}^{-2} \mathrm{ppb}^{-1}$ both when using absorption cross sections from Oyaro et al. [2005] and Imasu et al. [1995]. Our estimate is $10 \%$ higher than in AR4.

4.1.7.5. HCFE-235ca2 (enflurane) $\left(\mathrm{CHF}_{2} \mathrm{OCF}_{2} \mathrm{CHFCl}\right)$ [221] Previous studies of RE due to HCFE-235ca2 (enflurane) are in the range of $0.42-0.45 \mathrm{~W} \mathrm{~m}^{-2} \mathrm{ppb}^{-1}$ (mean: $0.43 \mathrm{~W} \mathrm{~m}^{-2} \mathrm{ppb}^{-1}$ ) [Andersen et al., 2012b; Dalmasso et al., 2006]. We have used the absorption cross sections from these two studies and calculated a mean $\mathrm{RE}$ value of $0.41 \mathrm{~W} \mathrm{~m}^{-2} \mathrm{ppb}^{-1}$ (range: 0.39 $\left.0.42 \mathrm{~W} \mathrm{~m}^{-2} \mathrm{ppb}^{-1}\right)$.

\subsubsection{HCFE-235da2 (isoflurane) $\left(\mathrm{CHF}_{2} \mathrm{OCHClCF}_{3}\right)$}

[222] Previous reports of RE due to HCFE-235da2 (isoflurane) are in the range of $0.37-0.48 \mathrm{~W} \mathrm{~m}^{-2} \mathrm{ppb}^{-1}$ (mean: $0.44 \mathrm{~W} \mathrm{~m}^{-2} \mathrm{ppb}^{-1}$ ) [Andersen et al., 2010c; Christidis et al., 1997; Ryan and Nielsen, 2010; Sihra et al., 2001]. IPCC AR4 accounted for stratospheric decay and reports a RE of $0.38 \mathrm{~W} \mathrm{~m}^{-2} \mathrm{ppb}^{-1}$ which is taken from Christidis et al. [1997]. We calculate a RE value of $0.42 \mathrm{~W} \mathrm{~m}^{-2} \mathrm{ppb}^{-1}$ both when using absorption cross sections from Andersen et al. [2010c] and from Ryan and 
Nielsen [2010]. Our estimate is about 10\% higher than in AR4.

4.1.7.7. HFEs Studied Theoretically by Blowers et al. [2007] and Blowers et al. [2008a]

[223] For some HFE compounds, no RE estimates based on experimental absorption cross sections exist, and the ab initio studies of Blowers et al. [2007] and Blowers et al. [2008a] provide the only RE estimates of these HFEs. These compounds are as follows:

\section{HFE-236ca $\left(\mathrm{CHF}_{2} \mathrm{OCF}_{2} \mathrm{CHF}_{2}\right)$}

Fluoro(methoxy)methane $\left(\mathrm{CH}_{3} \mathrm{OCH}_{2} \mathrm{~F}\right)$

Difluoro(methoxy)methane $\left(\mathrm{CH}_{3} \mathrm{OCHF}_{2}\right)$

Fluoro(fluoromethoxy)methane $\left(\mathrm{CH}_{2} \mathrm{FOCH}_{2} \mathrm{~F}\right)$

Difluoro(fluoromethoxy)methane $\left(\mathrm{CH}_{2} \mathrm{FOCHF}_{2}\right)$

Trifluoro(fluoromethoxy)methane $\left(\mathrm{CH}_{2} \mathrm{FOCF}_{3}\right)$

Trifluoro(trifluoromethoxy)methane $\left(\mathrm{CF}_{3} \mathrm{OCF}_{3}\right)$

[224] Note that Blowers et al. [2007] estimated REs for some hydrofluoroethers not listed in this section. Blowers et al. [2007] and Blowers et al. [2008a] calculated instantaneous REs by using the theoretical procedure described by Papasavva et al. [1997] combined with the Pinnock et al. [1995] method (their RE estimates are listed in Table S7 in the supporting information). Since absorption spectra were unavailable for the seven compounds listed above, no new calculations have been carried out here. Thus, we use the REs from Blowers et al. [2007] and Blowers et al. [2008a], accounting for stratospheric temperature adjustment and lifetime correction (see sections 3.3.2 and 3.3.4, respectively), and present new best estimate RE and GWP values in Table 15. The lifetime of HFE-236ca is from $W M O$ [2011], the lifetime of fluoro(methoxy)methane is from Urata et al. [2003], and a lifetime estimate could not be found for trifluoro(trifluoromethoxy)methane; thus, we only present RE assuming a uniform distribution for this compound. The lifetimes of the remaining compounds are taken from Blowers et al. [2008a]. The resulting REs are 0.56, 0.07, 0.17, 0.19, 0.30, 0.33, and $0.53 \mathrm{~W} \mathrm{~m}^{-2} \mathrm{ppb}^{-1}$ for HFE-236ca, fluoro(methoxy)methane, difluoro(methoxy)methane, fluoro(fluoromethoxy)methane, difluoro(fluoromethoxy)methane, trifluoro(fluoromethoxy)methane, and trifluoro(trifluoromethoxy)methane, respectively. However, it should be stressed that these REs are based on ab initio studies, and the uncertainties are therefore larger than for REs based on experimental absorption spectra, as discussed in section 3.6.1.

\subsubsection{HFE-236ea2 (desflurane) $\left(\mathrm{CHF}_{2} \mathrm{OCHFCF}_{3}\right)$}

[225] Previous studies of RE of HFE-236ea2 (desflurane) are in the range of $0.45-0.47 \mathrm{~W} \mathrm{~m}^{-2} \mathrm{ppb}^{-1}$ (mean: $0.46 \mathrm{~W}$ $\mathrm{m}^{-2} \mathrm{ppb}^{-1}$ ) [Andersen et al., 2010c; Imasu et al., 1995; Oyaro et al., 2005]. IPCC AR4 used a RE of $0.44 \mathrm{~W} \mathrm{~m}^{-2}$ $\mathrm{ppb}^{-1}$ which is taken from Imasu et al. [1995] as modified by $W M O$ [1999]. We calculate a mean RE value of $0.45 \mathrm{~W} \mathrm{~m}^{-2} \mathrm{ppb}^{-1}$ (range: $0.45-0.46 \mathrm{~W} \mathrm{~m}^{-2} \mathrm{ppb}^{-1}$ ) using absorption cross sections from three sources [Andersen et al., 2010c; Imasu et al., 1995; Oyaro et al., 2005]. Our RE estimate is in good agreement with AR4, but due to an updated lifetime estimate (10.8 years in WMO [2011] compared to 5.8 years in AR4), our GWP (100) value is much higher, despite the higher $\mathrm{AGWP}_{\mathrm{CO} 2}$ value used here.

\subsubsection{HFEs Studied by Imasu et al. [1995]}

[226] For a number of HFE compounds, Imasu et al. [1995] is the only study providing REs based on experimental absorption cross sections:

$$
\text { HFE-236fa }\left(\mathrm{CF}_{3} \mathrm{CH}_{2} \mathrm{OCF}_{3}\right)
$$

$\mathrm{HFE}-245 \mathrm{cb} 2\left(\mathrm{CF}_{3} \mathrm{CF}_{2} \mathrm{OCH}_{3}\right)$

HFE-245fal $\left(\mathrm{CHF}_{2} \mathrm{CH}_{2} \mathrm{OCF}_{3}\right)$

HFE-329mcc2 $\left(\mathrm{CHF}_{2} \mathrm{CF}_{2} \mathrm{OCF}_{2} \mathrm{CF}_{3}\right)$

HFE-338mmzl $\left(\left(\mathrm{CF}_{3}\right)_{2} \mathrm{CHOCHF}_{2}\right)$

HFE-338mcf2 $\left(\mathrm{CF}_{3} \mathrm{CH}_{2} \mathrm{OCF}_{2} \mathrm{CF}_{3}\right)$

HFE-347mcf2 $\left(\mathrm{CHF}_{2} \mathrm{CH}_{2} \mathrm{OCF}_{2} \mathrm{CF}_{3}\right)$

HFE-347mmy1 $\left(\left(\mathrm{CF}_{3}\right)_{2} \mathrm{CFOCH}_{3}\right)$

$\mathrm{HFE}-356 \mathrm{mec} 3\left(\mathrm{CH}_{3} \mathrm{OCF}_{2} \mathrm{CHFCF}_{3}\right)$

HFE-356pcf2 $\left(\mathrm{CHF}_{2} \mathrm{CH}_{2} \mathrm{OCF}_{2} \mathrm{CHF}_{2}\right)$

HFE-356pcf3 $\left(\mathrm{CHF}_{2} \mathrm{OCH}_{2} \mathrm{CF}_{2} \mathrm{CHF}_{2}\right)$

HFE-356pcc3 $\left(\mathrm{CH}_{3} \mathrm{OCF}_{2} \mathrm{CF}_{2} \mathrm{CHF}_{2}\right)$

1,1,1,3,3,3-Hexafluoro-2-(trifluoromethyl)-2-propanol $\left(\left(\mathrm{CF}_{3}\right)_{3} \mathrm{COH}\right)$

\section{2,2,3,3,4,4,5,5-Octafluorocyclopentanol (-( $\left.\left(\mathrm{CF}_{2}\right)_{4} \mathrm{CH}(\mathrm{OH})-\right)$}

\section{1,1,1,3,3,3-Hexafluoropropan-2-ol $\left(\left(\mathrm{CF}_{3}\right)_{2} \mathrm{CHOH}\right)$}

[227] Many of the compounds listed above have also been studied using ab initio methods in Blowers et al. [2007] and Bravo et al. [2011a] (see Table 14). As previously mentioned, the uncertainties are larger for theoretical studies and we choose to focus on the experimental studies when these are available. With the exception of $1,1,1,3,3,3-$ hexafluoro-2-(trifluoromethyl)-2-propanol, for which no lifetime estimate is available in the literature, all the 15 compounds listed above, and their REs, have been reported in AR4 based on Imasu et al. [1995] as modified by WMO [1999]. We have used the Imasu et al. [1995] cross sections to calculate new estimates of RE, taking into account both 
stratospheric temperature adjustment (by increasing the instantaneous RE by $10 \%$ as described in section 3.3.2) and fractional correction (by using the method described in section 3.3.4). Table 15 presents the results of our calculations and highlights the best estimate RE and GWP(100) values for each compound. For 5 of the 14 compounds which are listed above and included in AR4, our calculation of RE differed by more than 5\% compared to AR4. The differences in RE between our calculation and AR4 were larger for compounds which were not well-mixed in the atmosphere (with lifetimes typically less than a few years), because lifetime corrections were not considered in AR4 (recall from the introduction to section 4.1.7 that the Imasu et al. [1995] results were scaled to a CFC-11 value of $0.25 \mathrm{~W}$ $\mathrm{m}^{-2} \mathrm{ppb}^{-1}$ as explained in WMO [1999]). In many of the cases, the REs in our calculation were in good agreement with AR4, but the updated lifetimes, which we take from $W M O$ [2011], led to a change in the GWP(100) compared to AR4 (note also that the updated $\mathrm{AGWP}_{\mathrm{CO} 2}$ lead to $\sim 5 \%$ lower GWP(100) for all compounds compared to AR4).

\subsubsection{HFE-245fa2 $\left(\mathrm{CHF}_{2} \mathrm{OCH}_{2} \mathrm{CF}_{3}\right)$}

[228] Previous calculations of RE of HFE-245fa2 are in the range of $0.33-0.39 \mathrm{~W} \mathrm{~m}^{-2} \mathrm{ppb}^{-1}$ (mean: $0.37 \mathrm{~W} \mathrm{~m}^{-2} \mathrm{ppb}^{-1}$ ) [Christidis et al., 1997; Imasu et al., 1995; Oyaro et al., 2005; Sihra et al., 2001]. IPCC AR4 reports a RE of $0.31 \mathrm{~W}$ $\mathrm{m}^{-2} \mathrm{ppb}^{-1}$ which is taken from Christidis et al. [1997], but modified to approximately account for stratospheric decay as described in $W M O$ [1999]. We have used absorption cross sections from Oyaro et al. [2005], Sihra et al. [2001] and Imasu et al. [1995] and calculated a RE value of $0.36 \mathrm{~W} \mathrm{~m}^{-2} \mathrm{ppb}^{-1}$ for all three absorption spectra. The reason for the $16 \%$ higher $\mathrm{RE}$ value calculated here compared to AR4 is related to the different factors to account for the non-uniform distribution in the atmosphere. AR4 used a crude factor of 0.8 from Freckleton et al. [1998], while our method (see section 3.3.4) yields a factor of 0.93 for a lifetime of 5.5 years.

\subsubsection{2,2,3,3,3-Pentafluoropropan-1-ol $\left(\mathrm{CF}_{3} \mathrm{CF}_{2}\right.$ $\left.\mathrm{CH}_{2} \mathrm{OH}\right)$}

[229] Previous studies of RE due to 2,2,3,3,3pentafluoropropan-1-ol are in the range of $0.25-0.26 \mathrm{~W} \mathrm{~m}^{-2}$ $\mathrm{ppb}^{-1}$ (mean: $0.25 \mathrm{~W} \mathrm{~m}^{-2} \mathrm{ppb}^{-1}$ ) [Antiñolo et al., 2012b; Imasu et al., 1995; Sellevåg et al., 2007]. IPCC AR4 reports a RE of $0.24 \mathrm{~W} \mathrm{~m}^{-2} \mathrm{ppb}^{-1}$ which is taken from Imasu et al. [1995] as modified by $W M O$ [1999]. We calculate a mean $\mathrm{RE}$ value of $0.14 \mathrm{~W} \mathrm{~m}^{-2} \mathrm{ppb}^{-1}$ (range: $0.13-0.15 \mathrm{~W} \mathrm{~m}^{-2}$ $\mathrm{ppb}^{-1}$ ) using absorption cross sections from three sources [Antiñolo et al., 2012b; Imasu et al., 1995; Sellevåg et al., 2007]. Our estimate is much lower ( $42 \%$ different) than that in AR4. The short lifetime of 0.3 years [Antiñolo et al., 2012b] for this compound leads to a strong effect of the fractional correction factor which has been applied to account for non-uniform mixing (vertical and horizontal). It should be noted here that the uncertainties associated with this correction factor are very large on a percentage basis for such short-lived species (see Figure 9 and associated discussion in section 3.3.4), and we further note that our calculated instantaneous RE (i.e., without applying corrections for stratospheric temperature adjustment and lifetime correction) is in good agreement with the published instantaneous RE estimates (Table $\mathrm{S} 7$ in the supporting information).

\subsubsection{2. $\mathrm{HFE}-254 \mathrm{cb} 2\left(\mathrm{CH}_{3} \mathrm{OCF}_{2} \mathrm{CHF}_{2}\right)$}

[230] Previous calculations of RE of HFE-254cb1 are in the range of $0.29-0.30 \mathrm{~W} \mathrm{~m}^{-2} \mathrm{ppb}^{-1}$ (mean: $0.29 \mathrm{~W} \mathrm{~m}^{-2}$ $\mathrm{ppb}^{-1}$ ) [Heathfield et al., 1998; Imasu et al., 1995]. IPCC AR4 used a RE of $0.28 \mathrm{~W} \mathrm{~m}^{-2} \mathrm{ppb}^{-1}$ which is taken from Imasu et al. [1995] as modified by WMO [1999]. We calculate an $8 \%$ lower RE value of $0.26 \mathrm{~W} \mathrm{~m}^{-2} \mathrm{ppb}^{-1}$ using absorption cross section from Imasu et al. [1995].

\subsubsection{HFE-263fb2 $\left(\mathrm{CF}_{3} \mathrm{CH}_{2} \mathrm{OCH}_{3}\right)$}

[231] Previous reports of RE of HFE-263fb2 are in the range of $0.19-0.21 \mathrm{~W} \mathrm{~m}^{-2} \mathrm{ppb}^{-1}$ (mean: $0.20 \mathrm{~W} \mathrm{~m}^{-2} \mathrm{ppb}^{-1}$ ) [Imasu et al., 1995; Osterstrom et al., 2012; Oyaro et al., 2005]. IPCC AR4 gives a RE of $0.20 \mathrm{~W} \mathrm{~m}^{-2} \mathrm{ppb}^{-1}$ which is taken from Imasu et al. [1995] as modified by WMO [1999]. Using absorption cross sections from three studies [Imasu et al., 1995; Osterstrom et al., 2012; Oyaro et al., 2005] that give the same results we calculate a much lower $(81 \%)$ mean RE value of $0.04 \mathrm{~W} \mathrm{~m}^{-2} \mathrm{ppb}^{-1}$. The reason for the large differences between our estimate and the AR4 is the lifetime correction factor of 0.18 (for a lifetime of 23 days) [WMO, 2011] which has been applied here to account for non-uniform distribution (vertical and horizontal). It should be noted here that the uncertainties associated with this correction factor are very large on a percentage basis for such short-lived species (see Figure 9 and associated discussion in section 3.3.4). Our calculated RE is, however, in good agreement with the results from Imasu et al. [1995], and hence AR4, if we compare instantaneous RE (i.e., without applying corrections for stratospheric temperature adjustment and lifetime correction) (Table S7 in the supporting information).

\subsubsection{HFEs studied by Oyaro et al. [2005]}

[232] For the following HFE compounds, Oyaro et al. [2005] is the only study providing REs based on experimental absorption cross sections:

\section{HFE-263 $\mathrm{ml}\left(\mathrm{CF}_{3} \mathrm{OCH}_{2} \mathrm{CH}_{3}\right)$}

\section{1,1,2-Trifluoro-2-(trifluoromethoxy)-ethane $\left(\mathrm{CHF}_{2} \mathrm{CHFOCF}_{3}\right)$ \\ 1-Ethoxy-1,1,2,3,3,3-hexafluoropropane $\left(\mathrm{CF}_{3} \mathrm{CHFCF}_{2} \mathrm{OCH}_{2} \mathrm{CH}_{3}\right)$ \\ 1,1,1,2,2,3,3-Heptafluoro-3-(1,2,2,2-tetrafluoroethoxy)- propane $\left(\mathrm{CF}_{3} \mathrm{CF}_{2} \mathrm{CF}_{2} \mathrm{OCHFCF}_{3}\right)$}

[233] $\mathrm{Ab}$ initio studies are available for these compounds [Blowers et al., 2007; Bravo et al., 2011a] (Table 14), but we focus here on the experimental data from Oyaro et al. [2005]. They used the Pinnock et al. [1995] method to estimate instantaneous REs of $0.21,0.35,0.33$ and $0.56 \mathrm{~W} \mathrm{~m}^{-2}$ $\mathrm{ppb}^{-1}$ for HFE-263 m1, 1,1,2-Trifluoro-2-(trifluoromethoxy)ethane, 1-Ethoxy-1,1,2,3,3,3-hexafluoropropane, and 1,1,1, 2,2,3,3-Heptafluoro-3-(1,2,2,2-tetrafluoroethoxy)-propane, respectively. The corresponding RE estimates from our calculations (now taking into account stratospheric temperature 
adjustment and inhomogeneous distribution in the troposphere) are $0.13,0.35,0.33$ and $0.58 \mathrm{~W} \mathrm{~m}^{-2} \mathrm{ppb}^{-1}$, respectively, when using absorption cross sections from Oyaro et al. [2005] and lifetime estimates of 0.4 [Bravo et al., 2011a], 9.8, 0.4 and 67.0 years [Oyaro et al., 2005], respectively. None of these compounds are included in AR4, thus we provide new best estimates of RE and GWP for all these compounds.

\subsubsection{3,3,3-Trifluoropropan-1-ol $\left(\mathrm{CF}_{3} \mathrm{CH}_{2} \mathrm{CH}_{2} \mathrm{OH}\right)$}

[234] Previous experimental studies of 3,3,3-trifluoropropan1 -ol have reported values for RE in the range of $0.17-0.20 \mathrm{~W}$ $\mathrm{m}^{-2} \mathrm{ppb}^{-1}$ (mean: $0.19 \mathrm{~W} \mathrm{~m}^{-2} \mathrm{ppb}^{-1}$ ) [Jimenez et al., 2010; Sellevåg et al., 2007]. We have used absorption cross sections from Jimenez et al. [2010], Sellevåg et al. [2007] and Waterland et al. [2005] and calculated the same RE of $0.02 \mathrm{~W} \mathrm{~m}^{-2} \mathrm{ppb}^{-1}$ for all three spectra. Our calculated instantaneous REs of $0.21 \mathrm{~W} \mathrm{~m}^{-2} \mathrm{ppb}^{-1}$ and $0.17 \mathrm{~W} \mathrm{~m}^{-2} \mathrm{ppb}^{-1}$ using spectra from Jimenez et al. [2010] and Sellevåg et al. [2007], respectively, compare well with the previously published REs (which did not account for stratospheric temperature adjustment and lifetime correction). The lifetime of 12.0 days is taken from Jimenez et al. [2010].

\subsubsection{Sevoflurane, HFE-347mmz $1\left(\left(\mathrm{CF}_{3}\right)_{2} \mathrm{CHO}\right.$ $\mathrm{CH}_{2} \mathrm{~F}$ )}

[235] Experimental studies have reported RE values for sevoflurane in the range of $0.35-0.37 \mathrm{~W} \mathrm{~m}^{-2} \mathrm{ppb}^{-1}$ (mean: $0.36 \mathrm{~W} \mathrm{~m}^{-2} \mathrm{ppb}^{-1}$ ) [Andersen et al., 2010c; Ryan and Nielsen, 2010]. We have used the absorption cross sections from these two studies and calculated a RE value of $0.32 \mathrm{~W} \mathrm{~m}^{-2} \mathrm{ppb}^{-1}$ for both spectra. It should be noted here that Andersen et al. [2010c] and Ryan and Nielsen [2010] calculated the instantaneous RE using the Pinnock et al. [1995] method while we have accounted for stratospheric temperature adjustment and non-uniform distribution in the troposphere.

\subsubsection{HFE-347mcc3 (HFE-7000) $\left(\mathrm{CH}_{3} \mathrm{OCF}_{2} \mathrm{CF}_{2} \mathrm{CF}_{3}\right)$}

[236] Previous experimental studies of HFE-347mcc3 (HFE7000) have reported values for RE in the range of $0.32-0.35 \mathrm{~W}$ $\mathrm{m}^{-2} \mathrm{ppb}^{-1}$ (mean: $0.34 \mathrm{~W} \mathrm{~m}^{-2} \mathrm{ppb}^{-1}$ ) [Bravo et al., 2010a; Imasu et al., 1995; Ninomiya et al., 2000]. We have used the absorption cross sections from all these three studies and calculated a mean $\mathrm{RE}$ value of $0.35 \mathrm{~W} \mathrm{~m}^{-2} \mathrm{ppb}^{-1}$ (range: $0.33-0.36 \mathrm{~W} \mathrm{~m}^{-2} \mathrm{ppb}^{-1}$ ). Our estimate is in reasonable agreement with the RE of $0.34 \mathrm{~W} \mathrm{~m}^{-2} \mathrm{ppb}^{-1}$ in AR4 (which originated from Imasu et al. [1995] as modified by $W M O$ [1999]).

\subsubsection{HFE-347pcf2 $\left(\mathrm{CHF}_{2} \mathrm{CF}_{2} \mathrm{OCH}_{2} \mathrm{CF}_{3}\right)$}

[237] One experimental study has reported a value of RE for this HFE-347pcf2 [Heathfield et al., 1998]. The original value $\left(0.47 \mathrm{~W} \mathrm{~m}^{-2} \mathrm{ppb}^{-1}\right)$ was determined using the Pinnock et al. [1995] method. There is some confusion regarding the RE of this molecule. WMO [1999] (where it is referred to as HFE-347mfc2) use the Heathfield et al. [1998] value - this molecule then does not seem to appear in IPCC or WMO/UNEP ozone assessments tabulations until IPCC [2007] which recommends a value of $0.25 \mathrm{~W} \mathrm{~m}^{-2}$ $\mathrm{ppb}^{-1}$; this is perhaps a lifetime-corrected version of the earlier value, although no reference is given. We recommend instead, using the original Heathfield et al. [1998] value, applying our generic correction of a $10 \%$ increase to account for stratospheric temperature adjustment and applying the lifetime correction (assuming a lifetime of 6 years) from section 3.3.4 of 0.93 . This yields our recommended value of $0.48 \mathrm{~W} \mathrm{~m}^{-2} \mathrm{ppb}^{-1}$.

\subsubsection{HFE-356mff2 $\left(\mathrm{CF}_{3} \mathrm{CH}_{2} \mathrm{OCH}_{2} \mathrm{CF}_{3}\right)$}

[238] Previous experimental studies of HFE-356 $\mathrm{mff}^{-2}$ have reported values for RE in the range of $0.33-0.35 \mathrm{~W} \mathrm{~m}^{-2} \mathrm{ppb}^{-1}$ (mean: $0.35 \mathrm{~W} \mathrm{~m}^{-2} \mathrm{ppb}^{-1}$ ) [Oyaro et al., 2004; Sihra et al., 2001; Wallington et al., 1998]. We calculate a mean RE value of $0.17 \mathrm{~W} \mathrm{~m}^{-2} \mathrm{ppb}^{-1}$ (range: $0.17-0.18 \mathrm{~W} \mathrm{~m}^{-2} \mathrm{ppb}^{-1}$ ) using absorption cross sections from two sources [Oyaro et al., 2004; Sihra et al., 2001]. The non-homogeneous mixing of this short-lived compound was not accounted for in the three previous studies; our estimate of RE is consistent with the published values if we assume uniform mixing.

\subsubsection{HFE-356mmz1 $\left(\left(\mathrm{CF}_{3}\right)_{2} \mathrm{CHOCH}_{3}\right)$}

[239] Previous experimental studies of HFE-356mmzl have both reported values for RE of $0.31 \mathrm{~W} \mathrm{~m}^{-2} \mathrm{ppb}^{-1}$ [Imasu et al., 1995; Oyaro et al., 2004] (note that the Imasu et al. [1995] value is here scaled to our recommended CFC$11 \mathrm{RE}$ of $0.26 \mathrm{~W} \mathrm{~m}^{-2} \mathrm{ppb}^{-1}$ ). The Imasu et al. [1995] value (as modified by WMO [1999]) of $0.30 \mathrm{~W} \mathrm{~m}^{-2} \mathrm{ppb}^{-1}$ was used by IPCC AR4. We have used the absorption cross sections from Imasu et al. [1995] and Oyaro et al. [2004] and calculated a RE value of $0.15 \mathrm{~W} \mathrm{~m}^{-2} \mathrm{ppb}^{-1}$ for both of these spectra. Our estimate is $50 \%$ lower than AR4, and this is almost entirely due to the factor applied here to account for non-homogeneous mixing for this short-lived species (lifetime of 97.1 days) [Oyaro et al., 2004]. The best estimate RE and GWP values are shown in Table 15.

\subsubsection{1. $\mathrm{HFE}-365 \mathrm{mcf} 3\left(\mathrm{CF}_{3} \mathrm{CF}_{2} \mathrm{CH}_{2} \mathrm{OCH}_{3}\right)$}

[240] Previous experimental studies of HFE-365mcf3 have reported values for RE in the range of $0.28-0.33 \mathrm{~W}$ $\mathrm{m}^{-2} \mathrm{ppb}^{-1}$ (mean: $0.30 \mathrm{~W} \mathrm{~m}^{-2} \mathrm{ppb}^{-1}$ ) [Imasu et al., 1995; Oyaro et al., 2004; Thomsen et al., 2011] (note that the Imasu et al. [1995] value is here scaled to our recommended CFC-11 RE of $0.26 \mathrm{~W} \mathrm{~m}^{-2} \mathrm{ppb}^{-1}$ ). The Imasu et al. [1995] value (as modified by WMO [1999]) of $0.27 \mathrm{~W} \mathrm{~m}^{-2} \mathrm{ppb}^{-1}$ was used by IPCC AR4. In contrast to the published values we have accounted for stratospheric temperature adjustment and non-homogeneous mixing in the troposphere (assuming a lifetime of 19.3 days) [Oyaro et al., 2004], and calculated a RE value of $0.05 \mathrm{~W} \mathrm{~m}^{-2} \mathrm{ppb}^{-1}$ when using absorption cross sections from both Oyaro et al. [2004] and Imasu et al. [1995]. Our estimate is $\sim 80 \%$ lower than that in AR4, but it should be noted here that the uncertainties associated with the lifetime correction factors are very large on a percentage basis for such short-lived species (see Figure 9 and associated discussion in section 3.3.4), and we further note that our calculated instantaneous RE is consistent with the published estimates.

\subsubsection{HFEs Studied Theoretically by Bravo et al. [2011a]}

[241] For a number of HFE compounds, no RE estimates based on experimental absorption cross sections exist and the ab initio study of Bravo et al. [2011a] provides the only RE estimate of these HFEs. These compounds are as follows: 


\author{
HFE-365mcf2 $\left(\mathrm{CF}_{3} \mathrm{CF}_{2} \mathrm{OCH}_{2} \mathrm{CH}_{3}\right)$ \\ $\mathrm{HG}-02\left(\mathrm{HF}_{2} \mathrm{C}-\left(\mathrm{OCF}_{2} \mathrm{CF}_{2}\right)_{2}-\mathrm{OCF}_{2} \mathrm{H}\right)$ \\ HG-03 $\left(\mathrm{HF}_{2} \mathrm{C}-\left(\mathrm{OCF}_{2} \mathrm{CF}_{2}\right)_{3}-\mathrm{OCF}_{2} \mathrm{H}\right)$ \\ $\mathrm{HG}-20\left(\mathrm{HF}_{2} \mathrm{C}-\left(\mathrm{OCF}_{2}\right)_{2}-\mathrm{OCF}_{2} \mathrm{H}\right)$ \\ $\mathrm{HG}-21\left(\mathrm{HF}_{2} \mathrm{C}-\mathrm{OCF}_{2} \mathrm{CF}_{2} \mathrm{OCF}_{2} \mathrm{OCF}_{2} \mathrm{O}-\mathrm{CF}_{2} \mathrm{H}\right)$ \\ $\mathrm{HG}-30\left(\mathrm{HF}_{2} \mathrm{C}-\left(\mathrm{OCF}_{2}\right)_{3}-\mathrm{OCF}_{2} \mathrm{H}\right)$ \\ 1-Ethoxy-1,1,2,2,3,3,3-heptafluoropropane \\ $\left(\mathrm{CF}_{3} \mathrm{CF}_{2} \mathrm{CF}_{2} \mathrm{OCH}_{2} \mathrm{CH}_{3}\right)$ \\ Fluoroxene $\left(\mathrm{CF}_{3} \mathrm{CH}_{2} \mathrm{OCH}=\mathrm{CH}_{2}\right)$ \\ 1,1,2,2-Tetrafluoro-1-(fluoromethoxy)ethane \\ $\left(\mathrm{CH}_{2} \mathrm{FOCF}_{2} \mathrm{CF}_{2} \mathrm{H}\right)$
}

$\mathrm{HG}^{\prime}-10\left(\mathrm{CH}_{3} \mathrm{OCF}_{2} \mathrm{OCH}_{3}\right)$

$\mathrm{HG}^{\prime}-20\left(\mathrm{CH}_{3} \mathrm{O}\left(\mathrm{CF}_{2} \mathrm{O}\right)_{2} \mathrm{CH}_{3}\right)$

$\mathrm{HG}^{\prime}-30\left(\mathrm{CH}_{3} \mathrm{O}\left(\mathrm{CF}_{2} \mathrm{O}\right)_{3} \mathrm{CH}_{3}\right)$

[242] For all of the compounds listed above we have used the theoretical absorption cross sections from Bravo et al. [2011a] to calculate estimates of RE, taking into account both stratospheric temperature adjustment (by increasing the instantaneous RE by $10 \%$ as described in section 3.3.2) and fractional correction (by using the method described in section 3.3.4). For three of these compounds $\left(\mathrm{HG}^{\prime}-10\right.$, $\mathrm{HG}^{\prime}-20, \mathrm{HG}^{\prime}-30$ ), no lifetime estimates were found in the literature, and hence the RE estimates for these compounds assume a uniform vertical and horizontal distribution in the atmosphere. Lifetimes for the remaining nine compounds were taken from Bravo et al. [2011a]. The study of Bravo et al. [2011a] used the Pinnock et al. [1995] method to estimate instantaneous REs, and accounted for nonhomogeneous mixing by applying the exponential function from Sihra et al. [2001] (see section 3.3.4) for compounds where lifetime estimates were known. The RE estimates of Bravo et al. [2011a] are listed in Table S7 in the supporting information, while our results are presented in Table 15. In general, differences are small but reflect the use of an updated Pinnock et al. [1995] curve in this study, and that the stratospheric temperature adjustment was not taken into account in Bravo et al. [2011a]. None of the compounds listed above are included in AR4, thus we provide new best estimates of RE and GWP for all these compounds. It should, however, be kept in mind that RE estimates based on ab initio calculations are associated with larger uncertainties than estimates based on experimental cross sections, as discussed in section 3.6.1 (see also Table 1).

\subsubsection{HFE-374pc2 $\left(\mathrm{CHF}_{2} \mathrm{CF}_{2} \mathrm{OCH}_{2} \mathrm{CH}_{3}\right)$}

[243] Previous experimental studies of HFE-374pc2 have reported values for $\mathrm{RE}$ in the range of $0.31-0.32 \mathrm{~W} \mathrm{~m}^{-2} \mathrm{ppb}^{-1}$ (mean: $0.31 \mathrm{~W} \mathrm{~m}^{-2} \mathrm{ppb}^{-1}$ ) [Heathfield et al., 1998; Imasu et al., 1995]. AR4 uses a RE of $0.25 \mathrm{~W} \mathrm{~m}^{-2} \mathrm{ppb}^{-1}$ taken from Heathfield et al. [1998], but modified in WMO [1999] to crudely account for non-homogeneous mixing by applying a factor of 0.8 based on Freckleton et al. [1998]. We calculate a RE value of $0.30 \mathrm{~W} \mathrm{~m}^{-2} \mathrm{ppb}^{-1}$ using absorption cross sections from Imasu et al. [1995]. Due to the different methods used to account for non-homogeneous mixing, our estimate is $19 \%$ higher than in AR4. The lifetime of 5.0 years is taken from AR4.

4.1.7.24. 4,4,4-Trifluorobutan-1-ol $\left(\mathrm{CF}_{3}\left(\mathrm{CH}_{2}\right)_{2} \mathrm{CH}_{2} \mathrm{OH}\right)$

[244] Jimenez et al. [2010] used the Pinnock et al. [1995] method and report an instantaneous RE value for 4,4,4-trifluorobutan-1-ol of $0.11 \mathrm{~W} \mathrm{~m}^{-2} \mathrm{ppb}^{-1}$. We have used their absorption cross section and calculated the same instantaneous RE. When taking into account stratospheric temperature adjustment and non-homogeneous mixing in the troposphere (assuming a lifetime of 4.0 days) [Jimenez et al., 2010], our calculation yield a RE value of $0.01 \mathrm{~W} \mathrm{~m}^{-2} \mathrm{ppb}^{-1}$.

\subsubsection{HFE-43-10pccc (H-Galden 1040x, HG-11) $\left(\mathrm{CHF}_{2} \mathrm{OCF}_{2} \mathrm{OC}_{2} \mathrm{~F}_{4} \mathrm{OCHF}_{2}\right)$}

[245] Previous experimental studies of HFE-43-10pccc (H-Galden 1040x, HG-11) have reported values for RE in the range of $0.99-1.37 \mathrm{~W} \mathrm{~m}^{-2} \mathrm{ppb}^{-1}$ (mean: $1.12 \mathrm{~W} \mathrm{~m}^{-2}$ $\mathrm{ppb}^{-1}$ ) [Christidis et al., 1997; Myhre et al., 1999; Sihra et al., 2001; Wallington et al., 2009]. IPCC AR4 use a RE of $1.37 \mathrm{~W} \mathrm{~m}^{-2} \mathrm{ppb}^{-1}$ taken from Myhre et al. [1999]. We have used the absorption cross section from Wallington et al. [2009] and calculated a 26\% lower RE value of $1.02 \mathrm{~W}$ $\mathrm{m}^{-2} \mathrm{ppb}^{-1}$, which is the same as the estimate in Wallington et al. [2009]. It should be noted here that the spectrum from Wallington et al. [2009] supersedes previous Ford measurements of HG-11 [Christidis et al., 1997; Sihra et al., 2001] and that the cross section from Cavalli et al. [1998], which has been used in Myhre et al. [1999], is an overestimate [Wallington et al., 2009].

\subsubsection{HFE-449 s1 (HFE-7100) $\left(\mathrm{C}_{4} \mathrm{~F}_{9} \mathrm{OCH}_{3}\right)$}

[246] Previous studies of RE due to HFE-449 s1 (HFE7100 ) are in the range of $0.31-0.37 \mathrm{~W} \mathrm{~m}^{-2} \mathrm{ppb}^{-1}$ (mean: $0.34 \mathrm{~W} \mathrm{~m}^{-2} \mathrm{ppb}^{-1}$ ) [Bravo et al., 2010a; Sihra et al., 2001; Wallington et al., 1997]. IPCC AR4 report a RE of $0.31 \mathrm{~W} \mathrm{~m}^{-2} \mathrm{ppb}^{-1}$ which is taken from Wallington et al. [1997] as modified by WMO [1999]. We estimate a $17 \%$ higher $\mathrm{RE}$ of $0.36 \mathrm{~W} \mathrm{~m}^{-2} \mathrm{ppb}^{-1}$ using the absorption cross sections from two sources [Bravo et al., 2010a; Sihra et al., 2001] and applying our lifetime correction. The main reason for the higher estimate is due to lower lifetime correction with a factor of 0.92 instead of 0.8 applied in WMO [1999].

\subsubsection{HFEs Studied by Sihra et al. [2001]}

[247] For the following HFE compounds, Sihra et al. [2001] is the only study providing REs based on experimental absorption cross sections:

$$
\begin{aligned}
& n \text {-HFE-7100 }\left(n-\mathrm{C}_{4} \mathrm{~F}_{9} \mathrm{OCH}_{3}\right) \\
& i \text {-HFE-7100 }\left(i-\mathrm{C}_{4} \mathrm{~F}_{9} \mathrm{OCH}_{3}\right) \\
& i \text {-HFE-7200 }\left(i-\mathrm{C}_{4} \mathrm{~F}_{9} \mathrm{OC}_{2} \mathrm{H}_{5}\right)
\end{aligned}
$$


[248] Ab initio studies are available for these compounds [Blowers et al., 2007; Bravo et al., 2011a] (Table 14), but we focus here on the experimental data from Sihra et al. [2001]. They assumed homogeneous distribution in the atmosphere and estimated REs of $0.47,0.37$ and $0.34 \mathrm{~W} \mathrm{~m}^{-2}$ $\mathrm{ppb}^{-1}$ for $n$-HFE-7100, $i$-HFE-7100 and $i$-HFE-7200, respectively. Our calculations are consistent with the Sihra et al. [2001] results if we make the same assumption and use their absorption cross sections. When accounting for non-homogeneous vertical and horizontal distribution, our calculations yield lower REs with values of $0.42,0.35$, and $0.24 \mathrm{~W} \mathrm{~m}^{-2} \mathrm{ppb}^{-1}$ for $n$-HFE-7100, $i$-HFE-7100, and $i$-HFE-7200, respectively. We have then assumed that the lifetime of $n$-HFE-7100 and $i$-HFE-7100 are the same as for HFE-7100 (4.7 years) [WMO, 2011], and that $i$-HFE7200 has the same lifetime as HFE-7200 (0.8 years) [WMO, 2011]. None of these compounds are included in AR4, thus we provide new best estimates of RE and GWP for all these compounds.

\subsubsection{HFE-569sf2 (HFE-7200) $\left(\mathrm{C}_{4} \mathrm{~F}_{9} \mathrm{OC}_{2} \mathrm{H}_{5}\right)$}

[249] Previous studies of RE due to HFE-569sf2 (HFE7200 ) are in the range of $0.30-0.39 \mathrm{~W} \mathrm{~m}^{-2} \mathrm{ppb}^{-1}$ (mean: $0.33 \mathrm{~W} \mathrm{~m}^{-2} \mathrm{ppb}^{-1}$ ) [Bravo et al., 2010a; Christensen et al., 1998; Sihra et al., 2001]. IPCC AR4 report a RE of $0.30 \mathrm{~W}$ $\mathrm{m}^{-2} \mathrm{ppb}^{-1}$ which is taken from Christensen et al. [1998] as modified by $W M O$ [1999]. We have used absorption cross sections from two sources [Bravo et al., 2010a; Sihra et al., 2001] and calculated a mean RE value of $0.30 \mathrm{~W} \mathrm{~m}^{-2}$ $\mathrm{ppb}^{-1}$ (range: $0.29-0.32 \mathrm{~W} \mathrm{~m}^{-2} \mathrm{ppb}^{-1}$ ) -in agreement with AR4.

\subsubsection{9. n-HFE-7200 ( $\left(\mathrm{n}-\mathrm{C}_{4} \mathrm{~F}_{9} \mathrm{OC}_{2} \mathrm{H}_{5}\right)$}

[250] The only estimates of the RE of $n$-HFE-7200 are from the ab initio studies of Bravo et al. [2011a] and Blowers et al. [2007] who both used the Pinnock et al. [1995] method to calculate instantaneous REs of 0.47 and $0.55 \mathrm{~W} \mathrm{~m}^{-2} \mathrm{ppb}^{-1}$, respectively. We have used the theoretical absorption spectrum from Bravo et al. [2011a] and calculated a similar instantaneous $\operatorname{RE}\left(0.45 \mathrm{~W} \mathrm{~m}^{-2} \mathrm{ppb}^{-1}\right)$. When accounting for stratospheric temperature adjustment and non-homogeneous tropospheric distribution, our RE estimate is $0.35 \mathrm{~W} \mathrm{~m}^{-2} \mathrm{ppb}^{-1}$. We have then assumed that $n$-HFE-7200 has the same lifetime as HFE-7200 (0.8 years) [WMO, 2011].

\subsubsection{HFE-236ca12 (HG-10) $\left(\mathrm{CHF}_{2} \mathrm{OCF}_{2} \mathrm{OCHF}_{2}\right)$}

[251] The RE of HFE-236ca12 (HG-10) has been estimated to be $0.66 \mathrm{~W} \mathrm{~m}^{-2} \mathrm{ppb}^{-1}$ in Myhre et al. [1999], and this value was used in the AR4 report. We have used the absorption cross section from the same study and calculated a RE value of $0.65 \mathrm{~W} \mathrm{~m}^{-2} \mathrm{ppb}^{-1}$ — in good agreement with AR4. Due to an updated lifetime for this compound, from 12.1 years in AR4 to 25.0 years in $W M O$ [2011], our calculated GWP (100) value is considerably higher than in AR4, despite the higher $\mathrm{AGWP}_{\mathrm{CO} 2}$ value used here.

\subsubsection{HFE-338pcc13 (HG-01) $\left(\mathrm{CHF}_{2} \mathrm{OCF}_{2} \mathrm{CF}_{2} \mathrm{OCHF}_{2}\right)$}

[252] Myhre et al. [1999] have estimated a RE due to HFE-338pcc13 (HG-01) of $0.87 \mathrm{~W} \mathrm{~m}^{-2} \mathrm{ppb}^{-1}$, which is the value adopted by AR4. We have used the Myhre et al.
[1999] absorption cross section and calculated a similar RE value of $0.86 \mathrm{~W} \mathrm{~m}^{-2} \mathrm{ppb}^{-1}$. We use an updated lifetime of 12.9 years [WMO, 2011], compared to 6.2 years in AR4, and this leads to a GWP(100) value which is about a factor 2 higher than in AR4.

4.1.7.32. 2-Ethoxy-3,3,4,4,5-pentafluorotetrahydro2,5-bis[1,2,2,2-tetrafluoro-1-(trifluoromethyl)ethyl]furan $\left(\mathrm{C}_{12} \mathrm{H}_{5} \mathrm{~F}_{19} \mathrm{O}_{2}\right)$

[253] Javadi et al. [2007] used the Pinnock et al. [1995] method to estimate an instantaneous RE due to 2-ethoxy3,3,4,4,5-pentafluorotetrahydro-2,5-bis[1,2,2,2-tetrafluoro-1(trifluoromethyl)ethyl]-furan of $0.60 \mathrm{~W} \mathrm{~m}^{-2} \mathrm{ppb}^{-1}$. Since no new calculations have been carried out here for this compound, we apply our generic correction of a $10 \%$ increase to account for stratospheric temperature adjustment, and our lifetime correction factor (assuming a lifetime of 1.0 year [Javadi et al., 2007]) from section 3.3.4 of 0.74 , and recommend a RE value of $0.49 \mathrm{~W} \mathrm{~m}^{-2} \mathrm{ppb}^{-1}$.

\subsubsection{HFEs studied by Andersen et al. [2004]}

[254] For the following HFE compounds, Andersen et al. [2004] is the only study providing REs based on experimental absorption cross sections:

\section{$\mathrm{HG}^{\prime}-01\left(\mathrm{CH}_{3} \mathrm{OCF}_{2} \mathrm{CF}_{2} \mathrm{OCH}_{3}\right)$}

$$
\mathrm{HG}^{\prime}-02\left(\mathrm{CH}_{3} \mathrm{O}\left(\mathrm{CF}_{2} \mathrm{CF}_{2} \mathrm{O}\right)_{2} \mathrm{CH}_{3}\right)
$$

$$
\mathrm{HG}^{\prime}-03\left(\mathrm{CH}_{3} \mathrm{O}\left(\mathrm{CF}_{2} \mathrm{CF}_{2} \mathrm{O}\right)_{3} \mathrm{CH}_{3}\right)
$$

[255] RE estimates using ab initio calculations are available for these compounds [Bravo et al., 2011a] (Table S7 in the supporting information), but we focus here on the experimental data from Andersen et al. [2004]. They used the Pinnock et al. [1995] method to estimate instantaneous REs of $0.32,0.61$, and $0.83 \mathrm{~W} \mathrm{~m}^{-2} \mathrm{ppb}^{-1}$ for $\mathrm{HG}^{\prime}-01$, $\mathrm{HG}^{\prime}-02$, and $\mathrm{HG}^{\prime}-03$, respectively. The corresponding $\mathrm{RE}$ estimates from our calculations (now taking into account stratospheric temperature adjustment and inhomogeneous distribution in the troposphere) are $0.29,0.56$ and $0.76 \mathrm{~W}$ $\mathrm{m}^{-2} \mathrm{ppb}^{-1}$, respectively, when using absorption cross sections and lifetimes from Andersen et al. [2004]. None of these compounds are included in AR4; thus, we provide new best estimates of RE and GWP for all these compounds.

\subsubsection{HFE-329me3 $\left(\mathrm{CF}_{3} \mathrm{CFHCF}_{2} \mathrm{OCF}_{3}\right)$}

[256] Wallington et al. [2004] have calculated an instantaneous RE value of HFE-329me3 of $0.48 \mathrm{~W} \mathrm{~m}^{-2} \mathrm{ppb}^{-1}$ by using experimental absorption cross section and the Pinnock et al. [1995] method. We have used the absorption spectrum from the same study and calculated the same RE value when accounting for stratospheric temperature adjustment. Due to the relatively long lifetime of 40 years [Wallington et al., 2004], the compound is well-mixed in the troposphere and the lifetime correction factor does not impact the RE value.

\subsubsection{5. $\mathrm{HFE}-338 \mathrm{mec} 3\left(\mathrm{CF}_{3} \mathrm{CFHCF}_{2} \mathrm{OCF}_{2} \mathrm{H}\right)$}

[257] Previous experimental studies of RE due to HFE$338 \mathrm{mec} 3$ are in the range of $0.49-0.51 \mathrm{~W} \mathrm{~m}^{-2} \mathrm{ppb}^{-1}$ (mean: 
$0.50 \mathrm{~W} \mathrm{~m}^{-2} \mathrm{ppb}^{-1}$ ) [Oyaro et al., 2005; Wallington et al., 2004]. We have used the absorption cross sections from both these studies and calculated a mean RE value of $0.51 \mathrm{~W} \mathrm{~m}^{-2}$ $\mathrm{ppb}^{-1}$ (range: $0.51-0.52 \mathrm{~W} \mathrm{~m}^{-2} \mathrm{ppb}^{-1}$ ) when assuming a uniform distribution in the atmosphere. This is probably an upper estimate as no fractional correction factor has been applied because of the large disagreement found in the literature of the lifetime for this compound [Oyaro et al., 2005; Wallington et al., 2004].

4.1.7.36. HFEs Studied by Waterland et al. [2005]

[258] For the following HFE compounds, Waterland et al. [2005] is the only study providing experimental absorption cross sections:

3,3,4,4,5,5,6,6,7,7,7-Undecafluoroheptan-1-ol $\left(\mathrm{CF}_{3}\left(\mathrm{CF}_{2}\right)\right.$ $\left.{ }_{4} \mathrm{CH}_{2} \mathrm{CH}_{2} \mathrm{OH}\right)$

3,3,4,4,5,5,6,6,7,7,8,8,9,9,9-Pentadecafluorononan-1-ol $\left(\mathrm{CF}_{3}\left(\mathrm{CF}_{2}\right)_{6} \mathrm{CH}_{2} \mathrm{CH}_{2} \mathrm{OH}\right)$

$3,3,4,4,5,5,6,6,7,7,8,8,9,9,10,10,11,11,11-$ Nonadecafluoroundecan-1-ol $\left(\mathrm{CF}_{3}\left(\mathrm{CF}_{2}\right)_{8} \mathrm{CH}_{2} \mathrm{CH}_{2} \mathrm{OH}\right)$

[259] Waterland et al. [2005] did not estimate REs of the compounds listed above, but we have used their absorption cross sections to calculate REs of $0.06,0.07$ and $0.05 \mathrm{~W} \mathrm{~m}^{-2}$ $\mathrm{ppb}^{-1}$ for $3,3,4,4,5,5,6,6,7,7,7$-undecafluoroheptan-1-ol, $3,3,4,4,5,5,6,6,7,7,8,8,9,9,9$-pentadecafluorononan-1-ol, and $3,3,4,4,5,5,6,6,7,7,8,8,9,9,10,10,11,11,11$-nonadecafluoroundecan-1-ol, respectively. The lifetimes for all three compounds were assumed to be 20 days based on Ellis et al. [2003].

4.1.7.37. 2-Chloro-1,1,2-trifluoro-1-methoxyethane $\left(\mathrm{CH}_{3} \mathrm{OCF}_{2} \mathrm{CHFCl}\right)$

[260] One experimental study has used the Pinnock et al. [1995] method to estimate an instantaneous RE due to 2chloro-1,1,2-trifluoro-1-methoxyethane of $0.26 \mathrm{~W} \mathrm{~m}^{-2} \mathrm{ppb}^{-1}$ [Dalmasso et al., 2006]. We have used their absorption cross section to calculate a slightly lower RE value of $0.21 \mathrm{~W} \mathrm{~m}^{-2} \mathrm{ppb}^{-1}$ (now taking into account stratospheric temperature adjustment and inhomogeneous distribution in the troposphere). The lifetime of 1.4 years is taken from Dalmasso et al. [2006].

\subsubsection{PFPMIE (perfluoropolymethylisopropyl ether)} $\left(\mathrm{CF}_{3} \mathrm{OCF}\left(\mathrm{CF}_{3}\right) \mathrm{CF}_{2} \mathrm{OCF}_{2} \mathrm{OCF}_{3}\right)$

[261] One experimental study has estimated RE due to PFPMIE (perfluoropolymethylisopropylether), with a value $0.65 \mathrm{~W} \mathrm{~m}^{-2} \mathrm{ppb}^{-1}$ [Young et al., 2006] which is used in IPCC AR4. We have used the same absorption cross section and calculated the same RE value. In contrast to the other compounds listed in this section, PFPMIE is lost by photolysis in the upper atmosphere and this results in a long lifetime of approximately 800 years [Young et al., 2006]. Hence, we have used the exponential fit from section 3.3.4 (equation (1) and red curve in Figure 9) rather than the $S$-shaped fit to account for a non-uniform vertical profile, although this has almost a negligible impact on the RE because such long-lived compounds are relatively wellmixed throughout the atmosphere.

\subsubsection{HFE-216 $\left(\mathrm{CF}_{3} \mathrm{OCF}=\mathrm{CF}_{2}\right)$}

[262] Mashino et al. [2000] have estimated the instantaneous RE of HFE-216 by using the Pinnock et al. [1995] method and report a value of $0.28 \mathrm{~W} \mathrm{~m}^{-2} \mathrm{ppb}^{-1}$. We have used their absorption cross section, accounted for stratospheric temperature adjustment and lifetime correction, and calculated a much lower $\mathrm{RE}$ value of $0.02 \mathrm{~W} \mathrm{~m}^{-2}$ $\mathrm{ppb}^{-1}$. The reason for the large difference is the short lifetime of 8.4 days [Mashino et al., 2000] which leads to a strong correction when accounting for non-homogeneous horizontal and vertical distribution in the troposphere. It should be noted here that the uncertainties associated with the lifetime correction factors are very large on a percentage basis for such short-lived species (see Figure 9 and associated discussion in section 3.3.4).

\subsubsection{HFEs Studied Theoretically by Bravo et al. [2011b]}

[263] For a number of HFE compounds, no RE estimates based on experimental absorption cross sections exist and the ab initio study of Bravo et al. [2011b] provides the only RE estimate of these HFEs. These compounds are as follows:

Trifluoromethyl formate $\left(\mathrm{HCOOCF}_{3}\right)$

Perfluoroethyl formate $\left(\mathrm{HCOOCF}_{2} \mathrm{CF}_{3}\right)$

Perfluoropropyl formate $\left(\mathrm{HCOOCF}_{2} \mathrm{CF}_{2} \mathrm{CF}_{3}\right)$

Perfluorobutyl formate $\left(\mathrm{HCOOCF}_{2} \mathrm{CF}_{2} \mathrm{CF}_{2} \mathrm{CF}_{3}\right)$

2,2,2-Trifluoroethyl formate $\left(\mathrm{HCOOCH}_{2} \mathrm{CF}_{3}\right)$

3,3,3-Trifluoropropyl formate $\left(\mathrm{HCOOCH}_{2} \mathrm{CH}_{2} \mathrm{CF}_{3}\right)$

1,2,2,2-Tetrafluoroethyl formate $\left(\mathrm{HCOOCHFCF}_{3}\right)$

1,1,1,3,3,3-Hexafluoropropan-2-yl formate $\left(\mathrm{HCOOCH}\left(\mathrm{CF}_{3}\right)_{2}\right)$

Perfluorobutyl acetate $\left(\mathrm{CH}_{3} \mathrm{COOCF}_{2} \mathrm{CF}_{2} \mathrm{CF}_{2} \mathrm{CF}_{3}\right)$

Perfluoropropyl acetate $\left(\mathrm{CH}_{3} \mathrm{COOCF}_{2} \mathrm{CF}_{2} \mathrm{CF}_{3}\right)$

Perfluoroethyl acetate $\left(\mathrm{CH}_{3} \mathrm{COOCF}_{2} \mathrm{CF}_{3}\right)$

Trifluoromethyl acetate $\left(\mathrm{CH}_{3} \mathrm{COOCF}_{3}\right)$

Methyl carbonofluoridate $\left(\mathrm{FCOOCH}_{3}\right)$

Fluoromethyl carbonofluoridate $\left(\mathrm{FCOOCFH}_{2}\right)$

Difluoromethyl carbonofluoridate $\left(\mathrm{FCOOCF}_{2} \mathrm{H}\right)$

Trifluoromethyl carbonofluoridate $\left(\mathrm{FCOOCF}_{3}\right)$

Perfluoroethyl carbonofluoridate $\left(\mathrm{FCOOCF}_{2} \mathrm{CF}_{3}\right)$

2,2,2-Trifluoroethyl carbonofluoridate $\left(\mathrm{FCOOCH}_{2} \mathrm{CF}_{3}\right)$ 
1,1-Difluoroethyl carbonofluoridate $\left(\mathrm{FCOOCF}_{2} \mathrm{CH}_{3}\right)$

Perfluoropropyl carbonofluoridate $\left(\mathrm{FCOOCF}_{2} \mathrm{CF}_{2} \mathrm{CF}_{3}\right)$

Trifluoromethyl 2,2,2-trifluoroacetate $\left(\mathrm{CF}_{3} \mathrm{COOCF}_{3}\right)$

Perfluoroethyl 2,2,2-trifluoroacetate $\left(\mathrm{CF}_{3} \mathrm{COOCF}_{2} \mathrm{CF}_{3}\right)$

1,1-Difluoroethyl 2,2,2-trifluoroacetate $\left(\mathrm{CF}_{3} \mathrm{COOCF}_{2} \mathrm{CH}_{3}\right)$

1,1,1,3,3,3-Hexafluoropropan-2-yl 2,2,2-trifluoroacetate $\left(\mathrm{CF}_{3} \mathrm{COOCH}\left(\mathrm{CF}_{3}\right)_{2}\right)$

Vinyl 2,2,2-trifluoroacetate $\left(\mathrm{CF}_{3} \mathrm{COOCH}=\mathrm{CH}_{2}\right)$

Ethyl 2,2,2-trifluoroacetate $\left(\mathrm{CF}_{3} \mathrm{COOCH}_{2} \mathrm{CH}_{3}\right)$

2,2,2-Trifluoroethyl 2,2,2-trifluoroacetate $\left(\mathrm{CF}_{3} \mathrm{COOCH}_{2} \mathrm{CF}_{3}\right)$

Allyl 2,2,2-trifluoroacetate $\left(\mathrm{CF}_{3} \mathrm{COOCH}_{2} \mathrm{CHCH}_{2}\right)$

Methyl 2,2,2-trifluoroacetate $\left(\mathrm{CF}_{3} \mathrm{COOCH}_{3}\right)$

Phenyl 2,2,2-trifluoroacetate $\left(\mathrm{CF}_{3} \mathrm{COOPh}\right)$

Methyl 2-fluoroacetate $\left(\mathrm{H}_{2} \mathrm{CFCOOCH}_{3}\right)$

Difluoromethyl 2,2-difluoroacetate $\left(\mathrm{HCF}_{2} \mathrm{COOCHF}_{2}\right)$

Methyl 2,2-difluoroacetate $\left(\mathrm{HCF}_{2} \mathrm{COOCH}_{3}\right)$

Difluoromethyl 2,2,2-trifluoroacetate $\left(\mathrm{CF}_{3} \mathrm{COOCHF}_{2}\right)$

[264] For all of the compounds listed above, we have used the theoretical absorption cross sections from Bravo et al. [2011b] to calculate estimates of RE, taking into account both stratospheric temperature adjustment (by increasing the instantaneous RE by $10 \%$ as described in section 3.3.2) and the fractional correction (by using the method described in section 3.3.4). For 14 of the 34 compounds listed above, no lifetime estimates were found in the literature; hence, the RE estimates for these compounds assume a uniform vertical and horizontal distribution in the atmosphere. Lifetimes for the remaining 20 compounds were taken from various sources [Blanco and Teruel, 2007; Bravo et al., 2011b; Chen et al., 2006; Christensen et al., 1998; Oyaro et al., 2004; Wallington et al., 1988; Wallington et al., 1997; WMO, 2011] (see Table S7 in the supporting information for details). The Bravo et al. [2011b] study used the Pinnock et al. [1995] method to estimate instantaneous REs, but they did not account for non-homogeneous mixing. The RE estimates of Bravo et al. [2011b] are listed in Table S7 in the supporting information, while our results are presented in Table 15. In general, differences reflect the use of an updated Pinnock et al. [1995] curve in this study, and that stratospheric temperature adjustment and lifetime correction were not taken into account in Bravo et al. [2011b]. None of the compounds listed above are included in AR4, thus we provide new best estimates of RE and GWP for all these compounds. It should, however, be kept in mind that RE estimates based on ab initio calculations are associated with larger uncertainties than estimates based on experimental cross sections, as discussed in section 3.6.1 (see also Table 1).

\subsubsection{2,2,3,3,4,4,4-Heptafluorobutan-1-} ol $\left(\mathrm{C}_{3} \mathrm{~F}_{7} \mathrm{CH}_{2} \mathrm{OH}\right)$

[265] One experimental study has estimated the instantaneous lifetime-corrected RE due to 2,2,3,3,4,4,4heptafluorobutan-1-ol with a value $0.20 \mathrm{~W} \mathrm{~m}^{-2} \mathrm{ppb}^{-1}$ [Bravo et al., 2010a]. We have used their absorption cross section and calculated the same RE value when also taking into account stratospheric temperature adjustment and when using our own lifetime correction method (Bravo et al. [2010a] used the exponential function of Sihra et al. [2001]). The lifetime of 0.6 years is taken from Bravo et al. [2010a].

\subsubsection{2,2,3,3-Tetrafluoro-1-propanol} $\left(\mathrm{CHF}_{2} \mathrm{CF}_{2} \mathrm{CH}_{2} \mathrm{OH}\right)$

[266] Previous experimental studies of RE due to 2,2,3,3tetrafluoro-1-propanol are in the range of $0.20-0.23 \mathrm{~W} \mathrm{~m}^{-2}$ $\mathrm{ppb}^{-1}$ (mean: $0.22 \mathrm{~W} \mathrm{~m}^{-2} \mathrm{ppb}^{-1}$ ) [Antiñolo et al., 2012b; Sellevaig et al., 2007]. We have used the absorption cross sections from these two studies and calculated a RE value of $0.11 \mathrm{~W} \mathrm{~m}^{-2} \mathrm{ppb}^{-1}$ for both sources. The lifetime correction applied here is the main reason for the lower value compared to earlier work where the instantaneous RE assuming constant distribution was estimated. The lifetime of 91.2 days is taken from Antiñolo et al. [2012b].

\subsubsection{2,2,3,4,4,4-Hexafluoro-1-butanol $\left(\mathrm{CF}_{3} \mathrm{CHFCF}_{2} \mathrm{CH}_{2} \mathrm{OH}\right)$}

[267] The experimental study of Sellevåg et al. [2007] has used the Pinnock et al. [1995] method to estimate an instantaneous RE due to 2,2,3,4,4,4-hexafluoro-1-butanol of $0.37 \mathrm{~W} \mathrm{~m}^{-2} \mathrm{ppb}^{-1}$. We have used their absorption cross section and calculated a RE value of $0.19 \mathrm{~W} \mathrm{~m}^{-2} \mathrm{ppb}^{-1}$ when taking into account stratospheric temperature adjustment and lifetime correction. The lifetime of 94.9 days is taken from Sellevåg et al. [2007].

\subsubsection{2,2,3,3,4,4,4-Heptafluoro-1-butanol $\left(\mathrm{CF}_{3} \mathrm{CF}_{2} \mathrm{CF}_{2} \mathrm{CH}_{2} \mathrm{OH}\right)$}

[268] One experimental study has estimated the instantaneous RE due to 2,2,3,3,4,4,4-heptafluoro-1-butanol, with a value $0.30 \mathrm{~W} \mathrm{~m}^{-2} \mathrm{ppb}^{-1}$ [Sellevåg et al., 2007]. We calculate a RE value of $0.16 \mathrm{~W} \mathrm{~m}^{-2} \mathrm{ppb}^{-1}$ using the absorption cross section from the same study. Our RE estimate accounts for stratospheric temperature adjustment and lifetime correction; the latter factor explains the lower $\mathrm{RE}$ calculated here. The lifetime of 0.3 years is taken from Sellevåg et al. [2007].

\subsubsection{1,1,2,2-Tetrafluoro-3-methoxy-propane $\left(\mathrm{CHF}_{2} \mathrm{CF}_{2} \mathrm{CH}_{2} \mathrm{OCH}_{3}\right)$}

[269] One experimental study has estimated the instantaneous $\mathrm{RE}$ due to 1,1,2,2-tetrafluoro-3-methoxy-propane with a value $0.24 \mathrm{~W} \mathrm{~m}^{-2} \mathrm{ppb}^{-1}$ [Oyaro et al., 2004]. We have used their absorption cross section and calculated a much lower RE value of $0.04 \mathrm{~W} \mathrm{~m}^{-2} \mathrm{ppb}^{-1}$ when taking into account stratospheric temperature adjustment and non- 
TABLE 16. GWP and GTP for Selected Gases

\begin{tabular}{|c|c|c|c|c|c|c|c|c|c|}
\hline \multirow[b]{2}{*}{ Acronym / name } & \multirow[b]{2}{*}{ Formula } & \multirow[b]{2}{*}{ Lifetime (year) } & \multirow[b]{2}{*}{$\mathrm{RE}\left(\mathrm{W} \mathrm{m}^{-2} \mathrm{ppb}^{-1}\right)$} & \multicolumn{3}{|c|}{ GWP } & \multicolumn{3}{|c|}{ GTP } \\
\hline & & & & 20 years & 100 years & 500 years & 20 years & 50 years & 100 years \\
\hline CFC-11 & $\mathrm{CCl}_{3} \mathrm{~F}$ & 45.0 & 0.26 & 6,900 & 4,660 & 1,490 & 6,890 & 4,890 & 2,340 \\
\hline CFC-12 & $\mathrm{CCl}_{2} \mathrm{~F}_{2}$ & 100.0 & 0.32 & 10,800 & 10,200 & 4,590 & 11,300 & 11,000 & 8,450 \\
\hline CFC-113 & $\mathrm{CCl}_{2} \mathrm{FCClF}_{2}$ & 85.0 & 0.30 & 6,490 & 5,820 & 2,390 & 6,730 & 6,250 & 4,470 \\
\hline HCFC-22 & $\mathrm{CHClF}_{2}$ & 11.9 & 0.21 & 5,280 & 1,760 & 503 & 4,200 & 832 & 262 \\
\hline HCFC-141b & $\mathrm{CH}_{3} \mathrm{CCl}_{2} \mathrm{~F}$ & 9.2 & 0.16 & 2,550 & 782 & 223 & 1,850 & 271 & 111 \\
\hline HCFC-142b & $\mathrm{CH}_{3} \mathrm{CClF}_{2}$ & 17.2 & 0.19 & 5,020 & 1,980 & 567 & 4,390 & 1,370 & 356 \\
\hline HFC-23 & $\mathrm{CHF}_{3}$ & 222.0 & 0.18 & 10,800 & 12,400 & 8,720 & 11,500 & 13,000 & 12,700 \\
\hline HFC-134a & $\mathrm{CH}_{2} \mathrm{FCF}_{3}$ & 13.4 & 0.16 & 3,710 & 1,300 & 371 & 3,050 & 703 & 201 \\
\hline HFC-152a & $\mathrm{CH}_{3} \mathrm{CHF}_{2}$ & 1.5 & 0.10 & 506 & 138 & 39 & 174 & 24 & 19 \\
\hline Methyl chloroform & $\mathrm{CH}_{3} \mathrm{CCl}_{3}$ & 5.0 & 0.07 & 578 & 160 & 46 & 317 & 34 & 22 \\
\hline Carbon tetrachloride & $\mathrm{CCl}_{4}$ & 26.0 & 0.17 & 3,480 & 1,730 & 504 & 3,280 & 1,570 & 479 \\
\hline Sulfur hexafluoride & $\mathrm{SF}_{6}$ & $3,200.0$ & 0.57 & 17,500 & 23,500 & 31,500 & 18,900 & 23,800 & 28,200 \\
\hline PFC-14 & $\mathrm{CF}_{4}$ & $50,000.0$ & 0.09 & 4,880 & 6,630 & 9,410 & 5,270 & 6,690 & 8,040 \\
\hline
\end{tabular}

homogeneous distribution in the troposphere (these factors were not taken into account in the published RE estimate). The lifetime of 14.2 days is taken from Oyaro et al. [2004], and it should be noted here that the uncertainties associated with the lifetime correction factor are very large on a percentage basis for such short-lived species (see Figure 9 and associated discussion in section 3.3.4),

\subsubsection{Perfluoro-2-methyl-3-pentanone $\left(\mathrm{CF}_{3} \mathrm{CF}_{2} \mathrm{C}\right.$ (O)CF $\left.\left(\mathrm{CF}_{3}\right)_{2}\right)$}

[270] No RE estimates of perfluoro-2-methyl-3-pentanone exist in the literature. Here we have used the absorption cross section from D'Anna et al. [2005] and calculate a RE value of $0.03 \mathrm{~W} \mathrm{~m}^{-2} \mathrm{ppb}^{-1}$ assuming a lifetime of 7.0 days [D'Anna et al., 2005].

\subsubsection{3,3,3-Trifluoro-propanal $\left(\mathrm{CF}_{3} \mathrm{CH}_{2} \mathrm{CHO}\right)$}

[271] No RE estimates of 3,3,3-trifluoro-propanal can be found in the literature, but here we have calculated its RE by using the absorption cross sections of Antiñolo et al. [2011] and Sellevag et al. [2004a]. Due to the very short lifetime of only 2.0 days for this compound [Antiñolo et al., 2011], our calculated $\mathrm{RE}$ rounds to $0.00 \mathrm{~W} \mathrm{~m}^{-2} \mathrm{ppb}^{-1}$ when applying the lifetime correction (section 3.3.4). Uncertainties related to the fractional correction are large for compounds with such short lifetimes. The mean RE calculated here when assuming a uniform horizontal and vertical distribution is $0.16 \mathrm{~W} \mathrm{~m}^{-2} \mathrm{ppb}^{-1}$, and should be considered an upper estimate.

\subsubsection{4,4,4-Trifluorobutanal $\left(\mathrm{CF}_{3}\left(\mathrm{CH}_{2}\right)_{2} \mathrm{CHO}\right)$}

[272] No RE or lifetime estimates of 4,4,4-trifluorobutanal can be found in the literature. Here we have used the absorption cross section from Antiñolo et al. [2012a] and calculated a RE value of $0.16 \mathrm{~W} \mathrm{~m}^{-2} \mathrm{ppb}^{-1}$ assuming a constant horizontal and vertical distribution in the troposphere. Hence, this RE value should be considered an upper estimate.

\subsubsection{2-Fluoroethanol $\left(\mathrm{CH}_{2} \mathbf{F C H} \mathrm{CH}_{2} \mathrm{OH}\right)$}

[273] In the experimental study of Sellevag et al. [2004b] a broadband model and a CTM were used to estimate the RE due to 2-fluoroethanol with a value $0.02 \mathrm{~W} \mathrm{~m}^{-2} \mathrm{ppb}^{-1}$. We have used their absorption cross section and calculated the same RE value. The lifetime of 20.4 days is taken from Sellevag et al. [2004b].

\subsubsection{2,2-Difluoroethanol $\left(\mathrm{CHF}_{2} \mathrm{CH}_{2} \mathrm{OH}\right)$}

[274] One experimental study has estimated RE due to 2,2-difluoroethanol, with a value $0.02 \mathrm{~W} \mathrm{~m}^{-2} \mathrm{ppb}^{-1}$ [Sellevag et al., 2004b]. We used their absorption crosssection and calculated a higher $\mathrm{RE}$ value of $0.04 \mathrm{~W} \mathrm{~m}^{-2}$ $\mathrm{ppb}^{-1}$. As discussed in section 3.3.4 and illustrated in Figure 9, the uncertainties when applying lifetime corrections are large for such short-lived compounds (lifetime of 40.0 days) [Sellevag et al., 2004b].

\subsubsection{2,2,2-Trifluoroethanol $\left(\mathrm{CF}_{3} \mathrm{CH}_{2} \mathrm{OH}\right)$}

[275] Previous experimental studies of $\mathrm{RE}$ due to 2,2,2trifluoroethanol are in the range of $0.09-0.19 \mathrm{~W} \mathrm{~m}^{-2} \mathrm{ppb}^{-1}$ (mean: $0.14 \mathrm{~W} \mathrm{~m}^{-2} \mathrm{ppb}^{-1}$ ) and stem from the work of Sellevag et al. [2004b] and Imasu et al. [1995] (note that the RE from the latter study has been scaled to our recommended CFC-11 $\mathrm{RE}$ of $0.26 \mathrm{~W} \mathrm{~m}^{-2} \mathrm{ppb}^{-1}$ ). We calculate a RE value of $0.10 \mathrm{~W}$ $\mathrm{m}^{-2} \mathrm{ppb}^{-1}$ when using the absorption cross-sections from both these sources. Our value is close to the RE of $0.09 \mathrm{~W} \mathrm{~m}^{-2}$ $\mathrm{ppb}^{-1}$ from Sellevag et al. [2004b] who used a CTM to account for the non-homogeneous tropospheric distribution. The lifetime of 0.3 years is taken from Sellevag et al. [2004b].

\subsubsection{HFEs Studied by Andersen et al. [2010b]}

[276] For the following HFE compounds, Andersen et al. [2010b] is the only study providing REs based on experimental absorption cross-sections:

1,1'-Oxybis[2-(difluoromethoxy)-1,1,2,2tetrafluoroethane $\left(\mathrm{HCF}_{2} \mathrm{O}\left(\mathrm{CF}_{2} \mathrm{CF}_{2} \mathrm{O}\right)_{2} \mathrm{CF}_{2} \mathrm{H}\right)$

1,1,3,3,4,4,6,6,7,7,9,9,10,10,12,12-hexadecafluoro2,5,8,11-Tetraoxadodecane $\left(\mathrm{HCF}_{2} \mathrm{O}\left(\mathrm{CF}_{2} \mathrm{CF}_{2} \mathrm{O}\right)_{3} \mathrm{CF}_{2} \mathrm{H}\right)$

1,1,3,3,4,4,6,6,7,7,9,9,10,10,12,12,13,13,15,15-eicosafluoro2,5,8,11,14-Pentaoxapentadecane $\left(\mathrm{HCF}_{2} \mathrm{O}\left(\mathrm{CF}_{2} \mathrm{CF}_{2} \mathrm{O}\right)_{4} \mathrm{CF}_{2} \mathrm{H}\right)$

[277] Andersen et al. [2010b] used the Pinnock et al. [1995] method to estimate instantaneous REs of these compounds. Since absorption spectra were unavailable for the three compounds listed above, no new calculations have been carried out here. Thus, we use the REs from Andersen et al. [2010b], accounting for stratospheric temperature adjustment 


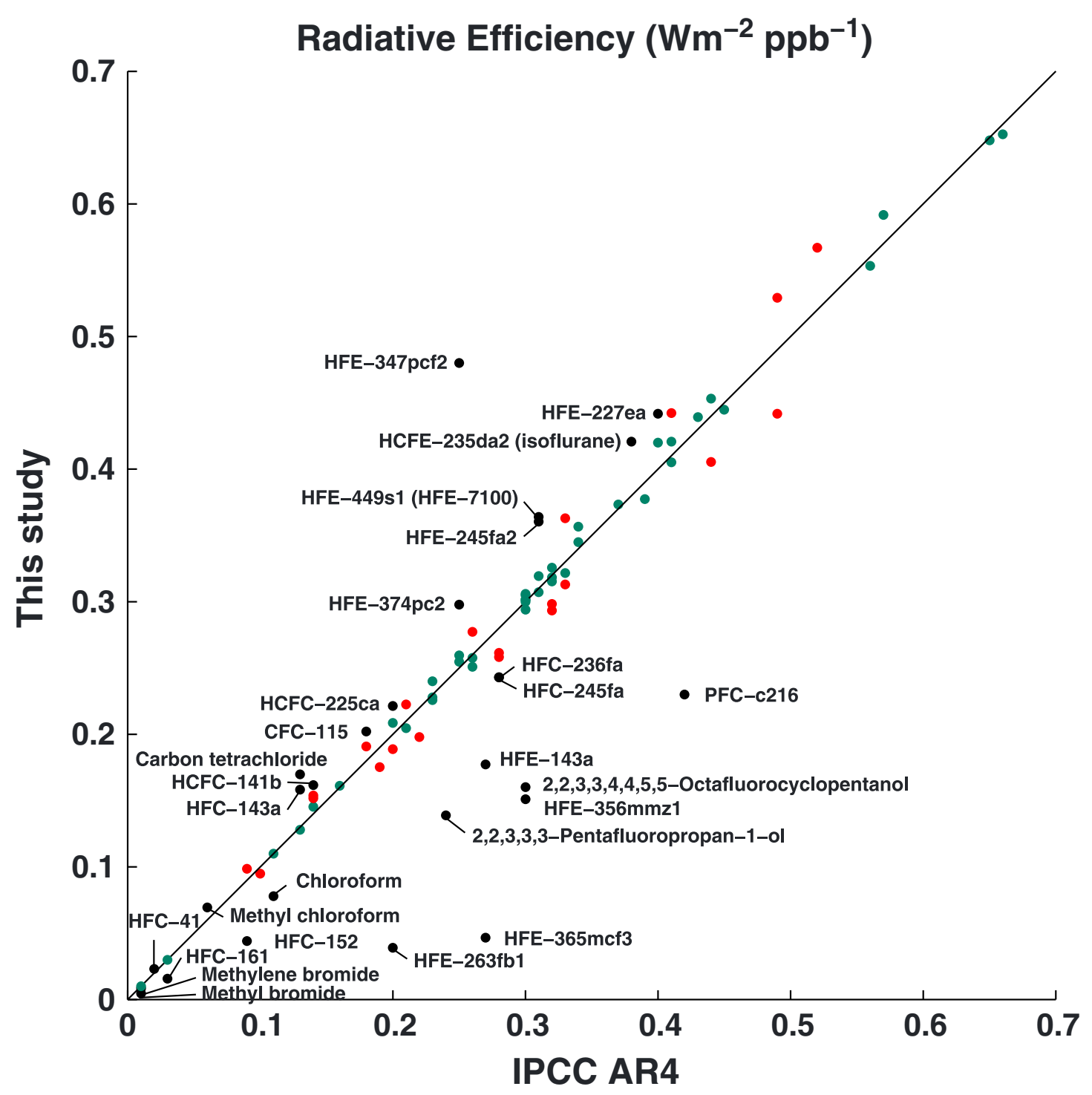

Figure 18. Comparison of radiative efficiencies calculated in this study (lifetime-corrected adjusted cloudy-sky) and from AR4 [Forster et al., 2007]. Green dots represent compounds where the RE in this study is less than $5 \%$ different from AR4, while red and black dots represent compounds where the REs are significantly different ( $>5 \%$ and $>10 \%$, respectively). Black dots have been labeled and represent compounds where the RE calculated here is more than $10 \%$ different from AR4. Two compounds are off scale and therefore not shown in the plot: HFE-43-10pccc (H-Galden 1040x, HG-11) with a RE of $1.02 \mathrm{~W} \mathrm{~m}^{-2} \mathrm{ppb}^{-1}$ calculated in the present study (compared to $1.37 \mathrm{~W} \mathrm{~m}^{-2} \mathrm{ppb}^{-1}$ in AR4) and HFE-338pcc13 (HG-01) with a RE of $0.86 \mathrm{~W} \mathrm{~m}^{-2} \mathrm{ppb}^{-1}$ calculated in the present study (compared to $0.87 \mathrm{~W} \mathrm{~m}^{-2} \mathrm{ppb}^{-1}$ in AR4).

and lifetime correction (see sections 3.3.2 and 3.3.4, respectively), and present new best estimate REs of $1.15,1.43$ and $1.46 \mathrm{~W} \mathrm{~m}^{-2} \mathrm{ppb}^{-1}$ for $1,1^{\prime}$-oxybis[2-(difluoromethoxy)1,1,2,2-tetrafluoroethane, 1,1,3,3,4,4,6,6,7,7,9,9,10,10,12,12hexadecafluoro-2,5,8,11-tetraoxadodecane and 1,1,3,3,4,4,6, $6,7,7,9,9,10,10,12,12,13,13,15,15$-eicosafluoro-2,5,8,11,14pentaoxapentadecane, respectively. We have used the same assumption as in Andersen et al. [2010b] of a lifetime for all three compounds of 26 years.

\subsection{Additional Metrics for the Most Important Gases: GTPs and GWPs for Other Time Horizons}

[278] While we have used a time horizon of 100 years in the main tables, we also show GWP values for 20 and 500 years for a selection of gases together with GTP values for the same gases in Table 16. The GTP values vary with time horizon in a way that depends on adjustment time and how this compares with the time scale for the response of $\mathrm{CO}_{2}$. For gases with short and medium lifetimes (e.g., HFC-152a and HCFC-22), the GTP falls rapidly with time horizon from 20 to 100 years. By contrast, the longer-lived gases, such as HFC-23 and CFC-12, show GTPs that increase from time horizons of 20 to 50 years, before decreasing, while for the very long-lived gases $\left(\mathrm{SF}_{6}\right.$ and PFC-14), the GTP values continue to increase out to 100 years. The contrast between the GWP and GTP values in Table 16 is particularly noticeable for gases with short and medium lifetimes - for example, for HCFC-22, the GWP drops by an about a factor of 3 between time horizons of 20 and 


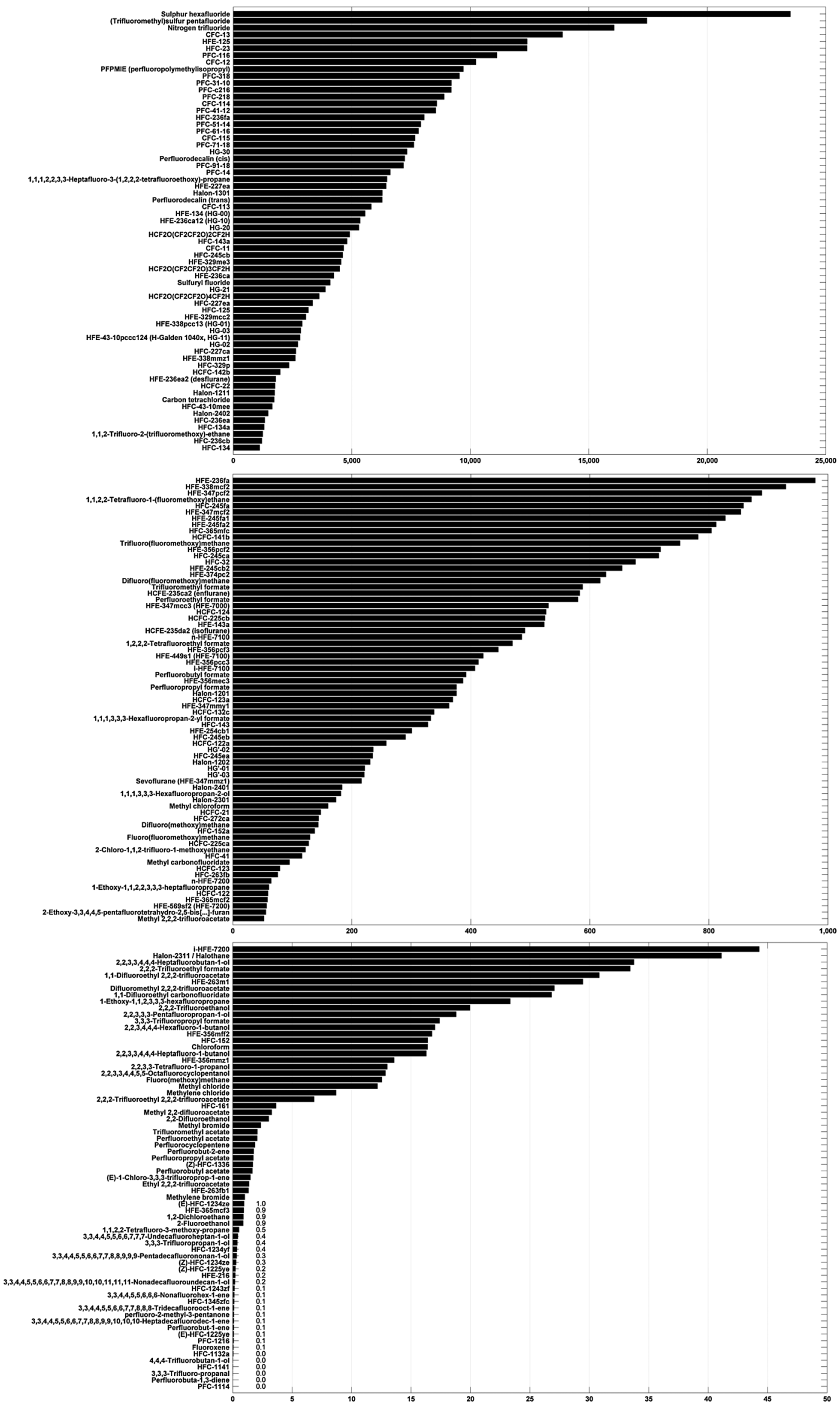

Figure 19. GWP 100 year of all compounds calculated in this study. 
100 years, whereas the GTP drops by more than an order of magnitude. This reflects the fact that the integral nature of the GWP means that it keeps the memory of the strong shortlived forcing, while the GTP, being an end-point metric, retains less of a memory, and the impact of the forcing pulse on temperature has largely disappeared after 100 years.

[279] Compared to Fuglestvedt et al. [2010], the GWP and GTPs for $\mathrm{CCl}_{4}$ are higher due to the higher RE calculated in this study compared to the recommended RE in AR4 (see discussion of $\mathrm{CCl}_{4}$ in section 4.1 .4 for details). The metric values for $\mathrm{SF}_{6}$ have also increased (except for GWP 500 year) due to the increase of the best estimate RE for this compound (see section 4.1.6).

[280] It should be noted that while the impulse response function for $\mathrm{CO}_{2}$ includes climate-carbon cycle feedbacks, no feedbacks are included for the non- $\mathrm{CO}_{2}$ gases. The magnitude of this bias has not been assessed for the gases addressed here. However, Gillett and Matthews [2010] found that for $\mathrm{N}_{2} \mathrm{O}$ and $\mathrm{CH}_{4}$ the GWP-100 values increased by $20 \%$ when climate-carbon cycle feedbacks were included; which gives some indication of the bias in the GWP values presented here.

\section{SUMMARY AND CONCLUSIONS}

[281] We present a comprehensive assessment of the radiative efficiencies (REs) for a large number of halocarbons and related radiatively active compounds including CFCs, HCFCs, bromofluorocarbons and bromochlorofluorocarbons (halons), HFCs, $\mathrm{PFCs}, \mathrm{SF}_{6}, \mathrm{NF}_{3}$, and related halogen containing compounds. A consistent method for calculating RE has been used for all compounds ruling out any differences related to the radiative transfer method. Further, our results have been compared with previously published literature and new best estimates have been presented for lifetimes, REs, and GWPs. A total of 223 compounds were included in this study. Here we summarize our main findings:

[282] Absorption cross-sections have been collected from various sources including freely available databases and requests to authors of individual studies. The absorption cross-section data used include experimental data and $\mathrm{ab}$ initio calculations. For most of the important halocarbons, several independent sources are available for absorption cross sections. However, we find insufficient data available (and hence encourage further studies) for HFC-23, HFC236ea, HFC-245ca, $\mathrm{CCl}_{4}$, and several HFEs.

[283] An updated version of the simplified method presented in Pinnock et al. [1995] to calculate REs was developed and is presented. In the updated version an improved representation of clouds and the spatial distribution of temperature and water vapor leads to changes in the estimated REs of up to $10 \%$ from those estimated using the values given by Pinnock et al. [1995]. For most compounds, we apply a generic correction to account for the effect of stratospheric temperature adjustment. The simulations by the simplified method are performed with a LBL model and results are presented on a $1 \mathrm{~cm}^{-1}$ resolution. There was very little (1-2\%) difference between REs calculated using $1 \mathrm{~cm}^{-1}$ or
$10 \mathrm{~cm}^{-1}$ resolution, but it is greater for some compounds, most notably $\mathrm{CF}_{4}$ where the difference is $8 \%$.

[284] Simulations using a chemical transport model and results from the existing literature were used to develop simple lifetime-dependent correction factors to account for inhomogeneous mixing in the atmosphere. Application of these correction factors is shown to be particularly important for very short-lived compounds and leads to substantially lower REs than generally reported in the literature.

[285] We estimate that the uncertainty (5-95\% confidence range) in RE of compounds for which we have experimental absorption cross sections is approximately $13 \%$ for gases with atmospheric lifetimes greater than 5 years, and approximately $23 \%$ for gases with lifetimes less than 5 years. For compounds for which only ab initio cross-sections are available, the estimated uncertainties are $16 \%$ and $25 \%$ for compounds with lifetimes greater and less than 5 years, respectively. These estimates assume that empirical corrections based on knowledge of the spectra of related compounds have been applied to the ab initio cross-sections to account for systematic errors in the calculation of the wavenumbers of the vibrational modes. Where more generic corrections have been made, the errors can be somewhat larger. Our estimated uncertainties are larger than the value of $10 \%$ given in IPCC AR4 for the RE of the long-lived greenhouse gases. The uncertainty in $\mathrm{GWP}_{\mathrm{HFC}-134 \mathrm{a}}$ is estimated to $24 \%, 34 \%$, and $37 \%$ for a 20,100 , and 500 year time horizon. For CFC-11 the GWP uncertainties are $23 \%$, $38 \%$ and $47 \%$ for a 20,100 , and 500 year time horizon.

[286] Compared to AR4, the REs presented here differed significantly (by more than 5\%) for 49 compounds, while 42 compounds had similar ( $<5 \%$ difference) $\mathrm{RE}$ as in AR4. For 7 of the compounds included in AR4, we have not carried out calculations because spectrally resolved absorption cross-section data were not available, but for two of these compounds, we have updated the recommended $\mathrm{RE}$ based on values from the literature. Best estimate REs and GWPs have also been presented for 112 compounds which were not included in AR4. For 20 additional compounds, we have only presented new REs and not GWPs due to missing lifetime estimates.

[287] Substantial updates in REs are made for several important gases: CFC-11, CFC-115, HCFC-124, HCFC225cb, HFC-143a, HFC-245fa, $\mathrm{CCl}_{4}, \mathrm{CHCl}_{3}$, and $\mathrm{SF}_{6}$.

[288] As shown in Figure 18, where there are substantial differences between the REs evaluated in the present work and those given in AR4, the values evaluated here tend to be lower than those given in AR4. This trend largely reflects an improvement in the methodology used to correct for the inhomogeneous mixing of shorter lived species (see section 3.3.4).

[289] $\mathrm{SF}_{6}$ has the highest $\mathrm{GWP}(100)$ with a value of 23,500 (relative to $\mathrm{CO}_{2}$ ) as a result of its high RE and very long lifetime. A majority of the compounds considered here have a GWP(100) below 1,000, and almost $40 \%$ of the compounds have a GWP(100) below 100. (See Figure 19 showing GWP(100) values in ordered ranking for all the compounds investigated in this study.) The AGWPs for 
$\mathrm{CO}_{2}$ have been updated, and this leads to a lowering of the GWP(100) values of approximately $6 \%$ compared to AR4.

[290] We have calculated GWPs for 20, 100, and 500 year time horizons and global temperature change potentials (GTP) for 20, 50 and 100 years. The contrast between the GWP and GTP values is particularly noticeable for gases with short and medium lifetimes and reflects the integral nature of the GWP which retains memory of the strong shortlived forcing, while the GTP, being an end-point metric, has less of a memory.

[291] The GWP and GTP values are expected to change in the future, reflecting changes related to the reference gas $\mathrm{CO}_{2}$ (i.e., $\mathrm{AGWP}_{\mathrm{CO} 2}$ and $\mathrm{AGTP}_{\mathrm{CO} 2}$ will be updated as background conditions change and models improve) and as our understanding of the RE and lifetimes of the compounds improve. In future reviews it will be important to distinguish between changes in GWP and GTP values that are due to changes in $\mathrm{RE}$ and/or lifetime of the non- $\mathrm{CO}_{2}$ gas and those that are due to the changes related to the reference gas $\mathrm{CO}_{2}$ (i.e., $\mathrm{AGWP}_{\mathrm{CO} 2}$ and $\mathrm{AGTP}_{\mathrm{CO} 2}$ ). Updated GWPs and GTPs can be obtained by multiplying old values with the ratio between old and new $\mathrm{AGWP}_{\mathrm{CO} 2}$ and $\mathrm{AGTP}_{\mathrm{CO} 2}$ values, respectively.

[292] Our main focus has been on providing a comprehensive and self-consistent set of new calculations of REs. A follow up study could be a detailed assessment of lifetimes with calculations of how uncertainties in lifetimes together with uncertainties in RE propagate to GWPs and GTPs.

[293] There are several important impacts of our new results. First of all, the large number of compounds included in the review, and the high degree of consistency in the method of calculating REs of each compound, make it a lot easier for researchers, industry and others to compare the potential climate impacts (i.e., the GWPs and GTPs) of molecules, and this may be helpful in choosing compounds that are more climate friendly. Such a consistent set of RE values may also be relevant for future assessment reports and could in turn have policy implications. Second, the contribution from halocarbons to the present-day total radiative forcing of anthropogenic greenhouse gases is also expected to change slightly as a result of our updated RE numbers. In particular, carbon tetrachloride $\left(\mathrm{CCl}_{4}\right)$ has a high atmospheric concentration and the $\mathrm{RE}$ for this compound is much higher in our study $\left(0.17 \mathrm{~W} \mathrm{~m}^{-2} \mathrm{ppb}^{-1}\right)$ than in AR4 $\left(0.13 \mathrm{~W} \mathrm{~m}^{-2} \mathrm{ppb}^{-1}\right)$. Finally, we provide the research community with an improved tool for calculating the RE, GWP and GTP of a compound in a relatively simple manner.

[294] ACKNOWLEDGMENTS. Ø. Hodnebrog, G. Myhre, and J. S. Fuglestvedt acknowledge funding from the Norwegian Climate and Pollution Agency (Klif), and the Research Council of Norway within the project "Climate and health impacts of Short-Lived Atmospheric Components (SLAC)." The authors would like to thank Lars Hoffmann for providing the MIPAS CFC-11 dataset and several people for kindly providing absorption cross sections: Andrea Pietropolli Charmet, Vladimir L. Orkin, Silvia Lane, Mads P. Sulbaek Andersen, Freja Østerstrøm, Elena Jiménez, Maria Antiñolo, and Ryoichi Imasu. We thank Borgar Aamaas for making Figure 10, and Glen Peters, Robbie Andrew, and Amund Søvde for useful discussions. The Reading authors acknowledge the help of Ivan Bravo for his early work on updating the Pinnock method, and for many useful discussions. G. Marston and K. P. Shine acknowledge the RAL Molecular Spectroscopy Facility for their role in facilitating halocarbon absorption cross-section measurements, including those under grants from the UK Natural Environment Research Council (NMSF/0506/06 and NMSF/1112/01). The Editor on this paper was Alan Robock. He thanks Donald Wuebbles and two anonymous reviewers for their review assistance on this manuscript.

\section{REFERENCES}

Acerboni, G., J. A. Beukes, N. R. Jensen, J. Hjorth, G. Myhre, C. J. Nielsen, and J. K. Sundet (2001), Atmospheric degradation and global warming potentials of three perfluoroalkenes, Atmos. Environ., 35(24), 4113-4123, doi:10.1016/S1352-2310(01)00209-6.

Anastasi, C., A. E. Heathfield, G. P. Knight, and F. Nicolaisen (1994), Integrated absorption-coefficients of $\mathrm{CHClF}_{2}$ (HCFC-22) and $\mathrm{CH}_{3} \mathrm{Br}$ in the atmospheric infrared window region, Spectroc. Acta Pt. A-Molec. Biomolec. Spectr., 50(10), 1791-1798, doi:10.1016/ 0584-8539(94)00132-4.

Andersen, M. P. S., D. R. Blake, F. S. Rowland, M. D. Hurley, and T. J. Wallington (2009), Atmospheric Chemistry of Sulfuryl Fluoride: Reaction with $\mathrm{OH}$ Radicals, $\mathrm{CI}$ Atoms and $\mathrm{O}_{3}$, Atmospheric Lifetime, IR Spectrum, and Global Warming Potential, Environ. Sci. Technol., 43(4), 1067-1070, doi:10.1021/es802439f.

Andersen, M. P. S., M. D. Hurley, V. F. Andersen, O. J. Nielsen, and T. J. Wallington (2010a), $\mathrm{CHF}_{2} \mathrm{OCHF}_{2}$ (HFE-134): IR Spectrum and Kinetics and Products of the Chlorine-Atom-Initiated Oxidation, J. Phys. Chem. A, 114(14), 4963-4967, doi:10.1021/ jp101507f.

Andersen, M. P. S., V. F. Andersen, O. J. Nielsen, S. P. Sander, and T. J. Wallington (2010b), Atmospheric Chemistry of $\mathrm{HCF}_{2} \mathrm{O}$ $\left(\mathrm{CF}_{2} \mathrm{CF}_{2} \mathrm{O}\right)_{\mathrm{x}} \mathrm{CF}_{2} \mathrm{H}(\mathrm{x}=2-4)$ : Kinetics and Mechanisms of the Chlorine-Atom-Initiated Oxidation, Chemphyschem, 11(18), 4035-4041, doi:10.1002/cphc.201000438.

Andersen, M. P. S., R. L. Waterland, S. P. Sander, O. J. Nielsen, and T. J. Wallington (2012a), Atmospheric chemistry of $\mathrm{C}_{\mathrm{x}} \mathrm{F}_{2 \mathrm{x}}+$ ${ }_{1} \mathrm{CH}=\mathrm{CH}_{2}(\mathrm{x}=1,2,4,6$ and 8): Radiative efficiencies and global warming potentials, J. Photochem. Photobiol. A-Chem., 233, 50-52, doi:10.1016/j.jphotochem.2012.02.020.

Andersen, M. P. S., O. J. Nielsen, T. J. Wallington, B. Karpichev, and S. P. Sander (2012b), Assessing the Impact on Global Climate from General Anesthetic Gases, Anesth. Analg., 114(5), 1081-1085, doi:10.1213/ANE.0b013e31824d6150.

Andersen, M. P. S., E. J. K. Nilsson, O. J. Nielsen, M. S. Johnson, M. D. Hurley, and T. J. Wallington (2008), Atmospheric chemistry of trans- $\mathrm{CF}_{3} \mathrm{CHCHCl}$ : Kinetics of the gas-phase reactions with $\mathrm{Cl}$ atoms, $\mathrm{OH}$ radicals, and $\mathrm{O}_{3}, J$. Photochem. Photobiol., A, 199(1), 92-97, doi:10.1016/j.jphotochem.2008.05.013.

Andersen, M. P. S., S. P. Sander, O. J. Nielsen, D. S. Wagner, T. J. Sanford, and T. J. Wallington (2010c), Inhalation anaesthetics and climate change, Br. J. Anaesth., 105(6), 760-766, doi:10.1093/bja/aeq259.

Andersen, M. P. S., M. D. Hurley, T. J. Wallington, F. Blandini, N. R. Jensen, V. Librando, and J. Hjorth (2004), Atmospheric chemistry of $\mathrm{CH}_{3} \mathrm{O}\left(\mathrm{CF}_{2} \mathrm{CF}_{2} \mathrm{O}\right)_{n} \mathrm{CH}_{3} \quad(\mathrm{n}=1-3)$ : Kinetics and mechanism of oxidation initiated by $\mathrm{Cl}$ atoms and $\mathrm{OH}$ radicals, IR spectra, and global warmin potentials, J. Phys. Chem. A, 108(11), 1964-1972, doi:10.1021/jp036615a.

Andersen, M. P. S., O. J. Nielsen, A. Toft, T. Nakayama, Y. Matsumi, R. L. Waterland, R. C. Buck, M. D. Hurley, and T. J. Wallington (2005), Atmospheric chemistry of $\mathrm{C}_{\mathrm{x}} \mathrm{F}_{2 \mathrm{x}+1} \mathrm{CH}=\mathrm{CH}_{2}(\mathrm{x}=1,2,4$, 6, and 8): Kinetics of gas-phase reactions with $\mathrm{Cl}$ atoms, $\mathrm{OH}$ radicals, and $\mathrm{O}_{3}, J$. Photochem. Photobiol. A-Chem., 176(1-3), 124-128, doi:10.1016/j.jphotochem.2005.06.015.

Andrews, T., and P. M. Forster (2008), $\mathrm{CO}_{2}$ forcing induces semidirect effects with consequences for climate feedback 
interpretations, Geophys. Res. Lett., 35, L04802, doi:10.1029/ $2007 \mathrm{GL} 032273$.

Antiñolo, M., E. Jimenez, and J. Albaladejo (2011), UV absorption cross sections between 230 and $350 \mathrm{~nm}$ and pressure dependence of the photolysis quantum yield at $308 \mathrm{~nm}$ of $\mathrm{CF}_{3} \mathrm{CH}_{2} \mathrm{CHO}$, PCCP , 13(35), 15936-15946, doi:10.1039/c1cp21368g.

Antiñolo, M., E. Jimenez, and J. Albaladejo (2012a), Photochemistry of $\mathrm{CF}_{3}\left(\mathrm{CH}_{2}\right)_{2} \mathrm{CHO}$ in air: UV absorption cross sections between 230 and $340 \mathrm{~nm}$ and photolysis quantum yields at $308 \mathrm{~nm}$, J. Photochem. Photobiol. A-Chem., 231(1), 33-40, doi:10.1016/j.jphotochem.2011.12.023.

Antiñolo, M., S. González, B. Ballesteros, J. Albaladejo, and E. Jiménez (2012b), Laboratory Studies of $\mathrm{CHF}_{2} \mathrm{CF}_{2} \mathrm{CH}_{2} \mathrm{OH}$ and $\mathrm{CF}_{3} \mathrm{CF}_{2} \mathrm{CH}_{2} \mathrm{OH}$ : UV and IR Absorption Cross Sections and $\mathrm{OH}$ Rate Coefficients between 263 and $358 \mathrm{~K}, J$. Phys. Chem. A 116(24), 6041-6050, doi:10.1021/jp2111633.

Anttila, R., C. Betrencourtstirnemann, and J. Dupre (1983), The infrared bands nu-2 and nu- 5 of $\mathrm{CH}_{3} \mathrm{Br}$ with coriolis interaction, J. Mol. Spectrosc., 100(1), 54-74, doi:10.1016/0022-2852(83) 90025-5.

Atkins, P. W., and R. S. Friedman (2010), Molecular quantum mechanics, Fifth Edition, Oxford, Oxford University Press.

Atkinson, R., D. L. Baulch, R. A. Cox, J. N. Crowley, R. F. Hampson, R. G. Hynes, M. E. Jenkin, M. J. Rossi, J. Troe, and T. J. Wallington (2008), Evaluated kinetic and photochemical data for atmospheric chemistry: Volume IV-gas phase reactions of organic halogen species, Atmos. Chem. Phys., 8(15), 4141-4496, doi:10.5194/acp-8-4141-2008.

Baasandorj, M., A. R. Ravishankara, and J. B. Burkholder (2011), Atmospheric Chemistry of $(\mathrm{Z})-\mathrm{CF}_{3} \mathrm{CH}=\mathrm{CHCF}_{3}$ : $\mathrm{OH}$ Radical Reaction Rate Coefficient and Global Warming Potential, $J$. Phys. Chem. A, 115(38), 10539-10549, doi:10.1021/jp206195g.

Baasandorj, M., G. Knight, V. C. Papadimitriou, R. K. Talukdar, A. R. Ravishankara, and J. B. Burkholder (2010), Rate Coefficients for the Gas-Phase Reaction of the Hydroxyl Radical with $\mathrm{CH}_{2}=\mathrm{CHF}$ and $\mathrm{CH}_{2}=\mathrm{CF}_{2}$, J. Phys. Chem. A, 114(13), 4619-4633, doi:10.1021/jp100527z.

Ballard, J., R. J. Knight, and D. A. Newnham (2000a), Infrared absorption cross-sections and integrated absorption intensities of perfluoroethane and cis-perfluorocyclobutane, J. Quant. Spectrosc. Radiat. Transf., 66(2), 199-212, doi:10.1016/S0022-4073(99) 00217-4.

Ballard, J., et al. (2000b), An intercomparison of laboratory measurements of absorption cross-sections and integrated absorption intensities for HCFC-22, J. Quant. Spectrosc. Radiat. Transf., 66(2), 109-128, doi:10.1016/S0022-4073(99)00211-3.

Ballard, J., et al. (2000c), SWAGG Project-Introduction, $J$. Quant. Spectrosc. Radiat. Transf., 66(2), 107-108, doi:10.1016/ S0022-4073(99)00225-3.

Barry, J., G. Locke, D. Scollard, H. Sidebottom, J. Treacy, C. Clerbaux, R. Colin, and J. Franklin (1997), 1,1,1,3,3,-pentafluorobutane (HFC$365 \mathrm{mfc}$ ): Atmospheric degradation and contribution to radiative forcing, Int. J. Chem. Kinet., 29(8), 607-617, doi:10.1002/(SICI)10974601(1997)29:8<607::AID-KIN6>3.0.CO;2-Y.

Bera, P. P., J. S. Francisco, and T. J. Lee (2009), Identifying the Molecular Origin of Global Warming, J. Phys. Chem. A, 113(45), 12694-12699, doi:10.1021/jp905097g.

Bera, P. P., J. S. Francisco, and T. J. Lee (2010), Design strategies to minimize the radiative efficiency of global warming molecules, Proc. Natl. Acad. Sci. U. S. A., 107(20), 9049-9054, doi:10.1073/ pnas.0913590107.

Berglen, T. F., T. K. Berntsen, I. S. A. Isaksen, and J. K. Sundet (2004), A global model of the coupled sulfur/oxidant chemistry in the troposphere: The sulfur cycle, J. Geophys. Res., 109, D19310, doi:10.1029/2003JD003948.

Blanco, M. B., and M. A. Teruel (2007), Atmospheric degradation of fluoroesters (FESs): Gas-phase reactivity study towards $\mathrm{OH}$ radicals at 298 K, Atmos. Environ., 41(34), 7330-7338, doi:10.1016/j.atmosenv.2007.05.013.
Blowers, P., and K. Hollingshead (2009), Estimations of Global Warming Potentials from Computational Chemistry Calculations for $\mathrm{CH}_{2} \mathrm{~F}_{2}$ and Other Fluorinated Methyl Species Verified by Comparison to Experiment, J. Phys. Chem. A, 113(20), 5942-5950, doi:10.1021/jp8114918.

Blowers, P., K. F. Tetrault, and Y. Trujillo-Morehead (2008a), Global warming potential predictions for hydrofluoroethers with two carbon atoms, Theor. Chem. Acc., 119(4), 369-381, doi:10.1007/s00214-007-0394-3.

Blowers, P., D. M. Moline, K. F. Tetrault, R. R. Wheeler, and S. L. Tuchawena (2007), Prediction of radiative forcing values for hydrofluoroethers using density functional theory methods, J. Geophys. Res., 112(D15108), doi:10.1029/2006JD008098.

Blowers, P., D. M. Moline, K. F. Tetrault, R. R. Wheeler, and S. L. Tuchawena (2008b), Global warming potentials of hydrofluoroethers, Environ. Sci. Technol., 42(4), 1301-1307, doi:10.1021/es0706201.

Bolin, B., and H. Rodhe (1973), Note on concepts of age distribution and transit-time in natural reservoirs, Tellus, 25(1), 58-62, doi:10.1111/j.2153-3490.1973.tb01594.x.

Bond, T. C., D. G. Streets, K. F. Yarber, S. M. Nelson, J. H. Woo, and Z. Klimont (2004), A technology-based global inventory of black and organic carbon emissions from combustion, J. Geophys. Res., 109(D14203), doi:10.1029/2003JD003697.

Boucher, O. (2012), Comparison of physically- and economicallybased $\mathrm{CO}_{2}$-equivalences for methane, Earth Syst. Dynam., 3, 49-61, doi:10.5194/esd-3-49-2012.

Boucher, O., and M. S. Reddy (2008), Climate trade-off between black carbon and carbon dioxide emissions, Energy Policy, 193-200.

Bravo, I., G. Marston, D. R. Nutt, and K. P. Shine (2011a), Radiative efficiencies and global warming potentials using theoretically determined absorption cross-sections for several hydrofluoroethers (HFEs) and hydrofluoropolyethers (HFPEs), J. Quant. Spectrosc. Radiat. Transfer, 112(12), 1967-1977, doi:10.1016/j.jqsrt.2011.05.001.

Bravo, I., Y. Diaz-de-Mera, A. Aranda, K. Smith, K. P. Shine, and G. Marston (2010a), Atmospheric chemistry of $\mathrm{C}_{4} \mathrm{~F}_{9} \mathrm{OC}_{2} \mathrm{H}_{5}$ (HFE-7200), $\mathrm{C}_{4} \mathrm{~F}_{9} \mathrm{OCH}_{3}$ (HFE-7100), $\mathrm{C}_{3} \mathrm{~F}_{7} \mathrm{OCH}_{3}$ (HFE-7000) and $\mathrm{C}_{3} \mathrm{~F}_{7} \mathrm{CH}_{2} \mathrm{OH}$ : temperature dependence of the kinetics of their reactions with $\mathrm{OH}$ radicals, atmospheric lifetimes and global warming potentials, PCCP, 12(19), 5115-5125, doi:10.1039/b923092k.

Bravo, I., Y. Diaz-de-Mera, A. Aranda, E. Moreno, D. R. Nutt, and G. Marston (2011b), Radiative efficiencies for fluorinated esters: indirect global warming potentials of hydrofluoroethers, $P C C P$, 13(38), 17185-17193, doi:10.1039/c1cp21874c.

Bravo, I., A. Aranda, M. D. Hurley, G. Marston, D. R. Nutt, K. P. Shine, K. Smith, and T. J. Wallington (2010b), Infrared absorption spectra, radiative efficiencies, and global warming potentials of perfluorocarbons: Comparison between experiment and theory, J. Geophys., 115, D24317, doi:10.1029/ 2010JD014771.

Brodbeck, C., I. Rossi, H. Strapelias, and J. P. Bouanich (1980), Infrared spectral absorption intensities in the $\mathrm{v}_{3}$ and $\mathrm{v}_{4}$ regions of $\mathrm{SF}_{6}$, Chem. Phys., 54(1), 1-7, doi:10.1016/0301-0104(80) 80029-2.

Brown, L. R., C. B. Farmer, C. P. Rinsland, and R. A. Toth (1987), Molecular line parameters for the atmospheric trace molecule spectroscopy experiment, Appl. Optics, 26(23), 5154-5182.

Calvert, J. G., R. G. Derwent, J. J. Orlando, G. S. Tyndall, and T. J. Wallington (2008), Atmospheric Oxidation of the Alkanes, ISBN 978-0-19-536581-8, Oxford, Oxford University Press.

Cappellani, F., and G. Restelli (1992), Infrared band strengths and their temperature-dependence of the hydrohalocarbons HFC-134a, HFC-152a, HCFC-22, HCFC-123 and HCFC-142b, Spectroc. Acta Pt. A-Molec. Biomolec. Spectr., 48(8), 1127-1131, doi:10.1016/0584-8539(92)80122-D.

Cavalli, F., M. Glasius, J. Hjorth, B. Rindone, and N. R. Jensen (1998), Atmospheric lifetimes, infrared spectra and degradation 
products of a series of hydrofluoroethers, Atmos. Environ., 32(21), 3767-3773, doi:10.1016/S1352-2310(98)00106-X.

Chapados, C. (1988), Infrared-absorption of $\mathrm{SF}_{6}$ from $32-\mathrm{cm}^{-1}$ to $3000-\mathrm{cm}^{-1}$ in the gaseous and liquid states, J. Mol. Spectrosc., 132(2), 323-351, doi:10.1016/0022-2852(88)90329-3.

Charmet, A. P., N. Tasinato, P. Stoppa, A. Baldacci, and S. Giorgianni (2008), Jet-cooled diode laser spectrum and FTIR integrated band intensities of $\mathrm{CF}_{3} \mathrm{Br}$ : rovibrational analysis of $2 v_{5}$ and $v_{2}+v_{3}$ bands near $9 \mu \mathrm{m}$ and cross-section measurements in the $450-2500 \mathrm{~cm}^{-1}$ region, Mol. Phys., 106(9-10), 1171-1179, doi:10.1080/00268970802026709.

Charmet, A. P., P. Stoppa, N. Tasinato, A. Baldan, S. Giorgianni, and A. Gambi (2010), Spectroscopic study of $\mathrm{CHBrF}_{2}$ up to 9500 $\mathrm{cm}^{-1}$ : Vibrational analysis, integrated band intensities, and ab initio calculations, J. Chem. Phys., 133(4), doi:10.1063/1.3460922.

Chen, L., S. Kutsuna, K. Tokuhashi, and A. Sekiya (2006), Kinetics and mechanisms of $\mathrm{CF}_{3} \mathrm{CHFOCH}_{3}, \mathrm{CF}_{3} \mathrm{CHFOC}(\mathrm{O}) \mathrm{H}$, and $\mathrm{FC}(\mathrm{O}) \mathrm{OCH}_{3}$ reactions with $\mathrm{OH}$ radicals, J. Phys. Chem. A, 110(47), 12845-12851, doi:10.1021/jp064917h.

Christensen, L. K., T. J. Wallington, A. Guschin, and M. D. Hurley (1999), Atmospheric degradation mechanism of $\mathrm{CF}_{3} \mathrm{OCH}_{3}$, J. Phys. Chem. A, 103(21), 4202-4208, doi:10.1021/jp984455a.

Christensen, L. K., J. Sehested, O. J. Nielsen, M. Bilde, T. J. Wallington, A. Guschin, L. T. Molina, and M. J. Molina (1998), Atmospheric chemistry of HFE-7200 $\left(\mathrm{C}_{4} \mathrm{~F}_{9} \mathrm{OC}_{2} \mathrm{H}_{5}\right)$ : Reaction with $\mathrm{OH}$ radicals and fate of $\mathrm{C}_{4} \mathrm{~F}_{9} \mathrm{OCH}_{2} \mathrm{CH}_{2} \mathrm{O}(\cdot)$ and $\mathrm{C}_{4} \mathrm{~F}_{9} \mathrm{OCHO}(\cdot) \mathrm{CH}_{3}$ radicals, J. Phys. Chem. A, 102(25), 4839-4845, doi:10.1021/jp981128u.

Christidis, N., M. D. Hurley, S. Pinnock, K. P. Shine, and T. J. Wallington (1997), Radiative forcing of climate change by CFC-11 and possible CFC-replacements, J. Geophys. Res., 102(D16), 19597-19609, doi:10.1029/97JD01137.

Clerbaux, C., and R. Colin (1994), Determination of the infrared cross-sections and global warming potentials of 1,1,2trifluoroethane (HFC-143), Geophys. Res. Lett., 21(22), 2377-2380, doi:10.1029/94GL02365.

Clerbaux, C., R. Colin, P. C. Simon, and C. Granier (1993), Infrared cross-sections and global warming potentials of 10 alternative hydrohalocarbons, J. Geophys. Res., 98(D6), 10491-10497, doi:10.1029/93JD00390.

Collins, W. D., et al.(2006), Radiative forcing by well-mixed greenhouse gases: Estimates from climate models in the Intergovernmental Panel on Climate Change (IPCC) Fourth Assessment Report (AR4), J. Geophys. Res., 111, D14317, doi:10.1029/2005JD006713.

Cometto, P. M., R. A. Taccone, J. D. Nieto, P. R. Dalmasso, and S. I. Lane (2010), Kinetic Study of $\mathrm{OH}$ Radical Reactions with $\mathrm{CF}_{3} \mathrm{CCl}=\mathrm{CCl}_{2}, \quad \mathrm{CF}_{3} \mathrm{CCl}=\mathrm{CClCF}_{3}$ and $\mathrm{CF}_{3} \mathrm{CF}=\mathrm{CFCF}_{3}$, Chemphyschem, 11(18), 4053-4059, doi:10.1002/cphc.201000430.

Cunnold, D. M., R. F. Weiss, R. G. Prinn, D. Hartley, P. G. Simmonds, P. J. Fraser, B. Miller, F. N. Alyea, and L. Porter (1997), GAGE/AGAGE measurements indicating reductions in global emissions of $\mathrm{CCl}_{3} \mathrm{~F}$ and $\mathrm{CCl}_{2} \mathrm{~F}_{2}$ in 1992-1994, J. Geophys. Res., 102(D1), 1259-1269, doi:10.1029/96JD02973.

D'Anna, B., S. R. Sellevag, K. Wirtz, and C. J. Nielsen (2005), Photolysis study of perfluoro-2-methyl-3-pentanone under natural sunlight conditions, Environ. Sci. Technol., 39(22), 8708-8711, doi:10.1021/es048088u.

Dalmasso, P. R., R. A. Taccone, J. D. Nieto, M. A. Teruel, and S. I. Lane (2006), $\mathrm{CH}_{3} \mathrm{OCF}_{2} \mathrm{CHFCl}$ and $\mathrm{CHF}_{2} \mathrm{OCF}_{2} \mathrm{CHFCl}$ : Reaction with $\mathrm{Cl}$ atoms, atmospheric lifetimes, ozone depletion and global warming potentials, Atmos. Environ., 40(38), 7298-7307, doi:10.1016/j.atmosenv.2006.06.031.

Daniel, J. S., S. Solomon, and D. L. Albritton (1995), On the evaluation of halocarbon radiative forcing and global warming potentials, J. Geophys. Res., 100(D1), 1271-1285, doi:10.1029/ 94JD02516.

Derwent, R. G. (1990), Trace gases and their relative contribution to the greenhouse effect, Rep, Atomic Energy Research Establishment Harwell Oxon UK. Report AERE- R13716.
Di Lonardo, G., and G. Masciarelli (2000), Infrared absorption cross-sections and integrated absorption intensities of HFC-125 and HFC-143a, J. Quant. Spectrosc. Radiat. Transf., 66(2), 129-142, doi:10.1016/S0022-4073(99)00212-5.

Dillon, T. J., A. Horowitz, and J. N. Crowley (2008), The atmospheric chemistry of sulphuryl fluoride, $\mathrm{SO}_{2} \mathrm{~F}_{2}$, Atmos. Chem. Phys., 8(6), 1547-1557, doi:10.5194/acp-8-1547-2008.

Douglass, A. R., R. S. Stolarski, M. R. Schoeberl, C. H. Jackman, M. L. Gupta, P. A. Newman, J. E. Nielsen, and E. L. Fleming (2008), Relationship of loss, mean age of air and the distribution of CFCs to stratospheric circulation and implications for atmospheric lifetimes, J. Geophys. Res., 113, D14309, doi:10.1029/ 2007JD009575.

Drage, E. A., D. Jaksch, K. M. Smith, R. A. McPheat, E. Vasekova, and N. J. Mason (2006), FTIR spectroscopy and estimation of the global warming potential of $\mathrm{CF}_{3} \mathrm{Br}$ and $\mathrm{C}_{2} \mathrm{~F}_{4}, J$. Quant. Spectrosc. Radiat. Transf., 98(1), 44-56, doi:10.1016/j.jqsrt.2005.05.071.

Dunn, D. S., K. Scanlon, and J. Overend (1982), The absolute intensities of the binary combination bands in the infraredspectrum of $\mathrm{SF}_{6}$, Spectroc. Acta Pt. A-Molec. Biomolec. Spectr., 38(8), 841-847, doi:10.1016/0584-8539(82)80103-7.

Ellingson, R. G., and Y. Fouquart (1991), The intercomparison of radiation codes in climate models-An overview, J. Geophys. Res., 96(D5), 8925-8927, doi:10.1029/90JD01618.

Ellis, D. A., J. W. Martin, S. A. Mabury, M. D. Hurley, M. P. S. Andersen, and T. J. Wallington (2003), Atmospheric lifetime of fluorotelomer alcohols, Environ. Sci. Technol., 37(17), 3816-3820, doi:10.1021/es034136j.

Farman, J. C., B. G. Gardiner, and J. D. Shanklin (1985), Large losses of total ozone in Antarctica reveal seasonal $\mathrm{ClO}_{\mathrm{X}} / \mathrm{NO}_{\mathrm{X}}$ interaction, Nature, 315(6016), 207-210, doi:10.1038/315207a0.

Fisher, D. A., C. H. Hales, W. C. Wang, M. K. W. Ko, and N. D. Sze (1990), Model-calculations of the relative effects of CFCs and their replacements on global warming, Nature, 344(6266), 513-516, doi:10.1038/344513a0.

Forster, P. M., and M. Joshi (2005), The role of halocarbons in the climate change of the troposphere and stratosphere, Clim. Change, 71(1-2), 249-266, doi:10.1007/s10584-005-5955-7.

Forster, P. M., R. S. Freckleton, and K. P. Shine (1997), On aspects of the concept of radiative forcing, Clim. Dyn., 13(7-8), 547-560, doi:10.1007/s003820050182.

Forster, P. M., et al. (2005), Resolution of the uncertainties in the radiative forcing of HFC-134a, J. Quant. Spectrosc. Radiat. Transf., 93(4), 447-460, doi:10.1016/j.jqsrt.2004.08.038.

Forster, P. M., et al. (2007), Changes in Atmospheric Constituents and in Radiative Forcing, In: Climate Change 2007: The Physical Science Basis. Contribution of Working Group I to the Fourth Assessment Report of the Intergovernmental Panel on Climate Change, edited by S. Solomon, D. Qin, M. Manning, Z. Chen, M. Marquis et al. Rep., 129-234 pp, Cambridge, United Kingdom and New York, NY, USA.

Forster, P. M., et al. (2011), Evaluation of radiation scheme performance within chemistry climate models, J. Geophys. Res., 116, D10302, doi:10.1029/2010JD015361.

Freckleton, R. S., E. J. Highwood, K. P. Shine, O. Wild, K. S. Law, and M. G. Sanderson (1998), Greenhouse gas radiative forcing: Effects of averaging and inhomogeneities in trace gas distribution, Q. J. R. Meteorol. Soc., 124(550), 2099-2127, doi:10.1002/qj.49712455014.

Fuglestvedt, J. S., T. K. Berntsen, O. Godal, R. Sausen, K. P. Shine, and T. Skodvin (2003), Metrics of climate change: Assessing radiative forcing and emission indices, Clim. Change, 58(3), 267-331, doi:10.1023/A:1023905326842.

Fuglestvedt, J. S., K. P. Shine, T. Berntsen, J. Cook, D. S. Lee, A. Stenke, R. B. Skeie, G. J. M. Velders, and I. A. Waitz (2010), Transport impacts on atmosphere and climate: Metrics, Atmos. Environ., 44(37), 4648-4677, doi:10.1016/j.atmosenv.2009.04.044. Garland, N. L., L. J. Medhurst, and H. H. Nelson (1993), Potential chlorofluorocarbon replacements- $\mathrm{OH}$ reaction-rate 
constants between 250 and $315-\mathrm{K}$ and infrared-absorption spectra, J. Geophys. Res., 98(D12), 23107-23111, doi:10.1029/93JD02550.

Gierczak, T., R. K. Talukdar, J. B. Burkholder, R. W. Portmann, J. S. Daniel, S. Solomon, and A. R. Ravishankara (1996), Atmospheric fate and greenhouse warming potentials of HFC 236fa and HFC 236ea, J. Geophys. Res., 101(D8), 12905-12911, doi:10.1029/96JD00059.

Gillett, N., and H. Matthews (2010), Accounting for carbon cycle feedbacks in a comparison of the global warming effects of greenhouse gases, Environ. Res. Lett., 5, 034011, doi:10.1088/ 1748-9326/5/3/034011.

Gohar, L. K., G. Myhre, and K. P. Shine (2004), Updated radiative forcing estimates of four halocarbons, J. Geophys. Res., 109, D01107, doi:10.1029/2003JD004320.

Golden, W. G., D. A. Horner, and J. Overend (1978), Intensities of binary overtone and combination bands in IR-spectrum of $\mathrm{CCIF}_{3}$, J. Chem. Phys., 68(3), 964-969, doi:10.1063/1.435835.

Good, D. A., J. S. Francisco, A. K. Jain, and D. J. Wuebbles (1998), Lifetimes and global warming potentials for dimethyl ether and for fluorinated ethers: $\mathrm{CH}_{3} \mathrm{OCF}_{3}$ (E143a), $\mathrm{CHF}_{2} \mathrm{OCHF}_{2}$ (E134), $\mathrm{CHF}_{2} \mathrm{OCF}_{3}$ (E125), J. Geophys. Res., 103(D21), 28181-28186, doi:10.1029/98JD01880.

Graner, G. (1981), The methyl-bromide molecule-A critical consideration of perturbations in spectra, J. Mol. Spectrosc., 90(2), 394-438, doi:10.1016/0022-2852(81)90136-3.

Graner, G., and W. E. Blass (1975), Vibration-rotation bands $v_{2}$ and $v_{5}$ of methyl-bromide, J. Phys., 36(9), 769-771, doi:10.1051/jphys:01975003609076900.

Gregory, J. M., W. J. Ingram, M. A. Palmer, G. S. Jones, P. A. Stott, R. B. Thorpe, J. A. Lowe, T. C. Johns, and K. D. Williams (2004), A new method for diagnosing radiative forcing and climate sensitivity, Geophys. Res. Lett., 31, L03205, doi:10.1029/2003GL018747.

Grossman, A. S., K. E. Grant, W. E. Blass, and D. J. Wuebbles (1997), Radiative forcing calculations for $\mathrm{CH}_{3} \mathrm{Cl}$ and $\mathrm{CH}_{3} \mathrm{Br}, J$. Geophys. Res., 102(D12), 13651-13656, doi:10.1029/97JD00611.

Hansen, J., A. Lacis, and M. Prather (1989), Greenhouse-effect of chlorofluorocarbons and other trace gases, J. Geophys. Res., 94(D13), 16417-16421, doi:10.1029/JD094iD13p16417.

Hansen, J., M. Sato, and R. Ruedy (1997), Radiative forcing and climate response, J. Geophys. Res., 102(D6), 6831-6864, doi:10.1029/96JD03436.

Hansen, J., et al. (2005), Efficacy of climate forcings, J. Geophys. Res., 110, D18104, doi:10.1029/2005JD005776.

Heathfield, A. E., C. Anastasi, A. McCulloch, and F. M. Nicolaisen (1998), Integrated infrared absorption coefficients of several partially fluorinated ether compounds: $\mathrm{CF}_{3} \mathrm{OCF}_{2} \mathrm{H}, \mathrm{CF}_{2} \mathrm{HOCF}_{2} \mathrm{H}$, $\mathrm{CH}_{3} \mathrm{OCF}_{2} \mathrm{CF}_{2} \mathrm{H}, \quad \mathrm{CH}_{3} \mathrm{OCF}_{2} \mathrm{CFClH}, \quad \mathrm{CH}_{3} \mathrm{CH}_{2} \mathrm{OCF}_{2} \mathrm{CF}_{2} \mathrm{H}$, $\mathrm{CF}_{3} \mathrm{CH}_{2} \mathrm{OCF}_{2} \mathrm{CF}_{2} \mathrm{H}$ and $\mathrm{CH}_{2}=\mathrm{CHCH}_{2} \mathrm{OCF}_{2} \mathrm{CF}_{2} \mathrm{H}$, Atmos. Environ., 32(16), 2825-2833, doi:10.1016/S1352-2310(97)00462-7.

Highwood, E. J., and K. P. Shine (2000), Radiative forcing and global warming potentials of 11 halogenated compounds, $J$. Quant. Spectrosc. Radiat. Transf., 66(2), 169-183, doi:10.1016/ S0022-4073(99)00215-0.

Highwood, E. J., K. P. Shine, M. D. Hurley, and T. J. Wallington (1999), Estimation of direct radiative forcing due to nonmethane hydrocarbons, Atmos. Environ., 33(5), 759-767, doi:10.1016/S1352-2310(98)00220-9.

Hoffmann, L., M. Kaufmann, R. Spang, R. Muller, J. J. Remedios, D. P. Moore, C. M. Volk, T. von Clarmann, and M. Riese (2008), Envisat MIPAS measurements of CFC-11: retrieval, validation, and climatology, Atmos. Chem. Phys., 8(13), 3671-3688, doi:10.5194/acp-8-3671-2008.

Hollas, J. M. (2004), Modern Spectroscopy (4th edition), John Wiley \& Sons, Chichester.

Hurley, M. D., J. C. Ball, and T. J. Wallington (2007), Atmospheric chemistry of the $Z$ and $E$ isomers of $\mathrm{CF}_{3} \mathrm{CF}=\mathrm{CHF}$; Kinetics, mechanisms, and products of gas-phase reactions with $\mathrm{Cl}$ atoms, $\mathrm{OH}$ radicals, and $\mathrm{O}_{3}$, J. Phys. Chem. A, 111(39), 9789-9795, doi:10.1021/jp0753530.
Hurley, M. D., T. Wallington, G. Buchanan, L. Gohar, G. Marston, and $\mathrm{K}$. Shine (2005), IR spectrum and radiative forcing of $\mathrm{CF}_{4}$ revisited, J. Geophys. Res., 110, D02102, doi:10.1029/2004JD005201.

Imasu, R., A. Suga, and T. Matsuno (1995), Radiative effects and halocarbon global warming potentials of replacement compounds for chlorofluorocarbons, J. Meteorol. Soc. Jpn., 73(6), 1123-1136.

Inoue, Y., M. Kawasaki, T. J. Wallington, and M. D. Hurley (2008), Atmospheric chemistry of $\mathrm{CF}_{3} \mathrm{CH}_{2} \mathrm{CF}_{2} \mathrm{CH}_{3}$ (HFC$365 \mathrm{mfc}$ ): Kinetics and mechanism of chlorine atom initiated oxidation, infrared spectrum, and global warming potential, Chem. Phys. Lett., 462(4-6), 164-168, doi:10.1016/j.cplett.2008.07.054. IPCC (1990), Climate Change: The IPCC Scientific Assessment, edited by J. T. Houghton, G. J. Jenkins and J. J. Ephraums, p. 410, Cambridge University Press, Cambridge.

IPCC (1994), Climate Change 1994: Radiative Forcing of Climate Change and an Evaluation of the IPCC IS92 Emission Scenarios, edited by: J.T. Houghton, L.G. Meira Filho, J. Bruce, Hoesung Lee, B.A. Callander, E.F. Haites, N. Harris and K. Maskell. Rep., Cambridge University Press, Cambridge, United Kingdom. IPCC (1995), Climate Change 1995, the science of climate change, edited by J. T. Houghton, L. G. Meira Filho, B. A. Callander, N. Harris, A. Kattenberg and K. Maskell, Cambridge.

IPCC (2001), Climate Change 2001: The Scientific Basis. Contribution of Working Group I to the Third Assessment Report of the Intergovernmental Panel on Climate Change, edited by J.T. Houghton, Y. Ding, D.J. Griggs, M. Noguer, P. J. van der Linden, X. Dai, K. Maskell, and C.A. Johnson, Rep., 881 pp, Cambridge University Press, Cambridge, United Kingdom and New York, NY, USA.

IPCC (2007), Climate Change 2007: The Physical Science Basis. Contribution of Working Group I to the Fourth Assessment Report of the Intergovernmental Panel on Climate Change, Rep., Cambridge University Press, Cambridge, United Kingdom and New York, NY, USA.

Ivy, D. J., M. Rigby, M. Baasandorj, J. B. Burkholder, and R. G. Prinn (2012), Global emission estimates and radiative impact of $\mathrm{C}_{4} \mathrm{~F}_{10}, \mathrm{C}_{5} \mathrm{~F}_{12}, \mathrm{C}_{6} \mathrm{~F}_{14}, \mathrm{C}_{7} \mathrm{~F}_{16}$ and $\mathrm{C}_{8} \mathrm{~F}_{18}$, Atmos. Chem. Phys., 12, 7635-7645, doi:10.5194/acp-12-7635-2012.

Jacquinet-Husson, N., et al. (2011), The 2009 edition of the GEISA spectroscopic database, J. Quant. Spectrosc. Radiat. Transf., 112(15), 2395-2445, doi:10.1016/j.jqsrt.2011.06.004.

Jain, A. K., B. P. Briegleb, K. Minschwaner, and D. J. Wuebbles (2000), Radiative forcings and global warming potentials of 39 greenhouse gases, J. Geophys. Res., 105(D16), 20773-20790, doi:10.1029/2000JD900241.

Jain, A. K., Z. J. Li, V. Naik, D. J. Wuebbles, D. A. Good, J. C. Hansen , and J. S. Francisco (2001), Evaluation of the atmospheric lifetime and radiative forcing on climate for 1,2,2,2-Tetrafluoroethyl Trifluoromethyl Ether $\left(\mathrm{CF}_{3} \mathrm{OCHFCF}_{3}\right)$, J. Geophys. Res., 106(D12), 12615-12618, doi:10.1029/2001JD900013.

Javadi, M. S., O. J. Nielsen, T. J. Wallington, M. D. Hurley, and J. G. Owens (2007), Atmospheric chemistry of 2-ethoxy3,3,4,4,5-pentafluorotetra-hydro-2,5-bis 1,2,2,2-tetrafluoro-1(trifluoromethyl)ethyl -furan: Kinetics, mechanisms, and products of $\mathrm{Cl}$ atom and $\mathrm{OH}$ radical initiated oxidation, Environ. Sci. Technol., 41(21), 7389-7395, doi:10.1021/es071175c.

Jimenez, E., M. Antinolo, B. Ballesteros, E. Martinez, and J. Albaladejo (2010), Atmospheric Lifetimes and Global Warming Potentials of $\mathrm{CF}_{3} \mathrm{CH}_{2} \mathrm{CH}_{2} \mathrm{OH}$ and $\mathrm{CF}_{3}\left(\mathrm{CH}_{2}\right)_{2} \mathrm{CH}_{2} \mathrm{OH}$, Chemphyschem, 11(18), 4079-4087, doi:10.1002/cphc.201000365. Johansson, D. J. A. (2012), Economics- and physical-based metrics for comparing greenhouse gases, Clim. Change, 110(1-2), 123-141, doi:10.1007/s10584-011-0072-2.

Joos, F., et al. (2013), Carbon dioxide and climate impulse response functions for the computation of greenhouse gas metrics: a multi-model analysis, Atmos. Chem. Phys., 13, 2793-2825, doi:10.5194/acp-13-2793-2013.

Joshi, M., K. Shine, M. Ponater, N. Stuber, R. Sausen, and L. Li (2003), A comparison of climate response to different radiative 
forcings in three general circulation models: towards an improved metric of climate change, Clim. Dyn., 20(7-8), 843-854.

Kagann, R. H., J. W. Elkins, and R. L. Sams (1983), Absolute band strengths of halocarbons F-11 and F-12 in the 8-mu-mu to 16-mu$\mathrm{m}$ region, J. Geophys. Res., 88(NC2), 1427-1432, doi:10.1029/ JC088iC02p01427.

Kiehl, J. T., and K. E. Trenberth (1997), Earth's annual global mean energy budget, Bull. Amer. Meteorol. Soc., 78(2), 197-208, doi:10.1175/1520-0477(1997)078<0197:EAGMEB > 2.0.CO;2.

Kim, K., R. S. McDowell, and W. T. King (1980), Integrated infrared intensities and transition moments in $\mathrm{SF}_{6}, J$. Chem. Phys., 73(1), 36-41, doi:10.1063/1.439883.

Ko, M., R. L. Shia, N. D. Sze, H. Magid, and R. G. Bray (1999), Atmospheric lifetime and global warming potential of HFC245fa, J. Geophys. Res.-Atmos., 104(D7), 8173-8181, doi:10.1029/1998JD100097.

Ko, M., N. D. Sze, W. C. Wang, G. Shia, A. Goldman, F. J. Murcray, D. G. Murcray, and C. P. Rinsland (1993), Atmospheric sulfurhexafluoride-Sources, sinks and greenhouse warming, $J$. Geophys. Res., 98(D6), 10499-10507, doi:10.1029/93JD00228.

Kratz, D. P. (2008), The sensitivity of radiative transfer calculations to the changes in the HITRAN database from 1982 to 2004, J. Quant. Spectrosc. Radiat. Transf., 109(6), 1060-1080, doi:10.1016/j. jqsrt.2007.10.010.

Kunde, V. G., B. J. Conrath, R. A. Hanel, W. C. Maguire, C. Prabhaka, and V. V. Salomons (1974), NIMBUS-4 infrared spectroscopy experiment .2. Comparison of observed and theoretical radiances from 425-1450 cm-1, J. Geophys. Res., 79(6), 777-784, doi:10.1029/JC079i006p00777.

Kutsuna, S., L. Chen, T. Abe, J. Mizukado, T. Uchimaru, K. Tokuhashi, and A. Sekiya (2005), Henry's law constants of 2,2,2-trifluoroethyl formate, ethyl trifluoro acetate, and nonfluorinated analogous esters, Atmos. Environ., 39(32), 5884-5892, doi:10.1016/j.atmosenv.2005.06.021.

Lashof, D. A., and D. R. Ahuja (1990), Relative contributions of greenhouse gas emissions to global warming, Nature, 344(6266), 529-531, doi:10.1038/344529a0.

Laube, J. C., A. Keil, H. Bönisch, A. Engel, T. Röckmann, C. M. Volk, and W. T. Sturges (2012), Observation-based assessment of stratospheric fractional release, lifetimes, and ozone depletion potentials of ten important source gases, Atmos. Chem. Phys., 13, 2779-2791, doi:10.5194/acp-13-2779-2013.

Le Bris, K., and K. Strong (2010), Temperature-dependent absorption cross-sections of HCFC-142b, J. Quant. Spectrosc. Radiat. Transf., 111(3), 364-371, doi:10.1016/j.jqsrt.2009.10.005.

Le Bris, K., R. Pandharpurkar, and K. Strong (2011), Mid-infrared absorption cross-sections and temperature dependence of CFC113, J. Quant. Spectrosc. Radiat. Transf., 112(8), 1280-1285, doi:10.1016/j.jqsrt.2011.01.023.

Le Bris, K., J. McDowell, and K. Strong (2012), Measurements of the infrared absorption cross-sections of HCFC-141b $\left(\mathrm{CH}_{3} \mathrm{CFCl}_{2}\right)$, J. Quant. Spectrosc. Radiat. Transf., 113(15), 1913-1919, doi:10.1016/j.jqsrt.2012.05.004.

Li, Z. H., and P. Varanasi (1994), Measurement of the absorption cross-sections of $\mathrm{CFC}-11$ at conditions representing various model atmospheres, J. Quant. Spectrosc. Radiat. Transf., 52(2), 137-144, doi:10.1016/0022-4073(94)90002-7.

Lovelock, J. E., and R. J. Maggs (1973), Halogenated hydrocarbons in and over Atlantic, Nature, 241(5386), 194-196, doi:10.1038/241194a0.

M.S.F./R.A.L. (n.d.) Molecular Spectroscopy Facility / Rutherford Appleton Laboratory, http://www.msf.rl.ac.uk, accessed April 2012.

Manne, A. S., and R. G. Richels (2001), An alternative approach to establishing trade-offs among greenhouse gases, Nature, 410(6829), 675-677, doi:10.1038/35070541.

Mashino, M., M. Kawasaki, T. J. Wallington, and M. D. Hurley (2000), Atmospheric degradation of $\mathrm{CF}_{3} \mathrm{OCF}=\mathrm{CF}_{2}$ : Kinetics and mechanism of its reaction with $\mathrm{OH}$ radicals and $\mathrm{Cl}$ atoms, J. Phys. Chem. A, 104(13), 2925-2930, doi:10.1021/jp9942264.
Massie, S. T., A. Goldman, D. G. Murcray, and J. C. Gille (1985), Approximate absorption cross-sections of F12, F11, $\mathrm{C}_{1 \mathrm{ONO}}$, $\mathrm{N}_{2} \mathrm{O}_{5}, \mathrm{HNO}_{3}, \mathrm{CCl}_{4}, \mathrm{CF}_{4}, \mathrm{~F} 21, \mathrm{~F} 113, \mathrm{~F} 114$, and $\mathrm{HNO}_{4}$, OAppl. ptics, 24(21), 3426-3427.

Maycock, A. C., and K. P. Shine (2012), Stratospheric water vapor and climate: Sensitivity to the representation in radiation codes, J. Geophys. Res., 117, D13102, doi:10.1029/2012JD017484.

McCulloch, A., P. M. Midgley, and D. A. Fisher (1994), Distribution of emissions of chlorofluorocarbons (CFCs) 11, 12, 113, 114 and 115 among reporting and non-reporting countries in 1986 , Atmos. Environ., 28(16), 2567-2582, doi:10.1016/1352-2310 (94)90431-6.

McDaniel, A. H., C. A. Cantrell, J. A. Davidson, R. E. Shetter, and J. G. Calvert (1991), The temperature-dependent, infraredabsorption cross-sections for the chlorofluorocarbons-CFC-11, CFC-12, CFC-13, CFC-14, CFC-22, CFC-113, CFC-114, and CFC-115, J. Atmos. Chem., 12(3), 211-227, doi:10.1007/ BF00048074.

McDowell, R. S., B. J. Krohn, H. Flicker, and M. C. Vasquez (1986), Vibrational levels and anharmonicity in $\mathrm{SF}_{6} .1$. Vibrational band analysis, Spectroc. Acta Pt. A-Molec. Biomolec. Spectr., 42(2-3), 351-369, doi:10.1016/0584-8539(86)80199-4.

McPheat, R., and G. Duxbury (2000), Infrared absorption crosssections and integrated absorption intensities of chloroform and fluoroform vapour, J. Quant. Spectrosc. Radiat. Transf., 66(2), 153-167, doi:10.1016/S0022-4073(99)00214-9.

Mills, I. M., W. B. Person, J. R. Scherer, and B. Crawford (1958), Vibrational intensities .9. $\mathrm{C}_{2} \mathrm{~F}_{6}$-Extension and revision, J. Chem. Phys., 28(5), 851-853, doi:10.1063/1.1744282.

Minschwaner, K., L. Hoffmann, A. Brown, M. Riese, R. Müller, and P. F. Bernath (2012), Stratospheric loss and atmospheric lifetimes of CFC-11 and CFC-12 derived from satellite observations, Atmos. Chem. Phys. Discuss., 12(11), 28733-28764, doi:10.5194/ acpd-12-28733-2012.

Molina, M. J., and F. S. Rowland (1974), Stratospheric Sink for Chlorofluoromethanes-Chlorine Atomic-Catalysed Destruction of Ozone, Nature, 249(5460), 810-812, doi:10.1038/ 249810a0.

Montzka, S. A., M. Krol, E. Dlugokencky, B. Hall, P. Jöckel, and J. Lelieveld (2011), Small Interannual Variability of Global Atmospheric Hydroxyl, Science, 331(6013), 67-69, doi:10.1126/ science.1197640.

Morcillo, J., L. J. Zamorano, and J. M. V. Heredia (1966), Infra-red intensities in $\mathrm{CH}_{2} \mathrm{~F}_{2}, \mathrm{CH}_{2} \mathrm{Cl}_{2}$ and $\mathrm{CF}_{2} \mathrm{Cl}_{2}$, Spectrochim. Acta, 22(12), 1969-1980, doi:10.1016/0371-1951(66)80048-6.

Myhre, G., and F. Stordal (1997), Role of spatial and temporal variations in the computation of radiative forcing and GWP, $J$. Geophys. Res., 102(D10), 11181-11200, doi:10.1029/97JD00148.

Myhre, G., E. J. Highwood, K. P. Shine, and F. Stordal (1998), New estimates of radiative forcing due to well mixed greenhouse gases, Geophys. Res. Lett., 25(14), 2715-2718, doi:10.1029/ 98GL01908.

Myhre, G., C. J. Nielsen, D. L. Powell, and F. Stordal (1999), Infrared absorption cross section, radiative forcing, and GWP of four hydrofluoro(poly)ethers, Atmos. Environ., 33(27), 4447-4458, doi:10.1016/S1352-2310(99)00208-3.

Myhre, G., F. Stordal, I. Gausemel, C. J. Nielsen, and E. Mahieu (2006), Line-by-line calculations of thermal infrared radiation representative for global condition: CFC-12 as an example, $J$. Quant. Spectrosc. Radiat. Transf., 97(3), 317-331, doi:10.1016/ j.jqsrt.2005.04.015.

Naik, V., A. K. Jain, K. O. Patten, and D. J. Wuebbles (2000), Consistent sets of atmospheric lifetimes and radiative forcings on climate for CFC replacements: HCFCs and HFCs, J. Geophys. Res., 105(D5), 6903-6914, doi:10.1029/1999JD901128.

Nanes, R., P. M. Silvaggio, and R. W. Boese (1980), Temperaturedependence of intensities of the $8-12 \mu \mathrm{m}$ bands of $\mathrm{CFCl}_{3}, J$. Quant. Spectrosc. Radiat. Transf., 23(2), 211-220, doi:10.1016/ 0022-4073(80)90008-4. 
Nemtchinov, V., and P. Varanasi (2003), Thermal infrared absorption cross-sections of $\mathrm{CCl}_{4}$ needed for atmospheric remote sensing, J. Quant. Spectrosc. Radiat. Transf., 82(1-4), 473-481, doi:10.1016/S0022-4073(03)00171-7.

Nemtchinov, V., and P. Varanasi (2004), Absorption cross-sections of HFC-134a in the spectral region between 7 and $12 \mu \mathrm{m}, J$. Quant. Spectrosc. Radiat. Transf., 83(3-4), 285-294, doi:10.1016/ S0022-4073(02)00356-4.

Newnham, D., J. Ballard, and M. Page (1996), Infrared band strengths of HFC-134a vapour, J. Quant. Spectrosc. Radiat. Transf., 55(3), 373-381, doi:10.1016/0022-4073(95)00164-6.

Nielsen, O. J., F. M. Nicolaisen, C. Bacher, M. D. Hurley, T. J. Wallington, and K. P. Shine (2002), Infrared spectrum and global warming potential of $\mathrm{SF}_{5} \mathrm{CF}_{3}$, Atmos. Environ., 36(7), 1237-1240, doi:10.1016/S1352-2310(01)00551-9.

Nielsen, O. J., M. S. Javadi, M. P. S. Andersen, M. D. Hurley, T. J. Wallington, and R. Singh (2007), Atmospheric chemistry of $\mathrm{CF}_{3} \mathrm{CF}=\mathrm{CH}_{2}$ : Kinetics and mechanisms of gas-phase reactions with $\mathrm{Cl}$ atoms, $\mathrm{OH}$ radicals, and $\mathrm{O}_{3}$, Chem. Phys. Lett., 439(1-3), 18-22, doi:10.1016/j.cplett.2007.03.053.

Nilsson, E. J. K., O. J. Nielsen, M. S. Johnson, M. D. Hurley, and T. J. Wallington (2009), Atmospheric chemistry of cis$\mathrm{CF}_{3} \mathrm{CHCHF}$ : Kinetics of reactions with $\mathrm{OH}$ radicals and $\mathrm{O}_{3}$ and products of $\mathrm{OH}$ radical initiated oxidation, Chem. Phys. Lett., 473(4-6), 233-237, doi:10.1016/j.cplett.2009.03.076.

Ninomiya, Y., M. Kawasaki, A. Guschin, L. T. Molina, M. J. Molina, and T. J. Wallington (2000), Atmospheric chemistry of $n-\mathrm{C}_{3} \mathrm{~F}_{7} \mathrm{OCH}_{3}$ : Reaction with $\mathrm{OH}$ radicals and $\mathrm{Cl}$ atoms and atmospheric fate of $n-\mathrm{C}_{3} \mathrm{~F}_{7} \mathrm{OCH}_{2} \mathrm{O}(\cdot)$ radicals, Environ. Sci. Technol., 34(14), 2973-2978, doi:10.1021/es991449z.

O'Neill, B. C. (2000), The jury is still out on global warming potentials, Clim. Change, 44(4), 427-443, doi:10.1023/A:1005582929198.

Olivié, D. J. L., and G. P. Peters (2012), The impact of model variation in $\mathrm{CO}_{2}$ and temperature impulse response functions on emission metrics, Earth Syst. Dynam. Discuss., 3(2), 935-977, doi:10.5194/esdd-3-935-2012.

Olliff, M. P., and G. Fischer (1994), Integrated absorption intensities of haloethanes and halopropanes, Spectroc. Acta Pt. A-Molec. Biomolec. Spectr., 50(13), 2223-2237, doi:10.1016/0584-8539 (93)E0027-T.

Oreopoulos, L., et al. (2012), The Continual Intercomparison of Radiation Codes: Results from Phase I, J. Geophys. Res., 117, D06118, doi:10.1029/2011JD016821.

Orkin, V. L., L. E. Martynova, and A. N. Ilichev (2010), HighAccuracy Measurements of $\mathrm{OH}$ Reaction Rate Constants and IR Absorption Spectra: $\mathrm{CH}_{2}=\mathrm{CF}-\mathrm{CF}_{3}$ and trans-CHF $=\mathrm{CH}-\mathrm{CF}_{3}$, J. Phys. Chem. A, 114(19), 5967-5979, doi:10.1021/jp9092817.

Orkin, V. L., E. Villenave, R. E. Huie, and M. J. Kurylo (1999), Atmospheric lifetimes and global warming potentials of hydrofluoroethers: Reactivity toward $\mathrm{OH}$, UV spectra, and IR absorption cross sections, J. Phys. Chem. A, 103(48), 9770-9779, doi:10.1021/jp991741t.

Orkin, V. L., A. G. Guschin, I. K. Larin, R. E. Huie, and M. J. Kurylo (2003), Measurements of the infrared absorption cross-sections of haloalkanes and their use in a simplified calculational approach for estimating direct global warming potentials, J. Photochem. Photobiol. A-Chem., 157(2-3), 211-222, doi:10.1016/S1010-6030(03)00057-1.

Orlando, J. J., G. S. Tyndall, A. Huang, and J. G. Calvert (1992), Temperature-dependence of the infrared-absorption cross-sections of carbon-tetrachloride, Geophys. Res. Lett., 19(10), 1005-1008, doi:10.1029/91GL01036.

Osterstrom, F. F., O. J. Nielsen, M. P. S. Andersen, and T. J. Wallington (2012), Atmospheric chemistry of $\mathrm{CF}_{3} \mathrm{CH}_{2} \mathrm{OCH}_{3}$ : Reaction with chlorine atoms and $\mathrm{OH}$ radicals, kinetics, degradation mechanism and global warming potential, Chem. Phys. Lett., 524, 32-37, doi:10.1016/j.cplett.2011.12.047.

Oyaro, N., S. R. Sellevag, and C. J. Nielsen (2004), Study of the $\mathrm{OH}$ and Cl-initiated oxidation, IR absorption cross-section, radiative forcing, and global warming potential of four $\mathrm{C}_{4}{ }^{-}$ hydrofluoroethers, Environ. Sci. Technol., 38(21), 5567-5576, doi:10.1021/es0497330.

Oyaro, N., S. R. Sellevag, and C. J. Nielsen (2005), Atmospheric chemistry of hydrofluoroethers: Reaction of a series of hydrofluoro ethers with $\mathrm{OH}$ radicals and $\mathrm{Cl}$ atoms, atmospheric lifetimes, and global warming potentials, J. Phys. Chem. A, 109(2), 337-346, doi:10.1021/jp047860c.

Papadimitriou, V. C., R. K. Talukdar, R. W. Portmann, A. R. Ravishankara, and J. B. Burkholder (2008a), $\mathrm{CF}_{3} \mathrm{CF}=\mathrm{CH}_{2}$ and $(Z)-\mathrm{CF}_{3} \mathrm{CF}=\mathrm{CHF}$ : temperature dependent $\mathrm{OH}$ rate coefficients and global warming potentials, PCCP , 10(6), 808-820, doi:10.1039/b714382f.

Papadimitriou, V. C., M. R. McGillen, E. L. Fleming, C. H. Jackman, and J. B. Burkholder (2013), $\mathrm{NF}_{3}$ : UV absorption spectrum temperature dependence and the atmospheric and climate forcing implications, Geophys. Res. Lett., 40(2), 440-445, doi:10.1002/grl.50120.

Papadimitriou, V. C., R. W. Portmann, D. W. Fahey, J. Muhle, R. F. Weiss, and J. B. Burkholder (2008b), Experimental and Theoretical Study of the Atmospheric Chemistry and Global Warming Potential of $\mathrm{SO}_{2} \mathrm{~F}_{2}$, J. Phys. Chem. A, 112(49), 12657-12666, doi:10.1021/jp806368u.

Papanastasiou, D. K., N. R. Carlon, J. A. Neuman, E. L. Fleming, C. H. Jackman, and J. B. Burkholder (2013), Revised UV absorption spectra, ozone depletion potentials, and global warming potentials for the ozone-depleting substances $\mathrm{CF}_{2} \mathrm{Br}_{2}, \mathrm{CF}_{2} \mathrm{ClBr}$, and $\mathrm{CF}_{2} \mathrm{BrCF}_{2} \mathrm{Br}$, Geophys. Res. Lett., 40, 464 469, doi:10.1002/grl.50121.

Papasavva, S., S. Tai, K. H. Illinger, and J. E. Kenny (1997), Infrared radiative forcing of CFC substitutes and their atmospheric reaction products, J. Geophys. Res.-Atmos., 102(D12), 13643-13650, doi:10.1029/ 97JD01013.

Person, W. B., and S. R. Polo (1961), Infrared intensities of the fundamental frequencies of $\mathrm{CF}_{3} \mathrm{Br}$, Spectrochim. Acta, 17(1), 101-111, doi:10.1016/0371-1951(61)80016-7.

Peters, G. P., B. Aamaas, T. Berntsen, and J. S. Fuglestvedt (2011), The integrated global temperature change potential (iGTP) and relationships between emission metrics, Environ. Res. Lett., 6(4), doi:10.1088/1748-9326/6/4/044021.

Petty, G. W. (2006), A first course in atmospheric radiation. Second Edition. Sundog Publishing.

Pinnock, S., and K. P. Shine (1998), The effects of changes in HITRAN and uncertainties in the spectroscopy on infrared irradiance calculations, J. Atmos. Sci., 55(11), 1950-1964, doi:10.1175/1520-0469(1998)055<1950:TEOCIH > 2.0.CO;2.

Pinnock, S., M. D. Hurley, K. P. Shine, T. J. Wallington, and T. J. Smyth (1995), Radiative forcing of climate by hydrochlorofluorocarbons and hydrofluorocarbons, J. Geophys. Res., 100(D11), 23227-23238, doi:10.1029/95JD02323.

Plattner, G.-K., T. M. Stocker, P. Midgley, and M. Tignor (2009), IPCC Expert Meeting on the Science of Alternative Metrics: Meeting Report., IPCC Working Group I, Technical Support Unit, Rep., Bern, Switzerland.

Prather, M. J. (1996), Time scales in atmospheric chemistry: Theory, GWPs for $\mathrm{CH}_{4}$ and $\mathrm{CO}$, and runaway growth, Geophys. Res. Lett., 23(19), 2597-2600, doi:10.1029/96GL02371.

Prather, M. J. (2007), Lifetimes and time scales in atmospheric chemistry, Philos. Trans. R. Soc. A-Math. Phys. Eng. Sci., 365(1856), 1705-1726, doi:10.1098/rsta.2007.2040.

Prather, M. J., and C. M. Spivakovsky (1990), Tropospheric OH and the lifetimes of hydrochlorofluorocarbons, J. Geophys. Res., 95(D11), 18723-18729, doi:10.1029/JD095iD11p18723.

Prather, M. J., and J. Hsu (2008), $\mathrm{NF}_{3}$, the greenhouse gas missing from Kyoto, Geophys. Res. Lett., 35, L12810, doi:10.1029/2008GL034542.

Prather, M. J., and J. Hsu (2010), $\mathrm{NF}_{3}$, the greenhouse gas missing from Kyoto, Geophys. Res. Lett., 37, L11807, doi:10.1029/ 2010 GL043831.

Prather, M. J., C. D. Holmes, and J. Hsu (2012), Reactive greenhouse gas scenarios: Systematic exploration of uncertainties and 
the role of atmospheric chemistry, Geophys. Res. Lett., 39, L09803, doi:10.1029/2012GL051440.

Rajakumar, B., R. W. Portmann, J. B. Burkholder, and A. R. Ravishankara (2006), Rate coefficients for the reactions of $\mathrm{OH}$ with $\mathrm{CF}_{3} \mathrm{CH}_{2} \mathrm{CH}_{3}$ (HFC-263fb), $\mathrm{CF}_{3} \mathrm{CHFCH}_{2} \mathrm{~F}$ (HFC$245 \mathrm{eb}$ ), and $\mathrm{CHF}_{2} \mathrm{CHFCHF}_{2}$ (HFC-245ea) between 238 and 375 K, J. Phys. Chem. A, 110(21), 6724-6731, doi:10.1021/jp056248y.

Ramanathan, V. (1975), Greenhouse effect due to chlorofluorocarbons-Climatic implications, Science, 190(4209), 50-51, doi:10.1126/science.190.4209.50.

Ramanathan, V., R. J. Cicerone, H. B. Singh, and J. T. Kiehl (1985), Trace gas trends and their potential role in climate change, J. Geophys. Res., 90(ND3), 5547-5566, doi:10.1029/JD090iD03p05547.

Ramanathan, V., et al. (1987), Climate-Chemical Interactions and Effects of Changing Atmospheric Trace Gases, Rev. Geophys., 25(7), 1441-1482, doi:10.1029/RG025i007p01441.

Ravishankara, A. R., S. Solomon, A. A. Turnipseed, and R. F. Warren (1993), Atmospheric lifetimes of long-lived halogenated species, Science, 259(5092), 194-199, doi:10.1126/science.259.5092.194.

Ravishankara, A. R., A. A. Turnipseed, N. R. Jensen, S. Barone, M. Mills, C. J. Howard, and S. Solomon (1994), Do hydrofluorocarbons destroy stratospheric ozone, Science, 263(5143), 71-75, doi:10.1126/science.263.5143.71.

Reisinger, A., M. Meinshausen, and M. Manning (2011), Future changes in global warming potentials under representative concentration pathways, Environ. Res. Lett., 6(2), doi:10.1088/1748-9326/6/2/024020.

Reisinger, A., M. Meinshausen, M. Manning, and G. Bodeker (2010), Uncertainties of global warming metrics: $\mathrm{CO}_{2}$ and $\mathrm{CH}_{4}$, Geophys. Res. Lett., 37, L14707, doi:10.1029/2010GL043803.

RETRO (2006), REanalysis of the TROpospheric chemical composition over the past 40 years. http://retro.enes.org, accessed 15 th of March 2012, edited.

Rigby, M., et al. (2013), Re-evaluation of the lifetimes of the major CFCs and $\mathrm{CH}_{3} \mathrm{CCl}_{3}$ using atmospheric trends, Atmos. Chem. Phys., 13, 2691-2702, doi:10.5194/acp-13-2691-2013.

Rinsland, C. P., S. W. Sharpe, and R. L. Sams (2003), Temperature-dependent absorption cross-sections in the thermal infrared bands of $\mathrm{SF}_{5} \mathrm{CF}_{3}$, J. Quant. Spectrosc. Radiat. Transf., 82(1-4), 483-490, doi:10.1016/S0022-4073(03)00172-9.

Robson, J. I., L. K. Gohar, M. D. Hurley, K. P. Shine, and T. J. Wallington (2006), Revised IR spectrum, radiative efficiency and global warming potential of nitrogen trifluoride, Geophys. Res. Lett., 33, L10817, doi:10.1029/2006GL026210.

Roehl, C. M., D. Boglu, C. Bruhl, and G. K. Moortgat (1995), Infrared band intensities and global warming potentials of $\mathrm{CF}_{4}$, $\mathrm{C}_{2} \mathrm{~F}_{6}, \mathrm{C}_{3} \mathrm{~F}_{8}, \mathrm{C}_{4} \mathrm{~F}_{10}, \mathrm{C}_{5} \mathrm{~F}_{12}$, and $\mathrm{C}_{6} \mathrm{~F}_{14}$, Geophys. Res. Lett., 22(7), 815-818, doi:10.1029/95GL00488.

Rogers, J. D., and R. D. Stephens (1988), Absolute infrared intensities for F-113 and F-114 and an assessment of their greenhouse warming potential relative to other chlorofluorocarbons, J. Geophys. Res., 93(D3), 2423-2428, doi:10.1029/JD093iD03p02423.

Rothman, L. S., et al. (2009), The HITRAN 2008 molecular spectroscopic database, J. Quant. Spectrosc. Radiat. Transf., 110(9-10), 533-572, doi:10.1016/j.jqsrt.2009.02.013.

Ryan, S. M., and C. J. Nielsen (2010), Global Warming Potential of Inhaled Anesthetics: Application to Clinical Use, Anesth. Analg., $111(1), 92-98$.

Sander, S. P., et al. (2010), Chemical kinetics and photochemical data for use in atmospheric studies, Evaluation Number 17, JPL Publication 10-6, NASA/JPL, Jet Propulsion Laboratory, California Institute of Technology, Pasadena, California, Rep.

Schatz, P. N., and D. F. Hornig (1953), Bond moments and derivatives in $\mathrm{CF}_{4}, \mathrm{SIF}_{4}$, and $\mathrm{SF}_{6}$ from infrared intensities, J. Chem. Phys., 21(9), 1516-1530, doi:10.1063/1.1699291.

Scott, A. P., and L. Radom (1996), Harmonic vibrational frequencies: An evaluation of Hartree-Fock, Moller-Plesset, quadratic configuration interaction, density functional theory, and semiempirical scale factors, J. Phys. Chem., 100(41), 16502-16513, doi:10.1021/jp960976r.

Sellevag, S. R., T. Kelly, H. Sidebottom, and C. J. Nielsen (2004a), A study of the IR and UV-Vis absorption cross-sections, photolysis and $\mathrm{OH}$-initiated oxidation of $\mathrm{CF}_{3} \mathrm{CHO}$ and $\mathrm{CF}_{3} \mathrm{CH}_{2} \mathrm{CHO}$, PCCP, 6(6), 1243-1252, doi:10.1039/b315941h.

Sellevag, S. R., C. J. Nielsen, O. A. Sovde, G. Myhre, J. K. Sundet, F. Stordal, and I. S. A. Isaksen (2004b), Atmospheric gas-phase degradation and global warming potentials of 2-fluoro ethanol, 2,2-difluoroethanol, and 2,2,2-trifluoroethanol, Atmos. Environ., 38(39), 6725-6735, doi:10.1016/j.atmosenv.2004.09.023.

Sellevåg, S. R., B. D’Anna, and C. J. Nielsen (2007), Infrared Absorption Cross-Sections and Estimated Global Warming Potentials of $\mathrm{CF}_{3} \mathrm{CH}_{2} \mathrm{CH}_{2} \mathrm{OH}, \mathrm{CHF}_{2} \mathrm{CF}_{2} \mathrm{CH}_{2} \mathrm{OH}, \mathrm{CF}_{3} \mathrm{CF}_{2} \mathrm{CH}_{2} \mathrm{OH}$, $\mathrm{CF}_{3} \mathrm{CHFCF}_{2} \mathrm{CH}_{2} \mathrm{OH}$, and $\mathrm{CF}_{3} \mathrm{CF}_{2} \mathrm{CF}_{2} \mathrm{CH}_{2} \mathrm{OH}$, Asian Chemistry Letters, 11(1-2), 33-40.

Shine, K. P. (2009), The global warming potential-the need for an interdisciplinary retrial, Clim. Change, 96(4), 467-472, doi:10.1007/s10584-009-9647-6.

Shine, K. P., and P. M. D. Forster (1999), The effect of human activity on radiative forcing of climate change: a review of recent developments, Glob. Planet. Change, 20(4), 205-225, doi:10.1016/S09218181(99)00017-X.

Shine, K. P., J. S. Fuglestvedt, K. Hailemariam, and N. Stuber (2005a), Alternatives to the global warming potential for comparing climate impacts of emissions of greenhouse gases, Clim. Change, 68(3), 281-302, doi:10.1007/s10584-005-1146-9.

Shine, K. P., T. K. Berntsen, J. S. Fuglestvedt, R. B. Skeie, and N. Stuber (2007), Comparing the climate effect of emissions of short- and long-lived climate agents, Philos. Trans. R. Soc. A-Math. Phys. Eng. Sci., 365(1856), 1903-1914, doi:10.1098/rsta.2007.2050.

Shine, K. P., L. K. Gohar, M. D. Hurley, G. Marston, D. Martin, P. G. Simmonds, T. J. Wallington, and M. Watkins (2005b), Perfluorodecalin: global warming potential and first detection in the atmosphere, Atmos. Environ., 39(9), 1759-1763.

Sihra, K., M. D. Hurley, K. P. Shine, and T. J. Wallington (2001), Updated radiative forcing estimates of 65 halocarbons and nonmethane hydrocarbons, J. Geophys. Res., 106(D17), 20493-20505, doi:10.1029/2000JD900716.

Smith, K., D. Newnham, M. Page, J. Ballard, and G. Duxbury (1996), Infrared band strengths and absorption cross-sections of HFC-32 vapour, J. Quant. Spectrosc. Radiat. Transf., 56(1), 73-82, doi:10.1016/0022-4073(96)00019-2.

Smith, K., D. Newnham, M. Page, J. Ballard, and G. Duxbury (1998), Infrared absorption cross-sections and integrated absorption intensities of HFC-134 and HFC-143a vapour, J. Quant. Spectrosc. Radiat. Transf., 59(3-5), 437-451, doi:10.1016/ S0022-4073(97)00114-3.

Spivakovsky, C. M., et al. (2000), Three-dimensional climatological distribution of tropospheric OH: Update and evaluation, $J$. Geophys. Res., 105(D7), 8931-8980, doi:10.1029/ 1999JD901006.

Stolarski, R., R. Bojkov, L. Bishop, C. Zerefos, J. Staehelin, and J. Zawodny (1992), Measured trends in stratospheric ozone, Science, 256(5055), 342-349, doi:10.1126/science.256.5055.342.

Stoppa, P., A. P. Charmet, N. Tasinato, S. Giorgianni, and A. Gambi (2009), Infrared Spectra, Integrated Band Intensities, and Anharmonic Force Field of $\mathrm{H}_{2} \mathrm{C}=\mathrm{CHF}, J$. Phys. Chem. A, 113(8), 1497-1504, doi:10.1021/jp808556e.

Stordal, F., I. S. A. Isaksen, and K. Horntveth (1985), A diabatic circulation two-dimensional model with photochemistry-Simulations of ozone and long-lived tracers with surface sources, J. Geophys. Res., 90(ND3), 5757-5776, doi:10.1029/JD090iD03p05757.

Sturges, W. T., T. J. Wallington, M. D. Hurley, K. P. Shine, K. Sihra, A. Engel, D. E. Oram, S. A. Penkett, R. Mulvaney, and C. A. M. Brenninkmeijer (2000), A potent greenhouse gas identified in the atmosphere: $\mathrm{SF}_{5} \mathrm{CF}_{3}$, Science, 289(5479), 611-613, doi:10.1126/science.289.5479.611. 
Suga, A., et al. (1994), Estimation of total infrared intensities of fluorinated ethyl methyl ethers, Chem. Lett., 23(12), 2365-2368, doi:10.1246/cl.1994.2365.

Søndergaard, R., O. J. Nielsen, M. D. Hurley, T. J. Wallington, and R. Singh (2007), Atmospheric chemistry of trans $-\mathrm{CF}_{3} \mathrm{CH}=\mathrm{CHF}$ : Kinetics of the gas-phase reactions with $\mathrm{Cl}$ atoms, $\mathrm{OH}$ radicals, and $\mathrm{O}_{3}$, Chem. Phys. Lett., 443(4-6), 199-204, doi:10.1016/j. cplett.2007.06.084.

Søvde, O. A., M. Gauss, S. P. Smyshlyaev, and I. S. A. Isaksen (2008), Evaluation of the chemical transport model Oslo CTM2 with focus on arctic winter ozone depletion, J. Geophys. Res., 113, D09304, doi:10.1029/2007JD009240.

Søvde, O. A., Y. J. Orsolini, D. R. Jackson, F. Stordal, I. S. A. Isaksen, and B. Rognerud (2011), Estimation of Arctic $\mathrm{O}_{3}$ loss during winter 2006/2007 using data assimilation and comparison with a chemical transport model, Q. J. R. Meteorol. Soc., 137(654), 118-128, doi:10.1002/qj.740.

Takahashi, K., Y. Matsumi, T. J. Wallington, and M. D. Hurley (2002), Atmospheric chemistry of $\mathrm{CF}_{3} \mathrm{CFHOCF}_{3}$ : Reaction with $\mathrm{OH}$ radicals, atmospheric lifetime, and global warming potential, J. Geophys. Res., 107(D21), 4574, doi:10.1029/2002JD002125.

Thomsen, D. L., V. F. Andersen, O. J. Nielsen, and T. J. Wallington (2011), Atmospheric chemistry of $\mathrm{C}_{2} \mathrm{~F}_{5} \mathrm{CH}_{2} \mathrm{OCH}_{3}$ (HFE365mcf), PCCP , 13(7), 2758-2764, doi:10.1039/c0cp01609h.

Tjemkes, S. A., et al. (2003), The ISSWG line-by-line intercomparison experiment, J. Quant. Spectrosc. Radiat. Transf., 77(4), 433-453, doi:10.1016/S0022-4073(02)00174-7.

Tol, R. S. J., T. K. Berntsen, B. C. O'Neill, J. S. Fuglestvedt, and K. P. Shine (2012), A unifying framework for metrics for aggregating the climate effect of different emissions, Environ. Res. Lett., 7(044006), 8 pp.

Trenberth, K. E., and L. Smith (2005), The Mass of the Atmosphere: A Constraint on Global Analyses, J. Clim., 18(6), 864-875, doi:10.1175/JCLI-3299.1.

Trenberth, K. E., J. T. Fasullo, and J. Kiehl (2009), Earth's global energy budget, Bull. Amer. Meteorol. Soc., 90(3), 311-323, doi:10.1175/2008BAMS2634.1.

Urata, S., A. Takada, T. Uchimaru, and A. K. Chandra (2003), Rate constants estimation for the reaction of hydrofluorocarbons and hydrofluoroethers with OH radicals, Chem. Phys. Lett., 368(1-2), 215-223, doi:10.1016/S0009-2614(02)01718-9.

van der Werf, G. R., J. T. Randerson, L. Giglio, G. J. Collatz, P. S. Kasibhatla, and A. F. Arellano (2006), Interannual variability in global biomass burning emissions from 1997 to 2004, Atmos. Chem. Phys., 6, 3423-3441, doi:10.5194/acp-6-3423-2006.

Vander Auwera, J. (2000), Infrared absorption cross-sections for two substituted ethanes: 1,1-difluoroethane (HFC-152a) and 1,2-dichloroethane, J. Quant. Spectrosc. Radiat. Transf., 66(2), 143-151, doi:10.1016/S0022-4073(99)00213-7.

Vanthanh, N., I. Rossi, A. Jeanlouis, and H. Rippel (1986), Infrared band shapes and band strengths of $\mathrm{CF}_{2} \mathrm{Cl}_{2}$ from 800 to 1200 $\mathrm{cm}^{-1}$ at 296 and $200 \mathrm{~K}, J$. Geophys. Res., 91(D3), 4056-4062, doi:10.1029/JD091iD03p04056.

Varanasi, P., and F. K. Ko (1977), Intensity measurements in freon bands of atmospheric interest, J. Quant. Spectrosc. Radiat. Transf., 17(3), 385-388, doi:10.1016/0022-4073(77)90116-9.

Varanasi, P., and S. Chudamani (1988a), Remeasurement of the absolute intensities of CFC-11 $\left(\mathrm{CFCl}_{3}\right)$ and CFC-12 $\left(\mathrm{CF}_{2} \mathrm{Cl}_{2}\right), J$. Quant. Spectrosc. Radiat. Transf., 39(3), 193-195, doi:10.1016/ S0022-4073(88)90026-X.

Varanasi, P., and S. Chudamani (1988b), Infrared intensities of some chlorofluorocarbons capable of perturbing the global climate, $J$. Geophys. Res., 93(D2), 1666-1668, doi:10.1029/JD093iD02p01666.

Varanasi, P., and V. Nemtchinov (1994), Thermal infraredabsorption coefficients of CFC-12 at atmospheric conditions, $J$. Quant. Spectrosc. Radiat. Transf., 51(5), 679-687, doi:10.1016/ 0022-4073(94)90124-4.

Varanasi, P., Z. Li, V. Nemtchinov, and A. Cherukuri (1994), Spectral absorption-coefficient data on $\mathrm{HCFC}-22$ and $\mathrm{SF}_{6}$ for remote-sensing applications, J. Quant. Spectrosc. Radiat. Transf., 52(3-4), 323-332, doi:10.1016/0022-4073(94)90162-7.

Vasekova, E., E. A. Drage, K. M. Smith, and N. J. Mason (2006), FTIR spectroscopy and radiative forcing of octafluorocyclobutane and octofluorocyclopentene, J. Quant. Spectrosc. Radiat. Transf., 102(3), 418-424, doi:10.1016/j.jqsrt.2006.02.023.

Velders, G. J. M., S. O. Andersen, J. S. Daniel, D. W. Fahey, and M. McFarland (2007), The importance of the Montreal Protocol in protecting climate, Proc. Natl. Acad. Sci. U. S. A., 104(12), 4814-4819, doi:10.1073/pnas.0610328104.

Vlachogiannis, D., et al. (2005), Assessment of the impact of $\mathrm{SF}_{6}$ and PFC reservoir tracers on global warming, the AEOLOS study, Environ. Sci., 2(2-3), 263-272, doi:10.1080/15693430500396170. Volk, C. M., J. W. Elkins, D. W. Fahey, G. S. Dutton, J. M. Gilligan, M. Loewenstein, J. R. Podolske, K. R. Chan, and M. R. Gunson (1997), Evaluation of source gas lifetimes from stratospheric observations, J. Geophys. Res., 102(D21), 25543-25564, doi:10.1029/97JD02215.

Wallington, T. J., M. D. Hurley, and O. J. Nielsen (2009), The radiative efficiency of $\mathrm{HCF}_{2} \mathrm{OCF}_{2} \mathrm{OCF}_{2} \mathrm{CF}_{2} \mathrm{OCF}_{2} \mathrm{H}(\mathrm{H}$-Galden 1040x) revisited, Atmos. Environ., 43(27), 4247-4249, doi:10.1016/j.atmosenv.2009.05.046.

Wallington, T. J., M. P. S. Andersen, and O. J. Nielsen (2010), Relative integrated IR absorption in the atmospheric window is not the same as relative radiative efficiency, Proc. Natl. Acad. Sci. U. S. A., 107(48), E178-E179, doi:10.1073/pnas.1008011107.

Wallington, T. J., P. Dagaut, R. H. Liu, and M. J. Kurylo (1988), The gas-phase reactions of hydroxyl radicals with a series of esters over the temperature-range $240-440 \mathrm{~K}$, Int. J. Chem. Kinet., 20(2), 177-186, doi:10.1002/kin.550200210.

Wallington, T. J., W. F. Schneider, J. Sehested, and O. J. Nielsen (1995), Hydrofluorocarbons and stratospheric ozone, Faraday Discuss., 100, 55-64, doi:10.1039/fd9950000055.

Wallington, T. J., M. D. Hurley, O. J. Nielsen, and M. P. S. Andersen (2004), Atmospheric chemistry of $\mathrm{CF}_{3} \mathrm{CFHCF}_{2} \mathrm{OCF}_{3}$ and $\mathrm{CF}_{3} \mathrm{CFHCF}_{2} \mathrm{OCF}_{2} \mathrm{H}$ : Reaction with $\mathrm{Cl}$ atoms and $\mathrm{OH}$ radicals, degradation mechanism, and global warming potentials, J. Phys. Chem. A, 108(51), 11333-11338, doi:10.1021/jp046454q.

Wallington, T. J., M. D. Hurley, J. C. Ball, T. Ellermann, O. J. Nielsen, and J. Sehested (1994a), Atmospheric chemistry of $\mathrm{HFC}-152-\mathrm{UV}$ absorption-spectrum of $\mathrm{CH}_{2} \mathrm{FCFHO}_{2}$ radicals, kinetics of the reaction $\mathrm{CH}_{2} \mathrm{FCFHO}_{2}+\mathrm{NO}->\mathrm{CH}_{2} \mathrm{FCHFO}+$ $\mathrm{NO}_{2}$, and fate of the alkoxy radical $\mathrm{CH}_{2} \mathrm{FCFHO}$, J. Phys. Chem., 98(21), 5435-5440, doi:10.1021/j100072a008.

Wallington, T. J., W. F. Schneider, D. R. Worsnop, O. J. Nielsen, J. Sehested, W. J. Debruyn, and J. A. Shorter (1994b), The environmental-impact of CFC replacements-HFCs and HCFCs, Environ. Sci. Technol., 28(7), A320-A326.

Wallington, T. J., A. Guschin, T. N. N. Stein, J. Platz, J. Sehested, L. K. Christensen, and O. J. Nielsen (1998), Atmospheric chemistry of $\mathrm{CF}_{3} \mathrm{CH}_{2} \mathrm{OCH}_{2} \mathrm{CF}_{3}$ : UV spectra and kinetic data for $\mathrm{CF}_{3} \mathrm{CH}(\cdot) \mathrm{OCH}_{2} \mathrm{CF}_{3}$ and $\mathrm{CF}_{3} \mathrm{CH}(\mathrm{OO} \cdot)$ $\mathrm{OCH}_{2} \mathrm{CF}_{3}$ radicals and atmospheric fate of $\mathrm{CF}_{3} \mathrm{CH}(\mathrm{O} \cdot)$ $\mathrm{OCH}_{2} \mathrm{CF}_{3}$ radicals, J. Phys. Chem. A, 102(7), 1152-1161, doi:10.1021/jp972933w.

Wallington, T. J., W. F. Schneider, J. Sehested, M. Bilde, J. Platz, O. J. Nielsen, L. K. Christensen, M. J. Molina, L. T. Molina, and P. W. Wooldridge (1997), Atmospheric chemistry of HFE-7100 $\left(\mathrm{C}_{4} \mathrm{~F}_{9} \mathrm{OCH}_{3}\right)$ : Reaction with $\mathrm{OH}$ radicals, UV spectra and kinetic data for $\mathrm{C}_{4} \mathrm{~F}_{9} \mathrm{OCH}_{2}$. and $\mathrm{C}_{4} \mathrm{~F}_{9} \mathrm{CH}_{2} \mathrm{O}_{2}$. radicals, and the atmospheric fate of $\mathrm{C}_{4} \mathrm{~F}_{9} \mathrm{OCH}_{2} \mathrm{O}$ center dot radicals, J. Phys. Chem. A, 101(44), 8264-8274, doi:10.1021/jp971353w.

Wang, W. C., Y. L. Yung, A. A. Lacis, T. Mo, and J. E. Hansen (1976), Greenhouse effects due to man-made perturbations of trace gases, Science, 194(4266), 685-690, doi:10.1126/science.194.4266.685.

Waterland, R. L., M. D. Hurley, J. A. Misner, T. J. Wallington, S. M. L. Melo, K. Strong, R. Dumoulin, L. Castera, N. L. Stock, and S. A. Mabury (2005), Gas phase UV and IR absorption spectra of 
$\mathrm{CF}_{3} \mathrm{CH}_{2} \mathrm{CH}_{2} \mathrm{OH}$ and $\mathrm{F}\left(\mathrm{CF}_{2} \mathrm{CF}_{2}\right)_{x} \mathrm{CH}_{2} \mathrm{CH}_{2} \mathrm{OH}(\mathrm{x}=2,3,4)$, J. Fluor. Chem., 126(9-10), 1288-1296, doi:10.1016/j.jfluchem.2005.06.010.

WMO (1999), Scientific Assessment of Ozone Depletion: 1998, Global Ozone Research and Monitoring ProjectReport No. 44, World Meteorological Organization, Geneva, Switzerland, Rep.

WMO (2003), Scientific Assessment of Ozone Depletion: 2002, Global Ozone Research and Monitoring Project-Report No. 47, Rep., 498 pp., Geneva

WMO (2007), Scientific Assessment of Ozone Depletion: 2006, Global Ozone Research and Monitoring Project-Report No. 50, edited, pp. 572, Geneva.

WMO (2011), Scientific Assessment of Ozone Depletion: 2010, Global Ozone Research and Monitoring Project-Report No. 50, 572 pp., World Meteorological Organization, Geneva, Switzerland, Rep.

WMO/GAW (2011), WMO Greenhouse Gas Bulletin. Number 7, 21 November 2011. http://www.wmo.int/pages/prog/arep/gaw/ ghg/documents/GHGbulletin_7_en.pdf,Rep.

WMO/GAW (2012), WMO Greenhouse Gas Bulletin. Number 8, 19 November 2012. http://www.wmo.int/pages/prog/arep/gaw/ ghg/documents/GHG_Bulletin_No.8_en.pdf,Rep.

Wuebbles, D. J. (1989), Beyond $\mathrm{CO}_{2}$ - the other greenhouse gases, Rep., Lawrence Livermore National Laboratory report UCRL-99883; Air and Waste Management Association paper 89-119.4.

Wuebbles, D. J., A. K. Jain, K. O. Patten, and K. E. Grant (1995), Sensitivity of Direct Global Warming Potentials to Key Uncertainties, Clim. Change, 29(3), 265-297, doi:10.1007/BF01091865.

Wuebbles, D. J., D. Youn, K. Patten, D. Wang, and M. Martinez-Aviles (2009), Metrics for Ozone and Climate: Three-Dimensional
Modeling Studies of Ozone Depletion Potentials and Indirect Global Warming Potentials, 297-326 pp., Springer, New York.

Young, C. J., M. D. Hurley, T. J. Wallington, and S. A. Mabury (2006), Atmospheric lifetime and global warming potential of a perfluoropolyether, Environ. Sci. Technol., 40(7), 2242-2246, doi:10.1021/es052077z.

Young, C. J., M. D. Hurley, T. J. Wallington, and S. A. Mabury (2009a), Atmospheric chemistry of perfluorobutenes $\left(\mathrm{CF}_{3} \mathrm{CFCFCF}_{3}\right.$ and $\left.\mathrm{CF}_{3} \mathrm{CF}_{2} \mathrm{CFCF}_{2}\right)$ : Kinetics and mechanisms of reactions with $\mathrm{OH}$ radicals and chlorine atoms, IR spectra, global warming potentials, and oxidation to perfluorocarboxylic acids, Atmos. Environ., 43(24), 3717-3724, doi:10.1016/j. atmosenv.2009.04.025.

Young, C. J., M. D. Hurley, T. J. Wallington, and S. A. Mabury (2009b), Atmospheric chemistry of $\mathrm{CF}_{3} \mathrm{CF}_{2} \mathrm{H}$ and $\mathrm{CF}_{3} \mathrm{CF}_{2} \mathrm{CF}_{2} \mathrm{CF}_{2} \mathrm{H}$ : Kinetics and products of gas-phase reactions with $\mathrm{Cl}$ atoms and $\mathrm{OH}$ radicals, infrared spectra, and formation of perfluorocarboxylic acids, Chem. Phys. Lett., 473(4-6), 251-256, doi:10.1016/j.cplett.2009.04.001.

Zhang, H., J. X. Wu, and Z. P. Shen (2011a), Radiative forcing and global warming potential of perfluorocarbons and sulfur hexafluoride, Sci. China-Earth Sci., 54(5), 764-772, doi:10.1007/s11430-0104155-0.

Zhang, H., J. X. Wu, and P. Luc (2011b), A study of the radiative forcing and global warming potentials of hydrofluorocarbons, J. Quant. Spectrosc. Radiat. Transf., 112(2), 220-229, doi:10.1016/j. jqsrt.2010.05.012.

Zou, Q., C. Sun, V. Nemtchinov, and P. Varanasi (2004), Thermal infrared cross-sections of $\mathrm{C}_{2} \mathrm{~F}_{6}$ at atmospheric temperatures, J. Quant. Spectrosc. Radiat. Transf., 83(2), 215-221, doi:10.1016/S00224073(02)00353-9. 